

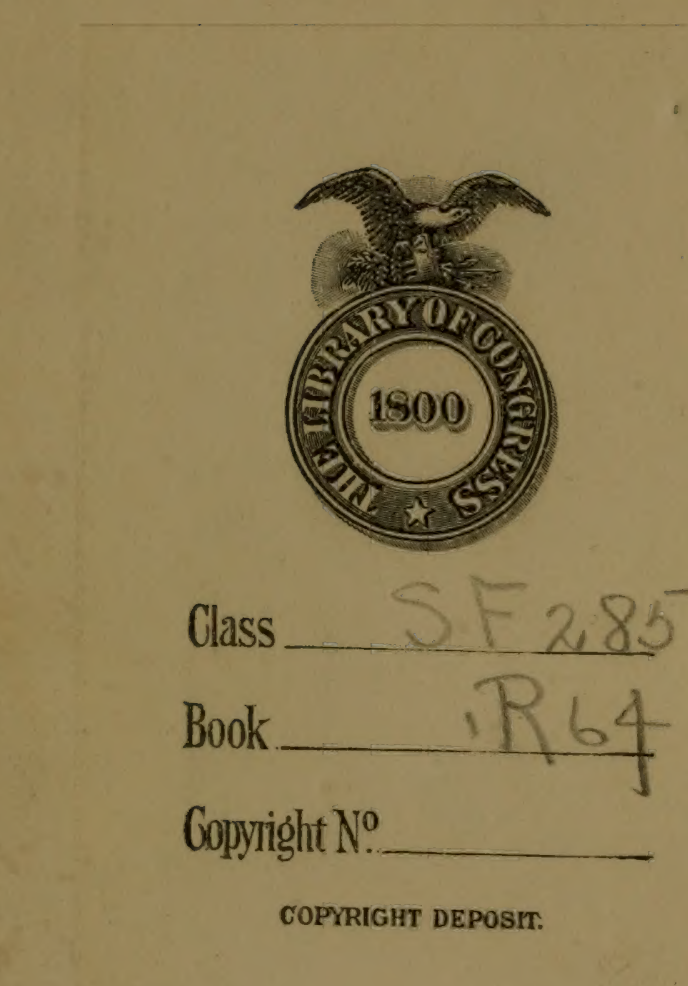












\section{The lRural Stience Setieg}

EDITED BY L. H. BAILEY

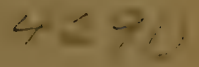

\section{THE HORSE}




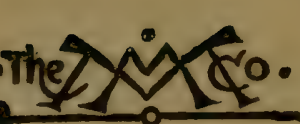



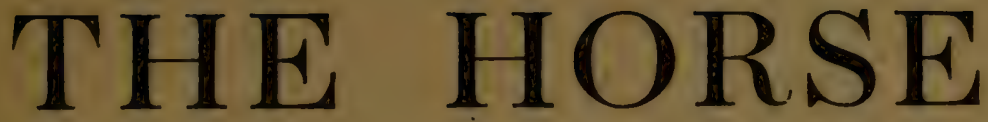

J3Y

\section{ISAAC PHILLIPS ROBERTS}

Emeritus Professor of Agriculture, Late Dean and Director of the College of Agriculture of Cornell. University; author of "Fertility of the Land,"

"The Farmstead," "The Farmer's Business Handbook."

\section{J2em Eork}

\section{THE MACMULLAN COMPANY.}

LONDON: MACMILLAN \& CO., LTD.

\section{5}




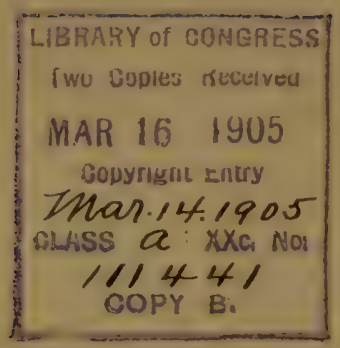

COPYRIGHT, 1905

\section{BY THE MACMILLAN COMPANY}

Set up and electrotyped March, 190\% 


\section{CONTENTS}

CHAPTER I

PAgrS

The Horse and His Master . . . . . . . . . . 1-20

CHAPTER II

Brief History of the Domesticated Horse . . . . . 21-32

Introduction of Improved Horses into England .... 26 The-Horse in France .................... 31

CHAPTER III

Horses of AMERICA . . . . . . . . . . . . 33-48

\section{CHAPTER IV}

Breeds, Subbreeds, Fanilies, Varieties, Cross Breeds and Grades ................ 49-60

CHAPTER V

The Thoroughbred; The TrotTer; THE PACER .....61-85 The Trotting Horse ..................... 70 The Pacing Horse ................... 78

CHAPTER VI

THE AMERICAN SAdDLER . . . . . . . . . . . 86-94

CHAPTER VII

The Coach-Horse ............... 95-109

The Trotter as a Sire of Coachers ....... 103

The French Coach ................. 105

CHAPTER VIII

The HaCkNeT .................... 110-114 


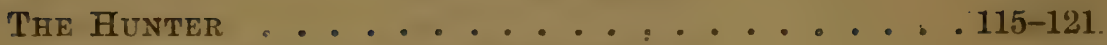

Breeding-Hunters and Saddle-Horses ........ 116

CHAPTER $\mathrm{X}$

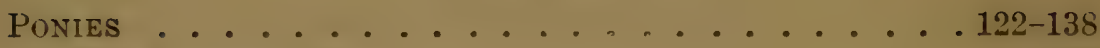

The Shetland Pony ........................ 125

The Welsh Pony .............. 130

Exmoor, Dartmoor and New Forest Ponies . . . . 130

Mustangs ............................ 133

The Indian Pony ................ 135

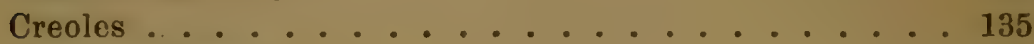

The Polo Pony ................... 137

CHAP'TER XI

Draft-Horses - Clydesdale, English Shire, Suffolk

PUNCH . . . . . . . . . . . . 139-155

English Shire............... 147

Suffolk Punch ................. 152

\section{CHAPTER XII}

French, Belgian and Flemish Draft-Horses . . . . 156-173

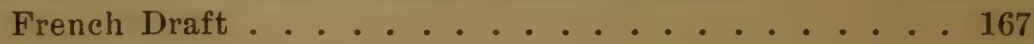

Boulonnais ........................ 168

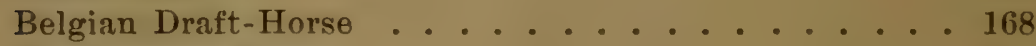

The Flemish Horse . . . . . . . . . . . 171

CHAPTER XIII

Principles of Breeding . . . . . . . . . . 174-201

Food . . . . . . . . . . . 187

Climato . . . . . . . . . . . . 189

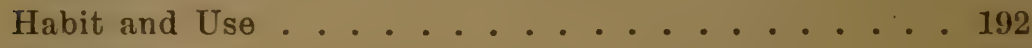

Selection . . . . . . . . . . . . . . 193

Relative Influence of Sire and Dam . . . . . . 197

The Governing of Sex ................. 198

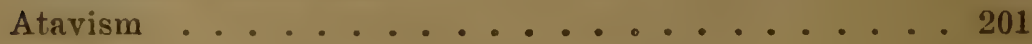




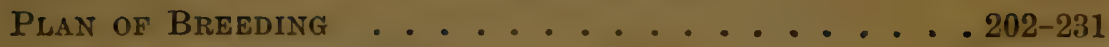

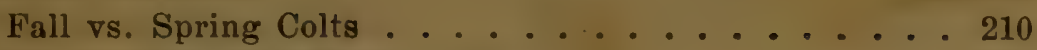

Plan for Rearing Winter Colts .......... 211

Feeding the Brood-Mare and Foal.......... 214

Period of Gestation and Parturition ........ 219

Suggestions for the Beginner . . . . . . . . 222

\section{CHAPTER XV}

Judging HoRses . . . . . . . . . . . . 232-266

\section{CHAPTER XVI}

BREEding Horses ................... 267-274

\section{CHAPTER XVII}

Education ANd Care of Roadsters and Other Light

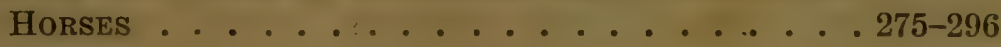

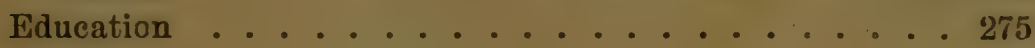

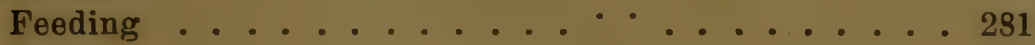

Foods . . . . . . . . . . . . . . 282

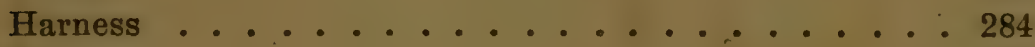

Driving . . . . . . . . . . . . 287

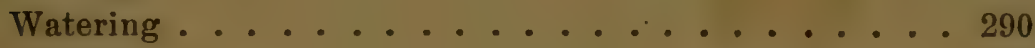

Grooming ......................... 292

CHAPTER XVIII

"HANDs" in DRIVING .................... 297-302

CHAPTER XIX

Care of Draft-Horses and Farm-Horses . . . . 303-315

Watering ....................... 308 Blankets .................................... 312

Size and Weight of Horses ....................... 313

Driving-, Farm- and Draft-Horses ....... 314 


\section{CHAP'TER XX}

- PAUES

The Horse's FeET - Shoeing . . . . . . . . . 316-332 Shoeing, to Improve Action . . . . . . . . . 330

\section{CHAPTER XXI}

Stables, Sanitation and Paddocks . . . . . . . 333-346

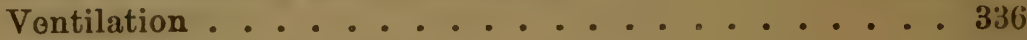

Manures . . . . . . . . . . . . . . 340

Floors, Stalls and Mangers . . . . . . . . . 342

Paddocks . . . . . . . . . . . . . 346

\section{CHAPTER XXII}

Line of Draft, Weight of Horses and Wagon Tires . 347-353

\section{APPENDIX I}

The Breeding in Canada of Horses for Army Use . . 354-359

\section{APPENDIX II}

Conputing Rations for Farm Animals $\ldots \ldots . . .360-382$

\section{APPENDIX III}

Live-Stock Registry Associations, With the Names of the SeCretaries or Edtors . . . . . 383-389

\section{APPENDIX IV}

Number and Value of Horses . . . . . . 390-394 


\section{LIST OF ILLUSTRATIONS}

Plowing .................... 9

Harvesting ......................... 11

The improved mustang .............. 38

A saddler at rest .................... 45

A superior pedigree............... 53

Alphea Czar. Pedigree ............... . 55

Genealogy of Moses...................... 57

A thoroughbred ......................... 67

Lou Dillon .................................. 72

Cresceus ............................... 75

Prince Alert .................... . . . 81

Dan Patch ............................ 83

Montgomery Chief ........................ 92

A good coacher ......................... 101

Paladin, French coach .............. 106

Imported German coacher............. 108

Imported Cadet, hackney ................ 111

Champion hackney stallion .................. 113

Heavy-weight hunter ................ 117

Ontario ........................... 120

A disgusted pony......................... 123

A pair of trick ponies .................... 124

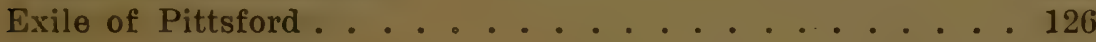

Bressay of Pittsford ............... . . 127

Champion Welsh pony mare ............ 129

Movement. Welsh pony gelding ........... 131

Julius Cresar ..................... 1332

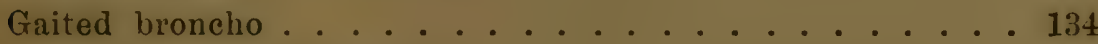

Lord Stewart, Clydesdale .............. . . 140

A quartette of Clydesdale colts ............ . . 142

Brothwick. Clydesdale stallion ............. 144 
Clydesdale mare . . . . . . . . . . . . . . . . . . . . . . . . . . . . 146 Shire stallion ........................ 148

Traitor. Shire stallion .............. 150

Tatton Bessie. Shire filly .............. 151

Suffolk Punch stallion ................ 152

Suflolk Punch mare ................... 154

Success. Percheron ................ 157

Calypso. Percheron stallion ............. 160

Paquerette. Percheron mare . . . . . . . . . . 163

Deguardi. Percheron stallion ............. 164

Picador. Percheron stallion ............. 166

Brilliant Du Basquet. Belgian stallion . . . . . . . 169

Colonel De Dompiere. Belgian stallion ........ . 170

German draft-horse . . . . . . . . . . . . . 172

A brood-mare .................... . . 205

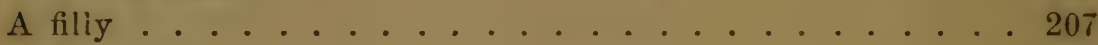

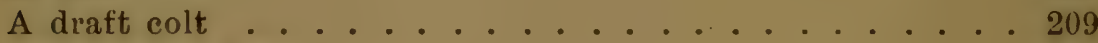

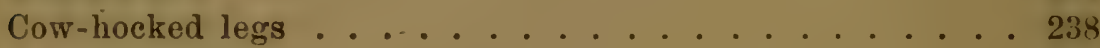

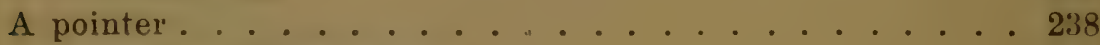

Reversion to original type .............. 239

A head showing bad breeding . . . . . . . . . . . 240

Ears badly set................... . . . 240

Goldsmith Maid................... . . 241

Photograph of a poor neck ............ . 242

An all-embracing neck ................ 243

'leeth of young colt. . . . . . . . . . . . 247

Teeth at four to six weeks of age........... 248

Teeth at ten months .................... 249

A milk tooth ...................... . . . 249

Lower nippers at two years old ............ 250

Lower nipper's at three years old ........... . . 251

Lower nippers at four years old ..... . . . . . 252

Side view of nippers at four ............... 253

Lower nippers at five years . . . . . . . . . . . 254

Side view of teeth at five............... . . 255

Lower nippers at six years of age . . . . . . . . . 256

Side view at six years of age . . . . . . . . . . 256 
Lower nippers of a seven-year-old horse . . . . . . . 257

Side view of the nipper's of a seven-year-old . . . . . 258

Lower nippers of an eight-year-old horse . . . . . . 259

Cross-section of an incisor tooth ........... 260

Side view of incisor teeth at eight years old . . . . . 261

Lower incisor teeth of an old horse . . . . . . . . 263

Side view of teeth of a very old horse . . . . . . . 264

Six views showing the wear of teeth .......... 265

Receiving their first lesson .............. . 277

Ready for the second lesson .................. 278

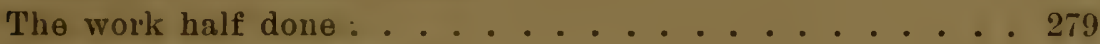

Brains versus brute force . . . . . . . . . . . . 280

A rein cruelly used . . . . . . . . . . . . . . . 286

Wonderful muscles displayed by a playful horse . . . . . 315

Foot of a draft-horse . . . . . . . . . . . . . 327

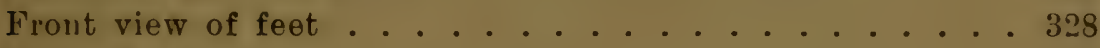

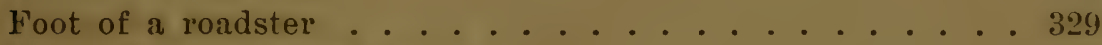

Gypsy Queen, a good saddler ........... 332

A swing-window .................. . . . 334

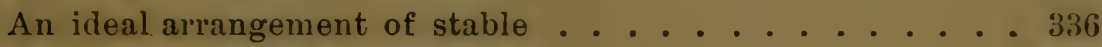

A straw chute and ventilator ............ 337

Better ways of saving manure ................ 341

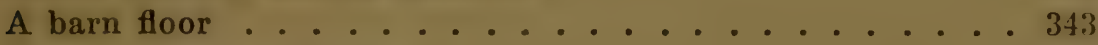

Energy efficiently applied ............. 347

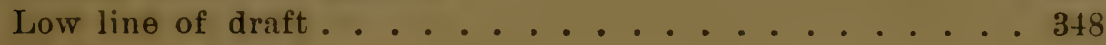

High line of draft .................... . . . . . . 349

A hansom-cab ................... . . . 353 



\section{THE HORSE}

\section{CHAPTER I}

\section{THE HORSE AND HIS MASTER}

THE American inherits from his European, and especially his English ancestor, a sincere love for the horse. This love has amounted to adoration in some cases. The family horse, if he outlived his master, inherited under the will a suffeient amount for luxurious support during life and a costly interment and monument at death, the same as the children. Although oxen were used by the pioneers for the most laborious work, fine horses were inported and bred in considerable numbers in the United States before 1776. Maryland, Virginia and South Carolina had established racecourses prior to that time. As the forests disappeared before the woodman's axe and the stumps slowly decayed, horses were gradually substituted for oxen as "work stock." As soon as settlements were made in the interior of the New England and middle states away from the natural water-courses, vast amounts of goods had to be "wagoned" from towns along the water-courses to the inland settlements. The rapid settlement of the middle states created a large demand 
for stout, serviceable horses, and this demand stimulated the importation of well-bred horses and the breeding of what has been erroneously called in modern days "a general-purpose horse."

The work-horses of America fall naturally into four general groups, each group overlapping the other. Although there are many subgroups, all of these are only connecting links between the four great groups and fall naturally into one, or sometimes, into two of them.

(1) Heavy draft-horses, designed and adapted for moving heavy loads in cities and forests and at mines.

(2) Medium draft, usually a mixture of the blood of the smaller individuals of the heavy draft and that of the larger animals of the third group; sometimes the blood of the light draft predominates; sometimes that of the lighter and quicker horse which traces back in some lines to oriental or "warm-blooded" ancestors. In many cases, the sires are largely of oriental descent and the dams of mixed draft type or of unknown blood. This group is quite variable, as might be expected from the indiscriminate mixing of the warm- (oriental) and cold- (draft) blooded breeds. Perhaps nine-tenths of the farm-horses of America belong to this nondescript class. It furnishes nearly all of the cavalry - and artillery-horses for the army. Since the best specimens of this group, produced by individual enterprise, furnish ample material from which to select, no attempt has been made by the United States govermment, as in Europe, to encourage the breeding of horses suited to these purposes. Horses 
of this group are also found in considerable numbers in the eity. They are used at light draft, delivery and street-car work, and at any other light work where a cheap horse, having more speed than the draft-horse and more weight than the roadster, can be used to advantage.

(3) The third group is designed for drawing light loads at a rapid pace. In America the term "roadster" has come to be applied in a generic way to all of this class, although some members of it are used exclusively in competitive speed contests.

(4) The fourth class comprises several breeds and mixed-blood varieties of small horses known as "ponies." Some trace their ancestry to the north of Great Britain; others, first to. southern and western United States and thence back to Spain.

The American, having all of these varied classes, groups and subgroups from which to select, and having opportunity to put the horse to many uses, both profitable and pleasurable; living in a country of magnificent distances, traveling over roads that were once bridle-paths and that are yet far from good; having easy and constant communication with Great Britain, and therefore many improved varieties of hor'ses to draw upon for foundation stock, has an inevitable and an inherited love for the horse. It is no wonder, then, that the American boy has always felt that he was robbed of his inalienable rights unless he owned a colt which was under his personal care and tutelage and which was "truly" his when it had grown to be a horse. 
Hay and grain have always been so abundant in America that every farmer conld afford to keep at least one horse, however small his holding. The business of all except the older great cities is still largely carried ou by men who were reared on the farm and who love the horse. This fact, coupled with cheap maintenance and abundant traffic, has filled the cities as well as the country districts with horses. Unfortunately, until the twelfth Census was taken, we have had no means of knowing the exact number.

When the pioneers reached the vast open grasscovered plains of the west and southwest, they might have expressed their surprise and wonder in the words of Byron:
"A thousand horse, the wild, the free,
Like waves that follow o'er the sea.
A thousand horse, and none to ride;
$O$ ! where are they the reins to guide?"

They did not stop to quote "Mazeppa," however, but proceeded to catch and tame the horse and to furnish him with a rider, who learned to keep a firm seat even though the horse frequently stood alternately on one end and then on the other. Thus American boys and men have become expert horsemen by reason of unique conditions not found in countries long settled. The word "expert" is not full and comprehensive enougb, for they love to own, rear, educate and drive the horse. The American is usually a kind, good caretaker, supplying the wants of his horse before his own are satisfied. Like the Arab, of all his possessions, he is proudest of his colt; and so the large number of good horses in 
our new, and, as yet, only partly developed country can be easily accounted for.

It is not strange, therefore, that the people of the United States, both urban and suburban, have always taken an intelligent interest in the horse. They have not only taken pains to improve the animals of mixed blood by selection and by improving their food and environment, but, even as early as the colonial period, horses of superior qualities, horses of oriental lineage and of great beanty, were imported at large cost. After the Revolution, as soon as the country began to recover from its long struggle for independence, the importation of horses was resumed.

The true draft-horse attracted comparatively little attention in America until permanent settlements had spread over the middle west. When the railways reached the western prairies, these vast fertile areas became valuable, since rapid and cheap communication with the east furnished facilities for reaching a steady and profitable market along these railways. Cities were soon built where, but a few years before, the bison roamed undisturbed except by his compeer, the American Indian. The opening of the prairies to the peaceful pursuits of agriculture, and the growing cities, created a demand for larger numbers of heavier horses than had hitherto been required. It will readily be seen how necessary the horse has been to the development of American agriculture, when it is stated that in 1890 the total number of horses on farms and ranges, not including 7,461 on Indian reservations and 2,314,785 mules and asses which take the place of horses as 
work stock in the southern states, was $15,258,783$. The population of the country, exclusive of Alaska and Island possessions, was $62,622,250$. This shows that there were approximately twenty-five horses, not counting those in cities, for every one hundred inhabitants of the entire country. If the mules and asses, and horses on Indian reservations be included, there would be twenty-eight of these wore animals for every one hundred inhabitants. The horses kept in the cities have never been enumerated in the Census until 1900; if they had been, the total showing above would be largely increased. If the people, as well as the horses of the cities, be excluded from the computation, it is seen that, in 1900 , for every three persons living on farms at least one horse was maintained. These facts emphasize as nothing else can the usefulness of the horse in rural pursuits and the great love of the Americans for one of the most useful, charming and pleasure-giving domestic animals.

The horses of Great Britain numbered, in 1899, $1,517,160$. The population, the same year, was $40,559,-$ 954. This shows that but one horse was maintained for every twenty-six, or four horses for every one hundred inhabitants. However, the horses in the cities, as well as the city population, are included in these computations and therefore are not strictly comparable with those of the United States. It is estimated by good authority that in 1900 , in the city of London, with a population of $4,504,766$, there are 600,000 horses in daily use. It is evident that neither steam nor electricity is likely entirely to supplant the horse, either in city or country, in the near future. 
In 1892 , the population of France was $38,333,000$. The number and classification of horses for the same year was as followis:

Horses Employed in Agriculture-

Geldings and stallions . . . . 1,080,000

Mares . . . . . . . . . . . 1,019,000

Stallions for breeding . . . . . $\quad{ }_{8,886}$

Mares for breeding . . . . . . . $\quad 178,237$

Colts, one to three years old $\ldots . \quad 328,099$

Colts, less than one year . . . . . 248,051

$2,862,273$

Horses Employed in Cities-

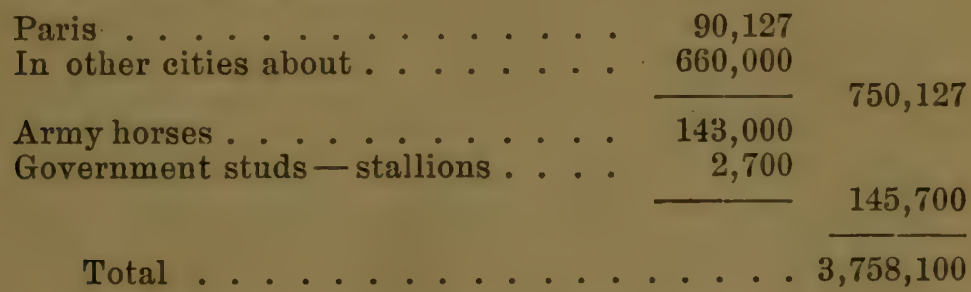

This gives one horse for every ten, or ten to every one hundred inhabitants. It may be said, however, that the exact number of horses maintained in cities cannot be secured but the estimate given above is believed to be very nearly correct.

The population of the German empire, in $\mathbf{1 8 9 5}$, was $52,279,901$; the number of horses (understood to include those in the cities) was $4,038,485$, or one horse for thirteen, or seven and seven-tenths horses to every one hundred inhabitants.

These three great European countries ${ }^{1}$ had a population, at the dates mentioned, of $131,172,855$ and $9,313,-$ 745 horses, or one horse to every fourteen inhabitants;

1 The figures for Great Britain, Germany, France and Holland were secured through the kindness of the American Consuls. 
while the United States, in 1890, had a population. of $62,622,250$ and the number of horses on the farms for the same year was $15,258,783$; or, roundly, one horse for every four inhabitants. The rural population at that time, including those who lived in the outskirts of the villages and cities and who kept horses in part for pleasure, as well as for cultivating land, was estimated at one-half of the total population. If this estimate, which is believed to be nearer correct than the former one, is taken as a basis for computation, it appears that in the rural districts of the United States there are half as many horses as inhabitants, or one horse for every two inhabitants; while in The Netherlands with its many canals, in 1897 , but one horse was maintained for every eighteen inhabitants. Fortunately, the horses in the cities have been enumerated in the Census of 1900 . The total number in the United States is $21,216,888 ; 866,771$ of which are in cities of over 25,000 inhabitants, $18,280,007$ on farms and ranges, and 2,070,110 not on farms or ranges. The total population in 1900 was $76,303,387$, and indicates that one horse was maintained for every 3.6 inhabitants.

It is evident that in America the farmers have learned to substitute brute for human energy. Agricultural teachers and inventors have tanght the farmer that human muscle, in the United States at least, is the dearest material from which to secure energy. The value of a day's labor for a horse may be put down at fifty cents, that of a man at one dollar. A horse properly directed is equal in productive energy to ten men. Just here lies the secret of American agriculture. 
A horse, intelligently handled, may be made to cheapen farm operations twenty fold over the old hand methods. Human muscle, however cheap, can never successfully compete in agriculture with improved implements,

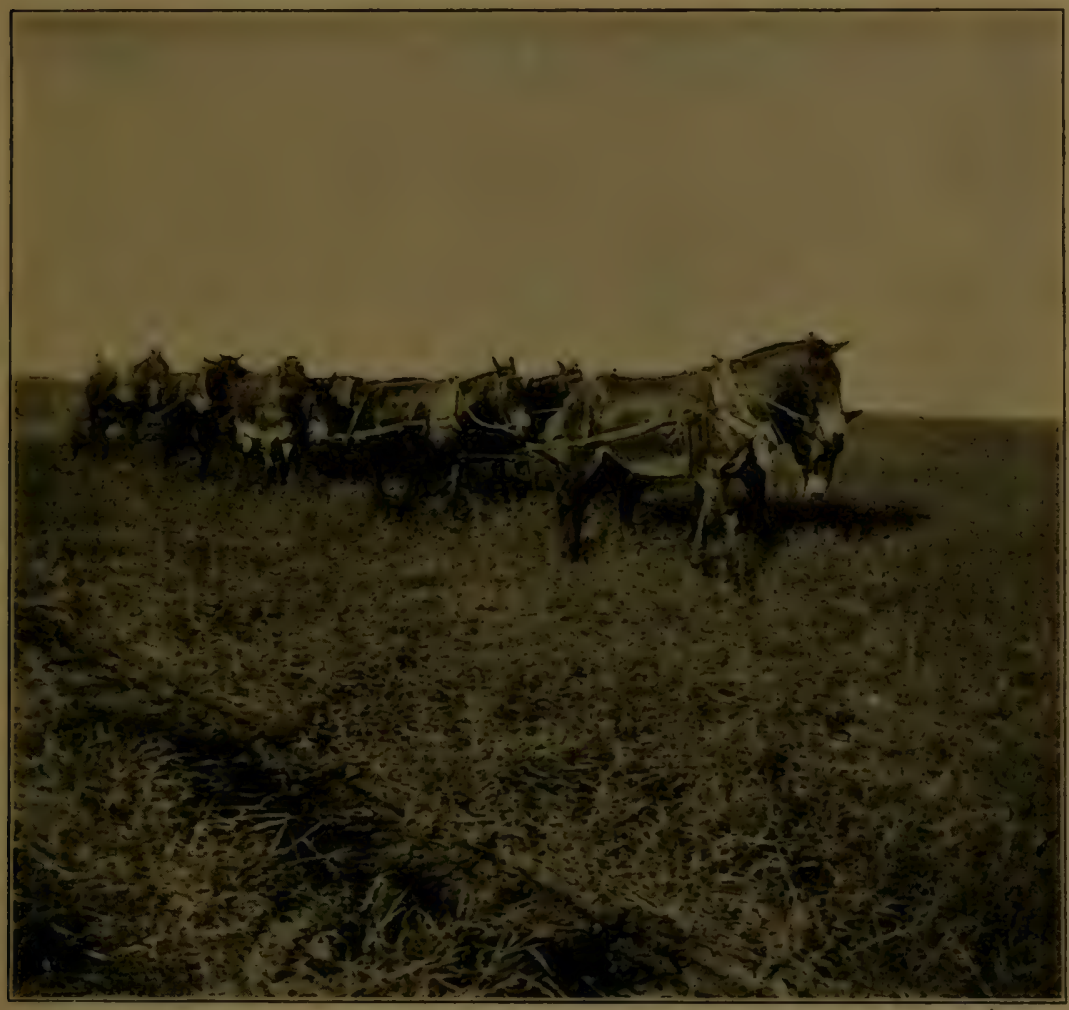

FIG. 1. Plowing: Conservation of human energy and concentration of cheap energy

operated by well bred-horses adapted to their work and directed by intelligent workmen. The American farmer is not usually content to direct the energies of but one horse at a time. He harnesses two, three, four, and even six, to a single implement of tillage. In 
the great wheat districts of the northwest, where the fields are often a mile long and where two plows are mounted on wheels and drawn by five horses (Fig. 1), and where ten rounds, or twenty miles, that is, forty miles of a single furrow, sixteen inches wide, is plowed in a day, a single workman accomplishes, in the pulverization and preparation of the six and a half acres, more than a hundred hand laborers could do in a day of the severest toil. Or a still more striking illustration of the economy of horse over man power may be given. In many of the great wheat-fields of California, from twenty-two to thirty-two horses are attached to a combined machine (Fig. 2) which cuts, threshes, cleans and sacks from one thousand to two thousand bushels of wheat per day. One man drives the horses and two or three others tend the machine and sew up the sacks of grain, the four spending less muscular energy than was formerly required merely to cut by hand a single acre.

Nearly as great economy of human muscle is seen in the large cities, by the substitution of horses for men in the transportation of heavy merchandise, for short distances. By reason of crowded streets and cost of maintenance, only one or two animals are usually harnessed" to a vehicle. Although only a few horses are brought together in this case to assist a single man, the American has seen to it that large, stout horses are provided, two of which are able to move a load of from four to ten tons over paved streets, - a load equal to that carried by a freight car in the early days of steain railways. 


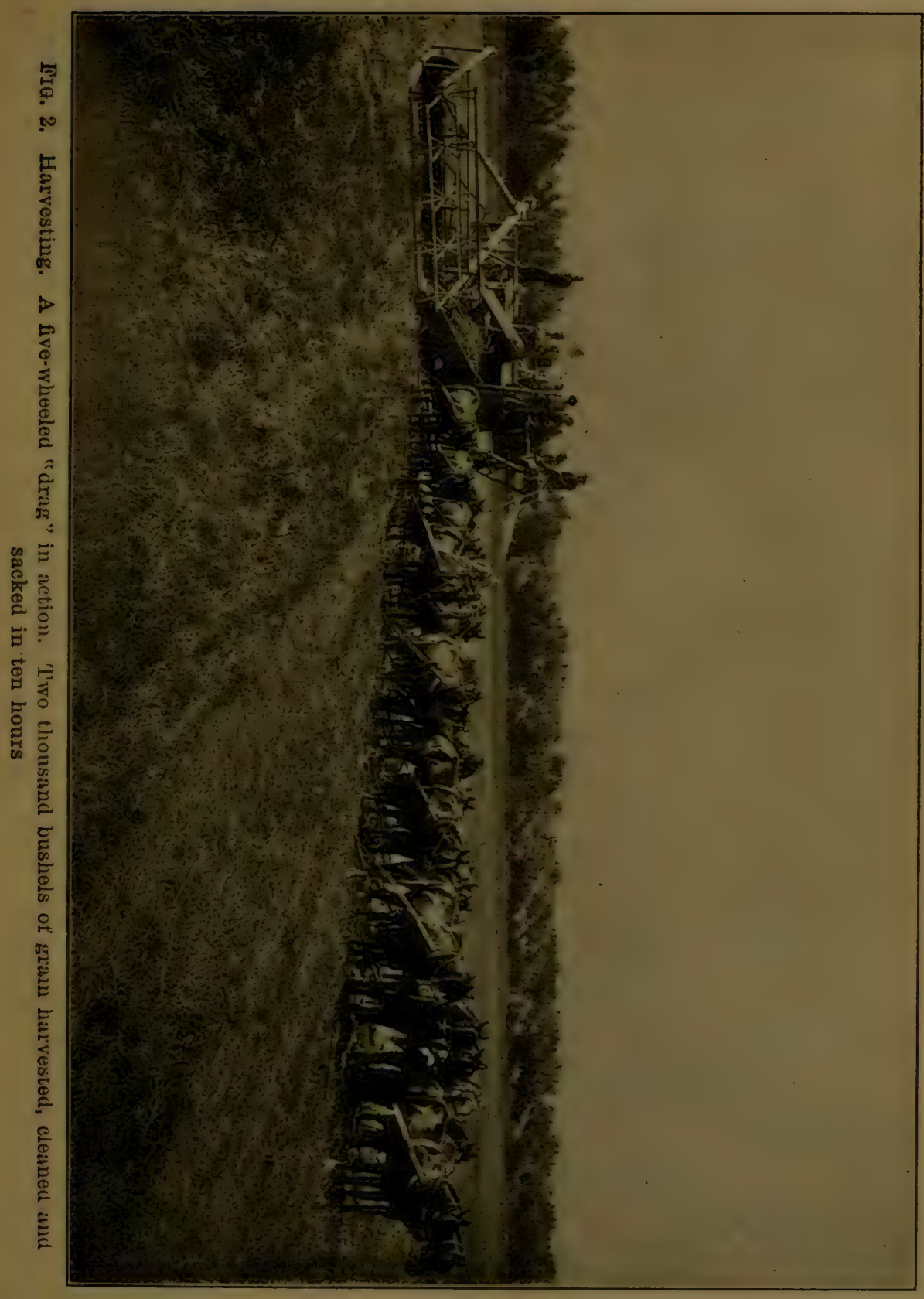


In 1890 there were, in round numbers, fifteen million horses and two inillion mules on farms. At least'onehalf of them were suitable to perform regular agricultural labor and were capable of doing work equal to eighty-five million hand laborers. What a vast addition to the productive power is here secured by the intelligent utilization of the horse; and what economy in using brute energy, which is only from onetenth to one-twentieth as expensive as human muscular energy!

If, then, the horse is such an economic factor in American production and progress, it behooves the American farmer to acquaint himself with the history of this useful and pleasure-giving animal, that not only good horses may be propagated, but that such selection of breeding stock may be made and such scientific compling, feeding and training be practiced as will secure not only the best horses but, that which is of quite as much importance, those which shall be best adapted to the work for which they are intended. It is evidently foolish to rear a horse which will increase a man's productive power only five times, when a more intelligent effort might have produced one which wonld increase it ten times.

So far, the horse has been spoken of as an animal which may be used to replace and alleviate human toil, to increase the efficiency of human effort and to give pleasure. But many horses in the community are beneficial in various other ways. They have a powerful influence in training the hand, and in developing both intellect and judgment. In ancient times, the ox and 
the ass were used to lighten toil, but horses seldom. At the present time, most half-civilized nations prefer the "senseless" ox or the stubborn, thick-skinned ass to the intelligent, spirited horse, which requires a high degree of skill, and judgment, if his energy is to be directed along the most economical and pleasure-giving lines. The well-bred horse is nearly worthless unless there is a trained mind to direct and control him. In traveling through foreign countries, one is minded of the superior horsemanship of the American farm-boy over that of the farmer's' sons of civilized as well as half-civilized countries, boys of Great Britain and her colonies excepted. It is sometimes said that the Ameri can mechanic has produced farm implements whereby the horse can be put to more effective uses. Due credit should be given to the mechanic, but the owners of horses invented nearly all the labor-saving horse implements. When, by reason of increased wants and the complexities of advancing civilized life, division of labor was forced upon us, the mechanic took such implements as were at hand and improved them. J. Stanton Gould ${ }^{1}$ graphically describes the inventor of the first plow in the following words: "While working the land with his sharpened stick, with his mind intent upon some mode of ameliorating his condition, he (the farmer) sees the bulls and cows grazing on the hillsides around him; they are stronger than he, and he desires to subjugate their strength to his service. Seeing a forked stick in his path, a bright thought dawns upon his mind: he will tie the long end of a ${ }^{1}$ Utica Plow Trial, 1867. 
stick to the horns of a bull, while the short end will run into the ground and stir it much faster than he could do it with a sharpened stick, and with much less labor to himself. He tries the experiment, and cries, 'Eureka!' or some barbarous equivalent for that Greek word. The germ of the plow is at length invented!" Not only was the crude wooden plow of our ancestors invented by men who had idle horses, which they saw could be far more efficient in tilling the land than men, but the cast plow as well. In like manner, the wagon, the sleigh, the harrow, the corn-harvester, the wooden hay-rake, hay-unloaders and many other similar implements were devised. So it will be seen that the owners of horses situated in a new, sparsely populated country, far removed from machine and implement factories, thought out many devices by which the strength of the horse conld be substituted for human labor. It will be seen along how many lines the intellect has been stimulated by this effort to utilize the horse. To breed, rear and train for various uses and to direct the encrgy of restless, courageous animals, requires no little intelligence and skill. I have yet to find a successful horseman who is not above the average intelligence of his associates in the same station of life.

In the ancient scripture, the Lord, to convince Job of his ignorance and weakness, used the strength, courage and fierceness of the horse to emphasize the argument: - "Hast thou given the horse strength? Hast thou clothed his neck with thunder? Canst thou make him afraid as a grasshopper? The glory of his nostrils is terrible. He paweth in the valley, and rejoiceth 
in strength. . . . He mocketh at fear, and is not affirighted." . . . "He swalloweth the ground with fierceness and rage."

By reason of long domestication, intelligent care and training, the horse has become more tractable and intelligent than he was in the time of Job. While neither men nor horses can inherit an education, they may inherit what is better,-the power to acquire it easily and rapidly. The colt, nevertheless, still retains enough courage, strength and fierceness to furnish opportunity for the use of the highest skill and courage in transforming him into the safe, well-trained, efficient horse. The Honorable George Geddes once said that the use of improved farm implements had been such a potent factor in stimulating thought and in giving dexterity to the hand of form-boys, that, if they had been of no other economic benefit, the education secured through their use would be full compensation for their cost.

The training of the American boy through the uni versal presence of the horse and the skill required in his use in operating farm implements and in ministering to pleasure may not be a full equivalent for the cost and maintenance of horses, but it is certain that these have been most potent factors in the intellectual development and manual training of the rural populations.

"The horse, by nature, is far from being an intelligent animal. I know this is contrary to the general conceded belief as to the ability of horses to receive education. I use the word "education" in the general 
sense, meaning the power to reason from acquired knowledge. The horse is one of the least responsive animals, so far as mental training is concerned. Ordinarily, a horse is required to know but little, and this little is drilled into him, and his obedience is the result of habit rather than of intelligent comprelıension.

"For common farm use, the training or 'breaking' requires very little time and pains. Once 'broken' he then is ready to be trained. By the most painstaking effort, lnng continued, he may acquire certain habits which may remain with him, and usually do, through life, but such habits are in no way an indication of high intelligence. The horse used on a milk-wagon, for instance, which makes frequent stops, for ever after retains this habit. It often requires weeks and months to develop a 'trick' horse.

"Some writers on the subject declare that no reliance can be placed on the effect of sounds when educating the horse. However, any sound which has been long used to indicate a particular performance, in time enforces obedience to such sound and establishes a habit, as, for iustance, the bugle blast of cavalry or the fire alarm of an engine-house.

"The marvelous feats of some trained horses are simply enforced habits, and are usually guided by some motion of the attendant rather than by sound. So markedly is this the case, that a good horse-trainer gives commands in a single word, as a command to stop, to start, to rear or to lie down. The horse cannot learn to receive two commands at the same time. 
"The surface nerves, rather than sound of the human voice, are used almost exclusively for training horses. The slightest pressure or touch nuay be the command. The ranch-horse obeys a touch of the rider's leg far more certainly and quickly than he does any vocal command. In fact, so true is this, that the expert horseman seldom speaks to his animal, but restrains or cheers or guides him simply by utilizing the surface nerves of his body." 1

It is the intelligence of the man, after all, rather than the intelligence of the horse, which determines use and performance. The intelligence of the horse, whatever it may be, his response to the driver's wishes, his courage and endurance, depend somewhat, perhaps largely, upon the blood of his ancestors-inheritancebreed. However, characteristics and disposition are greatly modified by climatic conditions. The very air he breathes, the temperature in which he lives, the elevation above sea-level and the humidity of the climate, are all important factors in modifying both the physical and mental peculiarities not only of breeds but of individuals of a breed as well. The Clydesdale horse brought from his native country to the dry district bordering on the Rocky mountains loses some of the abundant long fetlock hair-"feather"; and his offspring reared in this dry climate loses still more of this peculiar and apparently useless appendage. The "wind" of the lowland horse and his sluggishness are improved, in time, when he is taken to mountainous districts. The horses of the low coast districts of North Carolina and those

${ }^{1}$ Author of this quotation not known. 
of the mountains are much unlike in endurance and temperament. Both are largely of the same warm blood on their sire's side and of mixed and warm-blooded dams. It might be possible to place Clydesdale horses on the Shetland Islands and preserve their size and general characteristics by providing suitable and abundant food and as warm and comfortable quarters as are found in the valley of the Clyde. However, it would appear to be wiser and more economical to choose breeds of horses which have already become adapted to climate, use and environment, rather than to change food, environment and use to suit the breed.

Those who have had much experience with horses are often greatly disappointed in them at times. Sometimes they appear to learn rapidly, and then again they seem to lose all their education and become semimaniacs. It is no uncommon thing to drive a horse for years, trust him implicitly, assert that he would not run away even if the harness broke and the wagon ran against him, and then to find that the horse has suddenly forgotten all his education and will lose his self-possession and run away even if so much as a leaf flutters down before him. A splendid driving mare which had been used by the family with great pleasure for years, without any provocation whatever, on a level road, began kicking and did not cease until she had freed herself from the carriage and had seriously and permanently injured the two occupants. One old horse which had been used by two generations of children to transport them to school over a quiet road went crazy (perhaps this is too strong a term), ran away and 
caused great damage because a rooster flapped his wings and crowed beside the road.

Without denying the fact that some horses have shown great sense, have apparently learned to reason and appear to be always trustworthy, yet it often happens that a horse trusted because of his previous good behavior seems all of a sudden to become a fool. It is wiser, therefore, never to put oneself in jeopardy by too implicitly trusting in an animal much stronger than oneself, and one which too often is lacking in good sense. The pistol that is not loaded is always the one that goes off and kills somebody. 



\section{CHAPTER II}

\section{BRIEF HISTORY OF THE DOMESTICATED HORSE}

Wiтhout doubt the ass, an inferior member of the equine family, was domesticated long before the horse. It is believed that the horse was unknown to the Israelites until they sojourned in Egypt, and presumably up to that time it had not been domesticated. It is impossible to determine the place of its origin. It is enough to say that the horse is first spoken of as a domesticated animal during the famiue in Egypt, when it is stated that Joseph exchanged corn for horses about 1712 B. C. In 1898 B. C., Abimelech gave many and valuable presents to Abraham, such as oxen, sheep, man-servants and maid-servants, sheasses and he-asses, but no mention is made of horses, and, as horses became the most common and valued presents during the sixteenth century B. C., it is believed that the horse had not ret been brought under the dominion of man anterior to the beginning of the eighteenth century B. C. As soon as they were domesticated they became common in the most civilized countries, such as Media and Persia. Assyria at an early date employed large numbers of hor'ses in the cavalry division of the army. Some were also harnessed to war-chariots. That branch of the service which required horses was usually more effective than the infantry, as compared with modern times. 
It is probable that the horse, when first domesticated, was not used to any great extent as a burdenbearer or for tilling the soil. His chief uses in ancient times appear to have been for display and war. Horse-racing early became popular. From the standpoint of the uses to which horses were largely put, it appears that long before the Christian era the "points" of the war-horse had been carefully studied and were well understood. I quote Xenophon's description of a good horse of his time, ${ }^{1}$ with instructions to the purchaser. Note how carefully each point is set forth and how accurate the reasoning when applied to the brave, broad-breasted war-horse.

He says, "We will write how one may be the least deceived in the purchase of horses. It is evident, then, that of the unbroken colt one must judge by the bodily construction; since, if he have never been backed, he will afford no very clear evidence of his spirit. Of his body, then, we say that it is necessary to first examine the feet; for, as in a house, it matters not how fine may be the superstructure, if there be no sufficient foundations, so in a war-horse there is no utility, no, not if he have all the other points perfect, but be badly footed. But in examining the feet it is befitting first to look to the horny portion of the hoofs, for those horses which have the hoof thick are far superior in their feet to those which have it thin. Nor will it be well if one fail, next, to observe whether the hoofs be upright, both before and behind, or low and flat to the ground; for high 
hoofs keep the frog at a distance from the earth, while the flat hoofs tread with equal pressure on the soft and hard parts of the foot, as is the case with bandylegged men. And Simon justly observes that wellfooted horses can be known by the sound of their tramp, for the hollow hoof rings like a cymbal, when it strikes the solid earth. But, having begun from below, let us ascend to the other parts of the body. "It is needful, then, that the parts above the hoofs and below the fetlocks - the pasterns-be not too erect, like those of the goat; for legs of this kind, being stiff and inflexible, are apt to jar the rider, and are more liable to inflammation. The bones must not, however, be too low and springy, for in that ease the fetlocks are liable to be abraded and wounded, if the horse be galloped over clods or stones. The bones of the shanks should be thick, for these are the columns which support the body; but they should not have the veins and flesh thick, likewise. For, if they have, when the horse shall be galloped in difficult ground they will necessarily be filled with blood, and will become varicose, so that the shanks will be thickened, and the skin be distended and relax from the bone; and, when this is the case, it often follows, that the back sinew gives way and renders the horse lame. But if the horse, when in action, bends his knees flexibly at a walk, you may judge that he will have his legs flexible when in full career; for all horses, as they increase in years, increase in the flexibility of the knee. And flexible goers are esteemed highly, and with justice; for such horses are much less liable to blunder or to 
stumble than those which have rigid, unbending joints. But if the arms, below the shoulder blades, be thick and muscular, they appear stronger and handsomer, as is the case also with a man. The breast also should be broad, as well for beauty as for strength, and because it causes a handsomer action of the forelegs, which do not then interfere, but are carried wide apart. ${ }^{1}$

"And, again, the neck ought not to be set on, like that of a boar, horizontally from the chest; but, like that of a game cock, should be upright towards the crest, and slack towards the flexure; and the head being long, should have a small and narrow jaw bone, so that the neck shall be in front of the rider and that the erc shall look down at what is before the feet. A horse thus made will be the least likely to run violently away, even if he; be very high-spirited, for horses do nct attempt to pun away by bringing in, but by thrusting out, their heads and necks. It is also very necessary to observe, whether the mouth be fine or hard on both sides, or on one or the other. For horses which have not both jaws equally sensitive are likely to be hardmonthed on one side or the other. And it is better that a horse should have prominent than hollow eyes, for such a one will see to a greater distance. And widely open nostrils are far better for respiration than narrow; and they give the horse a fiercer aspect; for when one stallion is enraged against another, or if he become angry while ridden, he expands his nostrils to their full width. And the loftiel the crest, and the smaller the ears, the more horse-like and handsome is

I Evidently this does not describe a trotter. 
the head rendered; while lofty wither's give the rider a surer seat and produce a firmer adhesion between the body and shoulders. A double loin is also softer to sit upon, and pleasanter to look upon, than if it be single; and a deep side, rounded toward the belly, renders the horse easier to sit, and stronger, and more easy to be kept in condition; and the shorter and broader the loin, the more easily will the horse raise his fore-quarters, and collect his hind-quarters under him, in going: These points, moreover, cause the belly to appear the smaller; which, if it be large, at once injures the appearance of the animal and renders him weaker, and less manageable. The quarters should be broad and fleshly, in order to correspond with the sides and chest, and, should they be entirely firm and solid, they will be lighter in the gallop, and the horse would be the speedier. But if he should have his buttocks separated under the tail by a broad line, he will bring his hind legs nnder him, with a wider space between them; and so doing he will have a prouder and stronger gnit and action, and will, in all respects, be the better on them. A proof of which is to be had in men, who, when they desire to raise anything from the ground, attempt it by straddling their legs, not by bringing them close together. Stallions should not have the tetes large, and this ought not to be overlooked in foals.

"To conclude, in regard to the lower joints, of the shanks, namely, and the fetlocks and the hoofs, behind, I have the same remarks to make, and no others, than those which I have made above."

Little is known of the early history of the horse in 
England. It is believed, however, that the native horses (early introduced) were greatly benefited by crossès with the cavalry-horses of the Roman garrisons. During the Norman Conquest heavy cavalry-horses were introduced. These horses constituted the most rapid and efficient force of the army. A heavy horse was needed to carry the great weight of arms and armor in addition to the rider. For hundreds of years after the Conquest two distinct kinds of horses were imported, the heavy horse of Flanders and the light but more active horse of Spain and the Orient.

The earliest suggestion that horses were used in agriculture is said to be derived from a piece of Bayeux tapestry, where a horse is represented as drawing a harrow. This, however, must have been an exceptional case, for we know that oxen were used until a comparatively late time, and that in Wales a law existed forbidding horses to be used for plowing. ${ }^{1}$

It will not be necessary for our purpose to give here the history of the horse previous to his introduction into England and France for the purposes of agriculture and road work, except so far as it may be necessary to understand the causes which have produced the various breeds and varieties, and their distinctive characteristics.

\section{INTRODUCTION OF IMPROVED HORSES INTO ENGLAND}

King John ascended the throne in 1199 and paid great attention to the improvement of the farm-horse, importing (ne hundred heavy stallions from Flanders 1 Encyclopedia Britannica, Vol. VIII, p. 181. 
at one time. In the first quarter of the fourteenth century, Edward II imported both mares and horses of the draft type and fifty horses of Spanish blood. Before his time, England had enacted sumptuary laws in regard to horses, especially as to their exportation. Upon the whole, these laws were beneficial and did something toward improving the horse by retaining the good ones and by the exclusion, in part, for breeding purposes of inferior specimens. They were not repealed until the sixteenth century. They provided, among other things, that horses of a certain quality, or valued at a certain price, should not be exported. At the close of the fifteenth century, Heury VIII rigidly execnted the laws which prohibited the exportation of both stallions and mares that were above a certain value, which resulted in selling the poorer and keeping the better animals. He also decreed that no stallion under the height of fifteen hands (sixty inches) should run at large on the commons, and that all foals, filleys or mares that were ill-shapen or undersized should be killed. Thus for about three hundred years intelligent effort was made to improve the horses of Great Britain by selection and by the admixture of superior: blood of both Flemish and Spanish origin.

In order to satisfy the Puritans, Oliver Cromwell forbade racing, which had already become very common. Notwithstanding this, he was a lover of fast horses and purchased of Mr. Place a noted Arabian horse known as "White Turk," which was said to be the most beautiful horse of eastern origin ever imported into England. Many of the pedigrees of our present 
thoroughbred horses, and even of the trotters, trace directly in some lines to the noted animals imported before the close of Cromwell's reign, or to those imported prior to 1760 . The names of the most noted of several importations follow:

$\left.\begin{array}{l}\text { Place's White Turk . . . . . } \\ \text { Moroceo Barb . . . . Time of Common- } \\ \text { Helmsley Turk . . . . }\end{array}\right\} \begin{aligned} & \text { wealth, } 1653,1649- \\ & 1660\end{aligned}$

Damascus Arabia . . . . . . .

Three Turks from Hamburg, 1684$\}$ Charles II, 1660-1685

Royal Barb or Turkish mares...

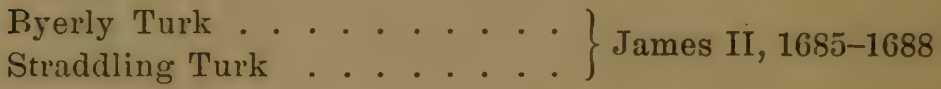

Darley Arabian. . . . . . . . Curwen's Barb Q... Carlisle's Turk .........

Perhaps the most noted Arabian horse that was ever imported into England was Godolphin Arabian, during the reign of King George II (1727 to 1760). It is believed that every fast rumning or trotting horse's pedigree reaches back in some lines to one or more of the horses named above, or to the royal mares. In some cases the pedigree runs back to more than one of these noted stallions and to the royal mares also. Invariably, the pedigree of the running horse traces back to these noted ancestors in more lines than does that of the trotting horse. The pedigree of the trotting horse, if traced back far enough, usually ends, on the dam's side, in a "noted road mare" of unknown blood. It seems to be the consensus of opinion that horses bred true to the thoroughbred line cannot be 
trained to trot as fast as those which have originated from out-crosses with animals not thoroughbreds, yet with some warm blood and built on lines similar to those of the thoroughbred, so modified as to better adapt them to a fast trotting or racking gait.

Charles II (1660-1685) paid great attention to the turf, sending his Master of the Horse to the Levant ${ }^{1}$ to import both mares and stallions, and it is to these imported mares that the name of "Royal Mares" has been given.

The Spanish horses imported into England, it is believed, were identical, or nearly so, with the oriental blood; and the reason for sometimes importing Spanish horses instead of those from the Orient, was that at this early period (first quarter of the fourteenth century, King Edward) some of the Spanish horses were more improved and better than Arabian horses. It is quite probable that some of the rumning horses of England and the trotting horses of America have first an infusion of warm blood through the Spanish horse, and later through direct importation from Arabia and contiguous countries.

${ }^{1}$ Levant, the east, the point where the sun rises, especially the countries of Turkey, Syria, Asia Minor, Greece, Egypt, etc., which are washed by the eastern part of the Mediterranean and its contiguous waters.

Various names are applied to the horse which has wholly, or in large part, the blood of the Orient; as the "hot-blooded," "thoroughbred," "running horse," "Arabian" and "Oriental horse." The term "Orient" (the east), as used in works on the horse, is usually applied to the countries of Arabia, Morocco, Barbary and Turkey. Although Arabia is now thought to possess horses of the best quality, the other countries mentioned, and eren Spain, in early days, are said to have possessed better horses than did Arabia. 
It will be seen that Great Britain derived her horses from those which were in the country at the time of Cæsar's invasion (55 B. C.), which subsequently were improved by importation of Flemish draft-horses and other's of the same type, and by the oriental horse from Barbary, Arabia and Turkey, and from Spain. It was not long before two distinct types were developed,- the draft-horse and the light thoroughbred. There were, indeed, many intermediate types, but these two types for a long time stood at the head of all others. From these have come varieties, a few of which have developed into breeds sometimes varying greatly in form and specialized qualities. Something analogous to this also transpired in France, and here, too, is seen the draft- or heavy horse and the light, quick mover.

The people of Great Britain have always been noted for their love of agriculture and the chase. From time immemorial, equine display accompanied the public appearance of royalty, and this encouraged outdoor sports among the people. Whoever maintained one or more horses found a ready passport into society, which conld not be entered in absence of such ownership. While Britain's greatest strength in modern times is her navy, she nevertheless maintains a numerous and efficient cavalry.

Not the least of the forces which have long been at work for the improvement of light horses is the universal love of the English for outdoor sports, and especially for those which test the speed and endurance of the horse, as well as the skill of its rider. The 
English farmer has also acquired a love for the horse. Although as a rule, he does not, participate in the race, he is everywhere conspicuous and has thus learned to admire, almost adore, the hunter. He also takes special interest in the agricultural- and draft-horses for their strong, symmetrical, plump form and size and their ability to work. Consequently, in breeding and improvement, the draft-horse has kept pace with those of lighter and fleeter forms. Perhaps no other people has done so much for the improvement of the horse, and the dissemination of well-bred animals, as the Anglo-Saxons. America is certainly indebted to Great Britain for a wealth of valuable foundation stock with which to begin horse-breeding.

\section{THE HORSE IN FRANCE}

Until quite recently, France has furnished to America only one breed of horses, the heavy Percheron, ${ }^{1}$ which has been imported very largely during the last third of the nineteenth century. Pereherons have been most popular in the west, while in the east the Clydesdales remain as popular as they were before the introduction of other draft-breeds.

The Percheron ${ }^{2}$ horse has a most interesting history, since he is a marked illustration of the successful mingling of the hot blood of the Orient with the cold-blood draft types. The blending of types so mark-

1 Known by several names; see Chapter VIII.

2 For" a full history of the early Percheron horse, see "Percheron Horse," translated from the French of Charles Du Huys (1868), Orange Judd Co., New York. 
edly dissimilar in nearly all characteristics, into a harmonious, prepotent breed, is not only difficult, but quite unusual.

Little is known of the character of the horses of France prior to admixture with foreign blood. A marked change in them began to appear soon after the battle of Tours (732 A. D.), in which Charles Martel defeated the famous Saracen chief, Abdurame, and killed the infidels to the number of three hundred thousand. The horses of the Saracens, like themselves, came from the East. Upon a division of the spoils, a large number of the horses were assigned to the men of LaPerche, Orléanais and Normandy, who composed the bulk of the French forces. The custom then, as now, was to leave most of the horses entire; therefore the magnificent cavalry-horses of Abdurame must have had marked beneficial effects on the native horses of France. These three provinces still constitute the central breeding districts of the Percheron.

Du Huys says, "The Percheron race comes from Arabia," but he adds that "the Percheron must have been especially modified by contact with the horses of Britanny." The present form and appearance of this breed give unmistakable evidence that great modifications and changes have taken place in recent years, and such changes can be ascribed only to an infusion of cold blood through some well-defined breed or variety of draft animals. 


\section{CHAPTER III}

\section{HORSES OF AMERICA}

THE horse, as we know it, is not indigenous to North America. All horses that are found in America, except those that have been brought into the country within the last few years, are offspring of imported stock. Since the imported animals from which our liurses are derived were of widely different characteristics and have been kept under radically different climatic, food and use conditions, the offspring have presented until recently few fixed and distinguishing characteristics. Especially has this been the case when the imported stock or their full-blood offspring were mixed with the nondescript ${ }^{1}$ females which often contained the mixed blood of several breeds or varieties differing radically in size, color and disposition. This unintelligent mixing of several unlike breeds with mixed-blooded animals, combined with unwise selection, has produced horses devoid of marked or specialized qualities. While there are modern methods practiced to a limited extent where the breeding of horses is pursued along scientific lines, so that the specialized qualities of parents are perpetuated with some degree of certainty, yet most of the horses bred in America are of mixed origin; that is, they trace their genealogy

${ }^{1}$ An animal of mixed and unknown ancestry. 
to nearly as many breeds, subbreeds, nondescripts and varieties as they have American ancestors. Hence, in the rural districts we see many inferior horseshorses of varied colors, conformation, temper, size and degrees of usefulness. Some are worth ten times as much as others, yet the least valuable cost as much for maintenance and nearly as much for rearing as the animals that sell for the higher prices. This brief outline of the method in the breeding of the general horse of America may in part serve to explain the discussions that follow.

All the wild horses of modern times are, without doubt, the offspring of those which escaped from domestication in earlier centuries. Those of the Volga, the steppes of northern Asia, and those of the northern districts of China are supposed to be the offspring of horses liberated at the siege of Azof, 1657; those of Texas, of horses abandoned by DeSoto (1539-1542), or possibly of those turned loose at the time the Spaniards retired from Buenos Ayres and which were the foundation of the wild horses of South America. It is scarcely probable, however, that those liberated in South America would wander from a district where pasture was abundant and the climate mild, northward through the swamps of the tropical isthmus into Texas. It may be concluded then, that the wild horses of North and South America sprang from two distinet groups, both of which were of Spanish blood. No fossil remains of the modern horse have been discovered either in America, Australia or the islands of the Pacific. It may, therefore, be concluded that the horse 
as now known was not indigenous to those countries. On the other hand, fossil remains of the horse of supposed extreme antiquity have been discovered in Great Britain, in the Kirkdale cave in Yorkshire, as well as in other caves, mingled with the bones of the elephant, rhinoceros, ox and tiger, and it is therefore presumed that horses were abundant in Great Britain at an early period.

The first importation of horses to this country was made by Columbus in 1493. These all perished. A second importation, forty-two in number, was made in 1527 ; a third was made by DeSoto in 1540 . However, Cortez landed sixteen hor'ses in Mexico, in $1519 .{ }^{1}$ In 1608 , the French horse was brought to Canada, and in 1629 the Dutch horse to New York. The Dutch horse was round, short-legged and might properly be classed as a farm- or light draft-horse. These horses soon spread into Pennsylvania, and later were probably crossed with the English draft-horse. The progeny soon formed a somewhat distinctive type, developing into a distinct variety known as the Conestoga. This comparatively light draft-horse, bred primarily for freighting heavy merchandise across the mountains and over primitive roads, was, notwithstanding his lightness, as compared with the modern draft-horse, well adapted to the pioneer's farm, where much work required patience, strength and hardiness. It is unfortunate that some genius did not, by selection and inbreeding, improve and preserve this nascent variety of animals until its valuable qualities had become fixed and

${ }^{1}$ Conquest of Mexico, Prescott, Vol. I, page 218. 
potent. Here was the foundation ready to be moulded by the hand of the scientific breeder into a permanent breed. This variety of horses had been in the country long enough to become thoroughly acclimated and adapted to environment, and had been used for draft purposes from the first; and therefore its conformation had become especially adapted to draft purposes, and this, too, without becoming a sluggish, spiritless mountain of flesh. Unfortunately, this variety has become extinct or has merged into other draft types.

The Canadian horses, many of which have found their way into the States, were also originally of the draft or semi-draft type, though not so large as the draft-horse of modern times. In recent years, however, the importations from Canada have been principally grade thoroughbreds for saddle, and lightharness horses. Formerly many heavy-draft horses were imported. However, in recent rears the importations have fallen off. The French-Canadians imported horses from Normandy and Brittany, a warmer climate than that to which they were taken. The progeny, as might have been expected, lost something in weight, increased in thickness and length of hair, improved in texture of bone, and acquired more spirit than their ancestors. It may be said that these native-bred horses became well adapted in time to the needs of a cold, wooded, new country. Hardy, strong, alert, long-lived-it is unfortunate both for the Dominion and the States that the type has been lost by admixture, on the one hand, with the heavy draft type, and, on the other, with the blood of the light roadster, or thoroughbred. 
In like manner, the pacer, which was probably of Narragansett (Rhode Island) origin, and which seemed likely at one time to develop into a breed, has been lost as a distinct variety. Although there has never been an active demand for animals inheriting the pacing gait, yet there was a distinct place for them; and it is to be regretted that breeders did not continue along the lines which gave unmistakable evidence of the highest success. Instead of developing breeds of horses in America, we have, at great expense, been drawing upon Europe for breeding stock, which was not always potent enough to effect any improvement upon our home-bred animals.

In the Indian pony of the North, and the Indian mustang (Fig. 3) of the Southwest, and the bronco of the West, the foundation stock was ready at hand for the formation of a breed of light saddle-horses, unexcelled by any other saddle breed for traveling long distances on scanty food. Instead of utilizing this valuable material, we have imported numbers of shortlegged, pudgy ponies from Europe. It is objected that the wonderful little horse of the plains has not a good disposition. The same may be said of any other variety of high-mettled horses when subjected to ill treatment. On the plains he was merely trained; had he been fully domesticated and treated as kindly as the trotter has been, and as intelligently bred, there is no donbt that this class of horses, which will soon be extinct, would have developed into a most valuable breed. From this warm-blooded horse, though many generations removed from his Spanish ancestry, a pure saddle breed 
might have been formed, admirably adapted to the arid plains, and filling a place so difficult to fill that, as yet, no new variety or breed has been able to

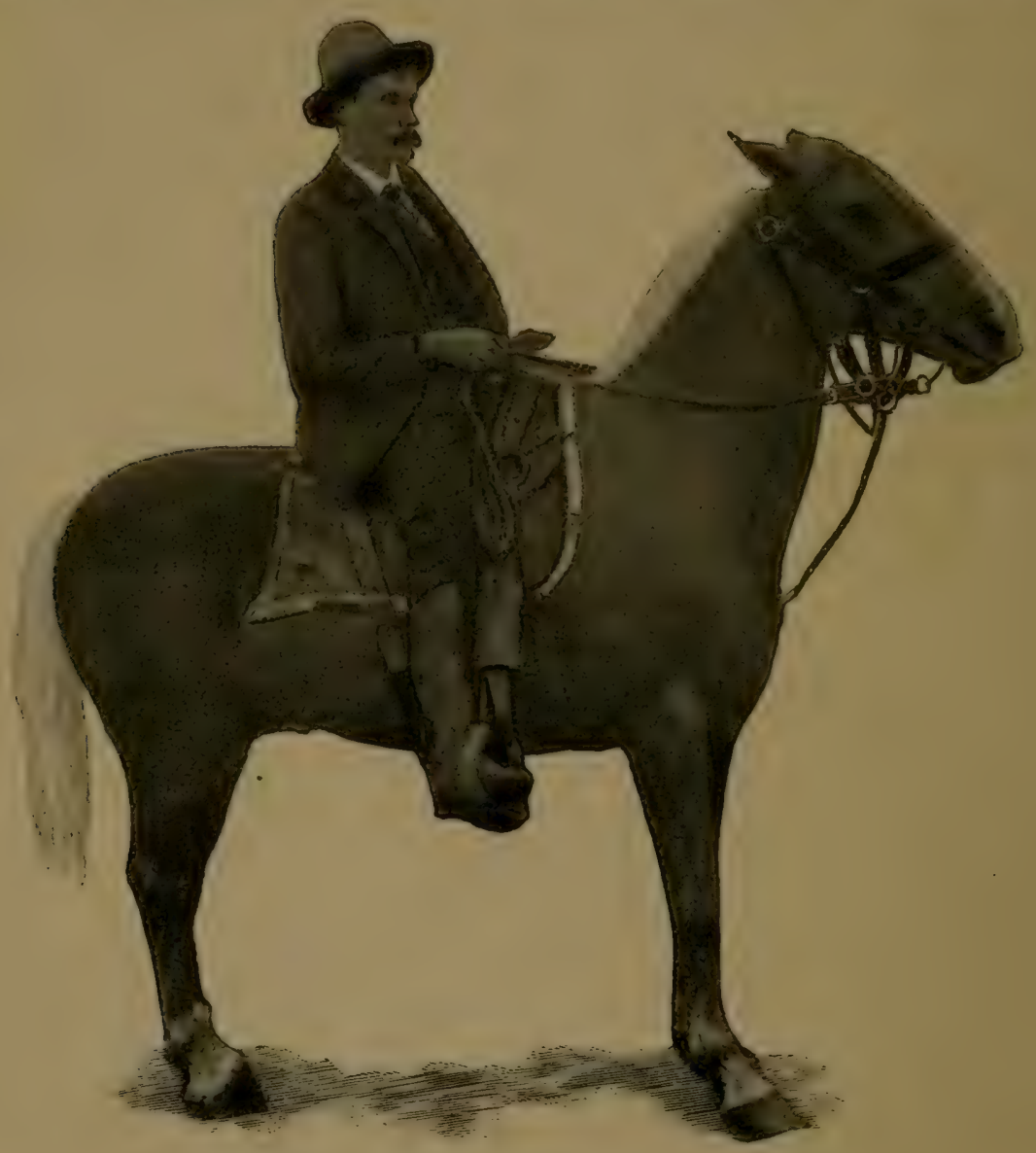

FIG. 3. An improved mustang saddler

fully supplant it, or to fill its place in all respects as a saddler of the plains.

Mr. Frank Forester, in his work on the American horse, after deploring the lack of attention to Ameri- 
can varieties, says: "On the contrary, while the Conestoga horse, the Canadian, the Indian pony of the North, the Indian mustang of the South, the Norman horse of the northeastern British Provinces, the pacer and the general working, or farm-horse, of the middle states, have no chronicler, we go on importing and studying elaborate treatises on the English hackney, the English cart-horse, the English drayhorse, the Suffolk Punch, the Cleveland bay, the Galloway, the Shetland pony, and I know not what else; when it is notorious to every horseman in the country that not one of these varieties does exist-ever did exist-except in the case of the individual importation; or, if they do exist, would be of any value or utility in North America." Perhaps this statement is somewhat overdrawn; nevertheless, it contains much truth.

Previous to the Revolutionary War, a number of thoroughbred horses had been imported, but none of the states or colonies had regularly established racecourses except Maryland, Virginia and South Carolina. The northerner paid little attention to the breeding of thoroughbreds until nearly half a century after the war. From the race-horse it was an easy step to the trotter. Out of the oriental racing blood, tracing back in some lines to the time of Charles II (1660-1685), has been developed in the United States a most valuable, it might be said wonderful horse, the American trotter or roadster. Many causes have led to his production. A single one, on account of its uniqueness, may be mentioned. To the Puritans, the running of 
horses was a sinful pastime, and the gait, therefore, a useless and a dangerous one, hence everything was done to discourage the breeding of a horse which was almost certain to be used largely for racing. The trotting gait was useful and not so likely to lead youths astray; so until quite recently running horses were excluded from the tracks of the State and County Agricultural Societies of the eastern and middle states, while trotting horses were freely admitted. Thus the Puritans unwittingly did much to encourage the improvemert of the trotter. The South followed more closely after English customs, hence racing in most of the southern states has always been popular; while in the North the trotting gait in horses has been more prized, and little attention has been paid to the running horse until the last two decades. $\mathrm{He}$ is now nearly as ropular in the North as in the Sonth.

From an admixture of the hot blood of the East with the best specimens of the mixed blooded horses of the North has come, when it has been judiciously mingled, a large number of superior roadsters, - horses of courage, endurance and speed, such as no other country possesses. These hor'ses have had a very marked effect on the strile and construction of our light wagons. They have also been the means by which the American boy has become a superior horse man. On the other hand, it is true that too often the warm-blooded horses have been bred to inferior nondescript mares, which resulted in progeny of diminished size and bone and undesirable temperament, 
without securing compensating benefits in any direction. The anatomical proportions of these grades were often bad, the limbs too light and crooked for the service required, a temperament too high for the slow work of the industries and not fast enough to secure either prize money or pleasure. By this unwise breeding many horses totally lacking in any specialized qualities have been produced,-liorses which tended to become unsound as soon as they were used either for purposes of gain or pleasure. In some sections more unsound horses may be found in a single county than can be seen in the whole of any great horse district of France or Great Britain.

The cold climate of the North made equestrianship unpleasant for half of the year. The trotter is not usually a good saddle-horse; hence roadsters have been bred in greater number's and perfection in the northeru and western parts of the United States than in any other part of the world. The comparatively fine condition of the roads in summer makes it possible for two or three persons, with one horse attached to a light vehicle, to travel as rapidly as the equestrian, and far more comfortably in bad weather. The ingenuity and skill of the American mechanic, exhibited in the various forms of road-wagons, have had a potent influence in the development of a class of rapid, pleasure - giving roadsters, such as no other country even approaches. On the plains and in the South the saddle-horse became a necessity. The highmettled horse well suited to the saddle was not the best animal for unskilled laborers to use in the cotton 
and cane fields of the South, so the mule came in to fill the gap.

It is difficult to explain why Americans have not produced a dozen breeds or varieties of horses, each as well fitted for its locality and use as the roadster is fitted for the place which he fills so well in our broad, diversified country. We had a rare foundation in the greatest of all the pioneer horses, the Morgan family, but were so slow in recognizing it that it has nearly slipped from our grasp. Perhaps this dearth of American breeds is due to the magic of that one word, "imported," which occupies the most prominent place on the breeder's hand-bills, when he calls attention to the animals bought, and bred. It is asserted that many grades, or at least animals of doubtful breeding, have been imported at long prices; - that magic word, "imported," serving to take the place of an authenticated pedigree long enough to insure that the animal really belonged to some well-defined breed.

Pedigrees taken from the first volumes of studbooks are appended, to show on what slender evidence the claim of pure breeding in early days was sometimes based. In both eases the full recorded pedigree is transcribed:

\section{0}

NAILOR

Bred by Thomas Barker, Fryton

356

WONDER

Sire Volunteer, 557 
A large number of similar pedigrees might be given, but they would serve no useful purpose. The object in transcribing these is to illustrate how little claim can be made to pure breeding of animals whose breeder's name, date of birth and name of sire and dam are all wanting. However, short pedigrees do not necessarily imply inferiority nor lack of prepotency of the animals to which they belong. While it is desirable to know as much as possible of every horse's ancestry, it is easy to lay too much stress on pedigree and too little on the intrinsic value of the horse for the use contemplated.

There has been no time during the last century when superb animals could not have been selected from varieties of horses in America with lineage well known for two or three generations. A little judgment in mating, rigid selection and improved food and environment would have resulted in the formation of breeds as valuable as those which have been imported at great expense and better adapted to climate, food and use than are the progeny, as a whole, of foreign-bred sires and dams. We have a marked illustration of the success of such an undertaking in the American trotter. It may be said that the foundation stock, in part at least, was imported. But if no effort had been made to produce a distinct American variety of horse, we should still be importing hot-blooded foundation stock of far less speed than is possessed by the home-bred animals. It is little wonder, then, that so distinguished a writer on the horse as Frank Forester should call attention, in 
most vigorous language, to the neglect of home-bred varieties and the craze for importing varieties (socalled breeds) so recent in their formation and of such doubtful lineage as to throw discredit on the purity of blood and the potency of some of the animals imported.

The saving factors which have been present in America for nearly one hundred years are-abundant, cheap, nutritious food and unusnally kind and intelligent treatment. So, notwithstanding mistakes and lost opportunities, we have large numbers of good horses, and some superior ones which compensate in part for the poor ones. One only regrets that a fuller utilization has not been made of the munsually favorable conditions in America for the rearing and improring of horses and the formation of breeds and varieties.

The South has always possessed many good saddlehorses, but it is only recently that any well-defined effort has been made to produce a distinct breed of them. The sonthern saddle-horse and all good carriage-horses have a strong infusion of warm blood. This, united with the best of what might be called native blood (nondescript), often produced superior animals. The material for forming the ideal saddlehorse has long been present, but only recently has any intelligent and persistent effort been made to produce a distinct sadrle breed or variety. (Fig. 4.) Such marked results have been reached by these few years of well-directed effort that the only wonder is the work had not been undertaken before. In a similar manner other American breeds, suited to their 


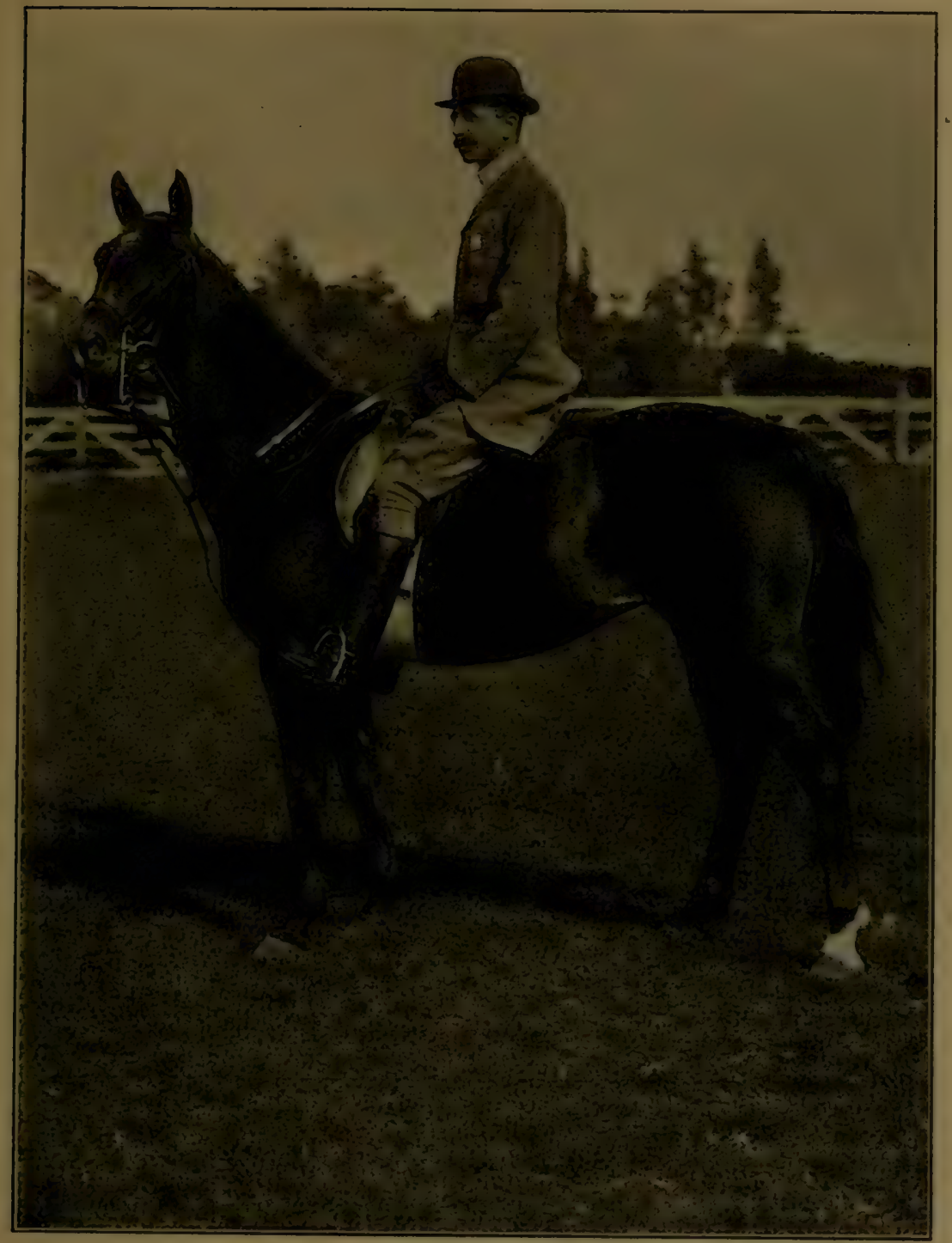

H'dt. 4. A saddler at rest 
work and environment as well as the saddle-horse and the trotter are to theirs, should have been produced; for good material in abundance has been at hand during the last half of this century. ${ }^{1}$

Notwithstanding the neglect and want of appreciation of the material at hand for forming breeds, vast numbers of good nondescript horses are raised each year. 'The great city markets and the expert purchasers of cavalry-horses attest to the quality of one class of our horses at least when rapid movement and endurance are desired. The climate, food and environment of the American-bred horse must certainly be superior, since, in a majority of cases, but little science has been observed or pains taken in mating the parents with a view to the production of definite results.

The breeders who are improving the horses of the country by breeding with one or more distinct purposes in view, and who are securing definite results of great value, are so few as compared with those who breed to the cheapest or the most convenient stallion, that the improvement of the great mass of hor'ses is very slow. From 1890 to 1900 , poor and common horses brought low and unremunerative prices; while the prices of good horses, though sales were a little slow, fell but slightly. The mistake should not again be made of breeding vast herds of third-rate animals. It has been discovered that Europe stands ready to purchase at fair prices large numbers of horses, provided they have some style, are sound, active, symmetrical, of good color and of about nine to twelve ${ }^{1}$ See Chapters IV to VIII for details of breeds. 
hundred pounds weight. This class of horses should now be produced cheaply, if pains are taken in bringing together the appropriate strains of blood. The foundation stock for the production of this class of animals is at hand and abundant. Such horses are well adapted to more than three-fourths of the work performed by horses in the United States. What is wanted is a slightly modified and enlarged old-fashioned Morgan horse, with feet like iron, legs like steel, hair like silk, courage that never falters and placidity that never degenerates into sluggishness. Such a horse will charm the multitude, though he be not a mountain of flesh, nor as fleet as a grey-hound, nor his name be writ high in the roll of aristocratic equines. He will only be a distinguished commoner, a citizen of the great horse republic. Such a horse will not be a so-called "generalpurpose horse," neither will he be specialized toward draft or speed,- - just a mighty handy fellow to have around, ready and willing at all times to "fetch and carry," so long as he is not asked to fetch with lightning speed or carry the elephant's burden. He will not be a true, high-priced coach-horse, nor the ideal saddle-hor'se.

In imagination I see this commoner horse ready to serve the citizen: Bay in color, black points, short back with neck which has a little suggestion of the peacock's and an eye that meets your gaze bravely; a collar seat which lovingly embraces the shoulders, a breast which protrudes like the prow of a schooner, legs wide enough apart to prevent their interfering and to give room for the inside leg museles strong 
enough firmly to attach the limbs to the body; so close-ribbed that one will not continually be reminded of a slatted corn-crib that can never be kept full, and yet not so close-ribbed as to prevent long action, for it is evident that a short-bodied, very closeribbed horse must be short-gaited; that symmetrical development of hind legs, rump and levers which can neither be fully described nor illustrated, but the symmetry of which the trained eye takes in at a glance, and the judgment approves because the propeller end of this complex machine gives evidence that it will make things move in this work-a-day world.

Who will breed these horses, always salable at fair prices, wanted not only in America but in Europe as well, in countless numbers? There is a superabundance of foundation stock from which to select. Such an animal as has been described is not difficult or expensive to produce. He may be of mixed-blood ancestry and yet be very good in his class. He will stand intermediate between the two extremes and might be bred on the principle described by the owner of a very superior dog, who, when asked about the blood of the $\mathrm{dog}$, replied that he was "half pointer, quarter setter and the remainder just plain dog." 


\section{CHAPTER IV}

BREEDS, SUBBREEDS, FAMILIES, PARIETIES, CROSS-BREEDS AND GRADES

THE term "breed," as used by the farmer, signifies a group or class of animals having a number of distinctive qualities and characteristics in common, and the power to transmit those distinctive traits with a good degree of certainty. Such groups of animals have distinctive names, such as "thoroughbred," "Clydesdale," "Percheron," "Shorthorns" and recorded pedigrees usually tracing back for two, three or more generations. In the case of a long-established breed, as the Shorthorns, the recorded pedigree may go back a hundred years or more and for many generations.

A breed is usually started by selecting two or more unusually good animals from a group that has been produced in a locality by reason of better food, environment and intelligent selection, and which is usually superior to the animals of the same species in other localities. These few having been selected, inbreeding is practiced to a greater or less extent for the purpose of perpetuating and intensifying one or more desired characteristics. At first this work is usually carried on by one, or at most a few, of the most intelligent breeders, who, by improving conditions, have first improved the quality of their own 
stock. From time to time animals with some superior characteristics are selected from the nascent variety, and these are inbred for a time, producing a variety which may develop into a breed. Again, a family may be formed within the breed by selection and inbreeding. For instance, the breed of Shorthorn cattle contains several quite noted families, such as the Duchess and the Waterloo. The term "tribe" is sometimes used instead of "family" in this connection. A small group of animals which have been improved but have not yet taken on all of the fixed characteristics of a breed should be called a "variety." Under skilful management it may, and usually does, ripen into a breed. When the breeders of a group or variety decide that the distinctive characteristics are reasonably well fixed, they publish what is known of the breeding of the better animals of this variety in a first volume of a stud-book, herd- or flock-book, and thus the breed makes it official appearance. In the United States and Canada there are now published by the various livestock registry associations twenty-one pedigree records of horses, twenty-five of cattle, thirty-one of sheep and twenty-two of swine. A volume for each breed is usually published annually. (See-Appendix, for further information.)

It will readily be seen that when the attempt is made to launch a breed and establish a record of genealogy, or pedigree, for the various animals selected for such record, the first pedigrees must be based on unpublished records. Not infrequently, some of the foundation stock are recorded simply by name, and 
nothing is said of ancestors, because nothing is known of them. In the case of trotting-horses the pedigree may end abruptly on the dam's side by the statement "out of a good road mare." Fortunately, the launching of a new breed and the admission of animals to registry are placed in the hands of an expert and reliable committee or commission. The rules governing the registration of animals of different breeds in the first volume, and sometimes in a few subsequent volumes, are quite variable, and half-bloods, three-fourths bloods and even animals of unknown origin are sometimes registered in the first instance. As the years go by, the rules for admission to registration are made more strict, and finally no animal is eligible for record whose sire and dam are not recorded. Most recorded animals have three, four, or more generations of recorded ancestors on both the dam and the sire side. The Shorthorn Herdbook serves well to illustrate the subject of pedigrees, and has been selected for illustration because the first volume was compiled with great care and subsequent issues have been supervised most critically. The first volume was issued when pedigrees were little prized by livestock farmers, yet the utmost care was taken to verify the quality and breeding of animals admitted to record, as well as the reliability of the breeders.

The following records are taken from the first volume of Coate's English Shorthorn Herd-book. It will be seen that apparently no information whatever as to breeding was obtainable; nevertheless, we are not to suppose that these animals were not above the average of the cattle in their locality. In most herd 
books the males and females are designated by both names and numbers, while no number is given to the female shorthorns:

No. 77 , Blossom.

No. 84 , Blutcher.

No. 87 , Booth.

So closely have the pedigrees of more recent recorded animals been supervised that it is possible to trace for from six to ten, and even to more generations, the ancestry of animals bred as far back as 1870 with scarcely a single break. One of many illustrations which might be cited is the pedigree, so far as the page will allow, of the Eighth Duchess of Geneva (Fig. 5), sold at public auction September 10, 1873, at New York Mills for $\$ 40,600$. It would require a strip of paper some ten feet wide and three hundred feet long to give her entire pedigree and to record all of the names of her well-authenticated ancestors in ordinary writing in the form given below, in which but six generations are set down. As the number of ancestors in each generation increases in a geometrical ratio, the seventh generation would contain one hundred and twenty-eight ancestors, the tenth generation one thousand and twenty - four, and the fifteenth generation thirty-two thousand seven hundred and sixtyeight ancestors. There are many animals now living which have still more extended pedigrees then the Eighth Duchess of Geneva. Some animals are recorded in both the English and the American herd-books. The numbers in parentheses refer to the English, the others to the American records. 


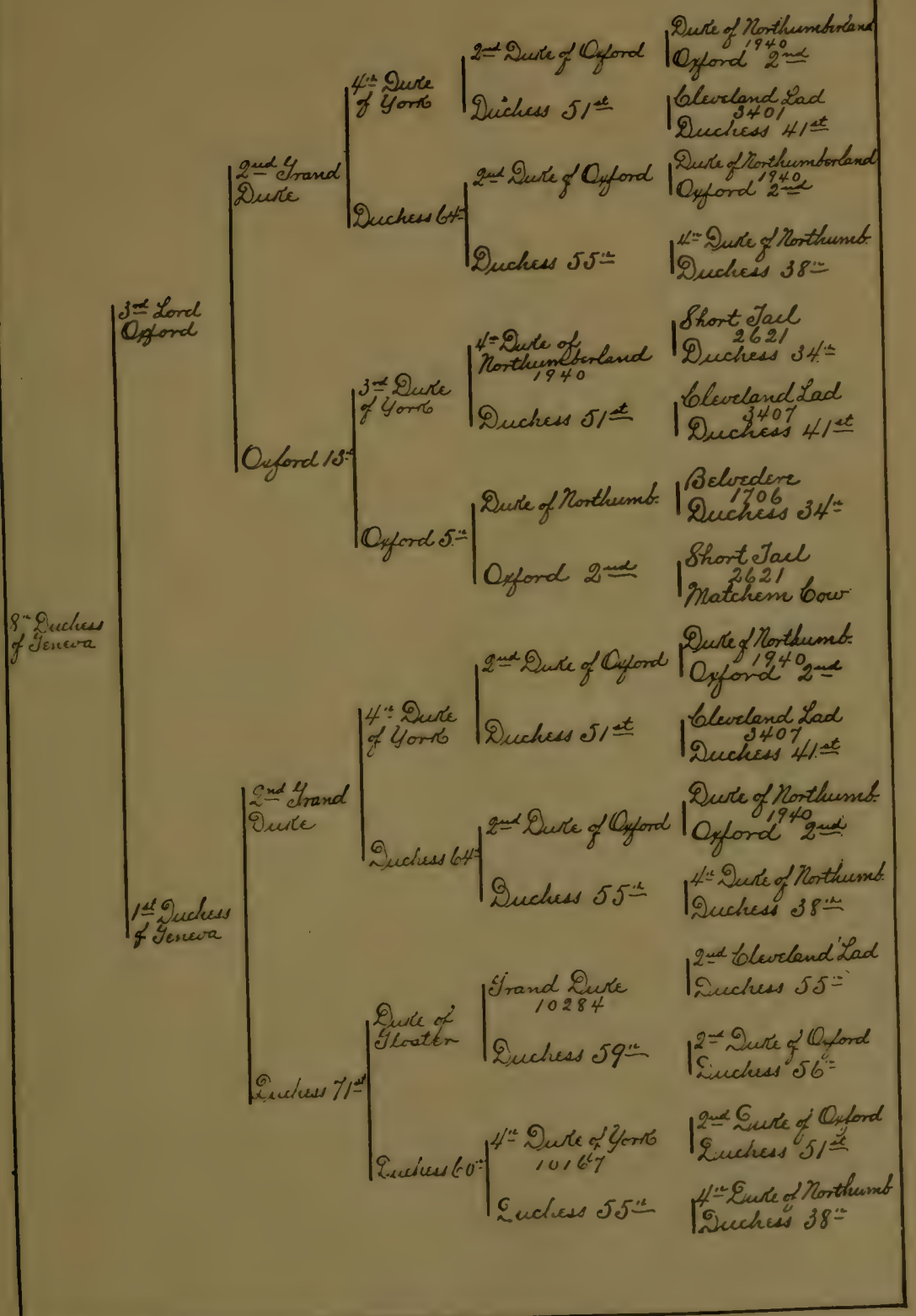

Fra. 5. A superior pedigree 
As a rule, the longer the pedigree of the sire and dam the more closely will the offspring resemble its immediate parents, especially if they have been somewhat inbred. If the pedigree of an animal contains the names of many noted ancestors, it gives value to the animal over and above that of one with a pedigree which contains few or no distinguished ancestors, provided that the animals are equally meritorious. These latter are called "plain" pedigrees. But a long pedigree does not necessarily add value to the animal which possesses it. The pedigree value, then, consists largely in showing that the animal to which it belongs has been bred without any admixture of blood outside of the breed so far back as the pedigree extends, and it may also be of value in revealing the names and numbers of unusually meritorious ancestors. However, animals of unusual merit occasionally have short pedigrees; the genealogical value of such a pedigree being based largely on the animal's prepotency, or on that of its near ancestors, and not on the length of time which has elapsed since its ancestors were first recorded.

Both long and short pedigrees are found not only in the records of Shorthorns but in those of other breeds of animals, though most of the Shorthorns of today have longer recorded and better authenticated pedigrees than many other breeds of domesticated animals.

A short and a long pedigree are given below and well illustrate the evolution of pedigree-making:

Angus Ladd (1046).

Foaled May, 1856.

Sire, a horse belonging to the Eari of Strathmore.

Pedigree unknown. 


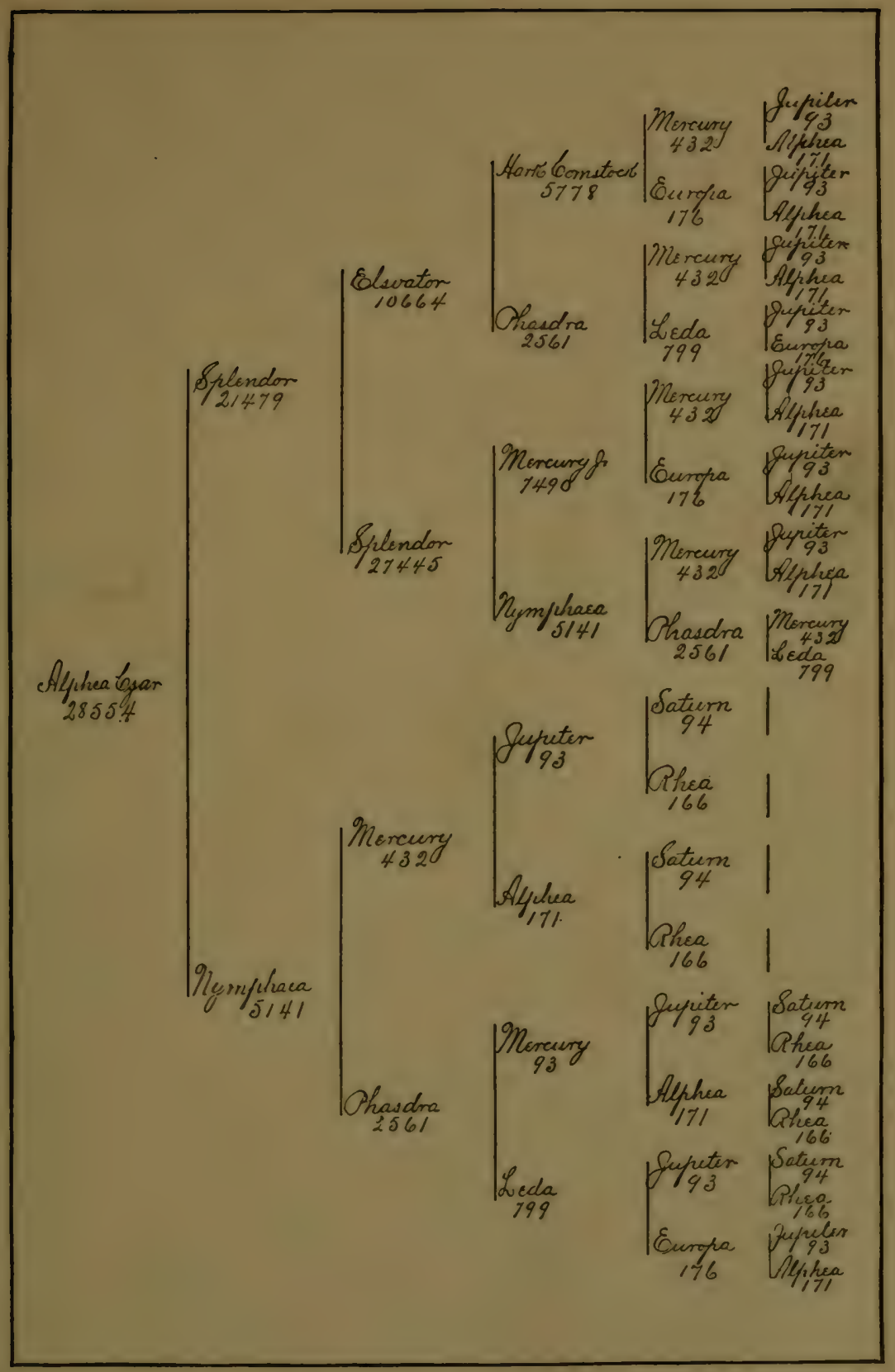

FrG. 6. A marked case of in-and-in breeding 
The pedigree of Alphea Czar (Fig. 6) is one of many which might be cited to illustrate persistent inbreeding. It should be said, however, that the strict meaning of the term "inbred" is not well defined. In a general way it is used to designate the mingling of the blood of animals more closely related than second or third cousins.

It will be noted that the genealogy of Moses (Fig. 7) traces back ten times to Terah, and that so far as the record goes the ancestry of the father and mother of Moses are identical, with the exception of two paternal and one maternal ancestors. The fact should not be overlooked, however, that there are but fortyseven ancestors recorded, whereas he had in the eight generations four hundred and ten ancestors, and that in the last, or eighth, generation there are one hundred and twenty - eight maternal ancestors, only two of whom are mentioned in the record, and one hundred and twenty-eight paternal ancestors, only five of whom are mentioned. Stated mathematically, Moses' genealogy in the eighth generation traces back to two hundred and fifty-six ancestors and shows that he received two two-hundred-and-fifty-sixths of his blood from Haran, five two-hundred-and-fifty-sixths from Terah and two-hundred and forty-nine two-hundred-and-fiftysixths from unknown and unrecorded blood. It is probable, however, that the ancestors of Moses not recorded were related more or less closely to those which are enumerated. In the case of domestic animals, the probabilities are that the unrecorded ancestors were not closely related, nor is it probable that they 


\section{Pedigree of Mroses}

The Meghtest Leader Lawgwer Mirmen and

"Thes was the fraverct warnor Statioman of Ancuent or Miodem Cimes That war fuctlid sword

the the moet gifted frot

That wer breateded a word And nuer cartles philospher. Traced wret hin godden fun

On the deatheres pare, tritha haly so sage

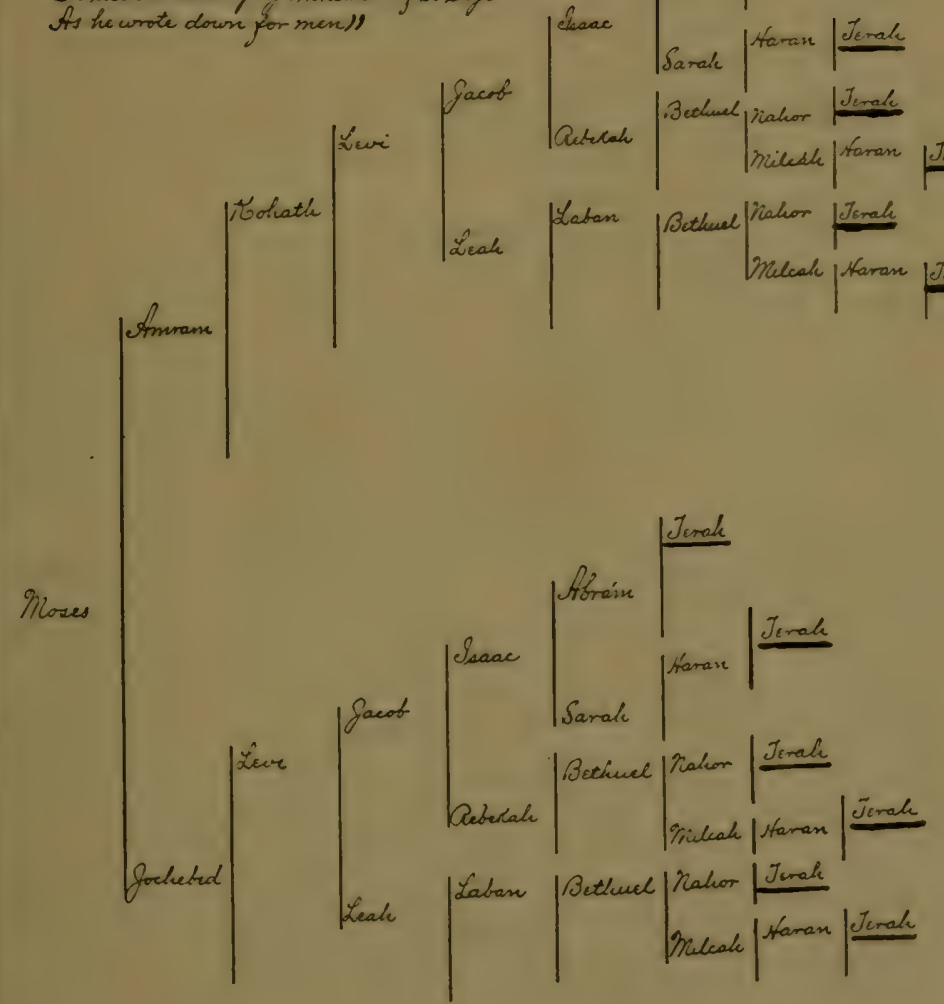

FIG. 7. Genealogy of Moses 
came from homogeneous blood. For an extended discussion of inbreeding, see Chapter XII.

A grade is the progeny of a full-blood and a "nondescript," the latter term meaning, in this connection, an animal usually having little or no improved blood and of no authenticated and recorded ancestry. The term "high grade" is usually applied to animals which have derived seven-eighths or more of their blood from the full-blooded ancestry. This term is seldom used to indicate the lineage of horses, they being specifically termed half-blood, three-fourths blood, and so on.

Subbreeds are formed by selecting, from a breed, two or more animals which may vary slightly from the usual type of the breed, and then by accentuating the differences by means of improved food, management and selection. A good illustration of a subbreed is the Delaine Merino sheep. This subbreed was started by selecting animals that produced wool longer than the average. These were put under better conditions and when the offspring varied toward wool of a longer staple and yet of good quality, they were preserved. Those were discarded which did not show improvement along the line desired and also those which tended to revert to the shorter-wooled type. If the increase in the length of wool had been secured by a cross with one of the long-wooled breeds, then the term "cross-breed" wonld have been appropriate.

A cross-bred animal is the progeny of two distinct breeds, as the White Plymouth Rock, which was probably produced by crossing the White Leghorn with the 
Plymouth Rock. If the breed was formed as it is asserted, then a more appropriate name for these fowls would be Plymouth Leghorns.

If, then, as has been stated, a pedigree may be long or short, may be deficient or complete on the dam's side, may contain many, few or no distinguished ancestors, is it still helpful and valuable, and if so, in what ways? If a pedigree be scanned closely it may reveal first the time which has elapsed since the breed took on. well-defined characteristics. Other things being equal, the longer the breed has been established the greater are the chances that the offspring will closely resemble, in all of its characteristics, its ancestor's. If one is familiar with the breed under consideration, he will quickly recognize the names of the superior animals recorded in the pedigree. This will naturally lead to a study of the history and performance of these animals as set forth by the best informed writers who have been or are interested in the breeds; it gives assurance that the animal whose pedigree is being considered is pure bred and not a grade or a nondescript, and enables one to ascertain whether the animal in question is descended from superior specimens of the breed. It helps one to become acquainted with the methods practiced by the most successful breeders. A good knowledge of pedigrees and the possession of recorded animals are powerful stimulants, which are likely to result in an endeavor to improve the breed along one or more lines; and this in turn serves to stimulate an honest pride in the breeder's profession. 
On the other hand, reliance on pedigree alone may work disastrous results if followed blindly. Individual merit should accompany a pedigree. When, as sometimes happens, a pedigree is simply a record of degenerates, it only helps to mislead. The eye of the breeder that is quick to detect every improvement or note the least tendency to retrogression is the chief thing to be relied upon when breeding any kind of domestic animals for improvement. 


\section{CHAPTER V}

THE THOROUGHBRED; THE TROTTER; THE PACER

Chapter by ROE REISINGER

The American thoroughbred is descended in all his lines from the English race-horse, and he in turn from Arabian, Turkish and Barb stock. For more than a century and a half the English Stud-book has been maintained, in which has been registered every mare of thorough blood, by name, with her lineage and all her foals; the oldest and most remote of these mares tracing back their eight, nine or more generations to known Oriental horses, or horses known to be largely, if not wholly, Arabian, Turkish or Barb. No animal having an unknown or a cold cross within a hundred and fifty year's back in its line could be entered in the English Stud-book, and no American horse can be regarded as thoroughbred that does not meet as high requirements. There have been a number of high-class race-horses whose pedigrees have been short in one or more lines, but never in the history of the turf has a great sire appeared in whose blood was a near cross other than thoroughbred.

The British horse had a considerable degree of excellence before the Roman conquest and was a good subject for the later crossing with the Oriental breeds. Youatt, in his work on the horse, states that Cæsar 
thought the British horses so valuable that he carried many of them to Rome, and that for a considerable period afterward British horses were in great request in various parts of the Roman Empire. He states that, during the occupation of England by the Romans, the British horse was crossed to a considerable extent with the Roman horse; but he probably meant the foreign horses of the Roman mercenary or allied cavalry, from the fact that horses had been introduced into Britain from Gaul and chariot races were instituted long before the Christian era. This suggestion is adopted from the work of Herbert on the horse. In England, horse-racing early became a fixed custom: We learn from history that, after the reign of Alfred, running horses were imported from Germany. That the English, fully a thousand years ago, had produced a valuable breed is shown by the fact that in 930 A. D. a law prohibited the exportation of horses. Many Spanish horses were imported into England in Athelstan's reign. William the Conqueror rode a Spanish horse (probably of Oriental breed) at the battle of Hastings, and won the day by his cavalry. He imported many fine Norman, Flemish and Spanish horses and his great nobles followed his example. Early writers attest the value of the stock descending from these sources.

We learn from Fitz Stephen, a contemporary historian, that in the twelfth century a regular racecourse had been established in London. He thus describes the races: "When a race is to be run by horses which in their kind are strong and fleet, a shout is 
raised, and common horses are ordered to withdraw from out of the way. Two jockeys, then, or sometimes three, as the case may be, prepare themselves for the contest, such as are used to ride, and know how to manage their horses with judgment, the grand point being to prevent a competitor from getting before them. The horses, on their part, are not without emulation. They tremble, and are impatient and continually in motion. At last, the signal once given, they hurry along with unremitting velocity; the jockeys, inspired with the thoughts of applause and the hopes of victory, clapping spurs to their willing steeds, brandishing their whips, and cheering them with their cries."

The first Arab horse imported into Britain, of which we have certain knowledge, was presented by Alexander I., King of Scotland, to the Church of St. Andrew's, in the reign of Henry I. Richard I. imported two eastern horses, probably on his return from the Crusades. Their names were Favell and Lyard, and their qualities are thus set forth in Ellis' Metrical Romances:

"In the world was not their peer,

Dromedary, not destrere ${ }^{1}$

Steed; rabite, ne camayl,

That ran so swift sans fail.

For a thousand pounds of gold,

Should not that one be sold."

Edwaid I. brought horses from the East. One of the accusations against the Tempiars was that, in vio-

1 Destrere steed, a war-horse. 
lation of their vows of poverty and frugality, they maintained "eastern horses, dogs and birds for the chase and falconry, and other vain and worldly pleasures." Youatt narrates that Edward II. purchased thirty war-horses and twelve heavy draft-horses. Edward III. devoted one thousand marks to the purchase of fifty Spanish horses, and he prized them so highly that he made formal application to the kings of France and Spain to grant safe conduct to the troop.

In the reign of Richard II. laws were made regulating the price of horses and prohibiting their exportation. Similar regulations were enforced by other English sovereigns, and in the reign of Henry III. it was decreed that no stallion should be suffered to run at large on any waste or common, where the animals pastured and were of course liable to breed promiscuously, under the height of fifteen hands, on pain of forfeiture; and that all foals, fillies or mares likely to breed undersized or ill-shaped produce should be killed and buried. He also, by law, compelled all the nobility, gentry and higher order of the clergy to keep a number of horses proportionate to their rank. In Henry's reign, also, an enactment was enforced compelling the maintenance of a great number of fullsized mares and stallions in every deer park, and in every rural parish in the realm. These enactments could not fail to result in the great improvement of the horses of England. At that period an annual race was run at Chester. The prize was a wooden ball embellished with flowers, fixed upon the point of a lance. These trophies were provided by the company 
of saddlers. In the year 1510 a silver bell was substituted for the former prize, under the title of "St. George's Bell." Hence the common phrase to "bear the bell," as equivalent to being the victor.

King James I. purchased Markham's Arabian horse at the price of five hundred pounds. Race meetings were now regularly held at various places in the kingdom, and a well-ordered system of training the horses, and of running according to weight, age and distance was introduced. Pedigrees were kept, the best and stoutest horses and mares were reserved for breeding, and their progeny were for the most part set aside for racing purposes. Misson, who traveled in England about the year 1641, writes: "The English nobility take great delight in horse races. The most famous are usually at Newmarket, and there you are sure to see a great many persons of the first quality, and almost all the gentlemen of the neighborhood. It is pretty common for them to lay wagers of two thousand pounds sterling upon one race."

Thongh for nearly a century the best horsemen of England and America have held the thoroughbred horse to be no longer susceptible of improvement by a further infusion of Oriental blood, it must be borne in mind that there is very little of his blood that is not of the Arabian, Barb or Turk. In the year 1730 it is known that the following named foreign horses of note were in the stud in England: The Alcock Arabian, the Godolphin Arabian, the Bloody Buttocks Arabian, Hall's Arabian, the Blondy Shouldered Arabian, Johnson's Turk, the Belgrade Turk, 
Litton's Arabian, the Bethel Arabian, Matthew's Persian, Lord Burlington's Barb, Nottingham's Arabian, Crofts' Egyptian horse, Newton's Arabian, the Cypress Arabian, Pigott's Turk, the Duke of Devonshire's Arabian, Strickland's Arabian, Greyhound, a Barb, Wyun's Arabian, Hampton Court Grey Barb and Dodsworth, a Barb.

When the Puritan sect arose in England, they were violently opposed to horse-racing as a sinful pleasure, and those coming to New England carried with them that belief. In all the other early English settlements a contrary view prevailed. Race-courses were soon established at Long Island, Richmond, Charleston and other points, and the rich planters imported English thoroughbreds and raced them. The passion for racing among the landed gentry of Maryland, Virginia and South Carolina was as strong as in the mother country. Many of our early statesmen kept racehorses; notable among them were General Washington, General Jackson, Henry Clay, Thomas Jefferson and John Randolph. With Jackson, racing was a passion and he actually loved a race-horse. Until broken by age, his commanding figure was conspicuous at all the great southern courses. Among the earliest thoroughbred stallions brought to America was Brilliant, imported into Virginia in 1706 . He was foaled in 1691, and was by Phenomenon, dam by Pacolet, grand-dam by Matchem, great-grand-dam by Oroonoka, and great-great-grand-dam by Traveller, etc. Previons to the Revolution, a great many importations had been made and many native breeding 
establishments existed. As a fixed institution, until about the year 1800 , racing was almost entirely confined to the states of Maryland, Virginia and South Carolina. Nearly all of the horses imported into those states were descendants of the Godolphin Arabian, the Byerly Turk, Spanker, Greyhound, the

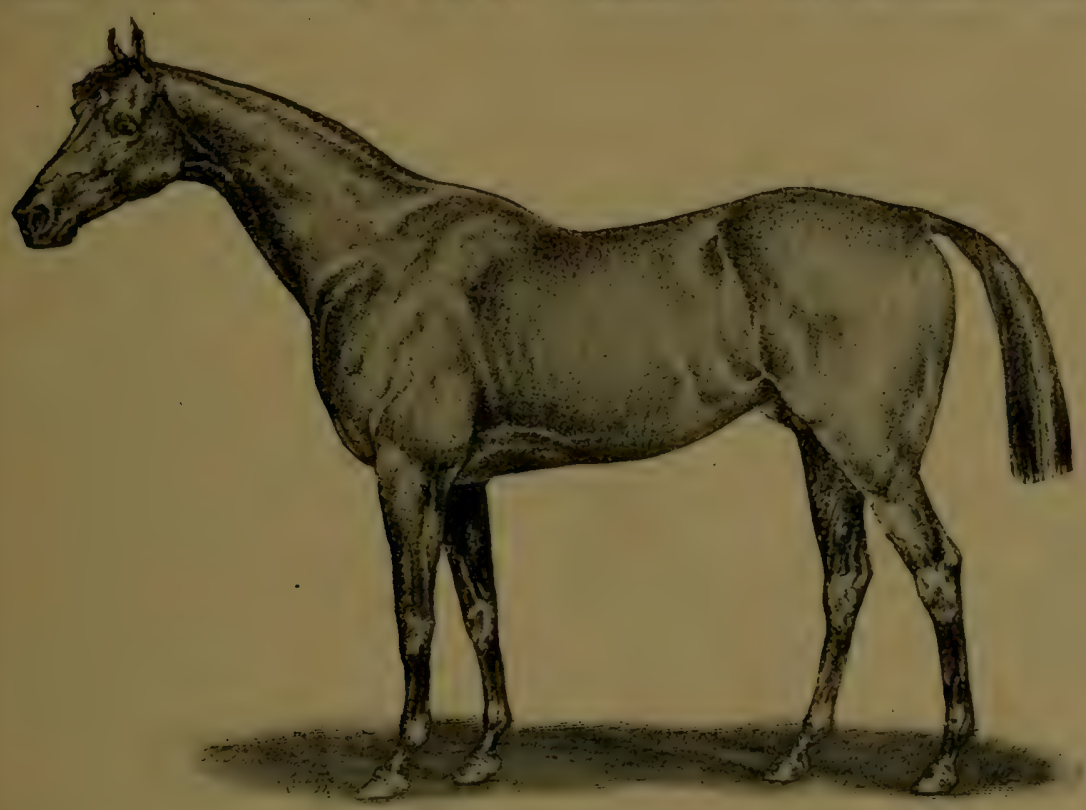

FIG. 8. Thoroughbred

White Turk, Dodsworth, and Layton's Violet Barb mare. Herbert notes the fact that early American thoranghbrecls ran through fewer generations to reach their Oriental parentage on both sides than the generality of English horses of the same date, and more fully showed the Arab and Barb or Turk charteristics in height, figure and qualities. In 1829 was begun the first publication of a work for recording 
the pedigrees and performances of the race-horse in America. Since that time stud-books have been maintained in which the pedigrees of all American thoroughbreds may be found. Throughout the last century English thoroughbreds have been imported and crossed with our own stock till at this time the blood in both countries is the same, and the turf contests between English and American horses, here and in England, show that in racing qualities they are equal. At this time English horses are being constantly imported and American thoroughbreds are raced on all the courses in Europe. It is sometimes asserted that the race-horse has deteriorated, but this opinion is not held by intelligent breeders and turfmen. Though races at distances above two miles are not now in fashion, it is but a few years since the fastest fourmile record was made, also the fastest for one and two miles. A recent writer thus contrasts early racing with that of the present day. "In old times horses ran seldom-often not more than five or six races in a year-often less. The races were over longer distances, but they were specially prepared for them, and, as handicaps were few, the best horse had a pretty easy time. Besides, the number of horses was small. The returns of 1880 showed six hundred and forty foals. In 1900 as many as three thousand eight hundred and twenty-seven were reported to the Jockey Club. A good horse of today runs from fifteen to thirty races in a season, meeting a large number of competitors, and is asked to concede weight, and is kept in training fully nine months in the year. If 
time is any criterion, there is no comparison between the horses of today and those of former years."

While the most general use of the thoroughbred horse now is for racing, it is true that he is capable of a much extended utility. As a cavalry-horse a stout thoroughbred cannot be excelled. In pursuit or retreat his speed and endurance make hirn superior to all others. In Kentucky and Tenuessee, where the thoroughbred is more common, he is often found doing excelleut service as a driver and as a saddle-horse, and sometimes even in the cart or at the plow. Racehorses that have been broken down on the tracks around New York City are sold and put to all manner of uses. In a fine carriage team at Woodburn Farm a few years ago was a thoroughbred gelding whose mate was a standard trotter. Colonel Brodhead declared the former to be far the best carriage-horse of the two. The favorite driving horse of the wife of Governor Stanford was a thoroughbred son of Don Victor.

It can be truthfully said that the blood-horse has almost reached the highest state of possible improvement, and is the most perfect of the horse kind. For beauty, intelligence, courage, speed and endurance nothing approaches him. The tribute of Job justly is his :

"Hast thou given the horse strength ? hast thou clothed his neck with thunder?

Canst thou make him afraid as a grasshopper? the glory of his nostrils is terrible.

He parveth in the valley, and rejoiceth in his strength: he goeth on to meet the armed men. 
He mocketh at fear, and is not affrighted; neither turneth he back from the sword.

The quiver rattleth against him, the glittering spear and the shield.

He swalloweth the ground with fierceness and rage; neither believeth he that it is the sound of the trumpet.

He saith among the trumpets, ha, ha! and he smelleth the battle afar off, the thunder of the eaptains and the shouting."

\section{THE TROTTING HORSE}

The trotting gait is natural to nearly all kinds of domestic animals, and also to many wild varieties, as the deer, the elk, the wolf. The wild horses on the plains of South America and on our western prairies go at a trot when moving neither very slowly nor at full speed. It is definitely known that since Greek and Roman times trotting has been the ordinary gait of the domesticated horse. Some exceptions should be mentioned. At an early date in England, fully six hundred years ago, ambling-horses were in use chiefly for women to ride. "Uppon an amblere esely sche sat" (Chaucer). We would now call them racking or pacing ponies, as their gait was a slow, irregular pace, or what ${ }^{\circ}$ was called, previous to the last forty years, a rack, and the horse in England, until as late as the year 1500 , was rarely above thirteen hands.

As, in later times, riding on horseback by women ceased as a custom, the ambler, racker or pacer went out of use and is not now found anywhere in England. The trotting-horse there completely occupies the field for riding, drawing coaches and light vehicles. Within 
the last twenty years, trotting races have become very popular in England, France, Italy, Austria and Russia, and breeding farms for trotters have been established in all of those countries. A large number of fast trotters have been purchased in the United States and taken to Europe for use on track and in the stud. The races there are for longer distances than prevail here, being from one- to five-mile heats. The custom could well be followed on American tracks, as it tends to produce horses of greater endurance on the track and on the road. The English riding-horse goes at the walk, trot and canter. No other gait is tolerated.

That the ambler or pacer in England should disappear where it was no longer desired, was the result of a natural law. His origin was due to breeding and training, and when all efforts in that direction ceased his extinction followed. English books on the horse, published more than two hundred years ago, contain cuts of horses being trained to amble, rack or pace by the use of mechanical devices, such as ropes on the legs, iron balls tied to the ankles and obstructions placed on the ground. In America, until within tre last century, the unsettled state of the country and the absence of wagon-roads made horseback-riding the usual mode of travel, and, for that reason, horses were desired possessing an easier gait under saddle than trotting. This made an extensive demand for the racker or broken-gaited horse. Aside from training, the use of a horse as a saddler, on rough roads, naturally tends to impair the purity of his gait as a trotter, as that gait is less comfortable to both himself and his 
rider. In localities where saddle-horses are needed it is a common thing to see horses which, when ridden, go at all the saddle gaits, but when driven are square trotters. Changed conditions in Arnerica have now made the

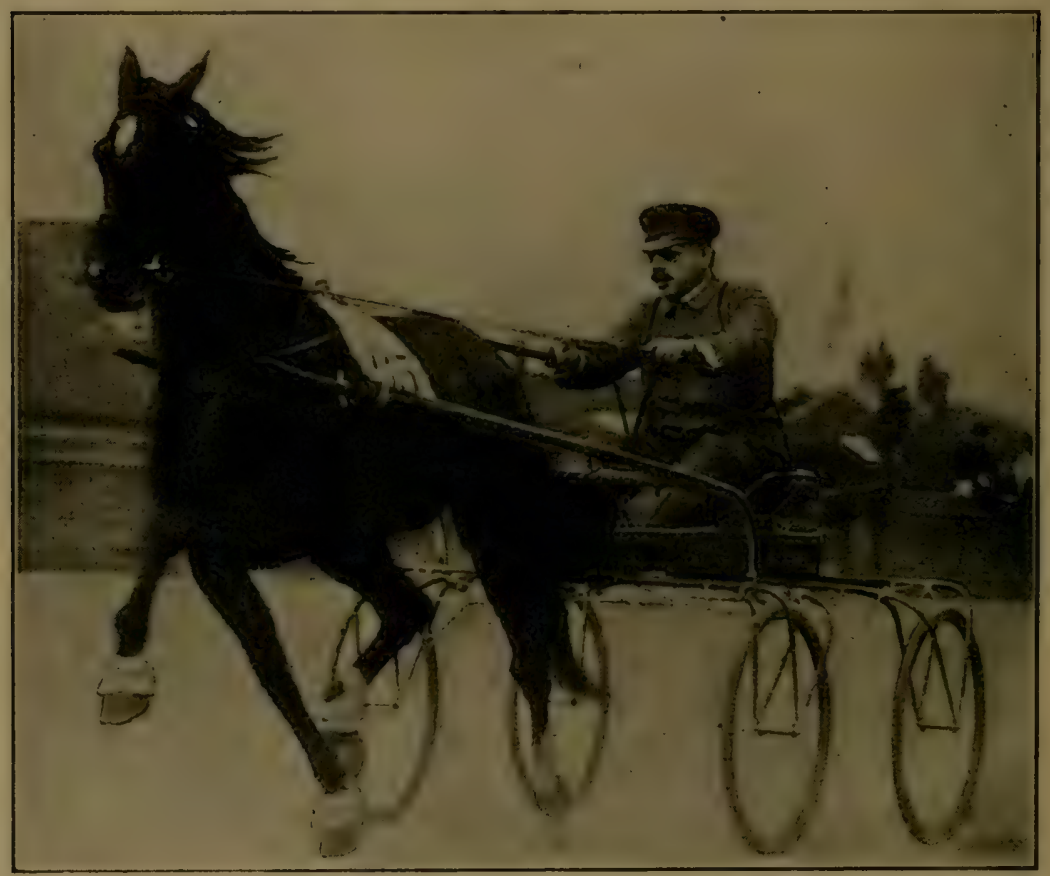

FIG. 9. Lou Dillon, 1:581/2, holuer of the world's trotting record

saddle-horse chiefly of use for pleasure, and the trotter overshadows him in importance.

For racing purposes the trotting-horse has a rival in America in the modern pacer, a variety that has been vastly improved within the past twenty-five years. (Reference is made to what is given under the heading, "The Pacing Horse.")

While the trotting-horse had reached a degree of 
excellence in England and on the continent nearly two centuries ago, and was capable of maintaining a considerable rate of speed in races of from four to twenty miles, up to the year 1806, no trotting-horses in Europe or America had taken a record of a mile in less than three minutes. In that year the horse Yankee took a record, on a half-mile track, of $2: 59$, at Harlem, N. Y. The record was gradually lowered, but thirtynine years passed before any horse trotted a mile in 2:30. In 1845, the gray mare Lady Suffolk won a race on Beacon Course, Hoboken, N. J., trotting in $2: 29 \frac{1}{2}$. The first trotter to beat $2: 20$ was Flora Temple, who took a record of $2: 19^{1} / 4$, in 1859 , at Kalamazoo, Mich. Following are the notable reductions of the trotting record since that time:

Dexter, $2: 17 \frac{1}{4}$, in 1867 .

Goldsmith Maid, $2: 14$, in 1874 .

Rarus, $2: 13 \frac{1}{4}$, in 1878 .

St. Julien, $2: 12^{1} / 4$, in 1879 .

Jay Eye See, 2:10, in 1884 .

Maud S., $2: 08^{3 / 4}$, in 1885 .

Sunol (a threo-year old), $2: 101 / 2$, in 1889 .

Nancy Hanks, $2: 04 \frac{3}{4}$, in 1892 .

Alix, $2: 03 \frac{3}{4}$, in 1894 .

The Abbot, $2: 03 \frac{1}{4}$, in 1900 .

Cresceus, $2: 02 \frac{1}{4}$, in 1902 .

Major Delmar, $1: 593 / 4$, in 1903 .

Lou Dillon, 1:58\%/2, in 1903.

The great increase in the speed of the trotting-horse is striking evidence of what may be done by intelligent breeding and training, but it must not be thought that the records of Yankee, 2:59, in 1806; Lady Suffolk, $2: 29 \frac{1}{2}$, in 1845 , and Lou Dillon, $1: 58 \frac{1}{2}$, (Fig. 9) in 
1903, constitute a true measure of the increase of speed in the trotter. It should be borne in mind that great improvement has been made in tracks, sulkies, harness and all the equipments of the fast trotter. The performance of Lady Suffolk in trotting a mile in $2: 29 \frac{1}{2}$, in 1845 , was fully equal to a mile in $2: 15$ under present conditions. When Maud $\mathrm{S}$. took her record of $2: 08 \% 4$, in 1885, she drew an old-fashioned high-wheeled sulky, on a regulation track; a feat that stood unmatched for nearly twenty years. In 1891, Sunol, by Electioneer, trotted a mile to a high-wheeled sulky in $2: 08 \% / 4$, but it was done on a kite-shaped track, which some horsemen believe to be a shade faster than the oval, when attempts are made at extreme speed. The stallion Palo Alto, also by Electioneer, took his record of $2: 08 \%$ to a high-wheeled sulky, but this performance, like that of Sunol, was on a kite-shaped track. Sunol, Maud S., Palo Alto, Cresceus Major Delmar and Lou Dillon mark the highest development of speed of the trotter. The progress in breeding has been steadily upward. Though so much has been accomplished, it cannot be said that there has yet been produced a breed of trotters in the sense that the thoroughbred horse, the setter and collie dog, and the game and Dorking chicken, are ranked as breeds. This is due to the comparatively late period of the commencement of anything like a systematic effort to establish a breed, and to the irrational methods of many breeders. A striking illustration of this proposition is the fact that the National Trotting Horse Breeder's' Association for years had rules which admitted for 
butter record to registry in the Shorthorn Herd-book. Years ago the folly of such action was seen and the rule was abrogated, but, while it stood, hundreds of short-sighted breeders fell into the delusion and used pacing sires and dams in the vain hope of producing fast trotters. The fallacy of it is now so clearly seen that no breeder of intelligence is misled by it.

All rules may have exceptions, but the general rule that "Like produces like or the likeness of some ancestor," is as well settled as is the truth of the multiplication table. A number of breeders of exceptional ability and exceptional opportunities have had phenomenal success in some seeming departures from the principle of this rule, as Governor Stanford in his use of Electioneer upon thoroughbred mares, but it must be kept in mind that in his power to impart the trotting gait to his progeny, Electioneer stands alone. The fact is also important that Governor Stanford had a very large number of thoroughbred mares from which he selected those which he bred to Electioneer. In choosing them he thoughtfully looked to the question of size, conformation, disposition and gait, regarding the last two qualities as of the utmost importance. He saw clearly certain deficiencies in the trotter which he believed wonld be remedied by a thoroughbred cross, and the production of Sunol, Palo Alto and Arion justified his theory; the first two having thoroughbred dams, and the dam of the last being also very highly bred. The same thing has been done by Senator Rose, and Mr. Alexander, of Woodburn Farm. The young breeder may ask, Was not this a departure from the 
rule that like produces like? I answer, Na. The trotter lacked certain qualities, or did not have them to the degree found in the thoroughbred, among which were courage, or never-say-die gameness, such as has. made a racer run out a finish on a broken leg, saundness of limb, the perfection of lung and heart action and intelligence.

All these are essential in the make-up of the fast trotter, and the resort to the blood of the thoroughbred to get them was but an intelligent application of the great rule in breeding. The rule to guide the average breeder in the production of a tratter is to breed a fast trotting-mare to a fast trotting-stallion. Many other things should be considered to insure desirable qualities aside from mere speed, among which are purity: of gait, size, beauty, color, soundness, disposition, etc. It is but stating the rule in another form to say, have in the sire and dam the qualities you wish in the foal. Unsoundness of every form shonld be avoided, as in nine cases out of ten the unsoundness is hereditary and will reappear in the progeny, and in the tenth case the weakness that produced it is probably due to inheritance. Contracted feet, in a given case, may be immediately due to neglect or bad shoeing, while the primary cause is a natural tendeney to that infirmity, nnherited from sire or dam. The same may be said of crooked or curby hocks, spavins, ring-bones and other forms of unsoundness. No ore ean afford to use animals so affected for breeding purposes, no matter how desirable they may be in other respects; as vices and defects are more easily reproduced than good 
qualities. Above nearly all things, choose for both sire and dam, a pure-gaited trotter, for the gait of the ideal trotting-horse is as the swing of the pendulum. A trotter should carry his toe-weights in his head. When Lou Dillon trotted a mile in $1: 58 \frac{1}{2}$ she covered more than forty-four and a half feet to the second. How plainly this points to the importance of perfect trotting action! The foregoing rules apply not only to the breeding of trotters for the track, but for all purposes. The farmer, mechanic or other man of small means, not a professional breeder, cannot expect, with his limited opportunities, to produce grand circuit flyers, for under the best conditions they are accidents; but by adherence to the course here given he can breed, with reasonable certainty, handsome, sound and speedy trotters for carriage and light wagon, and also desirable coachers. Horses of this kind should be of good color,-bay, brown, black or sorrel. As a rule, bay or brown horses command the best prices; grays and roans do not sell well. Beauty and style of movement are qualities highly prized. Roadsters and coachers should have a higher, bolder action in front than is usually found in the fast trotter; and this quality, like all others, should be sought in the sire and the dam.

\section{THE PACING-HORSE}

Regarding the origin and history of the pacer previous to the last thirty years, nothing need be said additional to what is given in the pages devoted to the trotter. Until a comparatively recent period, 
pacers were chiefly used for saddle purposes. It sometimes happened that individual animals showed much speed, and, when possessed of a considerable portion of the blood of the thoroughbred horse, had the stamina and bottom to go races of one-, twoand three-mile heats. However, for racing purposes the pacer played an unimportant part, and when horse-back riding ceased as a custom, pacers were rarely seen. Persons unskilled in horsemanship may wonder that pacers should not meet the requirements for road-horses, both for pleasure and utility. For this there are many substantial reasons. For mere speed on a track, or very smooth road, the pace is a shade faster than the trot. This is the only thing that can be said in favor of the pacer as a driver. In no other quality can he rank with the trotter. In considering him as a horse for pleasure-driving, it should be observed that as a type he lacks beanty of form, having, as a rule, poorer quarters and a tendency to upright shoulders and a sloping rump. He does not often have a proud carriage of the tail, and goes with a low head. In general bodily conformation he is decidedly inferior to the trotter. The high, bold action which so charms the eye is impossible to the pacing movement. A pair of pacers as coachers would be an absurdity. It may be asked why pacers would not do for the saddle. It must be remembered that the old-fashioned pacer or racker, once popular as a riding-horse, had a broken gait like some of the easy movements of the modern saddle-gaited horse. The present-day pacer has a true pacing gait, and is 
the worst possible horse under saddle. These considerations have such weight in the judgment of horse-owners that the porportion of trotters to pacers throughout the United States is fully one hundred to one; this, notwithstanding the general prevalency of pacing on the race-tracks.

Within the last tweuty-five years great advances have been made by pacing-horse breeders, and an animal has been produced with which the old-time pacer is not worthy of comparison. These breeders had in mind the creation of a type of fast and game pacers for racing on the track. This was the chief purpose they had in view, and their wisdom is shown by their success. They did not attempt to make of the pacer a road- or general driving-horse, or a saddler, but aimed solely at his improvement as a racing animal. As a result the pacing record has been lowered below the two-minute mark by the following named horses: Dan Patch, 1:56, by Joe Patchen, 2:01/1/4, Prince Alert, 1:57, and Star Pointer, 1:591/4, by Brown Hal, 2:12\%. Among pacers whose records are close to two minutes are Little Boy, $2: 01 \frac{1}{2} ;$ Anaconda, $2: 01 \frac{3}{4} ;$ Coney, $2: 02$, and a great many others.

An analysis of the pedigrees of the great pacers will show that the highest results have come from the use of sires that were themselves fast pacers. The rule of intelligent breeders is to have for both sire and dam pure-gaited pacers with speed and endurance. Soundness and other plainly necessary qualities are, of course, not ignored. 


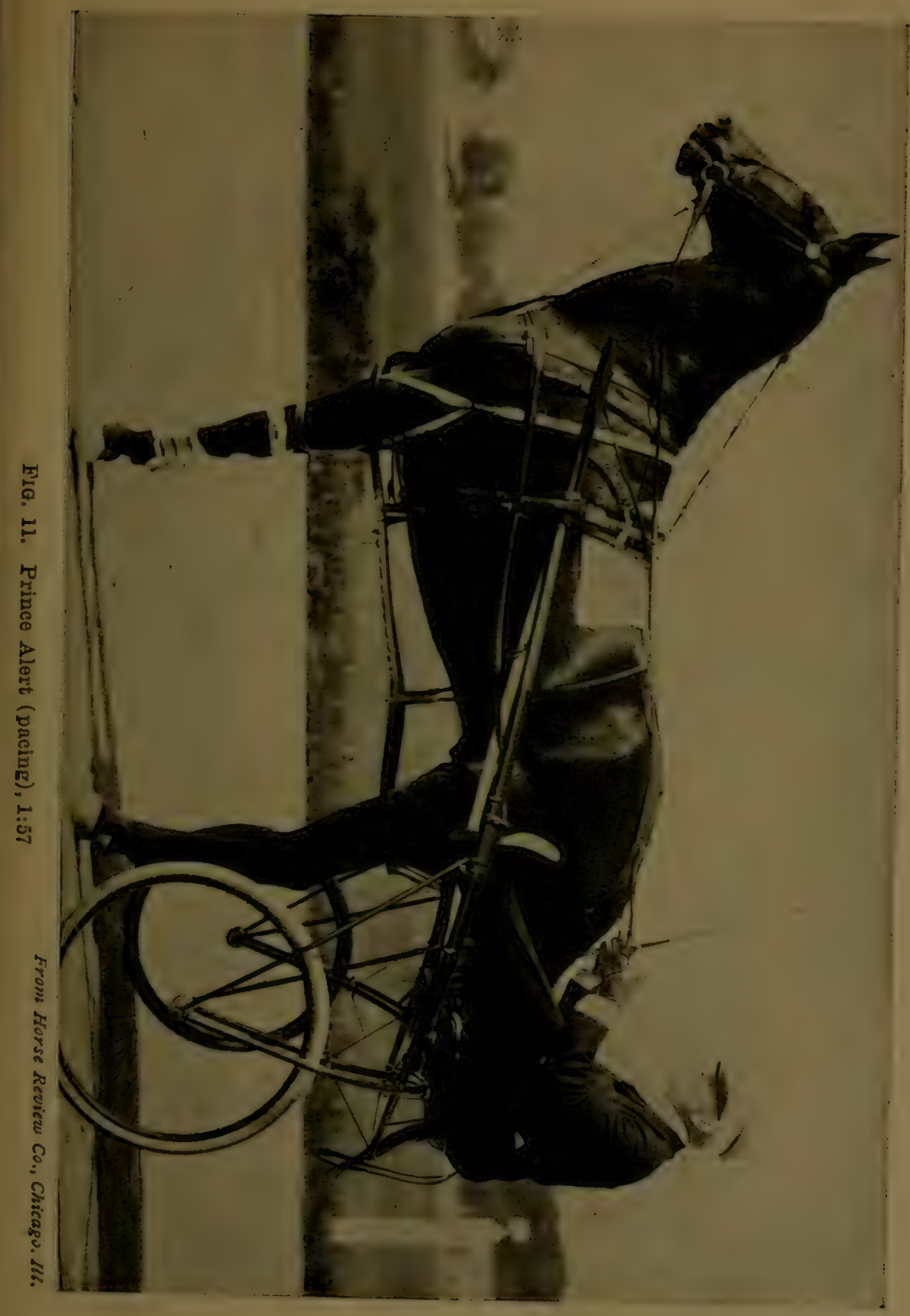


It is true that the fast pacer of to-day carries a large proportion of the blood of the thoroughbred, which is an indispensable part of his make-up, but no breeder would now resort to a further thoroughbred cross. At one time a class of theorists advocated the production of fast trotters and pacers by a continual crossing of trotters and pacers, but it is now only remembered as an amusing vagary. As an illustration of what follies a spirit of controversy may lead an otherwise sane man into, the case may be eited of a prominent writer on breeding topics fifteen or twenty years ago, who used to argue that pacing and trotting were "two different manifestations of the same gait."

While all must admit the success of the effort to breed fast pacers for the track, it camnot be contended that in point of usefuluess it could not claim higher eredit were the pacer more suited to the general wants of the people. The highest art of the breeder may alike be shown in the production of tumbler pigeons and beef cattle, while the importance of the work will allow of no comparison. A parallel is found in the vast rivalry among naval architects in the endeavor to produce the fastest sailing yacht whose use is confined to the cup races.

It seems to be demonstiated that the pace is naturally a faster gait than the trot, to the extent of several seconds in the mile. The reason for this is an interesting question. The record of Dan Patch (Fig. $12)$, the champion pacer, is $1: 56$, while that of Lou Dillon, the fastest trotter, is $1: 58 \frac{1}{2}$, two and a half 
seconds slower. Most horsemen will agree that there is that amount of difference in the natural speed of the two methods of locomotion. The mechanical difference is that the pacer at speed strikes the ground

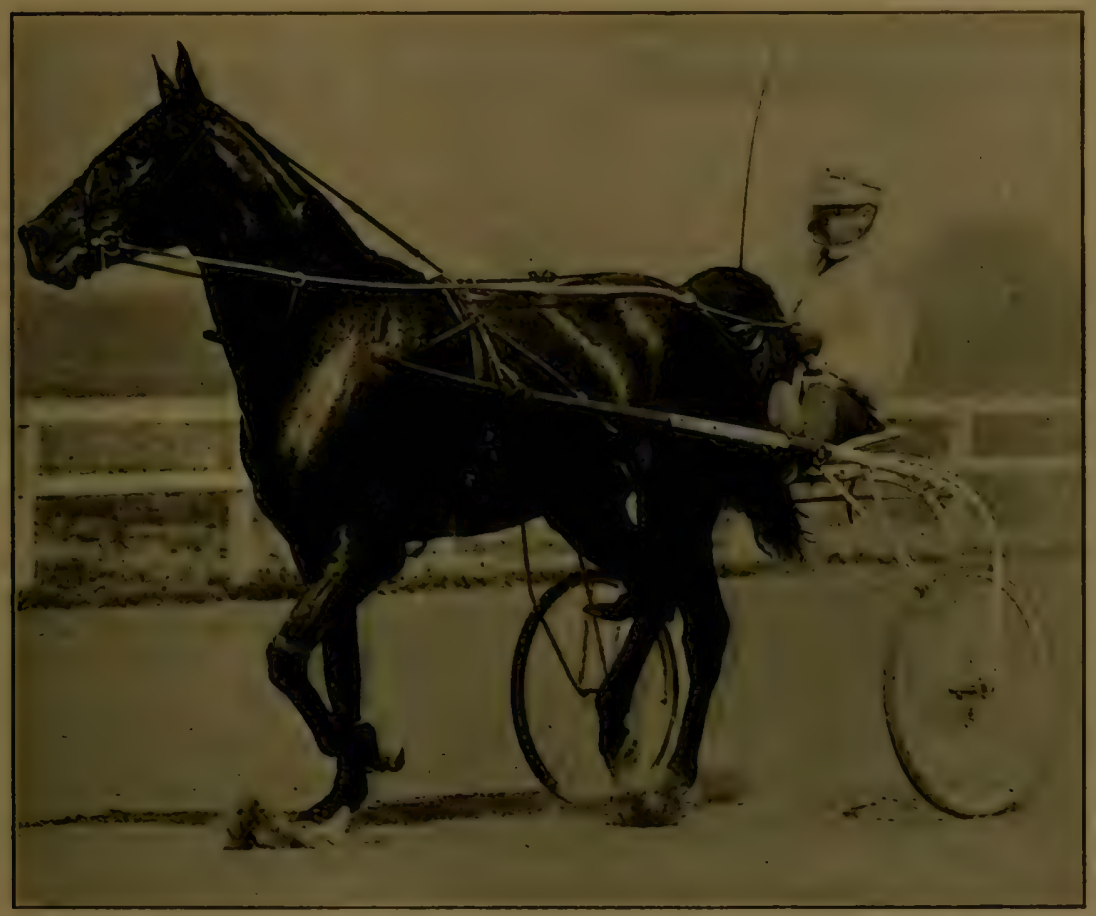

By permission of L. N. Legerdre, photographer, New York

Fre. 12. Dan Patch, 1:56

Holder of the world's pacing record

simultaneously with the fore and hind feet on the same side, while the trotter puts them down alternately. Instantaneous photographs of trotters at speed show that no two feet are on the ground at the same time. From these considerations it seems clear that in the pacing movement the play 
of the muscles is more smooth and free, thus conducing to increased speed. This greater freedom and harmony of muscular action is probably an important factor. The pacer also has an advantage in the simultaneous planting of both feet on the same side, for the reason that he can make the freest possible stride without fear of the hind foot catching the front one. A great danger to a trotting-horse in racing is the cutting of his quarters by treading on them with the hind foot, and the horse knows it. When the animal is propelling his body forward at the rate of more than forty feet to the second, the interval between the raising of the fore foot and the following movement of the hind foot is but the flash of an eye. A man when running very swiftly instinctively exercises his utmost alertness to guard against a fall. Is it not reasonable to believe that a trotter when going twice as fast may also feel the necessity from his more complicated gait of modifying his speed in a degree, for self protection? These observations are not based on the ideas expressed by other writers, but it is believed they give the most rational way of accounting for the difference in speed between the pacer and the trotter.

It may be thought by some that the pacer may ultimately become popular as a driver when, by reason of the country being older, our highways will be improved. This is very unlikely to occur, as in European countries having the finest possible roads he is practically unknown.

Within the last ten years has become quite prev- 
alent the reprehensible practice of driving horses wearing hopples in pacing races. Broken-gaited horses that will neither pace nor trot naturally, but have some speed, will be put in strong leather hopples, where it is impossible for them to go at any other gait than the pace, and in that way compelled to pace, often being unmereifully punished the greater part of the course. This practice should be prohibited by law. On many race-courses hoppled horses are not allowed to compete. It is very dangerous to drivers, as a tired horse in hopples is liable to fall. Numerous deaths of men and horses have occurred from such accidents. It is also injurious to the breeding interests, for many foul-gaited pacing stallions have taken low records while driven in hopples, which are worthless for breeding purposes. They may be taken to places where they are unknown and acquire custom in the stud on the strength of a record which is, in reality, fraudulent. 


\section{CHAPTER VI}

\section{THE AMERICAN SADDLER}

Adapted largely from the best modern authorities on "The American Saddler," for use in the class-room.

THE first use made of the horse by man was for riding bareback. Later he was furnished with the saddle. This noble animal was first used in war long before he became employed in peaceful industry. Even after he was used in harness, his first connection with it was in drawing chariots of war. These ancient war-horses were a great factor in molding history. The decline of Rome was partly due to the horsemanship of the Huns, who originated in the country north of the Chinese wall, and whose barbaric hordes poured over the Empire. The Arabs were warlike and conquering because of their horses; where would the Boers have been if it were not for their active saddle ponies?

Such has been the association between horse and man for so long a time that it is no wonder he should have inherited a love for the arimal.

In the northern United States, the winters are too cold for horseback riding and in summer the roads are better cared for than in the South; hence road horses became more common than saddler's and the road wagon more in evidence than the saddle. The running 
horse, the foundation of the saddler, was always a special pet of the southerner, who was not driven to the use of the trotter by the strict puritau ideas of New England; hence the South, particulary Kentucky, is preëminently the home of the American saddler, formerly called the Kentucky saddle-horse. When the pioneers went to that state, it was a choice between going on horseback or on foot, and practically everybody rode. In those old times there were no railroads, and the highways were too poor for wheel vehicles, so that the inhabitants were compelled to use the saddle for traveling both short and long distances. But the saddlers of those days were not the high, stylish steppers of the present.

Some of the best foundation horses came from Canada, where the pace, or ambling gait, has been most encouraged; while Virginia and the South Atlantic States have given more attention to race-horses. This type of Canadian horses is said to be a cross of early French stock with stallions brought from New York and New England, and combined the hardiness and perhaps gait of the former with the better size of the latter. About 1830, there were imported into Kentucky the thoroughbred and half-bloods from Virginia, and a few of the pacers from Canada. These were crossed, and produced a more useful animal for saddle purposes than any bred there before. It was found that certain strains of the thoroughbred blood made the best cross with the pacers or any native strains, for the production of horses with saddle gaits. Those which were thus best suited for 
the purpose were selected and bred in and in. Especially distinguished among these, and today the most famous, was Denmark, who had three sous notable under the saddle and wiuners in the show ring. Of these, Gaines' Denmark was the best, and stands at the head of a family. Wherever his blood reached, fine saddle and harness qualities resulted. Many of the best Canadian pacers were crossed with Denmark, and this mingling of thoroughbred, trotting blood and old "side wheelers" (pacers) was the foundation of the grace and gaits of the American saddler. The thoroughbred alone is too high-mettled, and the other strains are too plodding, and lacking in spirit. There are about a dozen good strains, but all "nick" best with the Denmarks, and they in turn "nick" with certain strains of the thoroughbred or running-horse. Denmark is to the saddler what Rysdzke's Hambletonian is to the trotter. His family is said to be of uniformly good size and constitution, of pleasing color and disposition, with a fine high bearing and markedly prepotent powers. Besides the Denmark family, other families are coming into use, such as Cabell's Lexington (a Morgan strain), Dremon, Waxy, Eureka, Dillard and others. Cabell's Lexington and Dremon were progenitors of distinct family types, but both showed their Canadian blood in their heavy manes and tails. Dremon and John Waxey, son of Waxey, bore strong resemblance to the Canadian horse. With such composite blood, Kentucky early became famous for saddlers, which were equally good for harness.

These horses are the product of the southern bri- 
dle path, and have been thoroughly trained in gaits most comfortable to the rider and easy to the horsethe walk, trot, canter, running walk, fox trot and slow pace. Many gentlemen lived a good deal in the saddle, and gaits which the horse and rider could endure all day were necessary. The abrupt trot of the English hackney was not adapted to a warm climate, since it was hard on both horse and rider, and, though the "side wheeler" had an easy gait, he lacked in grace, hence the special saddle gaits were evolved.

During and following the civil war, Kentucky led in the breeding of saddle-horses. The superiority of the southern horse is shown by the fact that, for two years during the war, the northern cavalry was far inferior to that of the Confederates. Before and after the war, many stallions went to Tennessee, Missouri and Illinois. Missouri got the most, and is now nearly equal to Kentucky in the number and quality of her saddle horses, and many are now also being bred in Ohio, West Virginia, Virginia and Texas.

The first saddle-horse came by chance rather than by design; but experience with runner's and trotter's has taught the Kentuckians that to get an animal to be relied on for a highly : pecialized use, it must be bred for that use. This is a cardinal principle in saddle-horse breeding now, and, without it, snch breed of gaited horses would be impossible. In 1891, the National (now American) Saddle-Horse Breeders' Association was organized to recover from the debris of the trotting wreck the good qualities of the saddle. The president of the Association is General John 
B. Castleman, whose saddle-mare, Emily, took first prize at the World's Fair in 1893 and created a sensation at Madison Square Garden a little later. The third volume of the register has recently been issued.

So much for the history of the American saddler. Now let us look at the characteristics of this remarkable breed. They are fine and harmonious - "all points" and stylish-are hardy and very enduring if given proper care, but are easy to abuse; docile, courageous, proud and good-tempered if treated gently. They instantly resent ill-treatment with whip or spur, or by a rough groom.

A first-class saddle-stallion should be $15 \frac{1}{2}$ to $16 \frac{1}{4}$ hands high; in color, a bay, black, brown, red sorrel and light or dark chestnut. The surpassing beauty and greatness of Denmark seems to be handed down chiefly through his sons and sons of sons of black color. I regard Montrose (a bay) the pattern saddlehorse of the past twenty years; but it has been left to Black Squirrel, whose sire was Black Eagle to produce a type distinctly his own and that has never been approached, except by two of his sons, for grandeur and beauty. Dappled dark gray is allowed, but it is not desired. The coat is fine and silky and the mane of medium weight-not too coarse or too heavy. The tail comes out high on the rump and is carried high with a full sweep. The head is small and fine, with a mild, intelligent expression. The eyes are not deep-set, but lively, without showing much white. Ears erect and not too far apart, and held in place without lopping while in motion. The neck is arched 
gracefully from deep oblique shoulders, and the head earried high with perpendicular face, yet without breaking the line of curvature from the withers to the fore-top. The withers are narrow rather than broad and flat, and rise gently from the shoulder. The barrel is round and carried full back to the hips on both top and bottom lines. The top line is short and the bottom line relatively long. The legs are unusually fine, hard and flat with smooth and not too large joints. Pasterns are medium in length and moderately oblique, and the feet are usually high and wide at the heel.

The southern saddler has been bred for the rider's comfort, and, while he can gallop with a fine, open stride, and jump well, his peculiar merit is in what in the North are called artificial gaits, but what in the South are called natural gaits. The rack is the most laborious to the horse of all the five gaits and no horse can keep it up for more than a few miles without great fatigue. The running walkers cover six to eight miles an hour with great freedom from motion to the rider. An easy gait is necessary when the saddle takes the place of wheels. Contrary to the general impression, this gait is not tiresome to the horse, for he can go all day, and every day, with ease. There are two kinds of gaited saddlers, one a stylish, high-headed, spirited animal, going "in the air," and popular in cities and for park riding where show is desired; the other a level; smooth-going, swift road-horse for business men, doctors, sheriffs and farmers.

A first-class saddle-horse is expected to go at 
command, six or eight different gaits. There are several fancy gaits besides, which are modifications of the others, and depend upon the conformation of the horse and handling of the reins by a skilled rider. The fol-

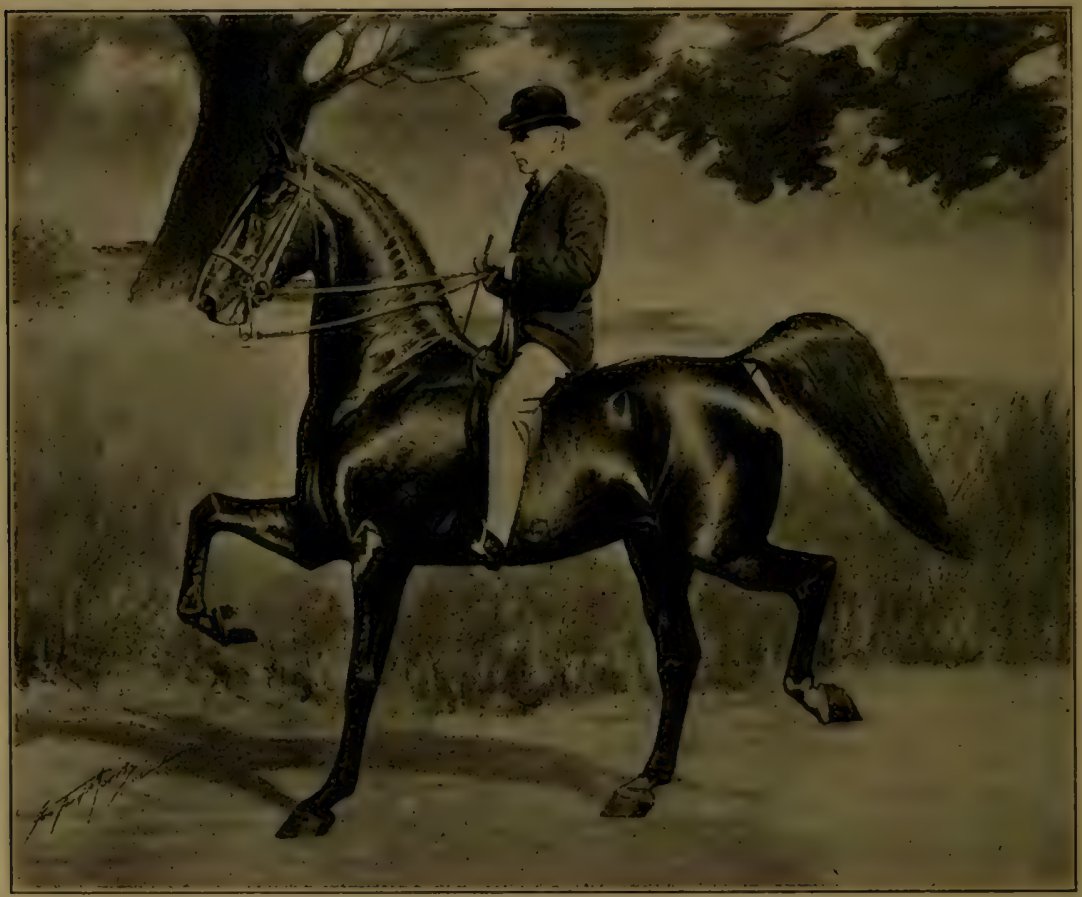

FII. 13. IIontgomery Chief. Rhythmical motion

lowing gaits are recognized for entry in the American Saddle Horse Register: wilk, trot, rack, canter, running walk, or fox trot, or slow pace. The walk, trot, pace and canter need no description

The fox trot is a broken trot in which the fore foot touches the ground an instant in advance of the diagonal hind foot. It has the slowest limits of the 
artificial gaits and can be kept up all day. It has four to six miles an hour rate, and is the utility gait of the general saddle-horse, and all are supposed to have it. A loose rein is always used, and the horse is apt to carry his head low.

The running walk is also a modification of the trot; but in this case the head is carried higher, and the hind foot touches the ground just in advance of the diagonal forefoot, breaking the concussion. A closer rein is held than with the fox trot, and the pace is faster, even up to a three-minute gait, before the horse is forced out of it. It is a more showy gait than the fox trot and gives a horse more of a climbing action in front. The feet take the ground in the same order as a walk, and it is a "walk on a run," if such a thing is possible.

The rack is a modified pace in which the hind foot touches the ground before the leading fore foot. It has a wide range of speed, from four miles an hour to a three-minute gait. It is suited to the side-saddle and is a favorite with ladies. Gentlemen do not like it so well as the fox trot, though it makes a good business gait. The rack is not an all-day gait. It is more readily taken to by horses with a pacing tendency.

The singlefoot is intermediate between a trot and a pace. Each foot moves independently of either of the others, and the same interval of time elapses between each footfall. It is usually not less than ten miles per hour, up to a three-minute gait. It is the smoothest of all gaits, because that part of the body 
supporting the saddle glides evenly forward, and there is no bounding or jolting. These four, with the natural gaits, are the most frequently used.

To do any of the gaits well, the horse should have what is called "shoulder action" as indicated by deep, oblique shoulders. These saddle-horses can be taught to go the eastern high-school gaits of the walk, trot and canter type, if such perversion of taste is desired. They are also fine roadsters and do not show their saddle gaits in harness. Contrary to general impressions, such use does not lessen their value as saddlers or make them forget their gaits.

The Englishman knows but three gaits on the road,-the walk, trot and canter. But in the South the warm climate has necessitated the easier gaits. The American saddler has not been popular in New York and other eastern cities. It requires skill to keep the gaited horse, and he is more expensive than the hackney. The Englishman has the best hunter, but the American breeds the best saddlehorse in the world.

We are now far from using the saddle-horse entirely for war. For power, he is giving place to steam and electricity; but, as the world progresses and becomes more wealthy, the saddle-horse will be popular as the most delightful means of locomotion and exercise, and of peaceful, restful and inspiring pastime.

See page 332 for illustration of "A saddler at rest," which by orersight was left out of this chapter. 


\section{CHAPTER VII}

\section{THE COACH - HORSE}

So many horses that do not belong to the true coachhorse type are called "coachers" and bought and sold as such that it is no wonder the farmer has no clear conception of the true "coacher," which always finds a ready market at long prices. If a horse is $16 \frac{1}{2}$ hands high or more, long of neck and leg and rather slim in the body, he is at once pronounced a "coacher," although he may be nothing but an overgrown weedy carriage-horse. The coacher should indeed be above the average height and should have longish neck and legs, but there are many other qualities and characteristics which must be possessed if the animal meets all the demands of the intelligent purchaser.

Perhaps a clearer mental photograph of the real coacher may be secured if the work which he is called on to do in the city is considered. It should be remembered, first of all, that coachers are designed for drawing coaches, not light carriages or road-wagons. The coach may weigh from ten to fourteen hundred pounds and the load, six to eight persons, may increase the weight by eight to twelve hundred pounds. The total weight of eighteen to twenty-six hundred pounds is carried on relatively small, rigid wheels which tend to greatly increase draft if the roadway is roughly paved. It is 
considered not good form to drive the genuine coacher fast; yet it is none of our concern that the coacher is sometimes used as a means of conspicuous display. As the coach rolls through the parks with aristocratic slowness, the turnout reveals to the onlooker's the wealth of the occupants, their freedom from harassing financial solicitude and the enjoyable leisure which so often comes to the American as the fruit of a strenuous successful business career.

Modern conditions make demands for two distinct classes of high-priced horses. In a previous chapter the trotter and the roadster have been fully treated, therefore we may devote all our attention to the coacher. Bear in mind that these two classes of horses approach each other closely, and even overlap in their less perfect forms.

The coacher, it has been said, shonld be above the average height, with long, slim, flexible neck set on the corner of the body and not on the end of it, like a pig's. The neck should be all-embracing where it joins the body, that both beauty and power to hold the head high without fatigne may be secured. Horses with good necks properly set, when moving usually slack the check-rein, if not reined too high, and will carry their heads loftily without being checked up. Many an otherwise fine coacher, if checked high, becomes a "star gazer," especially with an overdraw,that is, extends the nose upward until the face is nearly in a line with the neck; whereas, in a natural and easy condition, the head should be carried nearly at a right angle with the neck. It is really dis- 
tressing to see an imperfect neck checked up far above its capacity. This has led to unqualified condemnation of the overdraw check or, in fact, of checks in any form. (For a full discussion of harness, see Chapter XXII.) If a coacher has the ideal head and neck, many slight deficiencies of body may be overlooked. A tall, longish-necked horse not infrequently has a long, somewhat depressed back, which is objectionable. If the lofty neek, slim and flexible at the throat-latch, symmetrically attached to the shoulder of a selected dam, can be united in the foal with the strong, short back of the sire, much will have been accomplished toward producing a valuable coacher. (See Breeding, Chapter XIII.) But, "over all," the coacher must have good length, though if it be too great, especially if the back be too long, endurance and spirit are likely to be lacking. The legs, like the neck, should be flexible and long rather than short, with high action rather than long reach. While the old saying that "a coacher should travel with his knees in his throat-latch and his feet in a bushel basket" is so exaggerated as to lose force, still it helps to emphasize the fact that coachers should have high knee and hock action, in which case the reach will not be long. The coacher is not designed so much for speed as for display, coupled with hard work for short periods. The coacher should have courage and staying power, for it will require both if the proud, high, elastic trot is to be maintained for two or three consecutive hours over rough pavements with a load suited to a light pair at a walk. 
The coach-horse may be less rotund than the hackney. He is usually kept plump, even fat; but, if he has naturally the rotund pony form, he is likely to become sluggish and unresponsive. There is a vast difference between the pudgy build of most ponies and the longer, graceful lines of a well-formed coacher. Then, too, a fairly long-bodied horse need not of necessity have a long back. It is frequently said that no horse should have a long back. This is only relatively true. What really is meant is that the top line (back) should be short as compared with the bottom line (belly). Then, too, there is a marked difference between a thick, piglike neck and one that is strongly attached to the shoulders. While the neck of a coacher should be rather long and thin, it should have a high, firm seating on the shoulders and taper rapidly toward its intersection with the head. The demand is for smooth, rather long, flowing outlines. Horses of pudgy build or with ragged hips or angular conformation are not wanted. An arched, flowing, full tail, good feet and symmetrical limbs are indispensable.

When all is summed up, color has much to do with the price, and indicates to some extent, it is believed, quality and endurance, although superior horses are sometimes found with faded light colors and undesirable markings. Dark hoofs are, as a rule, tougher and better than light-colored ones. Seal browns, bright unfading bays, with strong well-defined black or dark points, are always in fashion and are to be preferred to all other colors. Blacks seldom hold their color when exposed to 
sun and rain. It is said that a black horse looks smaller than he really is and a dappled gray larger. Black horses are desirable for undertakers perhaps, but they are too suggestive of that particular trade to be in demand for private use.

Piebald and peculiarly marked animals sometimes sell well, but they are difficult to breed; that is, they are sports rather than the product of a well-defined variety or breed; "Calico horses," and sorrels with lightcolored manes and tails, find their best market in South America, where they are especially admired by the Spanish Americans. Most of this class of coachers belong properly in the carriage class, as they are seldom large enough for heavy coaching. As vet, few true coachers are bred in the United States. Many fine carriagehorses and roadsters are produced, and the larger ones serve fairly well for the lighter coaches but they seldom have the size requisite to give the turnout the stately front necessary to prevent the cuach from appearing too large and lofty for the team. A large coach with an elevated front seat and a tall driver has the effect of making the horses look smaller than they are. We judge most things by comparison. The expert horseman not infrequently exhibits his horse hitched to a low-wheeled sulky, phaeton or road-wagon, which has the effect of making the horse appear larger than he really is. Animals of all kinds exposed at public auction are sometimes placed on higher ground than the bidders, for the purpose of making the animals appear large. Even the complete lowering of the carriage-top seems to increase the size of the horse hitched to the vehicle. 
An outline of the work required of a coach-horse and a brief description of the horse that is likely to bring the highest prices have been given, and it only remains to be said that it is difficult to produce large, symmetrical coachers of the true type with high action coupled with the requisite courage and endurance. For some time to come, the true coacher is likely to be high-priced and difficult to procure in large numbers. Medium and small coachers are more easily produced than the large ones, but they bring less in the market. However, it may be said that they have a far wider range of customers, since the medium and small coachers may serve well for the double carriage, the phaeton or for family driving to either a one-or a two-seater.

Three quite common varieties or breeds of horses are now used in the production of coachers. Among the oldest of these is the Cleveland Bay. Ample material for the discussion of the origin and merits of the Cleveland Bay may be found in the Journals and stud-books. It is sufficient to say here that very little is positively known of the origin or breeding of most of the foundation stock.

The Cleveland bay has many of the coacher characteristics. The best specimens are good-sized, rangey, symmetrical and of good color-bright bay. When first introduced into America, it was said that he lacked staying power. That may have been true once, but probably is not so now. It should be remembered that, after the breed had attained prominence in England and after many specimens had been imported 
into the United States, it was neglected, and it was not until after 1865 that the remnants of the breed were hunted up and used as foundation stock for what might be called the improved Cleveland Bay ${ }^{1}$

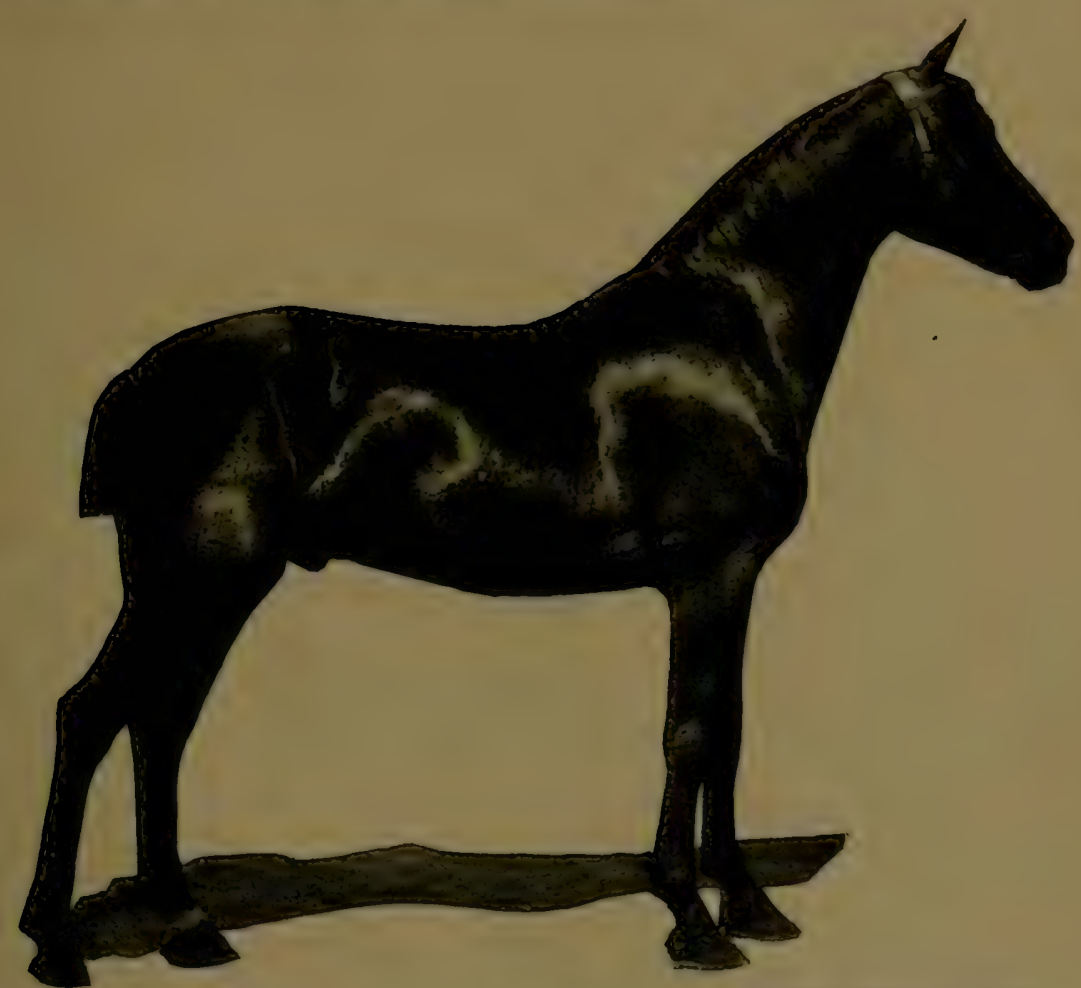

FiG. 14. A good coacher

Permission of F. S. Peer

If the reader is interested in foundation stock, he may first inspect the horse under consideration; if possible, find out something in detail of its immediate ancestry. If there is progeny, it also should be crit-

${ }^{1}$ See Cleveland Bay Stud-Book, "Retrospection Volume," September 1884. For American stud-books, see appendix. 
ically studied. If the animal under consideration is good, if his or her progeny is satisfactory and if the ancestors for two or three generations are of good repute, one need not be afraid to purchase although nothing of the breeding of the remote paternal ancestor may be known. Other things being equal, a long pedigree is better than a short one; but a short pedigree and an animal of known prepotency is better than a commonplace one with a long pedigree "tailed" by one or two noted animals bred fifty to seventy-five year's ago.

Description and Characteristics.-Color, bright bay, may be either light or dark; black mane and tail; black points; usually a small white spot between the "bulbs" of one or more of the heels; size, sixteen to seventeen hands; weight, 1,100 to 1,300 pounds. Head symmetrical, with kindly expression and intelligent east of face; neck long and arched and well set on sloping shoulder's. Back usually of good length and form; legs clean, of good length and symmetrically set on the body; feet and lower part of legs dark-colored, and fetlocks free from long hair. Sometimes the Cleveland is too light in weight for high-class coachers.

A printed description of a horse never fully satisfies the young, progressive horseman, although it may serve to assist the beginner in distinguishing one breed from another which is similar. A horse may fill the above description fairly well and yet be so deficient in action and courage and so unresponsive to the rein that all his other qualities fail to redeem him from the common herd. He is simply an unresponsive beauty. The moving, living horse must be studied before an accurate 
conception can be secured of what style, symmetry, harmonious motion and even-tempered high courage are.

\section{THE TROTTER AS A SIRE OF COACHERS}

Now and then a large trotting-bred stallion begets stylish coachers when bred to suitable mares. (See chapter on Breeding.) In fact, many coachers up to about 1875 were so produced. Soon after the war of 1861-65 an unusual demand arose for coachers, and the market soon demanded better horses, or, rather, far better prices were received for really superior coachers than had formerly been realized. The rapid increase in wealth during the last quarter of the 19th century has made it possible to sell really good coachers at double and triple the prices secured for them in early years. This demand not only stimulated the importation of both English and French coach stallions, but also the breeding of coachers from large trotting sires and large symmetrical mares having a dash, at least, of thoroughbred blood. In fact, some good coacher's have been produced by this method of breeding. It is unexplainable why the lovers of horses did not, when the demand arose for coachers, select and systematically unite the good blood already possessed in the large trotter and beautiful mixed-blooded mares. With such animals as foundation stock, a few generations of skilful breeding, coupled with judicious but liberal feeding, would have produced a coacher of sufficient size to meet the most exacting demands, and of superior endurance, style and courage. It is not yet too late 
to produce an American coacher, if we can be weaned from the notion that, of necessity, everything imported has quality and value above the home production. Out of the thoroughbred and selected superior mixedblooded road-mares has been developed in America a superb, unequaled, ntilitarian and pleasure-giving animal, unexcelled in any other country. From the same blood and by similar methods, in less time and at far less expense and pains than have been incurred in producing the trotter, a potent breed of coacher might have been produced. Sooner or later it will have to be done, or rather it will be done; and then an imported coacher will be as rare as imported Merino sheep, or an imported steam-locomotive.

It may be said, the fact that Europeans are purchasing large numbers of horses in America for cavalry mounts and other army purposes proves conclusively that many good sires and dams, usually of mixed blood, are possessed by American farmers. As these pages are being written, it is reported that nearly 20,000 army horses have been shipped from New Orleans to South Africa for war purposes during the last two months. It would seem that while we have good foundation stock for the production of cavalryhorses, we are importing Demi-Sang cavalry-stallions from France to be used for siring coachers. If, then, the largest and best of French cavalry-stallions are suitable for producing coachers, why can not the largest and best of the American Demi-Sangs, or mixed-bloods, also be used for producing coachers? Since they are virtually of the same lineage, - that is, they have a liberal infusion 
of "warm" or oriental blood liberally mixed with good but unknown or nondescript blood.

THE FRENCH COACH - DEMI-SANG (HALF-BLOOD )

Some of the European governments find difficulty in securing enough suitable horses for mounting eavalry and for other army uses. Because of this shortage some governments, notably the French, have given aid and encouragement to the horse breeders, especially those who were endeavoring to produce superior animals suited to such purposes. No claim is made that these horses are thoroughbred or even pure-bred. The same may be said of the American trotter. It appears that really very good and desirable horses can be produced by uniting two good animals, though only one or neither are classed as pure-bred. They are simply Demi-Sangs, although without doubt the blood of the English thoroughbred (Orient) largely predominates.

Some time during the last quarter of the eighteenth century, thoroughbred stallions were introduced into France from England. The services of these horses and the best of their get were offered at low rates to breeders of this class of stock. A bonus was granted by the Government to owners of superior stallions, on the condition that the stallions so subsidized should remain in the country for service. All stallions advertised for service had to be approved by the Government, and none but superior ones were subsidized: This Government control did not extend 


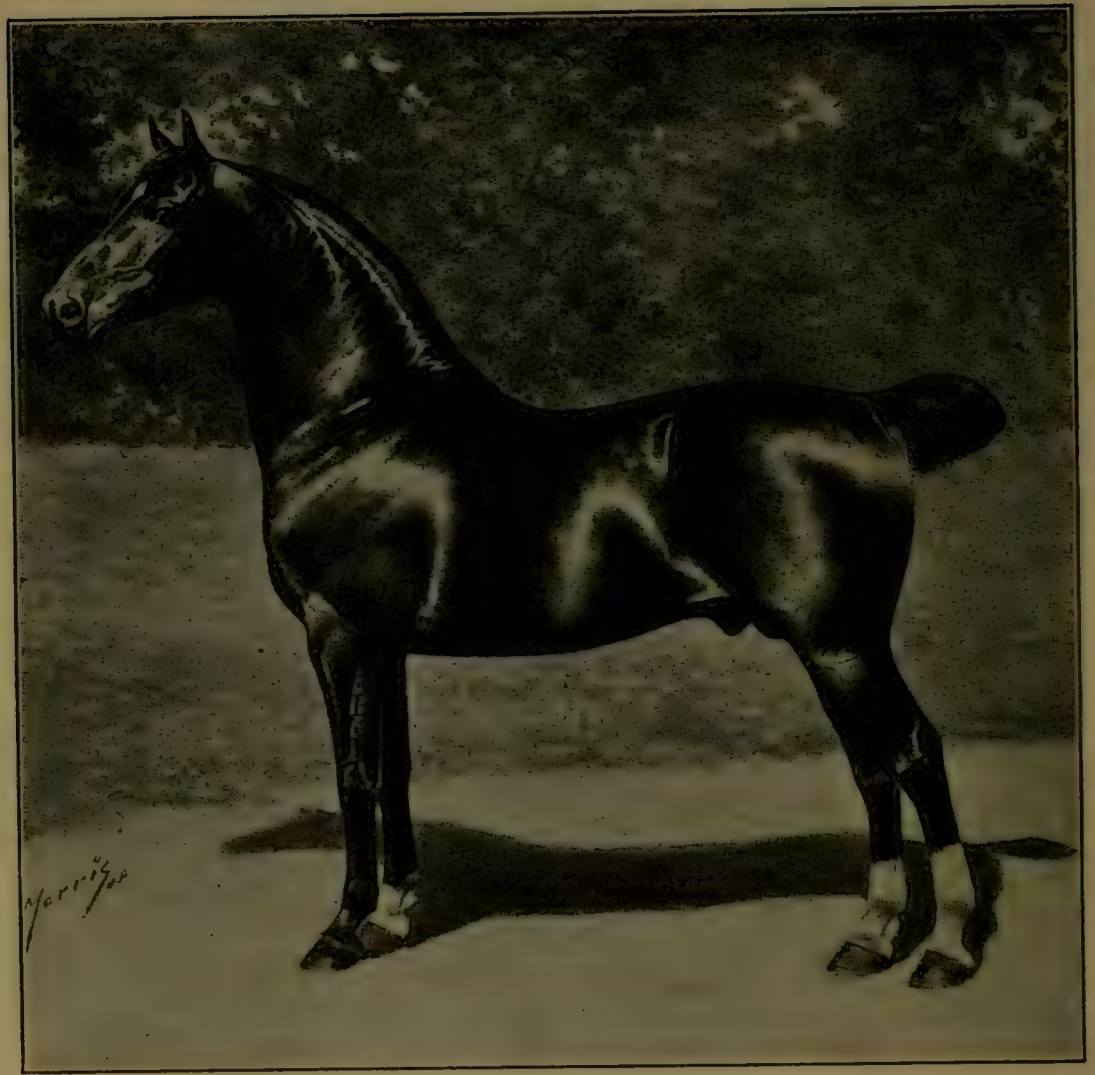

FrG. 15. French coach stallion Paladin, 1968

Championship winner over all coach and carriage breeds, including hackneys, German coachers, trotters, thoroughbreds and Cleveland Bays, Chicago Horse Show, 1897.

Bred, owned and now in service at Oaklawn Farm, Wayne, Du Page County, Illinois.

throughout the country; hence the breeding of horses specifically for cavalry use was confined chiefly to the departments of Orne, Calvados and Seine-Inférieure.

Description.-The color of the French coach-horse may be bay, chestunt or black, thongh bars are far the most common and universally selected by Ameri- 
can importers. In weight they are nearly equal to the Cleveland, though usually not quite as tall. Their average weight ranges from 1,050 to 1,250 for stallions. The head is blood-like, small, clean and expressive. The neck is only moderately long, well arched and symmetrically set on long, sloping shoulders. The back is short; hips moderately long and well up; legs of moderate length, clean, symmetrical; feet tough and well formed. The best specimens are so symmetrical, the parts so harmonious, the movement so rhythmical, that one finds little to criticize except lack of size; and it may be a question whether the size can be much increased without developing some undesirable characteristics, especially coarseness. It is quite possible that it would be better to attempt to produce a little larger coacher by coupling with large dams. The danger in this is that large dams are often coarse in make-up, and if the stallion should not be usually prepotent the outcome would be a coacher lacking in symmetry. Be this as it may, the breeders are rightly making an effort to increase the size of this horse without diminishing his courage, his symmetry, style and endurance.

It is probable that, in time, even better material for producing a variety of American coachers than is now found in the trotter may be secured from the get of these French horses. If the attempt is ever made, it should not take many generations in skilful hands to produce a breed. Some horsemen, whose opinions have much weight, contend that the Cleveland bay and French coachers are large enongh for 
coachers since so many streets now present smooth, well-graded surfaces, and since the art of building strong light vehicles by using steel and wood in

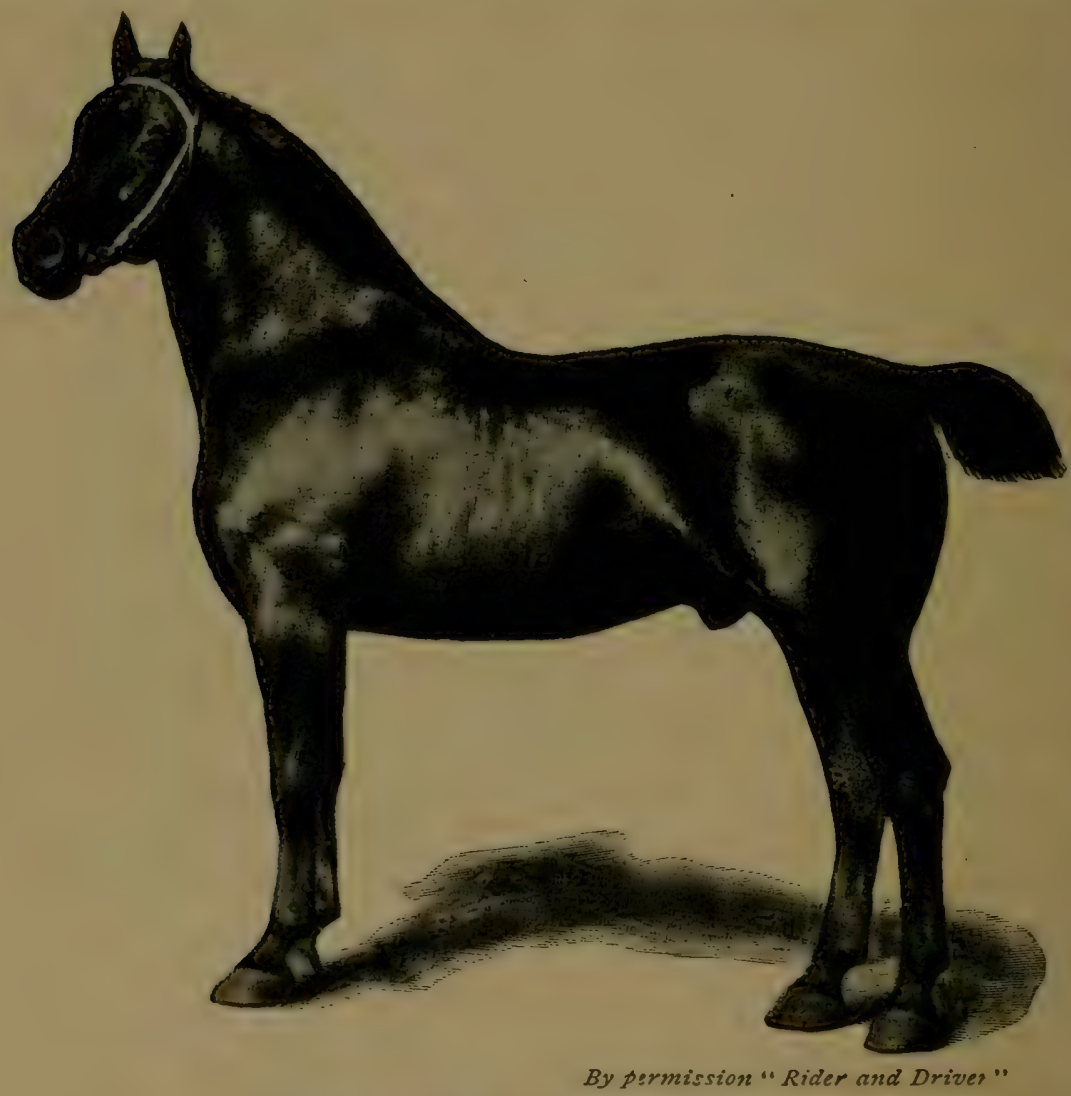

FiG. 16. Imported German coach stallion

Property of J. Crouch \& Son, Lafayette Stock Farm, Lafayette, Ind.

the most scientific combinations has been arquired, the effort should be to lighten the weight and draft of the coach rather than to increase the size of the coacher. But the fact still remains that large coachers, 
other things being equal, sell for more than do those of medium size.

No other breeds or varieties of horses other than those mentioned above have attracted wide attention as progenitors of coachers. For a more detailed discussion of coachers, consult the authors mentioned in the bibliography.

The German coach, since the World's Fair held at Chicago, 1893, has had some admirers, and there are now good specimens of them in the United States. Here we have a horse which fills the requirements as to size and color. In studying them closely, I frequently heard the following remark: "They are large and fine, but they lack somewhat that springy and easy action so much admired in coachers." My own impression was that they did not possess these characteristics as fully as desired. Notwithstanding these criticisms, I confidently believe that the German conch is likely to produce a superior coacher when bred to mares of suitable size and type, that is, to those having a liberal infusion of warm blood conpled with the indescribable finish, form and action sometimes found in mares of mixed blond, not infrequently described as "good road-mares," of great endurance and efficient service anywhere except at heavy draft.

The accompanying cut is that of a horse whose make-up is emphatically of the large coach type. Slightly modified to suit American tastes, this breed should find quick recognition in the large cities. For further particulars, consult German Coach Horse StudBook: also J. Crouch \& Sons, Lafayette. Indiana. 


\section{CHAPTER VIII}

\section{THE HACKNEY}

This breed of horses, recently introduced into the United States, has attracted marked attention. The hackney has a peculiarly striking and pleasing appearance difficult to describe. His chief charms consist in high action, unusual symmetry and suap. Though not so speedy as the trotter nor so well adapted to equestrianism as the American saddle-horse, nor so good for moving heavy loads as the draft-horse, yet he fills a useful place not occupied by any other breed. He is stout, active, sure-footed, courageous and possessed of a good constitution and a lovely temper. A good specimen of this breed satisfies the eye, whether he be viewed from the ground, the road-wagon or the saddle. His neck is well set on, all-embracing where it meets the shoulders, arched and long enough to be beantifuI. The head is clean and intelligent, the ears small and attractive. The back is ideal for the work usually demanded of him, being short and strong, while the hind quarters are long and powerful. The legs and feet appear slightly larger in proportion to size than do the speedier trotters', ret they are far from being coarse or draft-like. His limbs are flexible and are set on the body symmetrically.

The illustration (Fig. 17) shows a typical specimen 
of the breed and gives a better idea of the distinguishing characteristics than could be secured from an elaborate deseription. Not much is known specifically of the origin of the hackney. Johnson's Dictionary describes a hackney as being a hired horse. In early

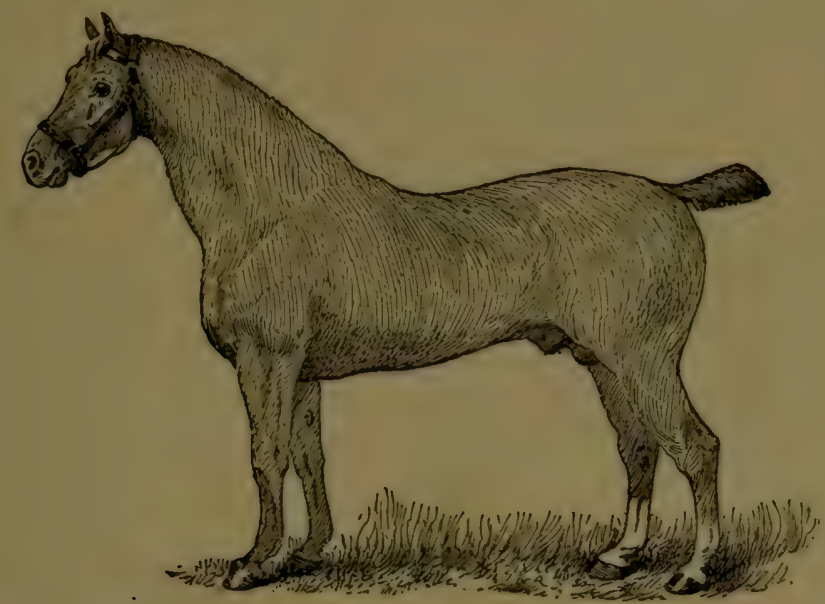

FIG. 17. Imported Cadet (1251) $10 \mathrm{Y}$. Chestuut stallion, foaled 1884

Bred by Hy. Moore, Esq., England. Owned by A. J. Cassatt, Esq., Chesterbrook Farm, Berwyn, Pa.

By Lord Derby, 2d 417. Dam 289 Princess, by Denmark. 1 Y Y

days, before Macadain discovered the art of roadbuilding, the highways of England were quite as bad as they are in America. At an early period, a hor'se had been developed similar, in many respects, to the modern improved hackney. The men who kept horses for lire soon learned to purchase those of this type because it was found they were the best to carry heavy riders and to use on the post-chaise and stage coaches, since they had extreme endurance and pluck and were easily kept in good flesh. By a modern infusion of 
warm blood, his mental endowments have been greatly improved, and his action and spirit also, while at the same time the "staying qualities" of the breed have been preserved.

There is some diversity of opinion as to the proper size of the hackney. Mr. Burdett Coutts is in favor of increasing the size by careful selection of sires and dams. Other expert breeders do not believe that the size can be increased without losing, to some extent, some of the valuable characteristics of the breed. I incline to the latter opinion; for the breed, if increased in size, would certainly either lose some of its snap and elastic force, or, in case these qualities were retained, the added weight would overtax the limbs. No animal with the high mettle and quick motion of the hackney can approach the weight of the draft-horse without being in danger of breaking down. An increase of weight implies, or shonld imply, a decrease in snap and quick movement. Of necessity, the horse of heavy weight should be somewhat phlegmatic in temperament, otherwise his limbs will soon give out. The old saying, "A good horse will wear out two sets of legs," is often true, and therefore a horse's limbs should never be overloaded by too heavy body weight.

The hackney, when full grown, should be not far from fifteen hands high. If he is rather slim of body, one or two inches more may not be objectionable, but if inclined to be "stocky" then his height would better not exceed the standard indicated.

Two hackneys,-Little Wonder, imported early in 


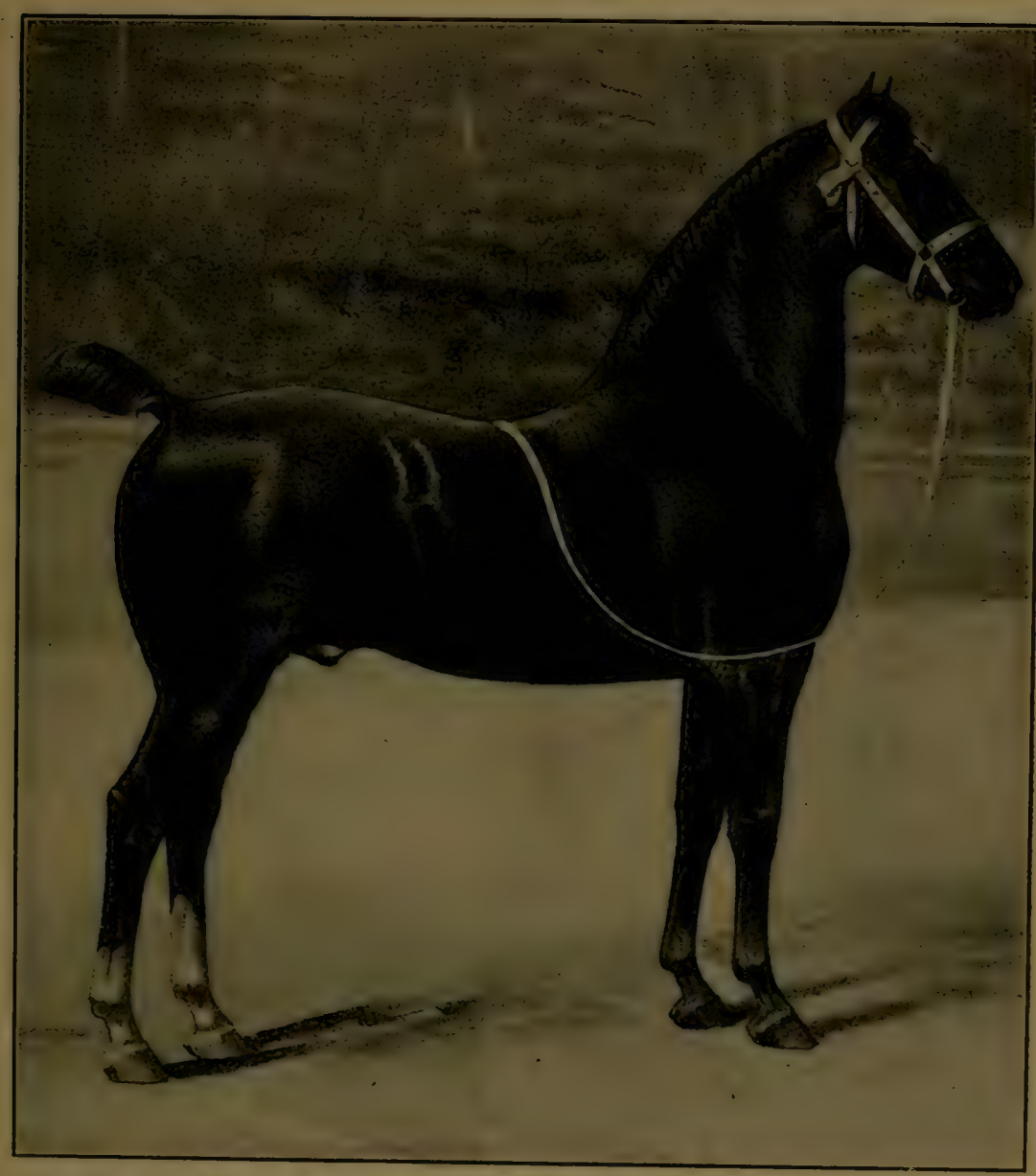

FIG. 18. Champion hackney stallion and champion sire Fandango 443 Winner of American Hackney Society's Challenge Cup, National Horse Show, New York, 1899-1900

Owned by Frederick C. Stevens, Maplewood Stock Farm, Attica, N. Y.

1883 by A. J. Cassatt, and Fashion, imported a year later by Prescott Lawrence, attracted wide attention. The hackney has grown into favor in recent years not only in the East but in the West as well. It is said 
that 181 hackney stallions were sold in England for exportation to the United States in the years 1888 to 1890 inclusive, a majority of which were taken west of the Ohio river. At the present time, there are many breeders of the hackney of wide reputation. No pains have been spared to select the best animals of England for importation. Too often the importations from Europe of some classes of animals have not been up to the highest standards of their respective breed. Fortunate it is that so many superior and so few inferior stallions of this breed have been brought to the United States. The standard was set high at first by wealthy and distinguished horse breeders, and it has been rigidly maintained. The beneficial results of this policy are evident, for one seldom sees a hackney full-blood or half-blood that is "weedy" or undesirable. 


\section{CHAPTER IX}

\section{THE HUNTER}

Chapter by F. S. PEER

THE organization of many new hunt-clubs throughout the eastern states, during the last ten years, has greatly increased the demand for horses suitable for cross-country riding. The demand for high-class saddle-horses - other than the gaited horse of Kentucky and ladies' and gentlemen's hacks (a borse for both riding and driving), has always been so poorly supplied that only comparatively few people who require them can be suited. The others must take up with trotting-bred horses, and other make-shifts that are poor substitutes, indeed, for the real thing. The breeding of the hunter is well within the range of the ordinary farmer. Many nondescript mares suitable, when coupled with good sires, for breeding hunters are already in the country, and might be utilized.

The requirements in a saddle-horse, or hunter, are such that they are produced only by a special line of breeding, as we shall presently attempt to show. The prices paid for them would indicate that they bring a greater return for the money invested in the animals for producing them, than any other class of horses. This is especially the ease with farmers of moderate means, and limited experience in breeding. Almost any 
well-bred farm-mares of suitable conformation,-even grade draft-mares and such general-purpose animals as are found on all farms, - make very excellent broodmares for producing this class of animals. If, on account of injury or blemishes, these thoroughbred grades fail to sell for the purposes intended, still they are the very best horses a farmer can have on the place for light road-and for light farm-work.

The one thing essential is to obtain the use of a thoroughbred (running-horse) for a sire. He may usually be secured at a,moderate price from racing establishments. I refer to such horses as have become injured or incapacitated for track work, but are still valuable for breeding purposes.

\section{BREEDING HUNTERS AND SADDLE-HORSES}

Selection of Sire and Dam.- On account of his inborn qualifications for saddle work, the thoronghbred running-horse is the only animal that is worth considering for a sire. Not only his low elnstic action, but his general conformation distinguishes him from all other breeds of horses as the most suitable for horseback riding. He has more intelligence, more courage and more endurance than any other breed of horses. The pure thoroughbreds are of a very nervous temperament, and it often requires a bit of horsemanship to get on with them. The half-or three-quarter-bloods, however, make the best all-round horse that it is possible to produce for hunting, ordinary saddle work, combination saddle and harness, cavalry, light artillery, or farm 
work, and I might add (barring action) light road work. The grade thoroughbreds have no equals; they can do any one, or all, of these things, and better than any other class, or family, or cross-bred animal that does not include thoroughbred blood. They will do all that any horse of their inches can, and then draw on their almost inexhaustible supply of energy - nerve force - to pull them through. This is my experience after years of breeding, rearing and schooling horses of all sorts. Any man with horsemanship or "horse sense" enough to avoid abusing or fighting with them, will, if his experience is my own, say they have spoiled him forever for having any other horses aboutexcept for heavy work. Of course, they are usually deficient in knee and hock action, which is so desirable in a high-class harness-horse. If they possessed it, however, they would become correspondingly less useful for saddle work.

I believe it is not too much to say that, as a rule, two good half- or three-quarter-bred horses will do as much as three ordinary horses of equal weight, They are as useful on the farm as they are ornamental in the hunting field, and under saddle; they are as indispensable in a cavalry charge as they are graceful in carrying a lady for a ride in a park. They can pull a harrow or bring back a gun-carriage after all their coldblooded relations have wilted and quit. So much for the blooded horse as a sire of high-class animals with courage and endurance, which qualifications are required in the hunter more than in any other class of horses.

As to selection of suitable dams to breed to a thor- 
oughbred stallion, the mare should be, first of all, sound and free from vices. Defects are usually transmitted through or inherited from the dam. Mares with full and high sloping withers, which keep the saddle well back where it belongs and free of the shoulder blades, are most essential. Low, full withers permit the saddle to turn. A low or only medium up-carriage of the head is desirable. High-headed hor'ses are very objectionable for hunters. A hunter or saddle-horse should carry the head so the eyes are about at the height of the withers. A "park hack" may carry a higher head. A stout, broad loin, but not too short in the back or coupling, is best. A short back for a saddle-horse sounds all right theoretically, but practically it is not altogether desirable. A horse must have length of body, or he cannot stride away. Short middle pieces usually accompany a correspondingly short, choppy gait, which is most uncomfortable for the rider. Hock and knee joints very large, even to coarseness, in the mares is very desirable. The true arm should be rather short and upright-the full sloping withers keep the saddle well back on the upper line, but a short, upright true arm is even more essential, as it places the fore legs of the animal well forward of the saddle girths, which enables the rider to sit back over the horse's center of gravity. A long oblique true arm may bring the fore legs so far back as to move the center of gravity of the rider too far forward, which makes the horse labored in his gait, and increases materially the chances of his falling or even turning a somersault on the landing side of a fence he is jumping. 
The mare should have depth of body in the forequarters rather than breadth. Horses that are thick or wide through the heart, or with springing ribs, which are so desirable in harness-horses, are most uncomfor-

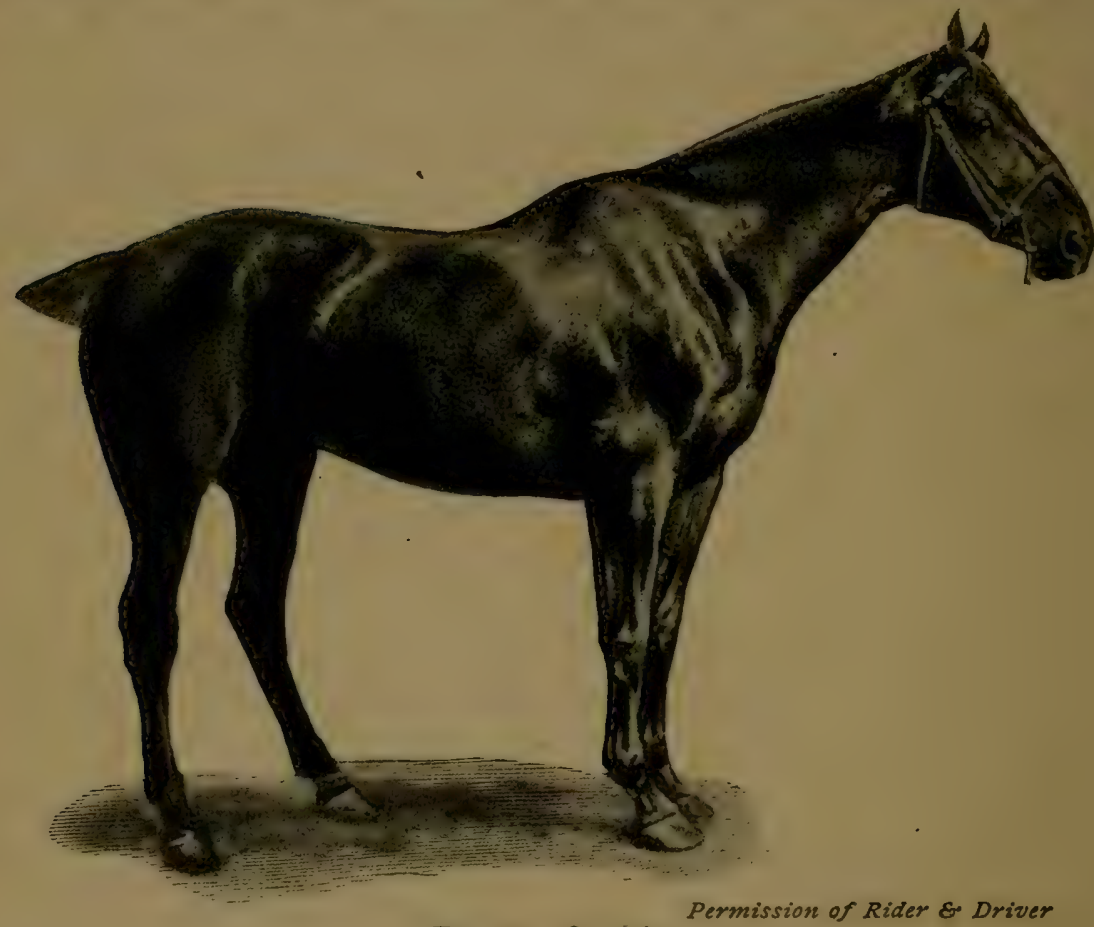

Fra. 20. Ontario

table for saddle-work, as they spread the rider's legs too far apart. Again, horses too broad in the breast (fore legs wide apart) are usually rough and rolling in their gait, which is also most objectionable. These are the principal features to be looked for and avoided in mating mares with a thoroughbred horse, for the purpose of getting high-class hunter's, saddle-horses or hacks of endurance. 
In undertaking this kind of breeding, it should be carried on as much as possible in communities, to attract buyers. The Province of Ontario, Canada; West Virginia and some sections of Missouri are the present headquarters for breeding this class of horses in America. Many thousand dollars for horses go annually to these center's from all parts of the eastern states. There is a very promising field for any community of eastern farmers undertaking to breed this class of horses. The great reputation won by Canada in the harness- and saddle-horse markets of the world, and in supplying the very highest class of remounts for the British army, is owing to the extensive use of the "blood" horse in some sections of the Dominion. Within a radius of twenty-five miles of the City of Toronto, for instance, there were reported, in $\mathbf{1 8 9 5 ,}$ sixty-odd thoroughbred stallions in service principally, almost entirely, to farm mares.

It is not too much to say that the general use among farmers of thoroughbred sires in Canarla has brought to that country the enviable reputation it now enjoys for breeding high-class horses both for saddle and harness, and that it has brought to our cousins across the lakes millions of American dollars that should have remained at home. 


\section{CHAPTER $\mathrm{X}$}

\section{PONIES}

THE breeds and varieties of ponies and small horses are numerous; even Asia and Africa possess many. Some are covered with hair which approaches bristles in coarseness and stiffness. Corsica had a breed of ponies as untamable as the zebra. It is said that the body length of the Asiatic horse about equals his height at the withers, while the body-length of the African horse is considerably less than his height.

The pig has evidently sprung from two distinct groups, Sus scrofa, of Europe, and Sus Indicus, of Asia. Professor Low questions whether the African and the Asiatic horses have not also sprung from two species, or groups, originally radically different. However, it is probable that differences in altitude, food and environment, and the time which has elapsed since the respective varieties were domesticated have furnished opportunity for variations to take place as wide as those noted. Moreover, the variations noted in horses are not wider than are found in the different breeds of domesticated sheep. As yet, nothing is positively known as to whether the modern horse sprang from one or two radically different species. It is sufficient here to call attention to the marked dissimilarity of horses in different localities and in different countries. 
The little bronco of Mexico and the United States has assumed several somewhat distinct types, due sometimes to slight admixture of blood, and to climate, environment and use. Specific distinguishing names have

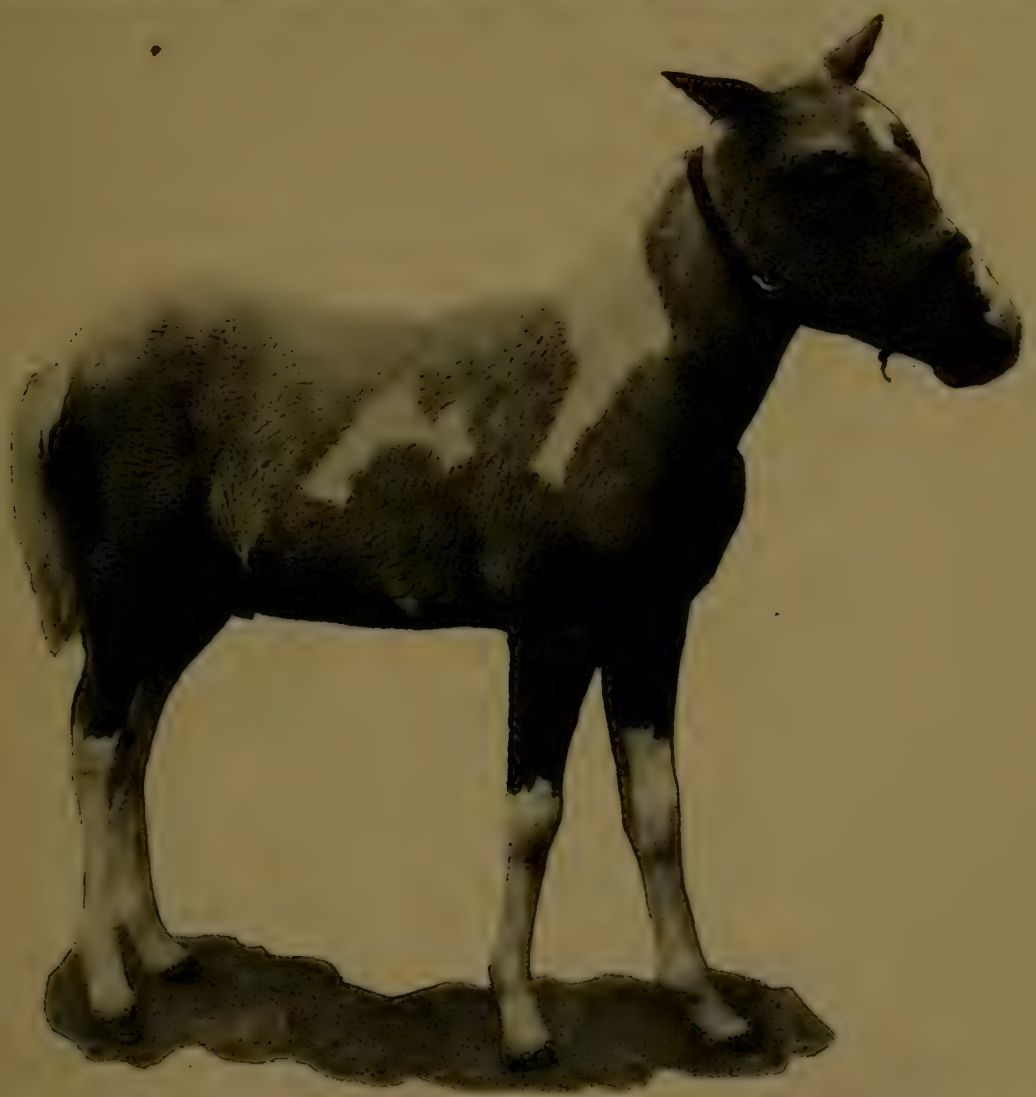

FIG. 21. Disgusted with the circus in six months

been given to some of these types,- - such as mustang, Creole, Indian and bronco.

In the United States, comparatively few ponies are now bred or used, except on the plains. If these are handsome and kind, they are salable to a limited extent 
at remunerative prices. The American lad, before he reaches his "teens," longs for a "truly" horse, one that has the form and action of the roadster and which requires more horsemanship to drive or ride than does

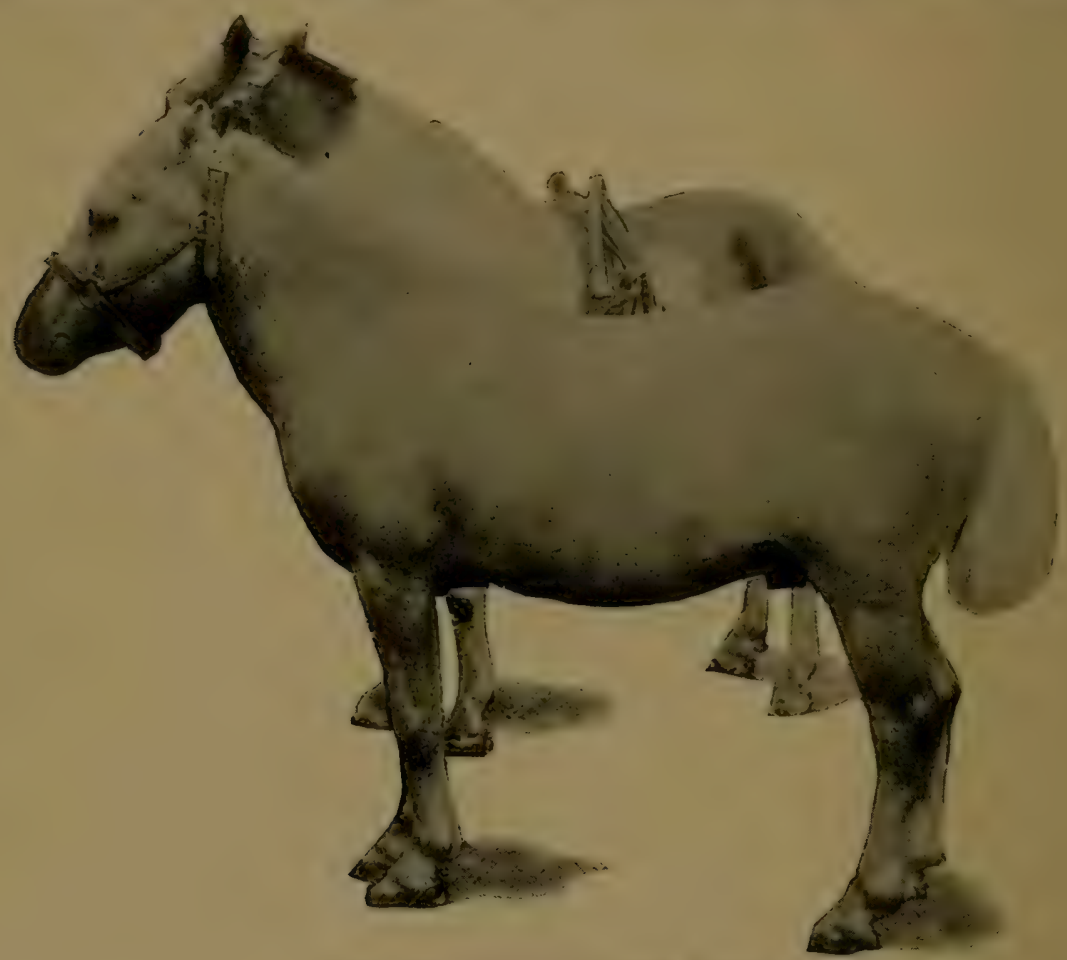

- FIG. 22. A pair of trick ponies

the pony. He may be satisfied with an animal fonrteen hands high, which, in some sections, is called a pony, in others, a light roadster; but, in any case, the animal must have many of the traits and approach the build of the snappy roadster. In other words, he must not be pudgy, short of pace and thick of neck; if he is, he is called a child's pony, and despised by the lad of sixteen. 
Those animals which are fourteen hands and under are usually classed as ponies; those above fourteen and under fifteen hands, if pony built, are, in England, called Galloways. However, this latter term is not commonly used in the States to designate a smallish horse. The name pony, used generically to designate a small or smallish horse, of pony build, is used so differently in different countries, and even in different districts of the same country, that it is often difficult to classify them with any degree of accuracy.

\section{THE SHETLAND PONY}

Until quite recently, the Shetland pony was the only one bred in considerable numbers in the eastern states. The Shetland is the smallest of the pony breeds and has long attracted marked attention, because of his smallness and not infrequently because of his peculiar and striking markings. Reared on the rugged Shetland Islands, north of Scotland, where a large animal would not serve the inhabitants so well as a small one, and in a climate so bleak that larger horses, even if introduced, would soon become dwarfed, they have not been crossed with larger breeds, except with the Iceland pony, which cross was not successful. These ponies are, in their native home, subjected to great hardships. They are usually allowed to roam in the open in the winter as well as in the summer. As the demand for them increased and the prices advanced, some pains have been taken to provide more abundant food and, not infrequently, rude shelter. However, the Shetland pony is so thickly 
coated, or double-coated, with fine, short, mossy hair and a long, coarser coat, that he seeks the shelter of a building only in extremely tempestuous weather. When removed to a milder climate and housed, it requires but a few generations to materially modify the hairy covering, and, in some cases, even the general form of the animal as well. The tendency is for them to grow taller,

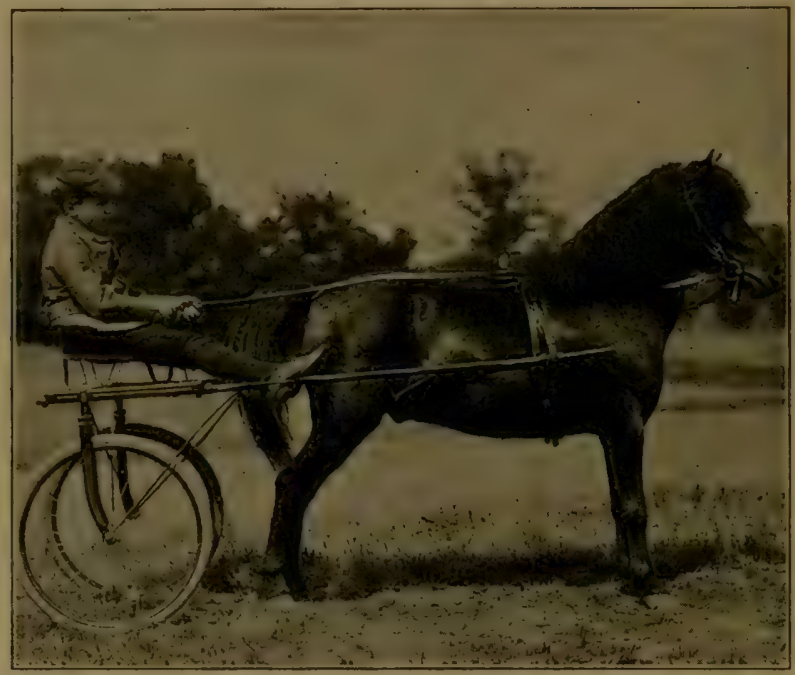

FIG. 23. Exile of Pittsford (4520). Height, $43 \frac{1}{2}$ inches. Owned by Mrs. Estelle F. Hawley, Pittsford, N. Y.

trimmer and of slightly less robust build if judicionsly fed. The well-bred, home-reared pony is likely to fill the eye of the American boy better than the imported. There are several varieties of the Shetland ponies, due, in part, to the aspect of the locality in which they are bred; in part to the different tastes of the breeders; and probably, in part, to slight differences in the foundation stock of the several varieties. However, 
they are sufficiently uniform to be classed as a single breed.

There is likely to be an increased demand for firstclass Shetlands. As wealth increases the demand increases; but this demand, as might be expected, is for high-class animals. The second-class pony has few

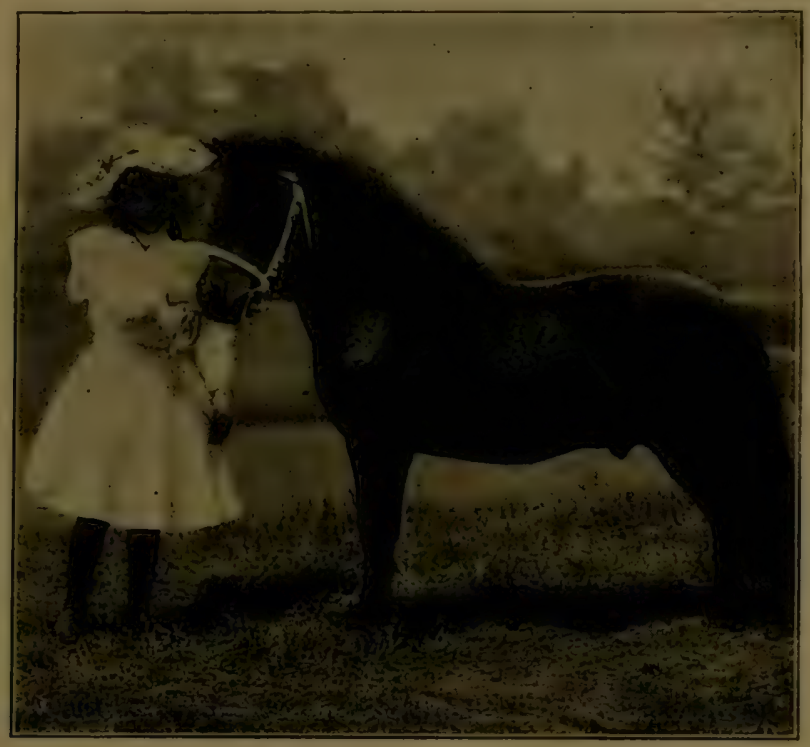

F1G. 24. 13ressay of Pittsford (3151). Height, 38 inches. Owned by Mrs. Estelle F. Hawley, Pittsford. N. Y.

purchasers, for, if the income justifies the purchase of a pony at all, it justifies the acquiring of one that is both good and beautiful. As yet, in America, there is no large place for the Shetland pony except as a child's horse.

While there have been several valuable breeds of ponies imported and bred in the United States, the little Shetland pony is not likely to lose his well-earned pop- 
ularity. The pony can be made very useful, under proper supervision. in educating children to be courageous, self-reliant, kind to and thoughtful of the brute creation. The American farm boy is usually an expert horseman, due, without doubt, to his early familiarity with colts and horses on the farm. The city lad may acquire much of the same expertness by handling ponies. This four-legged associate is often a safer companion, for a hot-headed youth, than a two-legged one. The question as to whether there is profit in raising ponies sinks into insignificance beside the larger oneIs there profit to the country in rearing self-reliant, strong, humanized citizens?

Other things being equal, the smaller ponies sell for higher prices than the larger ones, and the piebald or spotted ones often for more than those of solid colors. In any case, the Shetland is seldom more than thirteen hands high, fifty-two inches; the smaller ones but six to seven hands high. However, a large majority of these ponies range from thirty-five to forty-five inches in height. When placed under conditions similar to those of larger horses in America, the tendency is for them to increase in size and become somewhat phlegmatic and less-enduring. Then, too, they sometimes have a tendency to heaves or asthma. However, this tendency is largely or wholly due to idleness and overfeeding, especially of hay. The very fact that they are small and are pets results in their being fed too frequently and too liberally. In this country a hundred ponies are injured by overfeeding where one is injured by underfeeding. To keep ponies trim in form and 
lively, especially where they are used but little, the grain ration should be about one-half, and the hay ration one-fourth of that fed to the employed roadster. It is sometimes said that a pony can be bred and

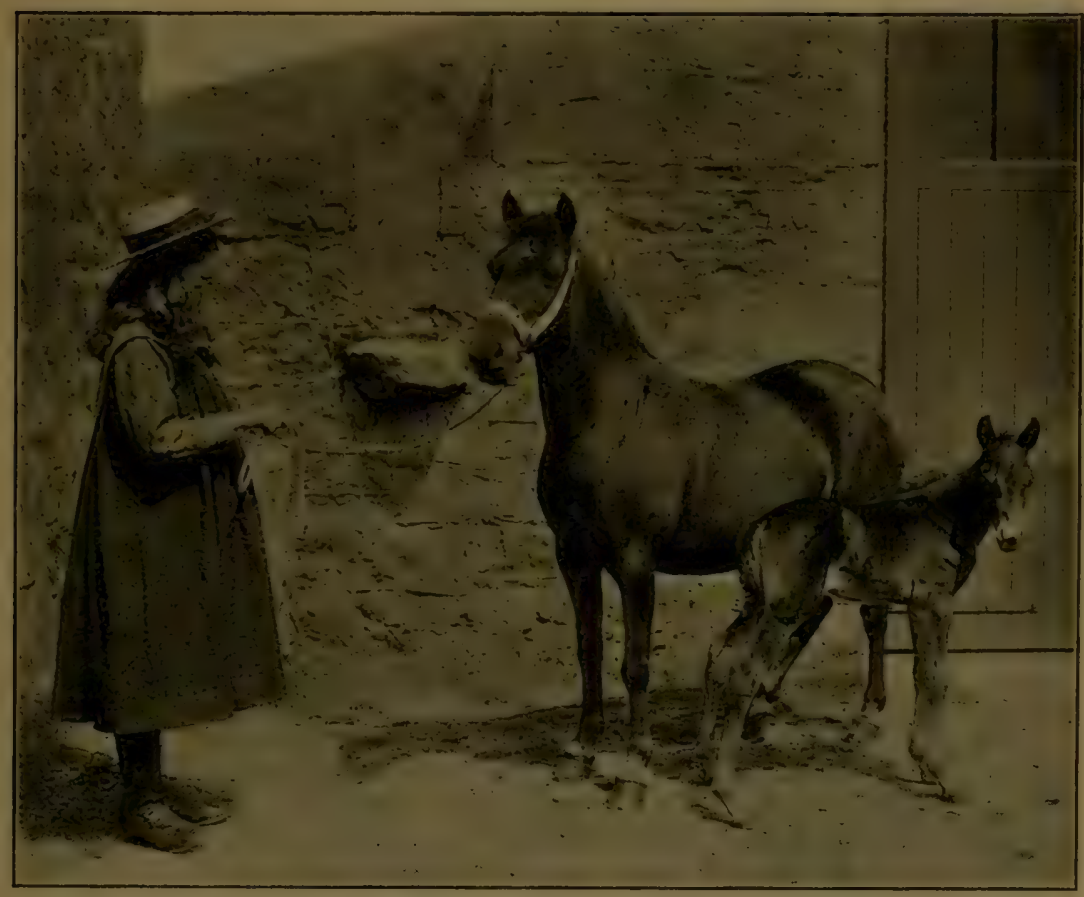

FIG. 25. Champion Welsh pony mare. Titor, $11 \frac{1 / 2}{2}$ hands high.

Owned by John Jones \& Sons, Colwyn Bay, North Wales, England

raised about as cheaply as a sheep. The raising of good ponies is a highly specialized business; therefore their breeding should not be begun hastily or ignorantly. Anybody can raise little horses at little expense, but they will have to be content with little prices. In pony breeding, something for a little or nothing is no more likely to be secured than in the production of other live 
stock. The same careful selection of foundation stock, the same judgment in mating and care as is taken in breeding the trotter or saddler, must be exercised, if the animals most in demand at remunerative prices are secured.

\section{THE WELSH PONY}

The Welsh pony averages nearly one hand higher than the Shetland, is less phlegmatic and hence not quite so easily handled by children as the Shetland. However, he is not vicious but more alert and quickermotioned, which is due, possibly, to an infusion, at some time, of Oriental blood. He is a tough little fellow, as are most ponies, performing, like the mustang, feats of endurance that seem incredible. Many of them have body and neck lines which closely approach those of well-built small horses. At the same time, something of the pony build is present. When all of these characteristics are harmoniously combined, the result is a most beautiful and valuable animal. Great success has lately been achieved by some breeders in Wales by crossing a hackney-pony stallion on Welsh mountain-pony mares. See illustration (Fig. 27), hackney-pony stallion, Julius Cæsar.

EXMOOR, DARTMOOR AND NET FOREST PONIES

In the breeding of Exmoors, as in the breeding of Shetland ponies, distinctive families have been produced. The Exmoor may be considered the parent or foundation stock of the Dartmoor and the New Forest families of the breed. These latter are so nearly identi- 
cal with the Exmoor that it will not be necessary for our purpose to treat them separately. In fact, the Welch pony, the Exmoor, the Dartmoor and the New Forest are sometimes so nearly alike as to deceive good judges

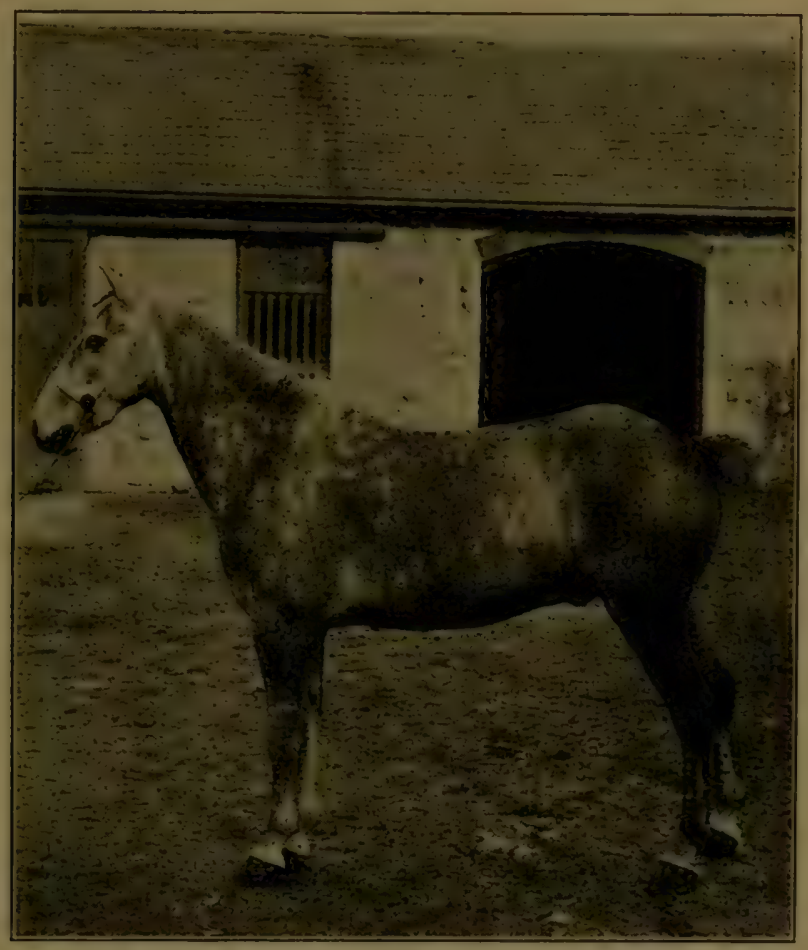

FIG. 26. Movement. Welsh pony gelding.

Owned by John Jones \& Sons, Colwyn Bay, North Wales, England

when an animal of one breed or variety is offered as belonging to another. There are no distinguishing color's in any of these breeds of ponies, and one sometimes merges so closely into another in size and characteristics, that but few persons ean accurately classify them off-hand. Then, too, a family or variety name 
is frequently used as a breed name. Even the marked characteristics of breeds and varieties, such as size, markings and activity, differ so little that it is often

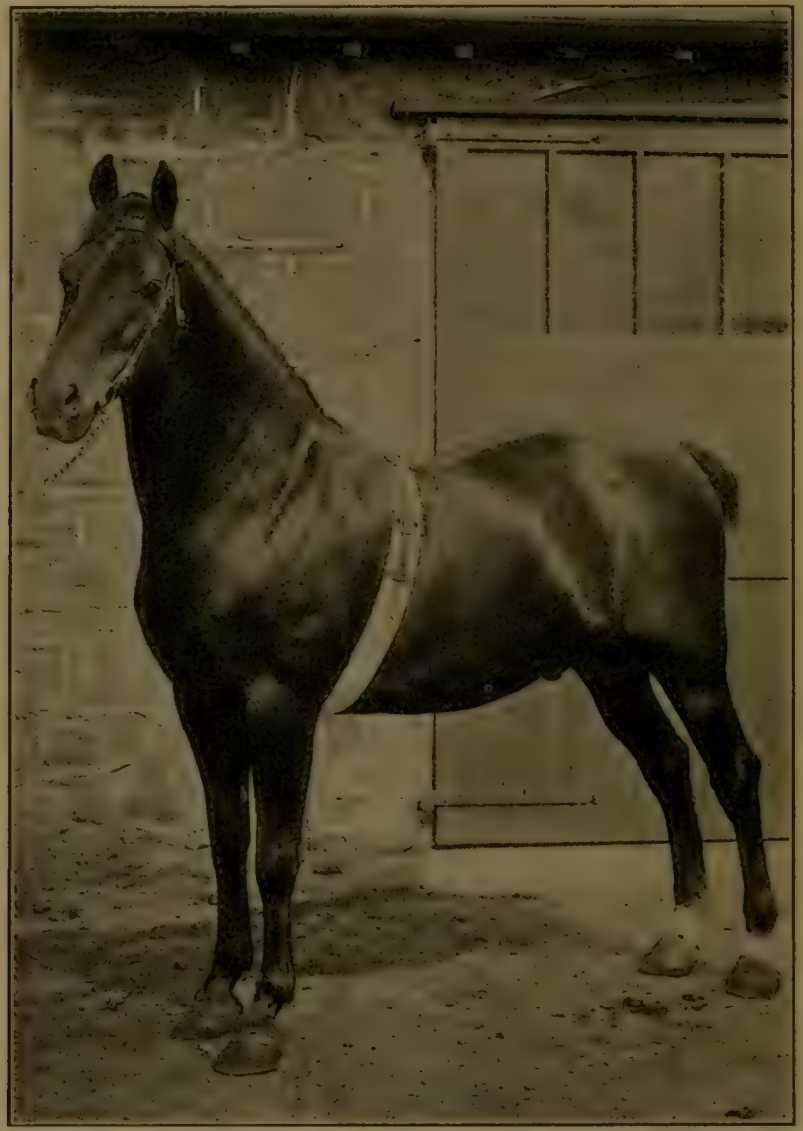

FIG. 27. Julius Cæsar II (5666).

Owned by John Jones \& Sons, Colwyn Bay, North Wales, England

impossible to distinguish one from another unless typical specimens of both are present for comparison. There is a constant multiplication of breeds and 
subbreeds, and this tends to confuse those who purchase the animals, while it gives opportunity, on the part of the seller, to misrepresent without being detected. However, multiplication of breeds and subbreeds tends to promote improvement. An honest, vigorous rivalry is indicative of growth and progress. The "battle of the breeds" may leave some slain by the wayside, but the fittest survive. The cyclonic arguments which periodically take place with some classes of breeders of live stock clear the atmosphere.

\section{MUSTANGS}

The pure mustang traces directly back to the Spanish horse, being the offspring of horses escaped from domestication. The horses brought from Spain during the Conquest of Mexico, 1519-22, formed the foundation stock for this hardy, vicious, wiry, unreliable, smokydun, yellow-clay, mouse-white or pink-roan, piebald, everlasting, bucking mustang. The forces of nature might have made a more erratic horse and one of tougher material, but never did. Happily, the same conditions which produced the horse produced a man able to tame and ride him. No other horse could have withstood the uses to which he was put, and no other man but the plains-man could have put a horse to such uses and abuses. The early civilization and conditions, and the climate, produced men who were not content unless something as exciting as lassoing a Texas steer, fighting wild Indians or riding the wilder mustang were a daily pastime. The mustang has been a most helpful 
little brute, and has played an important part in the substitution of sleek grade Herfords and Short-horns for the bull-headed bison and the treacherous coyote. Juicy, marbleized steaks have been substituted for the dry, leathery, tough bison meat; and farms and homes,

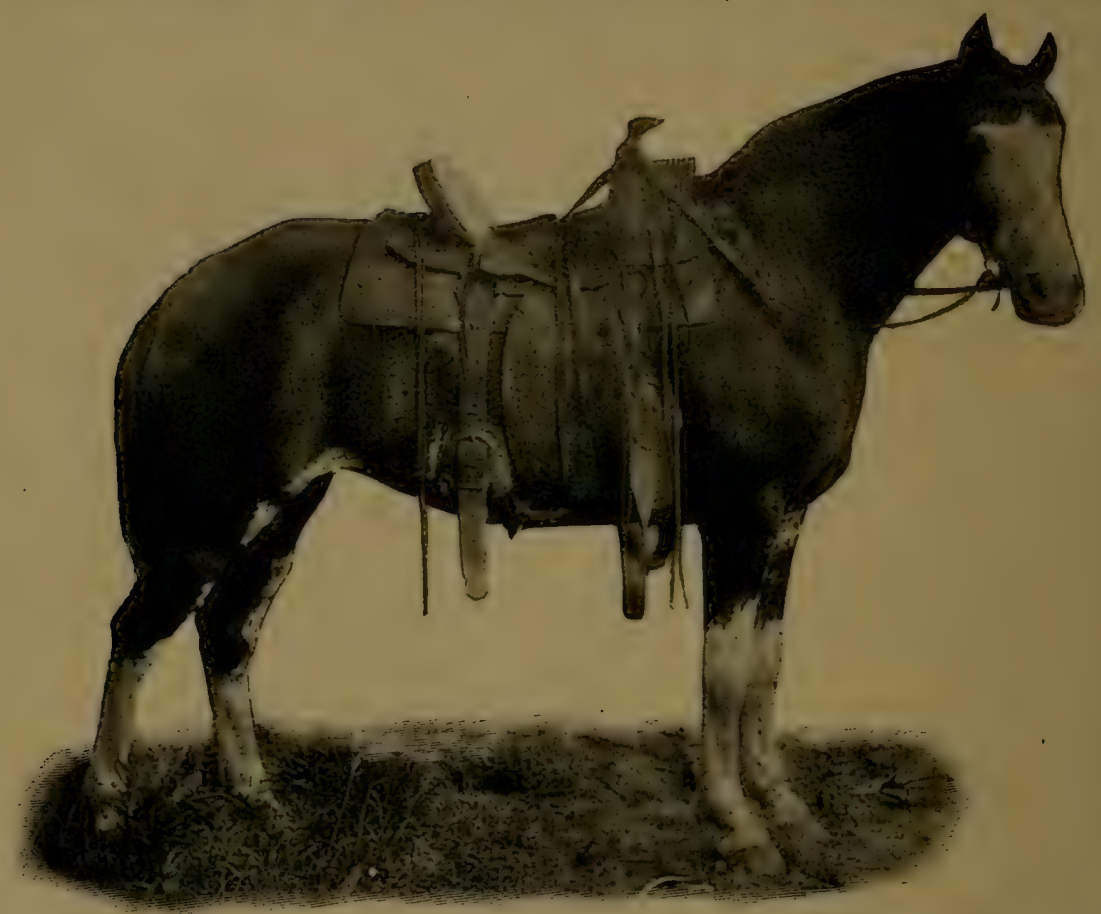

Permissin of Breeders Gazette

F1G. 28. Gaited broncho. American-bred

corn and cattle, and "God's country" have taken the place of the wigwam, the Indian, the coyote and the desert. Without him, the wild hordes of the rocky fortresses, and the illimitable windy plains now burning hot, now bleak and cold as Iceland, would not have been settled and civilized for many long years. But for the 
pony, communication could not have been had between the west and the east in the pioneer days. The pony overland express was as useful and as necessary in its day as are the transcontinental railways in our times.

\section{THE INDIAN PONY}

The Indian pony is an offshoot of the mustang. As the inustang drifted northward, he found a colder climate and, if not a more exacting, a less intelligent owner. While the pony was ridden by the brave, he was petted and starved in turn by the squaw. He was often called on to perform tasks which tried his courage to its utmost. What with close familiarity with the family and periods of semi-starvation during inclement winters, as he drifted northward he lost something of size and-power to perform, and much of the erratic temper due to his Spanish-Mexican origin. Like the mustang, he is found in many colors. When well nourished he inclines to be more rotund than the mustang. Some writers have suggested that this is due, in part, to a cross with the small horses of Canada. However this may be, there is not enough mixture of blood to hide the prominent mustang characteristics.

\section{CREOLES}

The little Creole pony is prized in some portions of Louisiana. They have been called "pocket editions of the thoroughbred race-horse." When crossed with the Shetland, ponies are often produced which are not only lively and hardy but gentle as well. 
There are several valuable breeds of ponies in South America. Those of the pampas are numerous and are from the same foundation stock as are those of North America. All of the native breeds and varieties of ponies, - and there are many of both in North and South America, - trace back to those found roaming wild over plains and pampas; and these, in turn, go back to a common ancestry - the smallish, warmblooded horses of Spain. Within the last few years, all of the ponies of the plains have become modified, and it is not now easy to find typical specimens of the ponies of half a century ago.

The ponies of the plains are not inferior broodmares, considering their diminutive size. They range from twelve to fourteen hands high and in weight from six hundred to nine hundred pounds. If mated with the large breeds, their progeny reaches a fair size. The blood of the ponies, when judiciously mingled with the phlegmatic draft breeds, - that is, when the difference in the size of sire and dam is not too great,-results in a fair-sized, active, good-tempered, courageous animal, suitable for moderate driving, the plow or light draft. So the Indian and mustang ponies have furnished some good acclimated brood-mares, without which the farmer and the breeder of the western plains would have been greatly inconvenienced in early days, in the production of the commoner's horse. With good roads and the increase of toilsome, productive work and wealth, must come the roadster, the coacher and the draft-horse, the stylish saddler and the children's safe horse. Like the Indians, these ponies become subject to that inexorable 
law, "the survival of the fittest," which is not stayed long by wish or will or painstaking effort.

\section{THE POLO PONY}

In recent years a demand has sprung up for a pony somewhat different from any yet deseribed. A wiry, active, courageous animal, of gond temper and unexcelled endurance. He should be from thirteen and a half to fourteen and a half hands high. Polo ponies larger than this are considered too tall, as they place the rider too far from his work. The small pony, one below thirteen hands, has not the speed, activity or power necessary to carry the rider successfully through a sharply contested game of polo. Of course, an ideal polo pony can be produced only by a liberal admixture of the Arabian or Oriental blood with that of selected mares of the Welch or Exmoor type, or with suitably shaped small mares which already have some of the warm-blood characteristics. The best-tempered mustang or Indian mares would form most excellent foundation stock, on the dam's side, for the production of an American breed of polo ponies. (See Fig. 4, Chap. III.) If the Arabian blood were once harmoniously united with the blood of the plains, the foundation, at least, would be laid of a breed of horses upon which an unexcelled breed of ponies suited to polo and other similar work could speedily be reared. The foundation stock for such a breed, though scattered, is abundant. Where is the genius who will take up the work of uniting the valuable scattered potential forces, and thus produce a breed 
of ponies, or small horses, which, if good, are likely to be much in demand in the near future. It certainly would not be as difficult to produce a breed, or at all events a variety, of ponies at least as well suited to the special needs of Americans as are the trotters, pacers and roadsters. There certainly is a large place for good small horses and ponies, as well as for large and fast ones. Now that good foundation stock is at hand for forming such a class of horses, it would be unfortunate if the opportunity were lost. Must we be importing forever, or shall we be wise and produce animals worthy of being exported to the best high-priced markets of Europe? 


\section{CHAPTER XI}

\section{DRAFT-HORSES-CLYDESDALE, ENGLISH SHIRE, SUFFOLK PUNCH}

ONE of the oldest, if not the oldest breed of British draft-horse, is the Clydesdale. As a variety, they attracted attention as early as 1715 ; but it was long afterward before they assumed that uniformity of character and potency which should be possessed by any class of animals before it can properly be called a breed. There appear to be good reasons for believing, and the most trusted authorities assert, that all of the heavy draft-breeds trace back to the wild Black Horse of Europe. This would seem to be a fair conclusion, since it is not probable that large draft-horses were developed from light, high-mettled, oriental foundation stock; though, without doubt, most, if not all of the draft-breeds have some admixture of warm blood. Horse-breeders from time immemorial have been fond of trying experiments; hence heavy stallions were, as they are now, sometimes bred to mixed-blooded mares, and not infrequently desirable female offspring resulted. These were then used to beget other offspring. Selections were then made according to the consensus of opinion of the best breeders, usually in a somewhat restricted district, as to the characteristics and qualities most desired. 
Almost nothing is known of the method by which the blood of the original Black Horse of Europe was transformed into the Flemish draft-horse. Suffice it to say, at an early period, a heavy, rotund, short-legged draft-animal, somewhat similar in type to the Clydesdale

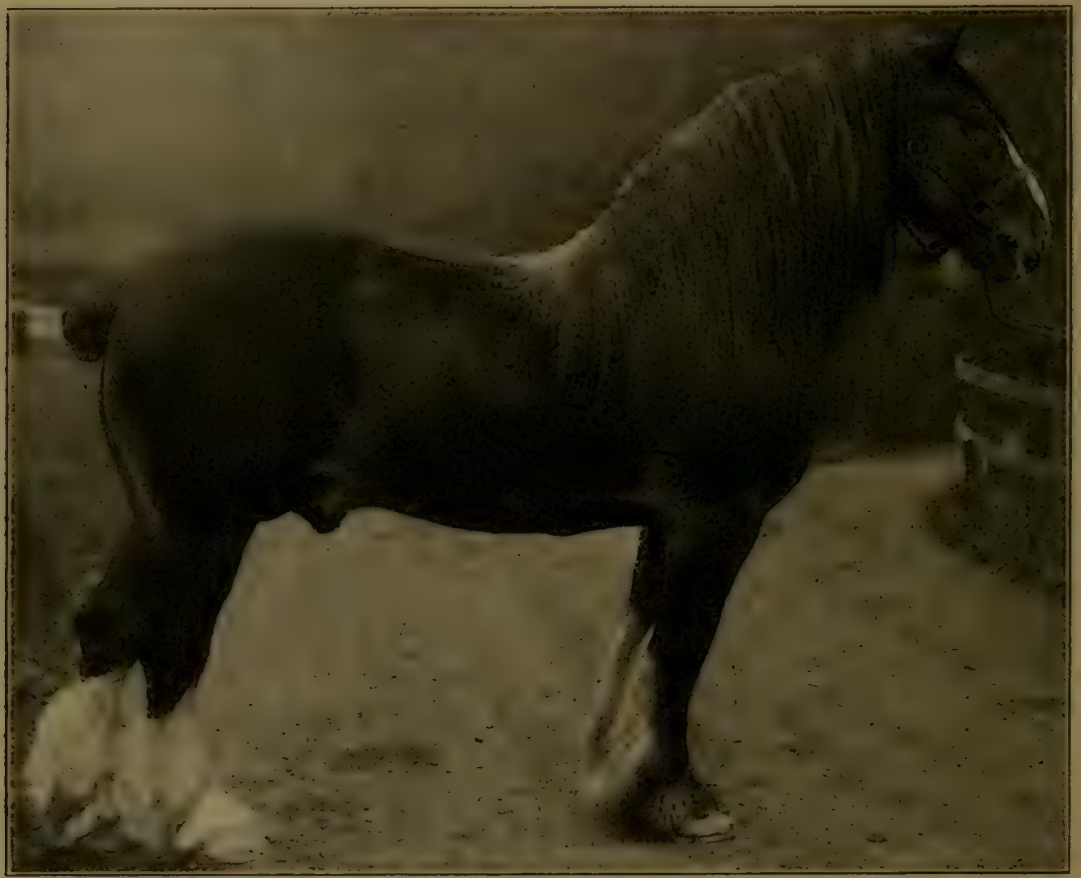

FrG. 29. Lord Stewart, Clydesdale stallion

Seaham Harbour Stud, Seaham Harbour, England

of the present day, had been developed in Flanders. These, or their progeny, in a more or less pure form, appear to have been used to give the desired weight and form to nascent varieties of heavy horses in Great Britain and France, and probably in other European countries as well. However, the Flemish type has been 
so changed, both in France and Great Britain, as to lose many of its original characteristics. Hence, notwithstanding the fact that more or less of the blood of the British and French draft-horses is of Flemish origin, these modern breeds are justly entitled to the names they bear, as they are a new production rather than an improvement of the old Flemish breed.

The memory of Mr. John Patterson, of Lochyloch, Scotland, pioneer in draft-horse breeding, and Robert Bakewell, pioneer in the breeding of mutton sheep, should be honored and preserved; for they gave an impetus to the improvement of live stock which is still felt wherever superior farm animals are loved and prized. Some time in the early part of the eighteenth century, Mr. Patterson brought from England a Flemish stallion, which is said to have so greatly improved the draft-horses of Upper Ward as to make them noted all over Scotland, and in portions of England.

Description. - The color of the modern Clyde is generally bay or brown, sometimes with and sometimes withont white markings, though blacks and sorrels are occasionally seen. The white is usually confined to a strip in the face, "blaze," and the lower part of the legs. Formerly the colors were not so dark, nor were the animals so well formed as they are at the present time. They still occasionally retain some of their old characteristics of shape and color. The flanks, the inside of the thighs and the belly are frequently a light bay, fading out in the less-exposed parts to a dun. The Clyde belongs to the large breeds, the stallions weighing from 1,500 to 2,000 pounds, and mares from 1,300 to 


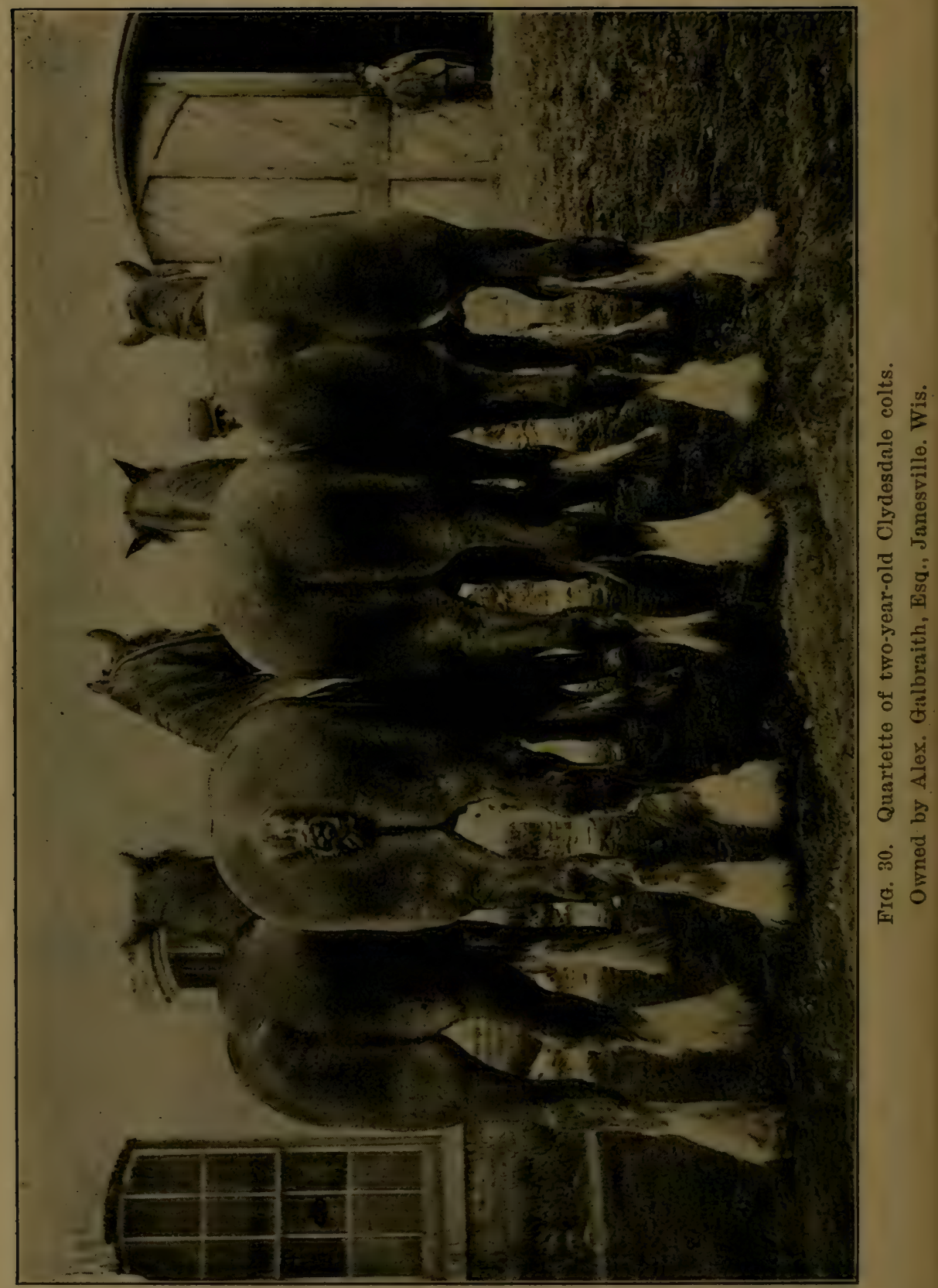


1,600 , although specimens of heavier weights are sometimes found. The Clyde is tall, sixteen to seventeen hands, rangey, yet smooth and symmetrical, with long head, medium or rather short neck, strong, short legs heavily fringed below the knee with hair, "feather," and unusually long, slanting shoulders for a draft-breed. The length of shoulder and the rather unusual slant indicate activity and ease of movement. They have a kind, quiet disposition, good courage, and quite enough spirit for heavy work. Some of the horses first imported had poor feet and too long limbs. Recent importations show great improvement, not only in these two points but in others as well. Some of the Clydes are too small at the waist, "wasp-waisted," in which case the floating ribs are too short and the flank is too high. Both of these characteristics, as well as the too steep rump, were observable in some of the earlier importations. However, it should be said that if the flank were bred down too low it would interfere with the long, rapid stride for which the Clyde is especially noted. Then, too, the feet of this breed, like those of all other draft-breeds, are not always so good as might be desired. It may be said, however, that few or none of these defects are discoverable in the better specimens of the modern Clyde.

Clydesdale, the valley of the Clyde river, which extends with its tributaries through the counties of Renfrewand Lanark, is fertile and moist, and hence it is often difficult to secure horses with as hard and cylindrical feet as desired. All large draft-breeds incline to be flat-footed. Abundant hair, "feather," on the lower part of the legs, is objectionable in many 
parts of the United States. Fortunately, Americanreared Clydesdales show a marked diminution of "feather," and improvement in the shape and character of the feet. Especially is this true in locations of light

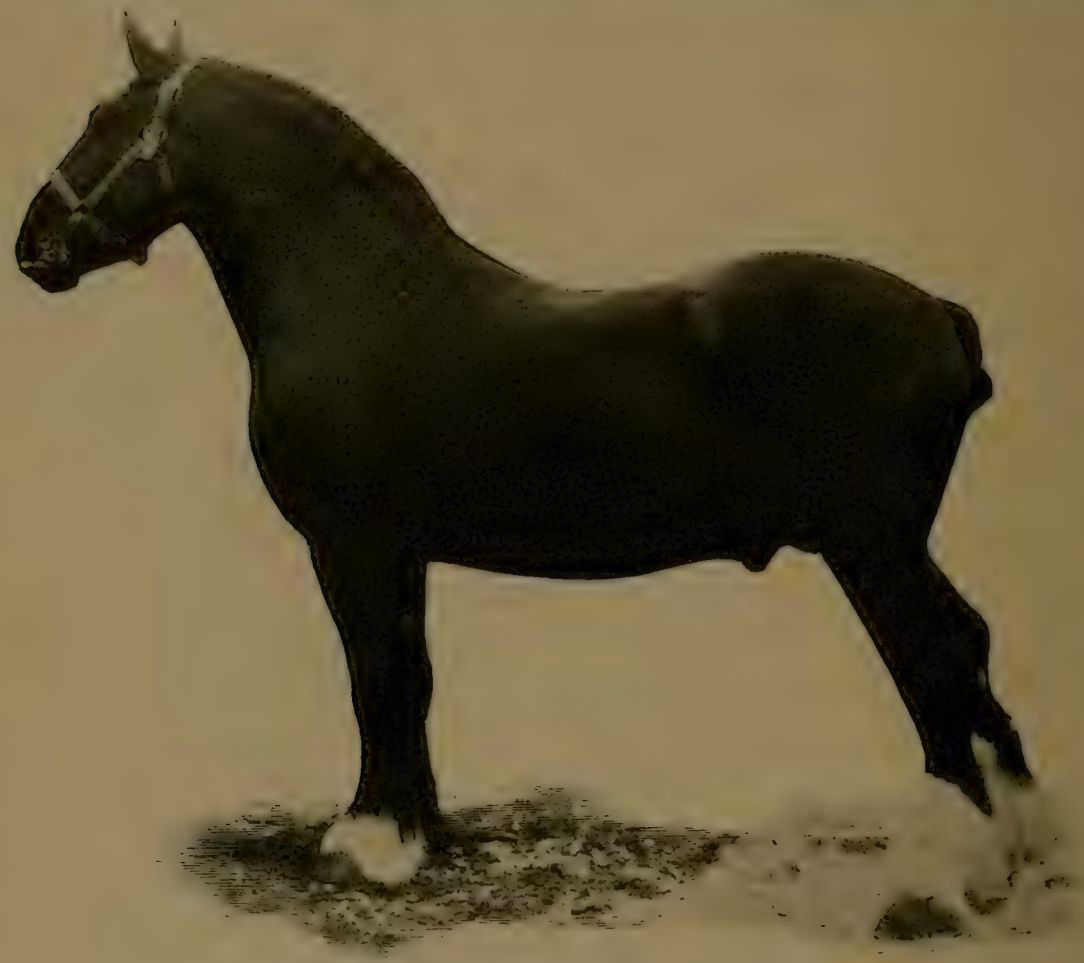

FrG. 31. Borthwick. Imported Clydesdale stallion.

Owned by Alex. Galbraith, Esq., Janesville, Wis.

rainfali and abumdant sunshine. Occasionally we still see "wasp-waisted" and "goose-rumped" Clydes, but they are becoming more and more rare. Better horses are now being bred in Great Britain; and better horses are being imported, and far better judgment is being exercised in mating and rearing in the United States, 
than formerly. The result is a large number of really superior Clydes and a relatively small number of poor, unsymmetrical animals.

The attempt is often made to show that a breed originates from one or a few animals of note, whereas such animals only improve or accentuate desirable qualities. They may be, and usually are, the first mile-stones from which the history and records of the breed are made up, so it has become customary to give credit, as the parent stock of the breed, to a few animals which showed marked improvement over other animals of similar characteristics. It is self-evident that the power to produce specimens above the average was present, though usually latent, in the ancestors which preceded the specimens which showed marked variations for the better. The valuable and distinguishing characteristics of a breed are not produced in a day or in a single generation. They come by slow growth, in accordance with the laws of evolution. However, for convenience in writing up the inception and development of a breed, we start with one or a few more or less noted animals, and largely or entirely ignore the ancestry which lies back of them. From a few more or less distinguished animals, the breed begins and is usually developed by in-breeding for a few generations. When a breed is being formed, often little is known of the ancestors of the females which are bred to the selected foundationmales. Several generations may elapse before an attempt is made to exclude from the preed, especially on the female side, animals which have less than seven-eighths of the selected or approved ancestry. 
The term "full blood" has been an extremely indefinite one, and when applied to recently formed breeds is still so. The flexible rules observed when a breed is being formed, instead of being a hindrance,

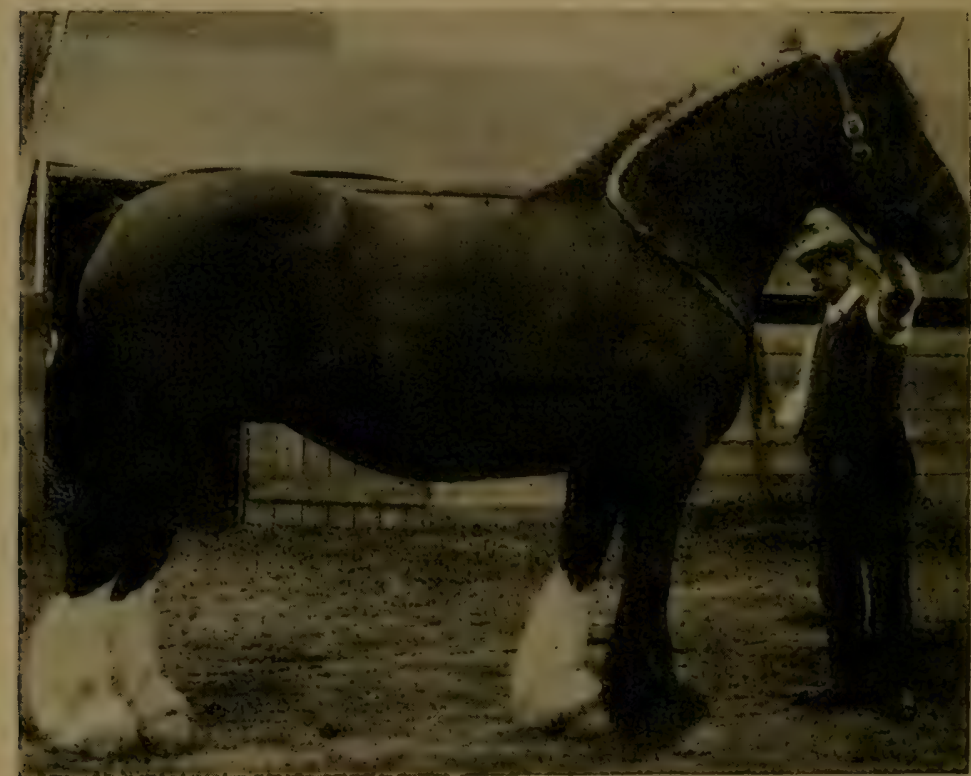

Perrission of F. S. Peer

FrG. 32. Clydesdale mare

are, in, fact, a great help, as they give wide opportunity for selecting the best animals and for making such crosses and combinations as give promise of securing improvement. The improvement once secured, "inbreeding," to some extent, must be resorted to, or the improvement is likely to disappear. (See Chapter XIII). However much the historian may be interested in the early history of the breed, - which too often is lamentably contradictory,-it does not follow that the 
busy farmer, or even the agricultural student, should go into the innumerable petty historical details, many of which are unverified. It is far better to learn the characteristics of a good animal, secure him, and then acquire the skill and knowledge necessary to preserve the standard of excellence already attained; or better still, to raise the standard higher. It matters little now whether the ancestor of your horse, fifteen generations removed, was Flying Childers, Periwinkle or Snodgrass. Those who desire a more extended historical sketch than is here given can secure it by reading some of the works devoted to this breed.

\section{ENGLISH SHIRE}

This breed of horses is so nearly like the Clydesdale that it hardly merits a distinctive name. It would be less misleading if it were called English Clydesdale. Most characteristics are common to both breeds. The Shires brought to the United States are, as a rule, splendid animals. They are close-ribbed, have a trifle shorter legs, and are a shade larger than the Clydesdale. Whether these slight changes have been brought about largely by selection, or by a slight infusion of some closely allied blood, or by both, we do not know,and it matters little whether the petty details of the methods used are ever known. It is enough to know that the Shire horse gets a grand inheritance in the main, if not entirely, from that valuable old breed, the Clydesdale. Perhaps it may be well, after all, that this off-shoot of the Clydesdale has been given another name, 
since it will create an honest rivalry between the breeders of these two breeds.

It is customary to use illustrations of the most perfect horses of a breed, and not infrequently the camera

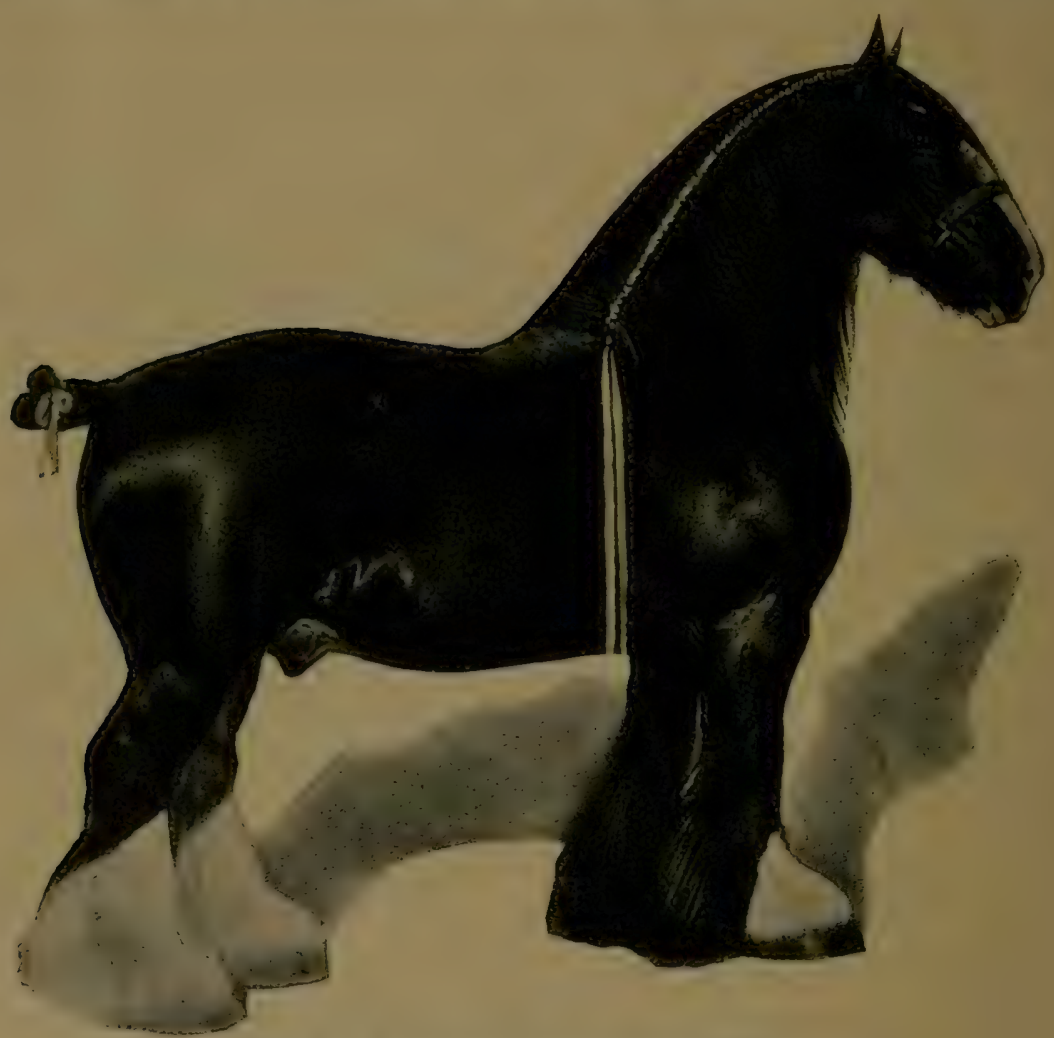

FIG. 33. Dunsmore Combination (17314),

Owned by Thomas Ewart, Dunsmore Home Farm, Rugby, England

and the artist improve the original. The breeders of dairy cows quickly learned which end of the animal to place nearest the camera. In photographing horses, it is more undesirable to change the normal perspective; for, in foreshortening lines, symmetry of form is distorted. 
Perhaps it is well to use the very best animals for illustration since it results in producing in the mind an ideal, however difficult it may be to attain to it. On the other hand, the amateur breeder, whose expectations have become great by reason of such beautiful illustrations, is sometimes greatly disappointed when his efforts fall far short of his expectations, founded on illustrations in the books. He has his animal photographed for the purpose of placing a true picture at the head of his handbill, but he discards it for a made-up one, which the untrained eye does not detect as an impossible horse. Such breeders may succeed in producing good animals; but, falling far short of their ideals, they lose interest and go out of the business in disgust. So it may be well to warn the beginner that the top is reached only by long-continued effort. The road to the summit is steep and rough, and strewn with the bones of many commonplace horses. The horse, like other living things, is responsive to environment, and changes rapidly for the worse if the conditions of his life become less congenial, his food less plentiful, or less nourishing, and his work more difficult, than in the past. The standard of excellence attained by slow, painstaking, laborious effort during two centuries is so high that it requires a genius even to maintain it; so the young farmer should not be disappointed if he is unable to produce horses that fully meet his desires or the high standard of excellence.

The illustrations should be studied closely and the living animals as well; and not only should those of ther draft-breeds be compared, but those of the lighter 


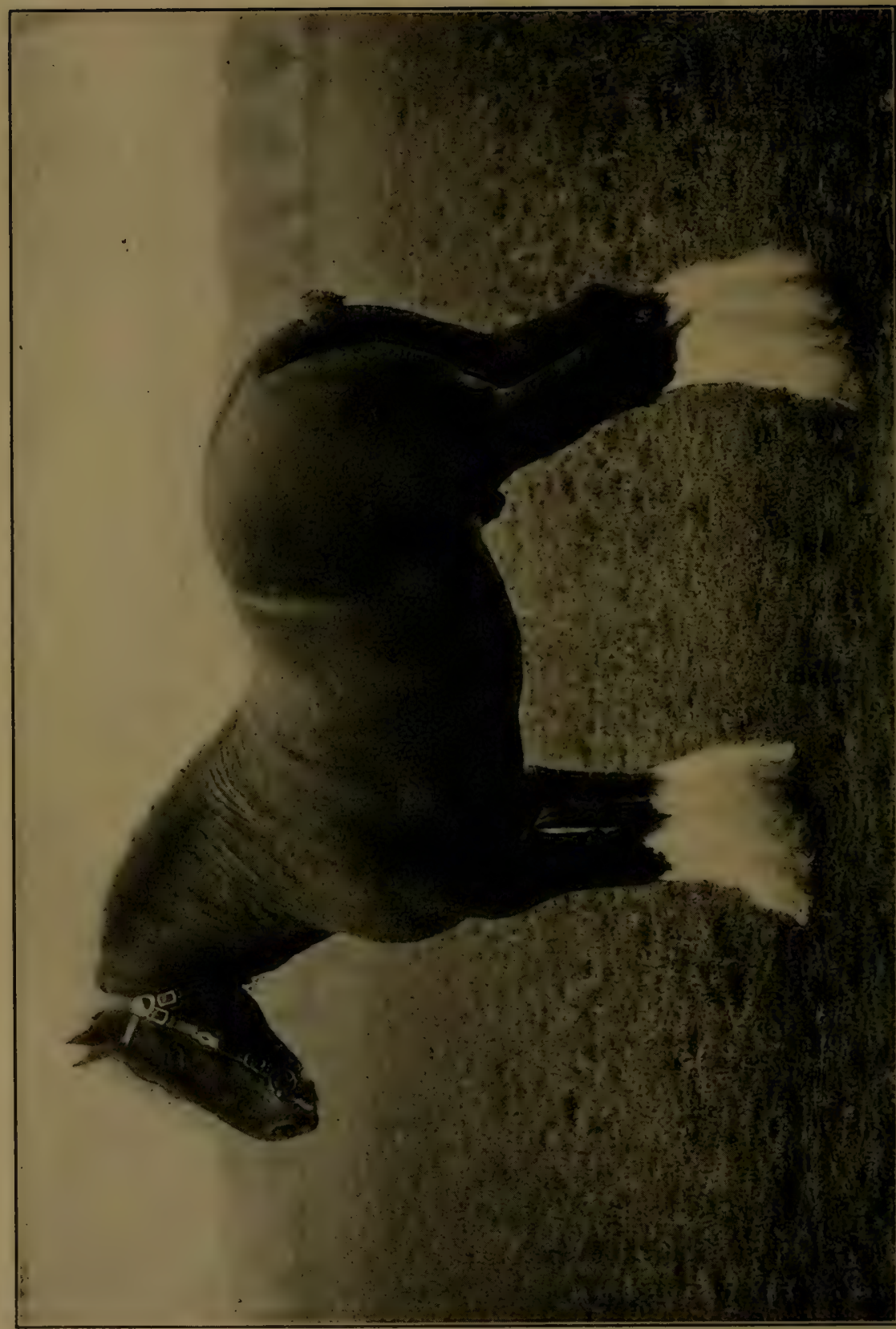

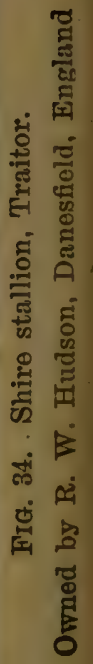


breeds with those of the heavy breeds. The student of Animal Industry has become careless and unappreciative of the educational value of the fine illustrations which have become so common. The man with uneducated tastes often treats them more carelessly than he does a

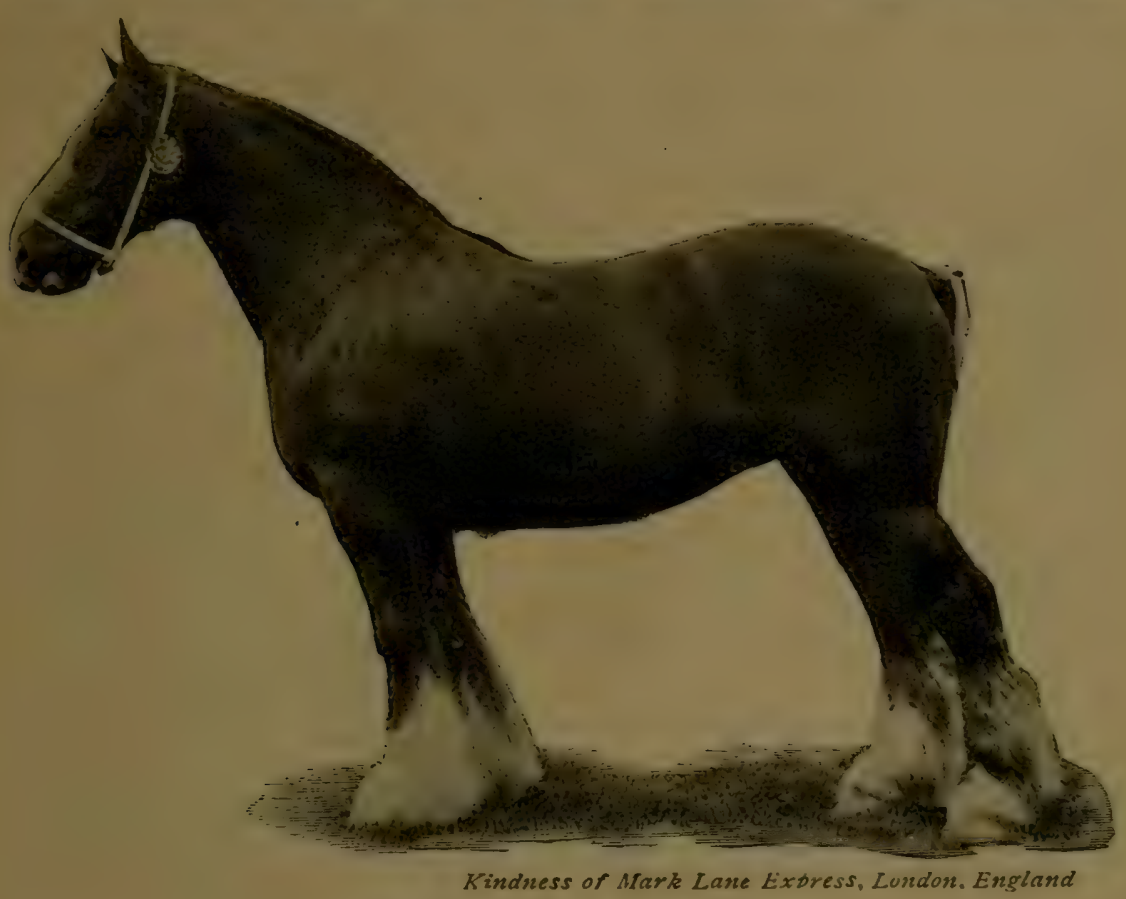

FIG. 35. Shire Filly, Tatton Bessie

circus-dodger. If the farmer had no other good pictures in his house than those contained in the "Breeders' Gazette" of December 19, 1900, he would have a respectable picture gallery of our larger domestic animals. I only regret that the size of the page in this book and the conditions under which it is published do not permit of more and larger illustrations. 
SUFFOLK PUNCH

The origin of this breed is obscure. Some have supposed that his color indicates that the foundation stock was produced by crossing stallions from France,

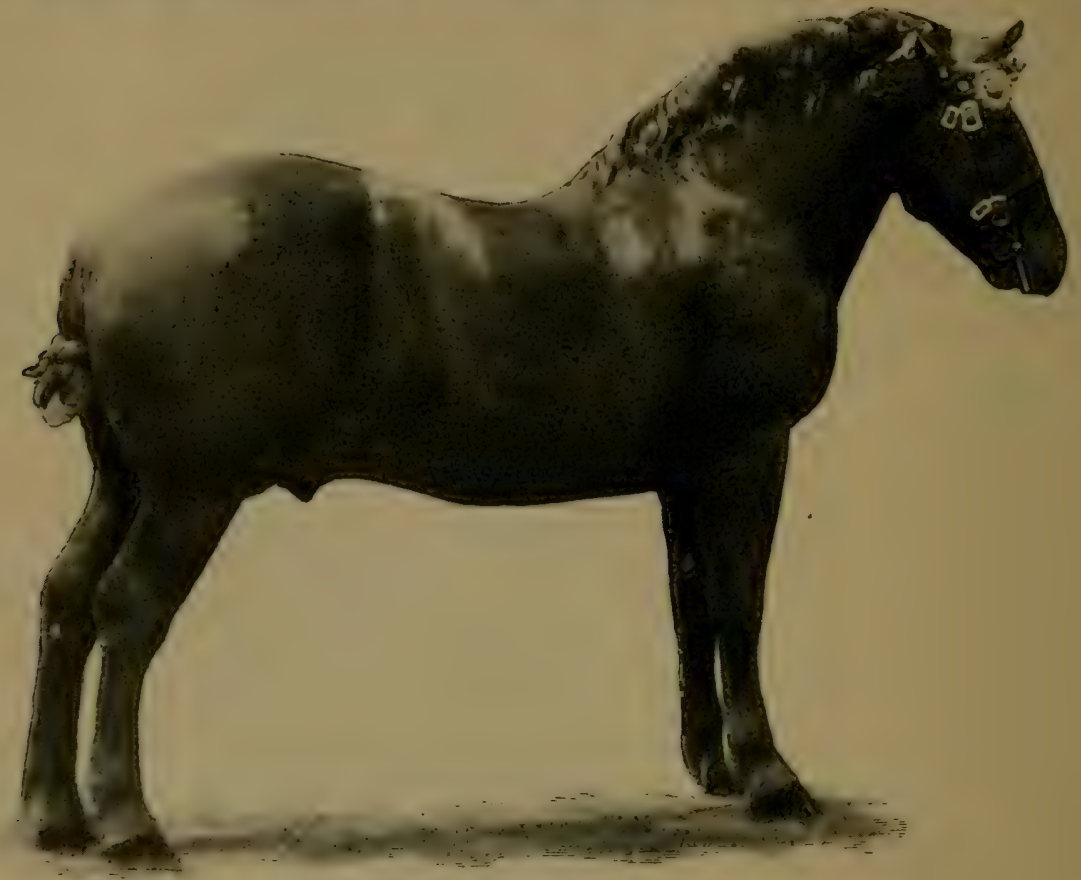

FIG. 36. Suffolk Punch stallion

Property of Alex. Galbraith, Esq., Janesville, Wis.

supposedly gray, and Suffolkshire mares, supposedly bay, which, it is assumed, would produce sorrels. Neither the form nor the color of this breed gives any clear evidence of the breed having been formed by such admixture. All over Great Britain, stout sorrel horses have been common from time immemorial. The crude material was at hand; all it wanted was 
some one with the instincts of a Bakewell to produce a breed of sorrel, bay, black, or piebald color. This breed should be none the less prized because little or nothing is certainly known of its early history, which began before the middle of the eighteenth century.

The Suffolks, like all other breeds of horses, have been greatly improved during the last third of the century just closed. The feet are now, as a rule, good. The breed has more of the short, rotund build than the two breeds previously mentioned, or the Percherons. The number in the United States is relatively small as compared with the Clydes and Percherons, although the breed as a whole, as seen in America, strikes one as having the ideal, harmonious proportion of parts, and conformation which should indicate endurance and power. A more extended test of them and their grade offspring will fully reveal how much they have of courage, with patience and endurance under severe usage,- both of which should be prominent characteristics in any draft breed. The Clydesdales and Percherons were first in the field, and, both being good, it is not easy tc supplant them.

Description.-The color of the Suffolk is more uniform than that of most other breeds, being almost invariably sorrel of some shade,-not infrequentlyso dark as to take on the semi-dappled, darkish, rich chestnut hue. Not quite so tall or heavy as the Clydes or Shires, but ranging in height from fifteen and onehalf to sixteen and one-half hands, and in weight from 1,400 to 1,800 pounds. The shoulders are of true draft 


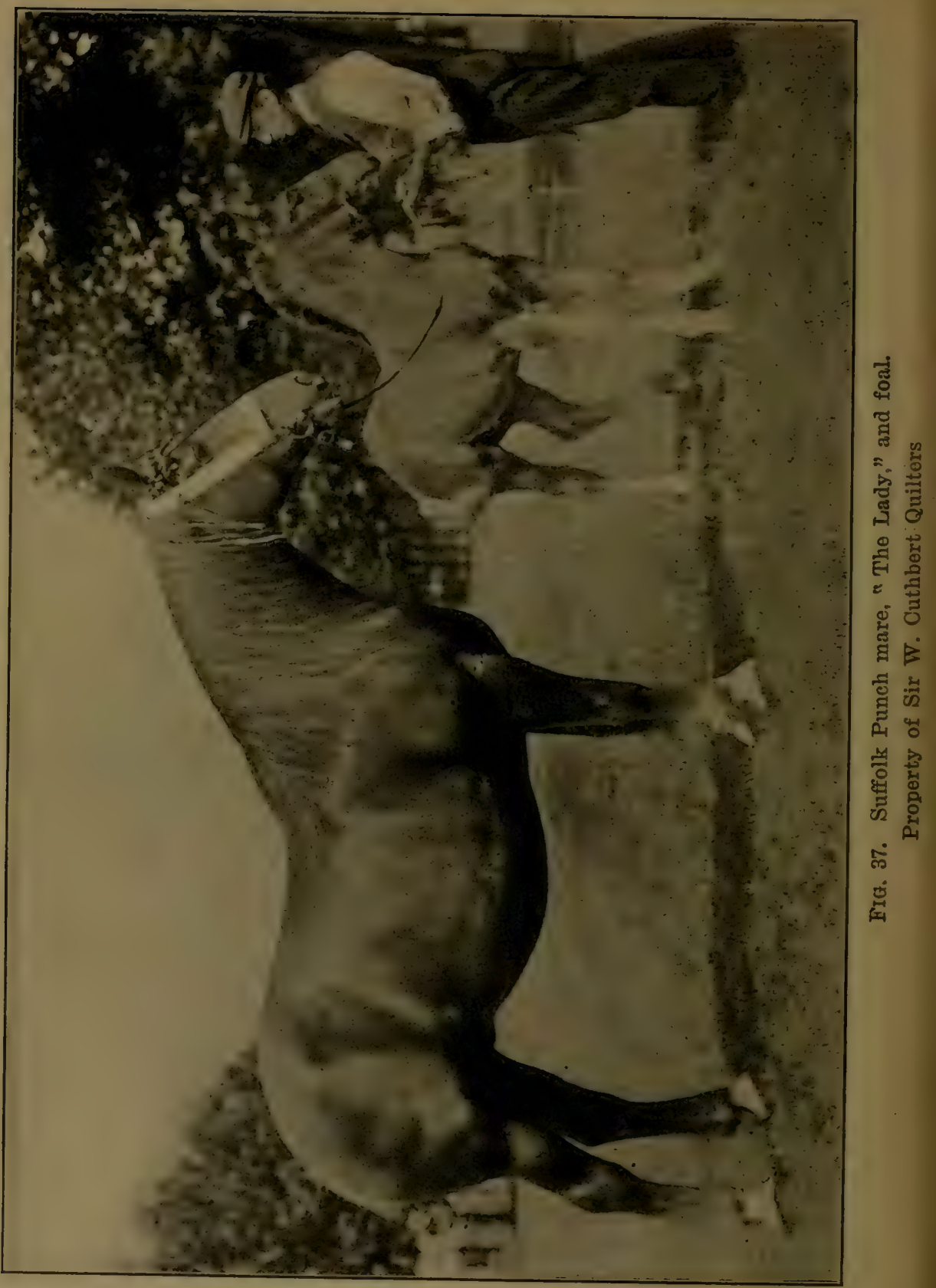


form, not being too oblique; shortish neck and legs, cleau head and limbs.

One cannot help getting the impression that they have not so much spirit nor so long a stride as the Clydesdale. Be that as it may, they are a valuable addition to our draft breeds, and time alone can reveal whether or not they can win their way to equally popular favor with the two leading breeds.

No breed or animal is perfect; every breed is likely to have some characteristic defects. There are few, if any, animais so perfect but that we would like to make some slight changes. But if a writer points out a slight defect in a breed, as shown when large numbers of animals are inspected, somebody gets hot "under the collar." Then, too, honest differences of opinion too often are not given respectful treatment. Some horsemen have yet to learn the philosophy of agreeing to disagree. A conservative horseman of high standing says, "I have yet to find a writer on the horse who dared to call attention even to slight defects of any one of the modern breeds except the bronco." On this little fellow he vents all his spite; and, what with writers and riders, it is no wonder that he occasionally strikes back or "bucks" in sheer self-defence of his longacquired right to freedom and self-protection. 


\section{CHAPTER XII}

\section{FRENCH, BELGIAN AND FLEMISH DRAFT-HORSES}

France, like Great Britain, has several breeds of draft-horses. Standing out prominently, as superior to all others, is the ancient Percheron.

He has a most interesting history, which is too voluminous to be recorded here. The student will be interested in perusing "The Percheron Horse," by Charles DuHays, which, through the efforts of William T. Walters, of Baltimore, has been translated. The illustrations enable one by comparison to judge of the improvement which has been made since it was written. A good idea of the general character of the best specimens of the Percheron before the breed took on its present distinctive draft type may be secured by studying the illustration of Success. (Fig. 38.)

Neither the kind, number nor character of the French horse is known prior to the battle of Tours. In 732, the Saracen chief, Abderame, was defeated by Charles Martel, at Tours, in one of the most famous battles of history. The invading army, 300,000 of which it is said were slain, was from the East, as were also the horses which the cavalry rode. While these horses were not supposed to have been of any particular breed, the fact that they were from the Orient gives assurance that they were not of the heavy-draft 
type, but had, without doubt, some of the characteristics of the horses which later were used to give style, stamina and speed to more phlegmatic varieties. The large number of eastern horses secured as a part

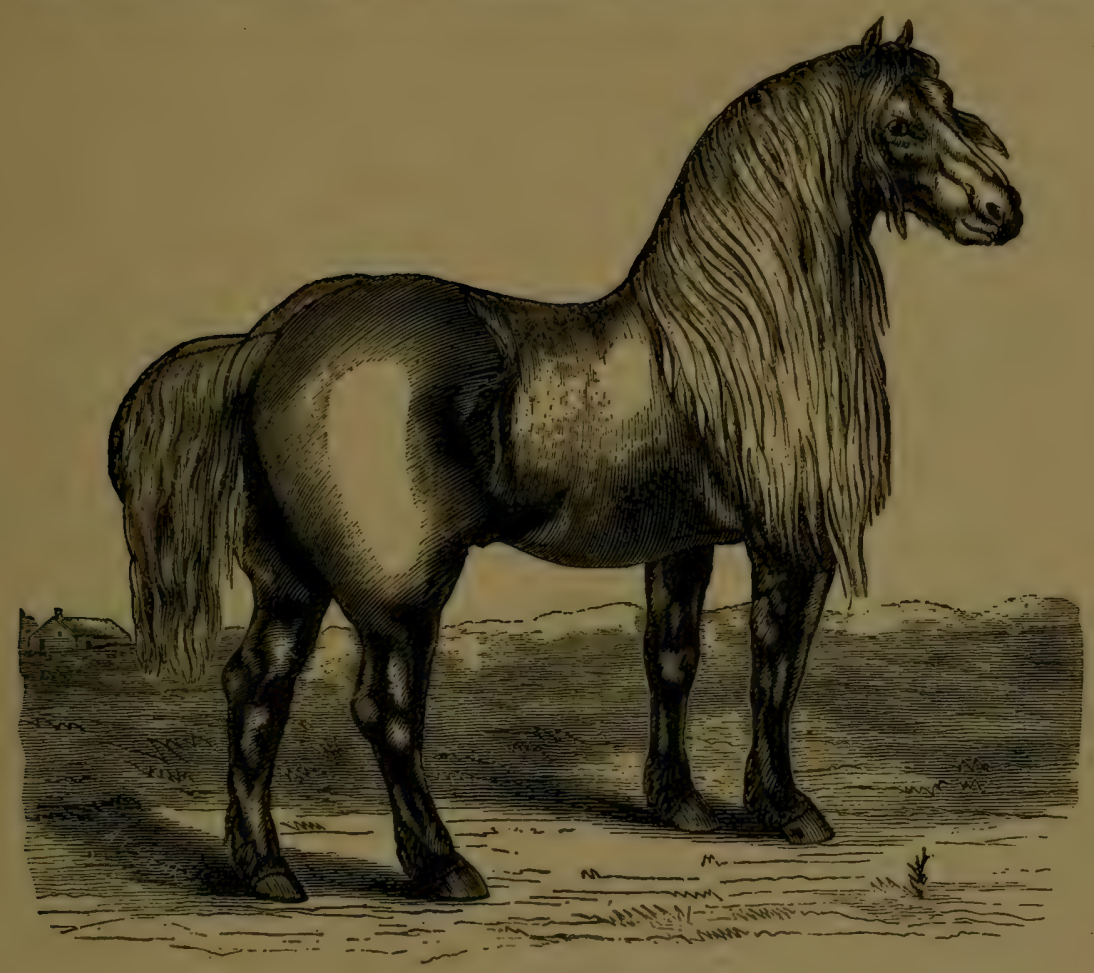

FIG. 38. Success.

Owned by M. W. Dunham, Wayne, Ill.

An indifferent picture of an historical Percheron before the breed assumed tho heavy-draft type

of the spoils of victory must have had a marked influence on the native horses of France. As time went on, agriculture improved, the care of the horse and his food became better and more abundant, and the natural result followed - larger and better horses. 
War still continued to be the chief and paramount vocation of large numbers of able-bodied men. As implements of warfare were improved and made more deadly, recourse was had to coats of mail for protection. At first these were of light weight, but, as the efficiency of weapons was increased, the armor was also increased in weight, until it not infrequently outweighed the warrior who wore it. Simultaneously with the increase of the weight to be carried, came an increase in the size and weight of the war-horse. Just how this was accomplished is not certain, but it is believed that resort was had to both English and Danish stallions. Later, the post-roads opened through the country also had an effect on the size and character of French horses in many districts.

The change from the old type, which had some of the characteristics of the Oriental horse, to a more distinctive draft type was accomplished by 1760 ; but, between this date and 732, many unrecorded influences were operating, without doubt, to change the small Arabian types of the horses of LaPerche to a larger draft type. As late as 1873, I saw a few specimens of the modified Oriental horses in the districts which had long since adopted a larger animal of the draft type. Up to 1820 , the draft-horses of France lacked the symmetry and finish which they now possess. It is not an easy task to harmoniously unite two varieties of horses so dissimilar as the Oriental and the English draft. Although the draft-blood was introduced as early as 1760 , up to 1820 it had not been satisfactorily united with the Oriental and native blood; for, about the latter date, a system- 
atic effort was made by the Government to eliminate the coarseness which had been introduced by the free and frequently injudicious use of draft-blood. About 1820, two noted gray Oriental stallions, Godolphin and Gallipoli, were introduced into the Government stables at Pin. These two prepotent stallions fixed the style of color and fastened it on an already susceptible breed. The refining process went on rapidly and the French heavy horse became a well-defined prepotent breed, which still shows some Arabian characteristics harmonionsly united with prominent draft qualities. The importation of these horses into the United States began about 1851, twenty-five years before the publication of the first Percheron stud-book in America. The Percheron Horse-breeder's' Association is the oldest draft-horse breeders' society, and was organized and published a stud-book several years before the Society Hippique Percheronne was organized in France.

G. W. Curtis says, "One of the stallions imported in 1851, under the name of French Horse, was sold to Dillon \& Co., of Normal, Ill.; and was shown under the name of 'Norman.' The early importers were at liberty to give any distinctive breed-name to the animals imported, for, as yet, there was no stud-book in France. Some of these early importations were from the old province of LaPerche, some from Normandy, some were purchased in the city of Paris, and some were gathered from no one knows where, - -though all appeared to have the general characteristics of the Percheron."

It will readily be seen how natural it was, under the circumstances, to attach different breed-names to horses 


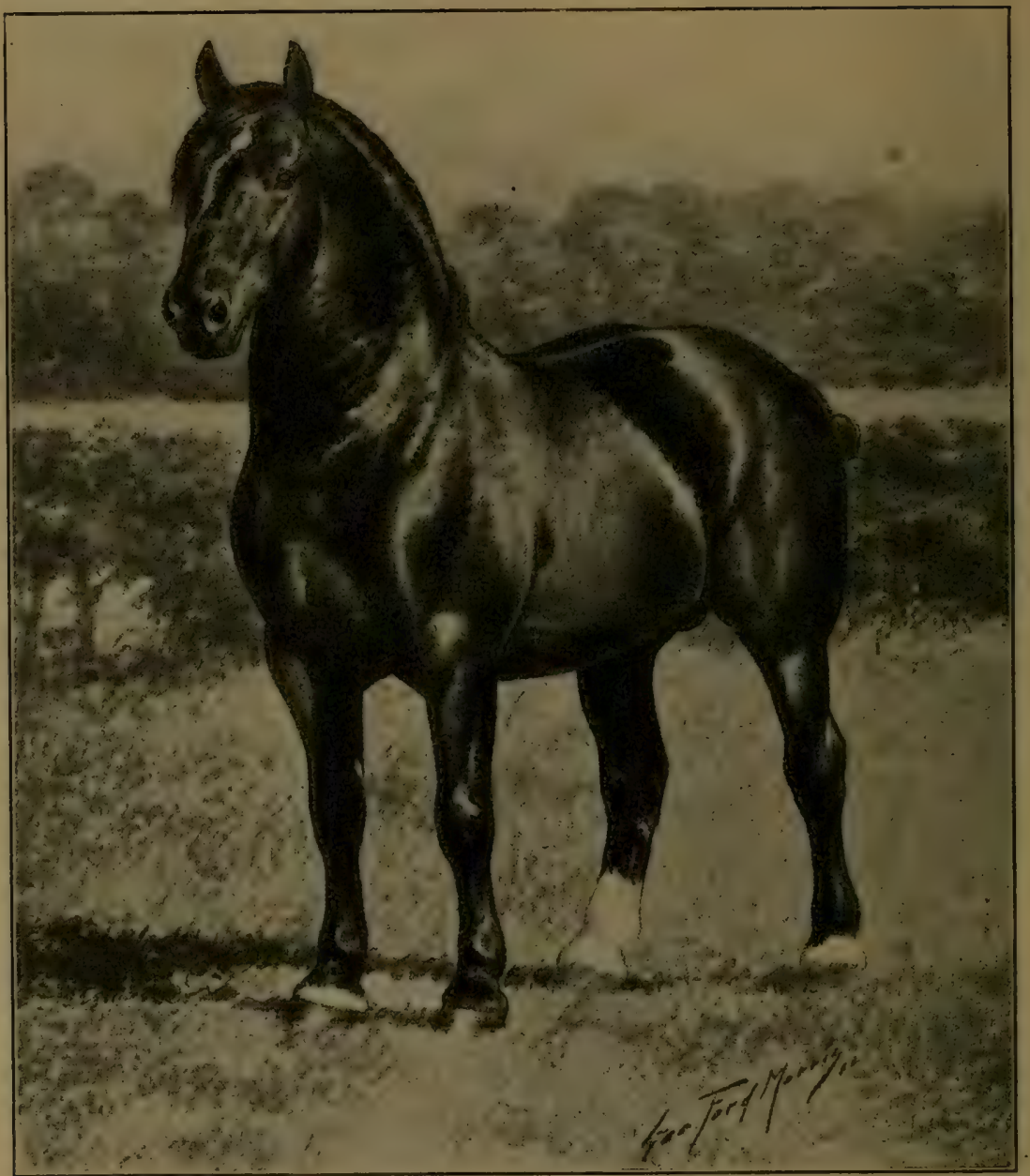

FIG. 39. Percheron stallion, Calypso 25017 (44577)

Imported by Dunham, Fletcher \& Coleman, Oaklawn Farm, Wayne, 111.

purchased in different localities; and, the name being adopted, right or wrong, how difficult it was to change it. In 1876, when the first volume of the stud-book was being prepared, the distinguishing name "Norman" was adopted. Mr. J. H. Saunders, then secretary of the 
Stud-Book Association, changed it to "Percheron Norman," which name was afterward ratified by the Association. This was unsatisfactory to some of the importers and breeders of the French draft-horses, since the distinguishing breed-name which had been used was of value, being in the nature of a trade-mark. So other stud-book societies were formed, and we now have three of them. (See Live Stock Registry Associations, Appendix.)

All this is unfortunate, since these books, as well as the French Stud-Book, record but cne breed of horses. Then, too, these various registers have different standards for admissions to registration. The Percheron society requires that all animals imported after January 1, 1884, must be recorded in the Percheron Stud-Book of France. The National Register of Norman Horses admits all draft-horses of French draft-blood, no matter to what family they belong. There is also a stud-book published in the United States known as the National Register of French Draft-Horses, with somewhat elastic rules for registration.

It is unfortunate that the breeders of the noble Percheron should have become divided into three somewhat hostile camps, and still more unfortunate that horses should, at this late date, be admitted to registration without full guarantee of breeding and of merit. Far better make the rules, even of the Percheron StudBook, still more rigid, and allow colts only a provisional registration; which could be changed to permanent registration when they reached five years of age; if, after examination, they were found to be worthy of 
propagating the breed. We must adopt something of this sort for all the breeds if we ever succeed in preserving the high standard seen in recently imported horses. In no other way can we hope to produce an American variety of Percherons better adapted for heavy work than those brought over at great pains and expense. The Percheron is capable of improvement; why not have a home-breed as much superior to the average foreign horse as the American Merino is superior to the imported Spanish Merino? The breeders of trotters and Holstein cattle are on the right track, and will win out at the end.

Already something is being done to change the somewhat objectionable light colors to dark ones. The coarse heads and goose rumps, formerly all too common in all of the draft-breeds, are becoming rare, and they can be entirely eliminated only by official and rigid selection. Our government is not paternal, and cannot and should not do this work, since the associations have the power to do it, and can do it better than the government officials. Which society will be the first to adopt more rigid and better rules for registration of horses?

Description.-The color of most Percherons is gray of varied shades. Sometimes it is quite light, becoming nearly pure white in old age. Again, the striking light and dark dapples are seen, and dark grays, almost black, with a few white hairs. Comparatively few blacks have, as yet, been bred, although dark colors are sought and are more common than formerly. The Anerican purchaser prefers darker rather than 


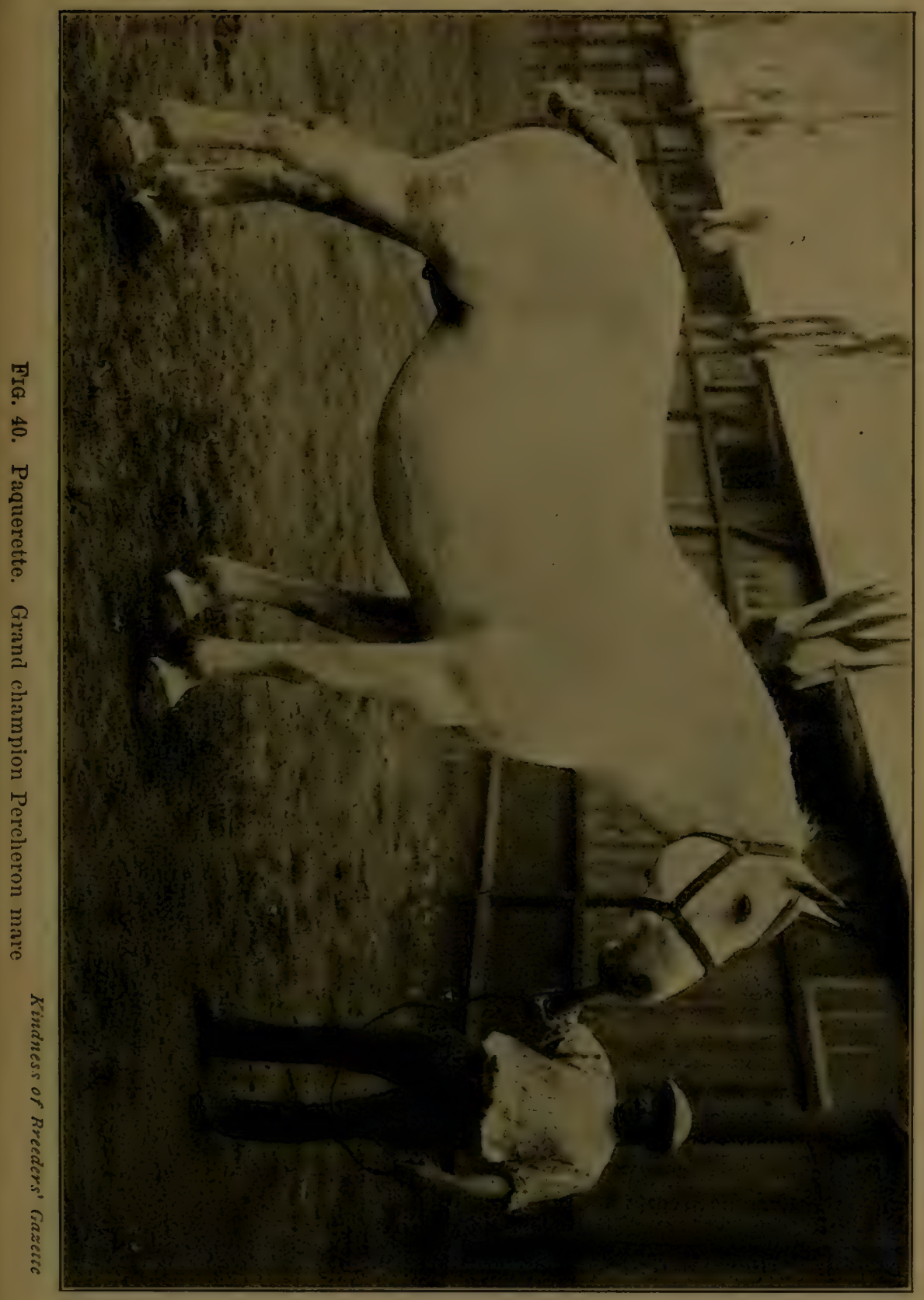




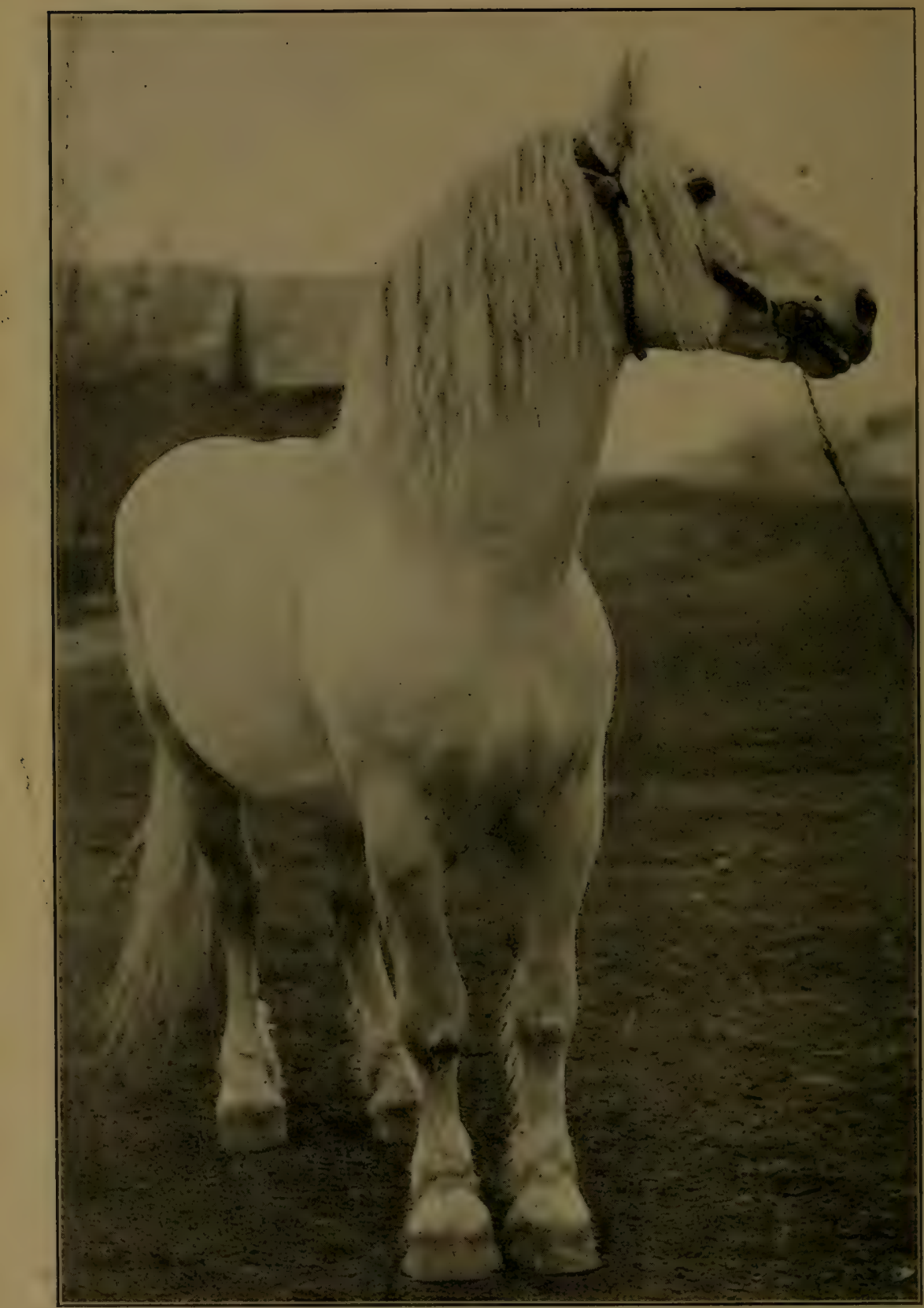

FIG. 41. Deguardi 11340.

Kindness of Breeders' Gazette

Orwed by Geo. B. and Chas. P. McPherson, Hereford, S. D. 
lighter colors; hence the effort in France is to produce darker colored animals than formerly. So, too, in the United States, dark grays are sought rather than light grays. It will take many generations to entirely eliminate the light colors, so long one of the characteristics of the breed; but this will be accomplished in time if Americans persist in preferring dark - rather than lightcolored draft-horses. This preference is not founded on a fad, for, other things being equal, dark-colored horses are to be preferred to light-colored ones.

The body of the Percheron has something of the pony compactness. Legs shortish with massive forearm, but clean and closely knit, especially below the knee, with pastern-joint free from "feather." Most specimens have fine heads. The true Percheron head is clean, expressive in all parts, of moderate size, topped with beautiful ears and well set on a magnificent flexible neck, although it is large at the base, where it is broadly attached to rather oblique shoulders, all of which give the appearance of strength with style and elasticity, with no suggestion of the pig's neck. All of the draftbreeds are remarkably free from bone diseases, considering their great weight and their severe work. The draft-horse of whatever breed has a thick skin, which is not as sensitive as is the skin of the warm-blooded horse. The not over-sensitive, thickish skin, coupled with difficult work and great weight, all tend to certain skin diseases which, fortunately, usually only injure the symmetry of the limbs and in most cases are of a mild character. The feet are firm, and usually a little more rotund and erect than are those of some of the other 
draft-breeds. The weight of the mature Percheron stallion, except in rare cases, is from 1,500 to 1,800 pounds, and that of the mares from 1,200 to 1,700 . Grade Percherons are quite variable in weight, owing to

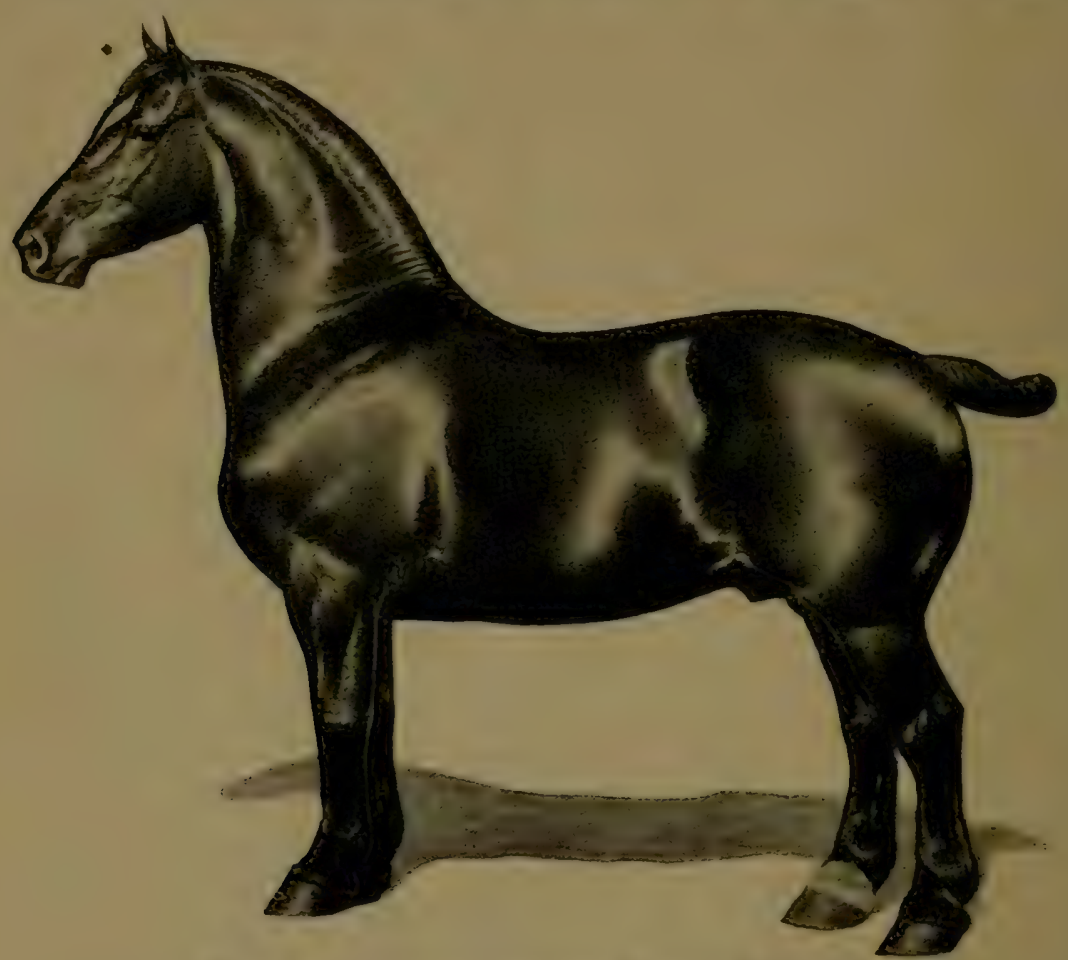

FIG. 42. Percheron stallion, Picador 27370 (48373).

Owned by Dunham, Fletcher \& Coleman, Oaklawn Farm, Wayne, Ill.

the wide difference in the size of their nondescript dams.

The illustrations, it is hoped, will give some help in the study of both the dark- and the light-colored Percherons; but the reader should not be satisfied until many individuals of this breed, under both unfavorable 
and ideal conditions, have been inspected. Flesh and comparative idleness combined sometimes deceive the purchaser as to harmony and beauty of outlines and courage and endurance.

\section{FRENCH DRAFT}

There is not only an American Stud-Book for recording the Percherons, but one for the French draft and one for Norman horses as well. We have, then, three distinct Stud-Books for recording what is virtually one breed of horses, In other words, we have a sharp distinction without a difference. If fifty horses of each of these groups were turned loose in the show-ring, neither a Frenchman nor an American could place the animals correctly by groups. This is confusing, when the beginner starts out to learn something of drafthorses; nevertheless, good is likely to come out of this war of breeds, since the breeders of these various French horses will keep up a sharp, and, it is hoped, peaceful and honest rivalry. Breaking up a breed into groups sometimes results in great good. In time, the survival of the fittest will solve many questions which arguments and a multitude of words fail to explain.

Some of the imported French horses are not eligible to record in the Percheron Stud-Book, hence there appears to be good reason for establishing another one. All this leads to the question, Why not establish another Stud-Book of "Approved American-French Draft-Horses," as previously outlined ?

It is not necessary separately to describe either the 
French draft or the Norman, as the description of the Percheron already given will suffice.

\section{BOULONNAIS}

This variety of draft-horses is somewhat larger and not so active as are the Percherons. Their appearance leads to the conclusion that they have more of the blood of the heavy draft or Flemish, and less of the Oriental blood, than the Percheron, which they somewhat resemble. Though closely related to the Percheron, they are coarser in make-up, slower of movement and less desirable for American uses. The breed takes its name from the city of Boulogne. The colors are variable. Their most appropriate place is for heavy tandem draft-teams in the streets of Paris. They are not prized as highly in the United States as are most of the other draft-breeds.

\section{BELGIAN DRAFT-HORSE}

The Belgian horse has not been so popular in the United States as the Clyde and the Percheron. The reason why these two breeds have been imported and bred in far greater numbers than the other draft-breeds is believed to be due to the fact that both of these breeds possess not only good draft form, but superior action, courage and style, for horses produced as they were, largely from the phlegmatic branch of the genus Equus Caballus. Be this as it may, the American requires that even his draft-horse shall not pound the pavement too heavily, or be as slow and as unresponsive as an $o x$. 
It may be, that, to gratify this taste of the American for a lively stepper and a "bit champer," the breeders, in some cases, have produced a drafthorse with too long a neck and too slanting a shoulder. A distinguished im porter and breeder once said to me: 'The 'toppy' horses sell, but the shortnecks, while less stylish, wear best."

It is probable that the Belgian has little or no admixture of "hot blood." $\mathrm{He}$ certainly has quite as many of the true draft points as have the two breeds so largely admired. The illustrations of the best hor ses of the breed show a larger horse than the Clyde; the neck is

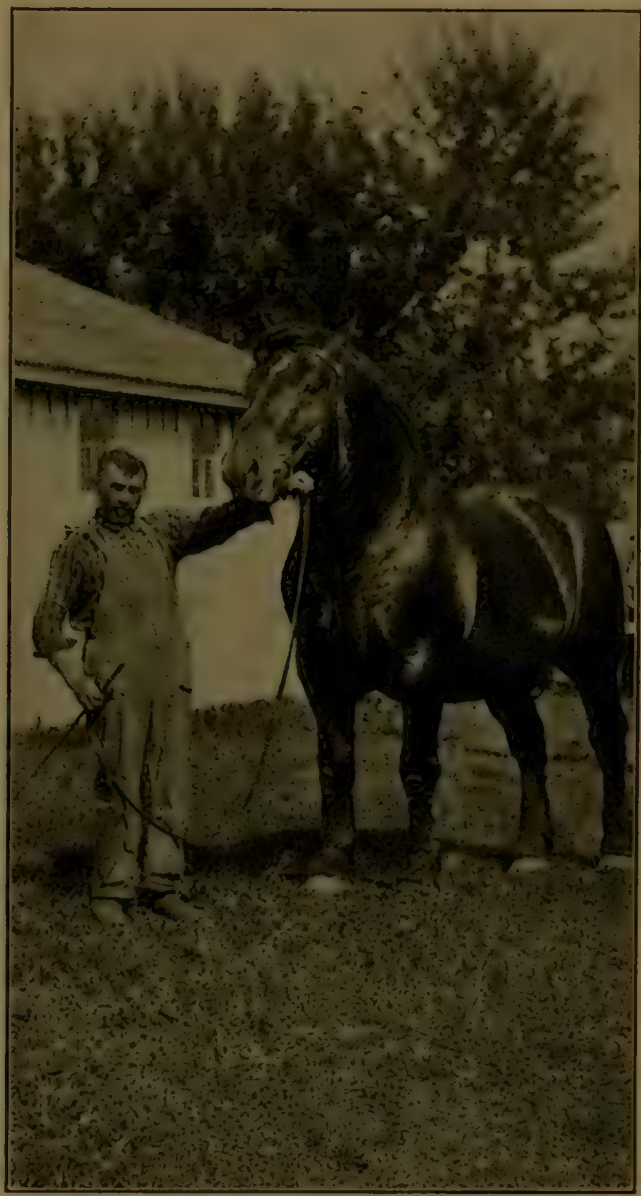

H'rG. 43. Brilliant Du Busquet.

Owned by Henry Lefebure, Fairfax, Iowa shorter, the breast wider, and the whole body-formation more blocky than is usually seen in the Clydesdales, and he has less feather than the Clyde. 


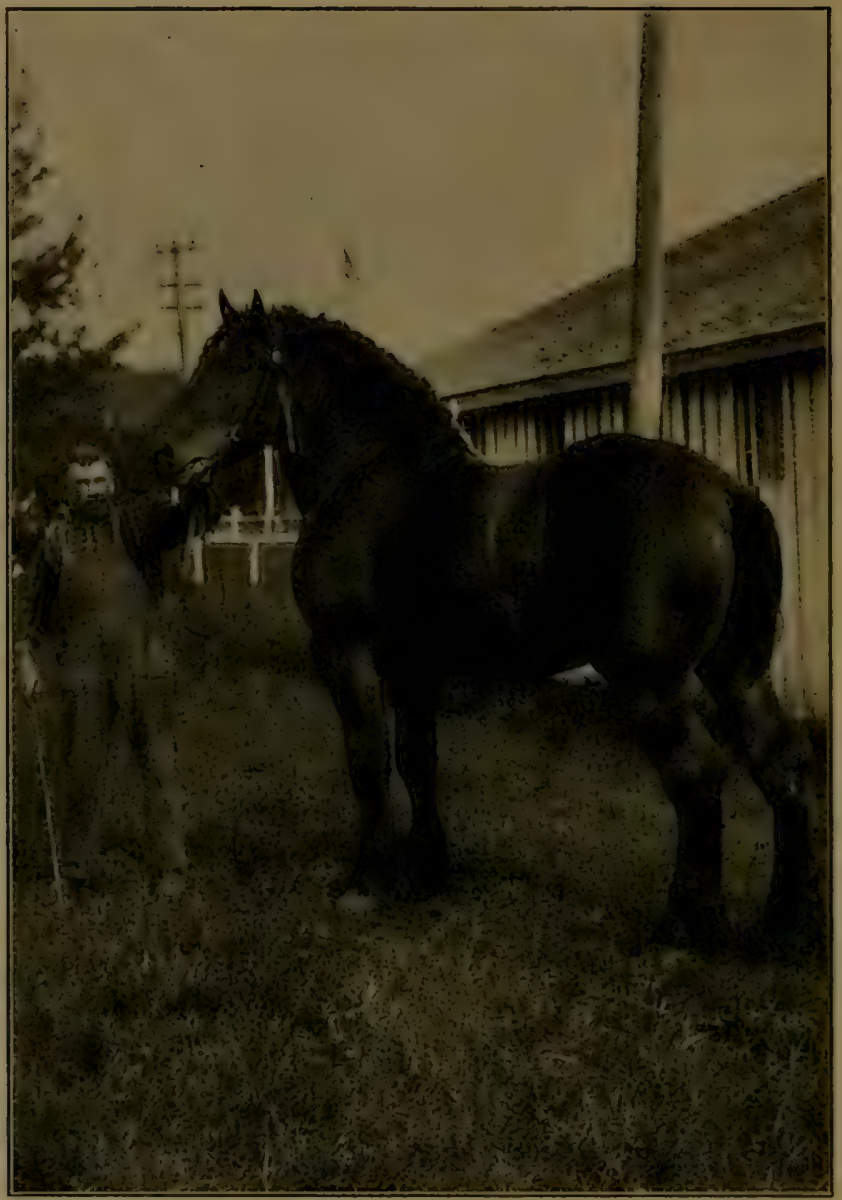

FiG. 44. Colonel De Dompiere.

Owned by Henry Lefebure, Fairfax, Iowa

It is a good thing for the horse industry that there are not only breeds of widely divergent characteristics, but also breeds so slightly different as to deceive the experts unless the breed name is placarded. All this serves to educate the eye and the judgment, as well as to form interesting topics for discussion. 
Horses imported since 1888 must be registered in the Government Register of Belgium (Society of Belgia Stock Farmers), to be eligible for registration in the American Register.

Description.-Color usually bay, dark and light browns - all good colors. They are somewhat larger than the Percherons. Selected mature stallions, such as are usually imported, weigh from 1,700 to $2,20$.$) pounds,$ and mature mares from $1,5,00$ to 1,900 pounds. The head is reasonably small; neck short and very powerful; chest wide and deep; back short and broad; closeribbed, and full over kidneys; hips fairly long, broad, smooth and symmetrical; legs short, flat, arm heavymuscled, with the usual open, rather low heel of the draft breeds. This breed has not been as popular as the Percherons and the Clydes. Probably this is due to its build, which indicates a breed of less activity than the two great leading draft breeds adopted by the Americans. As seen in his native country he does not strike one as having the long, elastic, quick stride of the Scotch or French draft-horse.

\section{THE FLEMISH HORSE}

The modern Flemish and Belgian horses are the giants of their race. Springing from a common ancestry, bred under similar conditions, put to common uses, it is no wonder that the two breeds are very similar. They are tall with heavy bodies, but sometimes the true muscular development is not in harmony with the bone structure. The color is usually bay or brown, both 


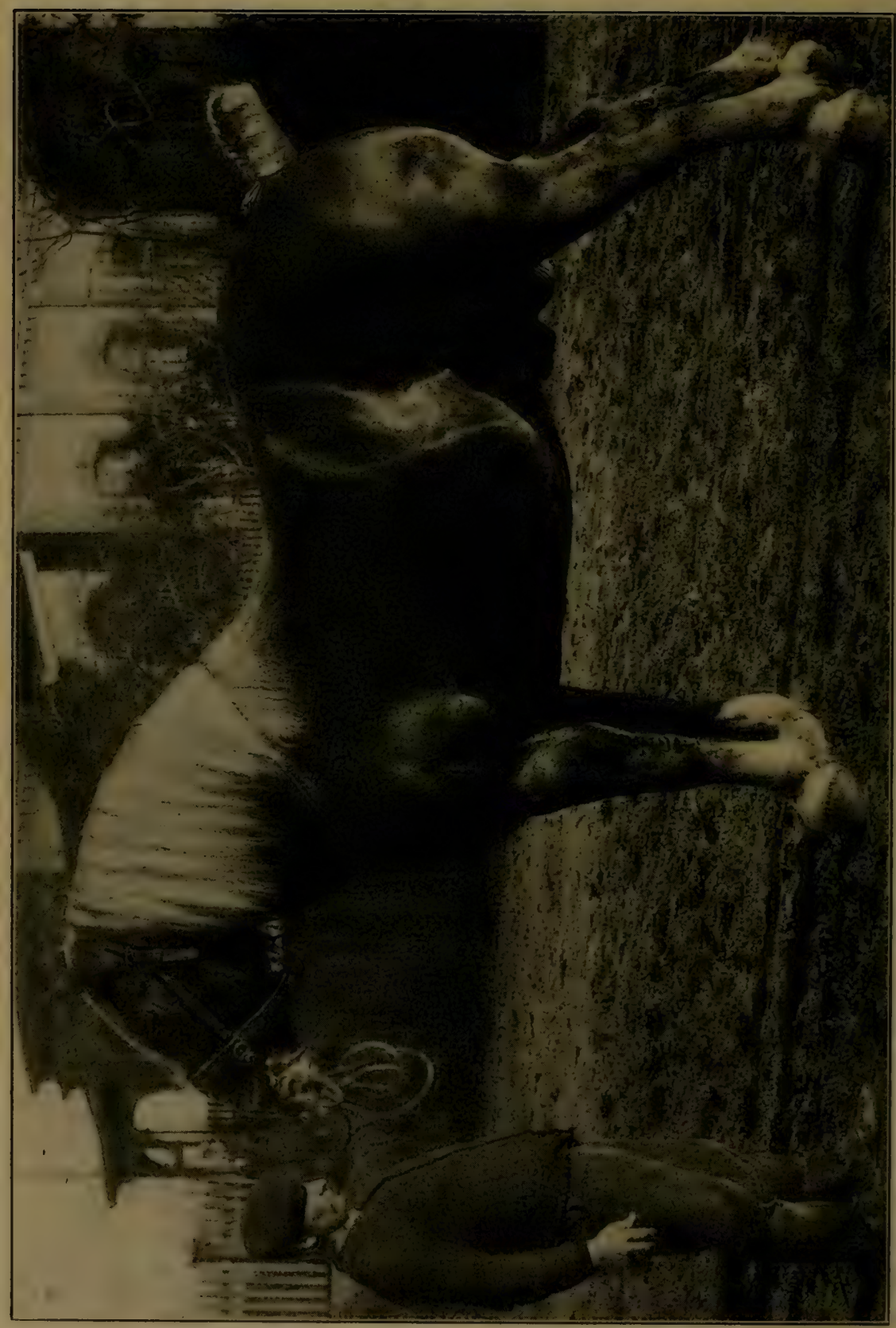

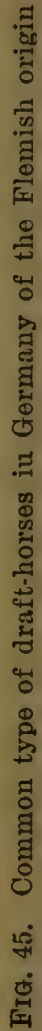


good. The collars used are not infrequently built up on the sides and the hames extend well above the collars, the ends being curved and furnished with bright metal mountings, giving a brave look to the horse so much admired by the Belgians. In harness the Flemish horses have a massive and superlatively strong appearance, especially when viewed from the front. They and their congeners, the Belgians, are in common use on farms in most parts of Belgium ${ }^{1}$; but they are too large for American farmwork, and, above all, they do not please the American boy, who wants a horse that can pull anything that is loose at one end or out-pull any other horse of the same size, and out-trot and out-jump and out-run any other horse in the settlement. He will become weaned from this extreme notion, in time, and learn to breed horses adapted to the soil on which they are reared and to the specific work which they will be called upon to perform. The Belgian draft will fill a demand and find an appropriate place in the large manufacturing cities.

1 West Flanders and East Flanders are now provinces, or counties, of Belgium, and not a distinct country. 


\section{CHAPTER XIII}

\section{PRINCIPLES OF BREEDING}

THE breeding of horses is usually carried on, first, in order to procure directly or indirectly the necessaries of life, and, second, to secure a profit. Occasionally they are bred simply for pleasure or pastime.

It would be out of place to discuss here what amount of surplus or reserve it is best to accumulate, or how fully the so-called necessaries of life should be supplied, in order that man may arrive at his best estate. We enter at once, therefore, upon the discussion of the laws and forces which underlie animal life and reproduction, growth, development and change, with the paramount object of increasing the quality and quantity of the necessaries of life, of diminishing labor, of increasing knowledge, and of adding to the world's surplus and pleasure.

If we attempt to investigate the laws and forces which govern animal growth and reproduction, we are necessarily brought face to face with the sciences and their application to reproduction, life and growth. The ancient authors enumerated seven of them, and Pope adds one more:

"Good sense, which only is the gift of Heaven, And, though not science, fairly worth the seven." 
So many mistakes have been made in the application of science to the breeding and improving of domestic animals, particularly horses, and so much suceess has been attained through careful and timely attention to the details of feeding and surroundings by men untrained in science, that the fact is often forgotten that their successes are due to the practical application of science which they have unwittingly absorbed. This has resulted in belittling science - that is, ascertained truth or knowledge duly arranged,- and in giving the credit to "common sense."

Such rapid advancement has been made within the last thirty years in the breeding and rearing of horses, that he who would now reap the largest reward must not only master the most minute details of breeding, but must also make himself acquainted with the many laws and forces that are ever acting, modifying and limiting each other,- some of them knowable, some of them unknown in our present state of research.

Much valuable information may be gained by studying the effects of laws with which we are only partially acquainted, or of which we are totally ignorant. For instance, we know that exercise or motion under certain conditions produces growth and development; under others the same exercise may produce weakness and decay. If we exceed the limit of exercise too far, we may not only fail to secure development, but may produce lasting injury. Observing results from certain methods, we try to formulate.in part, at least, the laws with which we are only imperfectly acquainted. We should not discard or hold any knowledge lightly (because our 
knowledge is not complete); neither should we discard knowledge which is not absolutely correct. Most knowledge is only relatively correct, but, if it is accurate enough to aid us in our research and enlighten our judgment, it is still valuable. The chemist cannot make his analyses absolutely correct. Are they therefore of no value? The steel rule may be shortened by a little cool air, and lengthened by the mild rays of the sun; is it therefore of no value in measuring length and breadth because it is slightly inaccurate when placed under slightly changed conditions? While the steel rule is never again absolutely a foot long after it is made, except when placed in the same temperature as that in which it was made, yet it varies only within narrow limits. So, although it is seldom absolutely accurate, it serves the world well for all uses to which it is ordinarily put.

We speak of the "science" of breeding. This term is used loosely, and is too often made to cover both the science and the practice of breeding. Science is usually defined as ascertained facts, truths logically arranged. For instance: it is a fact that like produces like under exactly the same conditions. If two parents are similar, or of nearly identical blood, and their environment and potency similar, their offspring will be similar to the parents. But it is also a fact that precisely the same conditions, in all particulars, are never present in the production of any two animals, and, therefore, no two animals, though from the same parents, are exactly alike. Thus it appears that the forces of reproduction and growth, food and environ- 
ment, teud to produce variation. Slight variations along one or more lines, continued and accelerated from generation to generation, through long periods of time, may produce very marked and permanent changes. If the acquired characteristics, due to variation, have been present for a long time, and the chief conditions which produced the variation are continued, then such acquired qualities are transmitted from parent to offspring, with a good degree of certainty; but perhaps not so surely as are the characteristics which were acquired earlier, when animals lived under less artificial conditions. Happily, the variations either for better or for worse, like those in the steel rule, are usually within very narrow limits in a single generation or even in several generations. If it were not so, one species would merge into another, breeds and families be extinguished, and finally lost in one indistinguishable whole. Variations in stock-breeding, like the error's due to variations in the steel rule, if multiplied, often may produce marked results.

The St. Louis bridge, though accurately drafted and accurately made, would not go together when moved to another and warmer temperature than that in which the pieces which constituted it were shaped. James B. Eads did not lay this trouble to chance or to sport. He knew that the lengthening of the girders of the bridge was due to an inexorable law, and, taking advantage of the law that governs expansion and contraction of iron and steel, he shortened the girders of the bridge by packing them in ice, thereby overcoming the difficulty. 
There is no such thing as chance, in the sense in which the word is often used. Laws, or modes of operation, reign supreme in the natural world, ever the same when subject to the same conditions. And this is not all. Every effect produced by the operation of a law is registered in some form, and somewhere. The vibration of the earth's particles produced by the eruption of Mount Pelée, in the Island of Martinique, were recorded in England by a most delicate and ingenious instrument. The particles of earth half way around the globe could not vibrate or hit each other without affecting all other particles of which the earth is composed. As breeders of horses, we are first to discover, if possible, Nature's modes of action and the effects of them. Failing in this, we attempt to decipher what has been registered, in order that something may be learned of the laws which produced the effects.

The American bison (Bos Americanus) illustrates well the power of a species to perpetuate a very close resemblance in the individuals. This is partly due to the similarity of the parents, partly to similarity of food and conditions, and partly to indiscriminate breeding. If variation from any cause appeared in one locality during a single generation, it would not be likely to be perpetuated. The bison roams over a large territory and mixes with other herds, so that the conditions which produced the variation would not be likely to be present again, neither would the parents of the animal in which the variation appeared be likely to breed together again. The variation would, therefore, almost certainly disappear, or, at the most, 
would make only a feeble and imperceptible impression on the common herd. Constant intermingling of animals which roam over wide areas tends to produce similarity; while, if the area be small, as when animals are reared in enclosed parks, variation is likely to be perpetuated. Wild species, even when kept pure, when brought under domestication often show marked variations from the original type, due not to admixture of blood, but to changed food and environment. Even when slightly restrained, as are the wild cattle of Chillingham Park, variations are quite common. Darwin, in speaking of the variations in the Park cattle, says that animals nearly in a state of nature, and exposed to nearly uniform conditions, if not allowed to roam freely, or to cross with other herds, do not remain as uniform as wild, unrestrained animals.

The feathered tribes usually make the first marked departure from the feral type in the color of the feathers. A good illustration of this is found in the many colored turkeys, all originating from a darkbronzed wild turkey. Horses, cattle and pigs, when brought under domestication, nsually vary first in form, although they may vary in color as well. The myriad departures from reproduction of exact likeness which we may see everywhere and at all times, do not argue that something has occurred without a cause, or that a miracle has been wrought, or that blind chance reigns instead of law. To perpetuate, then, the qualities and characteristics of a species or breed virtually intact, all the conditions must be made similar to those which prevailed in producing the breed. It should not be 
forgotten that horse-breeders usually aim at something more than simply preserving valuable qualities: they desire to produce variation for the better. This is difficult in ordinary practice with animals already highly improved. Many are satisfied if they can reproduce animals which are as good as the parents. If the standard of excellence were not so high, it would not be difficult, with our present knowledge, to make rapid advancement. I am speaking here of the best specimens of the various breeds of horses.

The differences are usually slight in the offspring of well-bred animals; but, however slight they may be, they are worth noting and studying. Just here is where the beginner fails. He does not lay enough stress on small things; and the eye and judgment, not being well trained, fail to see clearly or to interpret correctly the variations which tend toward improvement or deterioration. Variations, when multiplied through several generations, are easily discovered; but the cause or causes which produce slight variation in the immediate offspring are likely to elude our search unless extended knowledge and wide experience are possessed. Therefore the breeding of full-blooded animals designed for progenitors of their race should be in the hands of experts.

In order to study the breeding of horses critically, the subject is divided into eight principal headsInheritance, Food, Climate. Habit, Selection, Relative influence of sire and Dam, the Governing of Sex, and Atavism. 


\section{INHERITANCE}

Lo! what am I? A patch of things, Mere odds and ends of lives flung by

From age-long, rag-bag gatherings,

Pieced up by Fate full thriftily:

Somebody's worn-out will and wit,

Somebody's habits and his hair,

Discarded conscience, faith once fair

Ere Time, the moth, had eaten it;

My great-grandfather's chin and nose,

The eyes my great-grandmother wore,

And hands from some remote-who knows? -

Perchance prehensile ancestor;

Somebody's style, somebody's gait,

Another body's wrist and waist,

With this one's temper, that one's trait,

One's tastes, another's lack of taste;

Feelings I never chose to feel,

A voice in which I had no voice,

Revealing where I would conceal

Rude impulses without a choice;

Faults which this forefather or that

Unkindly fostered to my ill,

With others some one else begat

And made the matter worser still.

They $\operatorname{chose,~these~masters~of~my~fate,~}$

To please themselves, bequeathing me

Base pleasure in the things I hate,

Liking for what misliketh me.

Out of the ashes of their fires,

Out of the fashion of their bone,

They fashioned me, my mighty sires,

And shall I call my soul my own? 
This motley from the Past flung down;

This work with no artificer;

This prince, this poet, and this clown,

Deific, and a driveler;

This bequeathed brain which shall conceive

What things this borrowed frame shall do;

This will to serve, and will to leave

The outworn old, the untried new;

This quick made up of all the dead,

And this deep heart inherited,-

I call these mine, and I will be

King, emperor, tsar, and Deity!

The tenement may like me ill,

The garment ill-befitting be:

I will inhabit kingly still,

And wear my rags right regally.

These hands shall work my will, - not hers

Who fashioned them to other use;

These feet fare not as he prefers

Who shaped them, but as I shall choose;

Mine be the words these lips shall frame;

And through my great-grandmother's eyes

I front my world, not hers, and claim

Under no dead soul's sovereignties.

Ay, borrowed husk, head, heart and hand,

Slave on, and serve me till we die!

I am your Lord and your Command!

But only God knows - what am I.

-Grace Eltert Channing, Atlantic Monthly, January, 1902

Every skilled breeder is satisfied that vigor, speed, beauty and all other qualities are, more or less, hereditary; but, when variation appears, he is slow to search for the causes which have antagonized or arrested the law of transmission, and which, undisturbed, should produce close similarity. 
Since pure-bred animals are now usually reared under similar conditions (those of the North being protected from the vicissitudes of climate quite as much as those of the South), we may study pure-bred animals from the Darwinian standpoint, and expect that the inheritance of every long and well-established characteristic will be the rule and non-inheritance the exception. Without criticizing any of the breeds, it may be said that some of their characteristics have not been well established, because they have been aequired in the last few generations. The subject of inheritance of farm animals is difficult and complex, since all breeds of domestic animals may be said to be "made-up breeds"; for, in the stricter sense of the word, we have no purebred animals. But this does not concern us here and now. Under certain rules and regulations, we have agreed to call certain varieties of horses thoroughbred, pure-bred, or full-blood; but their pedigrees need not be traced back very far before they end in unknown or mixed-blooded ancestry.

A plausible but misleading theory of inheritance has been formulated as follows: The offspring receives one-half of its inheritance from its parents, - that is, one-fourth from its male and one-fourth from its female parent; one-fourth from its four grandparents, oneeighth from its eight great-grandparents, and so on. Mathematically expressed, the inheritance would be as follows:

\section{Generations-}

$\begin{array}{cccccc}\text { First } & \text { Second } & \text { '"hird } & \text { Fourth } & \text { Fifth } & \text { Total } \\ \frac{1}{2} & \frac{1}{4} & \frac{1}{8} & \frac{1}{16} & \frac{1}{32} & \frac{31}{32}\end{array}$


It will be seen that one-thirty-second of the inheritance is unaccounted for in the above. This is found in the generations beyond the fifth. It is evident that there were thirty-two ancestors in the fifth generation, and that the animal in the first generation gets but onethirty-second of its inheritance from all of them. The animal under consideration has sixty-two ancestors in the fifth generation. It might easily transpire that some one of these was eminently prepotent, and if not very remote would probably transmit far more than its mathematical proportion of its inheritance. Let it now be supposed that in-breeding has taken place, that the prepotent blood of the superior ancestors has been freely used in the process, and that such prepotent inbred blood comes down through the sire; then the offspring would inherit far more than one-fourth of its characteristics from the sire, and less than one-fourth from the dam. Or, suppose a prepotent animal appears in the second generation, the offspring might receive nearly all of its inheritance from this single animal. It is evident to every practical stock-breeder that the mathematical theory does not hold true.

Inheritance is modified from generation to generation by change of food, climate, environment and use, or habit. In rare cases it may be so strong that the dominant characteristics persist long in spite of radical changes in food and surroundings.

Characteristics which have been long present are more likely to be transmitted than those which have been but recently acquired. Characteristics which are similar are more likely to coalesce harmoniously than 
those which are widely divergent; therefore, animals of widely divergent form and color should not be bred together. To secure strong inheritance in the offspring, the sire and dam should give visible evidence that they have been produced by breeding along parallel lines. Two parallel streams of nearly the same volume and rapidity of flow unite harmoniously; two streams of unlike flow and volume, united at a sharp angle, produce many counter currents and unexpected results.

What may be inherited? Nearly everything or anything. It all depends on a multitude of conditions, and it is impossible to know certainly, before the parents are united, what defects of one or both of the parents will be transmitted. Comparatively few blemishes, as ring-bone, curb, spavin, and the like, are inherited; but what is equally undesirable is too often transmitted - the lack of power of resistance. When the organs which lack resisting power are put to severe tests, the blemish which afflicted the parent, or something similar to it, makes its appearance. Under favorable conditions and absence of severe tests, especially when young, the offspring, though from unsound parents, may, and often does go through life unblemished. It is only in rare cases that tuberculosis is inherited; but the lack of power to resist the specific organism which produces the disease may be inherited. All this leads to the conclusion that pains should be taken to select such strains of animals for breeding purposes as are known to possess power to withstand, to a good degree, unusual strain and adverse conditions. Individuals, and some- 
times breeds and families, show endurance and resisting power to an unusual degree.

May prepotency, or unusual power to transmit qualities, be discovered in an animal from outward characteristics? Not certainly. But something may be prophesied of the probable prepotency, or lack of it, by careful scrutiny of the animal; since there are certain outward indications which almost invariably accompany this unusual power. The eyes are bright, wide-open, alert, fairly wide apart and somewhat protruding,- or, at least, the reverse of sunken. The hair is fine and soit; the skin neither thick nor leathery, nor too thin and papery, nor of a flabby texture, but pliable, mellow and moderately thin. The bones are moderate in size and have the appearance of being of fine grain and strong, as indicated by head, limbs and feet. Such animals are usually symmetrical, although they may not be fat. In all of their movements they are vigorous, alert and powerful, and, above all, courageous; nervy, but not nervous, - all the powers being under full control, which gives courage and confidence and the ability to direct power along efficient lines. If the prepotent animal is a poor specimen of the breed ( poor animals are sometimes prepotent), then it would really be better if the prepotent quality were wanting, for then it might chance that the offspring would take after remote, instead of immediate ancestors.

Characteristics which are much in advance of the general average are likely not to be perpetuated in full force through even one or two generations. "Sports," that is offspring which from unknown causes have made 
a wide and abnormal departure from the types of a breed, are difficult, and usually impossible, to perpetuate. Inheritance is not all, and is never so persistent but that it can be greatly modified by food, climate and habit. He who trusts to a long pedigree alone, is certain to be disappointed; he who trusts to food, climate, habit and use, to produce desired qualities, and prastices haphazard breeding, will meet with greater disappointments. He is wise who makes full use of all the factors which enter into the maintenance and increase of valuable qualities.

\section{FOOD}

Food, next to inheritance, is the most potent factor in the improvement of the horse. "As a man thinketh, so is he"; as a horse eateth, so is he. This statement may be too sweeping, but, when taken in connection with inheritance, habit and climate, it is true. All the energy which a horse uses is the product of food consumed. Inheritance, climate and special development by use may so modify the structure, both mentally and physically, as to make the body a superior or inferior, an economical or a wasteful living machine through which the energy is expended. One piece of machinery may do a certain amount of work twenty per cent slower than another. This difference may be due to putting the machine at work for which it was not best adapted or to faulty mechanical construction. It may be said, however, that the machine has no mental capacity, while the added efficiency of the horse is fre- 
quently due to mental power or brain force. Brain work requires the energy of food to sustain it, - the same, in kind, as is required for work done by other muscular tissues. What really happens is that high mental capacity usually accompanies high muscular efficiency and harmony of the structure called upon to perform the work. The brain of the horse may be likened to the steam-gauge on the boiler; it indicates somewhat accurately the amount of energy ready for use. The results, or work performed, will depend largely on the perfection of the working parts of the engine. High courage usually attends great endurance, but this is not necessarily the case. Other things being equal, real efficiency is more likely to accompany superior and judicious nourishment rather than inferior nourishment. A few days of injudicious feeding of the trotter or racer, just before he makes a great effort, may lose him the prize.

Food plays a most important part, not only in growth and development, but in the efficiency and amount of work as well. Some most marked results are secured by the too liberal as well as the too scanty feeding of many young animals, such as pigs, calves and colts, during the first six months of their lives. Calves designed for the dairy may be greatly injured as to their future performance by being fed too liberally on concentrated food, or dwarfed and injured by being insufficiently nourished. In the same way, young colts, especially घicter they are weaned, may be handicapped for life by injudicious overfeeding or underfeeding.

Judicious liberal feeding tends to increase size and 
to produce slight variations in other directions. Food furnishes the material with which to produce variations; inheritance and use largely determine where and how the surplus material shall be used or stored. Liberal but judicious feeding and improved foods have been prime factors in the development of the horse, as well as in that of the great meat-producing animals. The progeny of the fleet trotter may be varied towards a draft-type in a few generations by feeding for increased weight and size and by changing habit from fast to slow, laborious work. Food and use not infrequently overpower inheritance. Uncongenial climate and injudicious feeding may prevent food from accomplishing its legitimate and desired end.

\section{CLIMATE}

Climate does not play so important a part in the United States in modifying animals and in producing variations as formerly, when stables were inferior and when it was sometimes the practice to allow horses and other domestic animals to find shelter around the strawstack. As the forests were cleared, it was not uncommon to provide an open shed, usually facing the south or east, in which horses, cattle and sheep were allowed to battle for the place least exposed to drafts of air. Even if enclosed stables were built, the floor and sides were so open that the heat generated by the animals kept in them made no perceptible change in the temperature. Many of these stables were more uncomfortable for the animals than open sheds, or the 
barnyard, if it chanced to be somewhat protected from the winds.

Under such conditions, climate played an important part in modifying the growth and structure of both horses and cattle. But little improvement could be made in animals where they were subjected for nearly half a year to climatic conditions as damp and rigorous as those found in the greater part of the eastern and middle states. The improvement in horses which has been made in the last half-century could not have taken place had not the rigorous climatic conditions been changed by the erection of suitable and better stables in which it is possible to radically modify environment. Low temperatures, especially when accompanied by humidity, tend to increase the protective covering of animals. They also tend to arrest the development of symmetrical top and bottom lines. The Shorthorn, which stands humped up for long periods, sooner or later transmits something of its enforced curvature of the spine to its offspring. Where there is constant suffering on account of cold and exposure, the hair thickens, the flank rises, the rear of the animal tends to diminish, while the front end, which contains what are known as the vital organs, tends to become relatively larger. Improve the climatic conditions so that the food energy will not have to be so largely expended to maintain bodily heat, and there is a steady tendency to restore the harmony between the rear and front ends of the animal. If, in addition to improving climatic conditions, the food be improved, the change for the better becomes rapid and marked. 
It should be remembered, however, that inheritance is always playing an important part, and that even favorable climate and food combined cannot radically change conformation and characteristics until long periods of time have elapsed.

Severe climatic conditions constantly tend to reduce size. Such reduction ceases only when the body structure has become adapted to all the forces acting upon it, or, in other words, when an equilibrium has been restored between energy prodnced and energy used. Natural forces do not respect man's wishes; they work along the lines which accomplish their purposes in the most economical way. Rigorous climatic conditions tend not only to diminish size but to eliminate highly specialized qualities and to produce hardiness - the prime characteristics which must be perpetuated if existence is maintained.

In America, serious mistakes have been made by placing some of the imported breeds under climatic conditions so much more rigorons than those to which they were accustomed as to preclude the possibility of securing expected results. Since we have become more humane in the winter-housing and treatment of animals, the breeds brought from a warmer climate than that in which they are placed in the States preserve their specialized qualities intact under skilful management. Still, there is always danger in moving animals from one climate to another radically different, especially if it be from a warmer to a colder one. 


\section{HABIT AND USE}

When one or several limbs or organs of an animal are called upon to do extra work, Nature immediately tries to strengthen such member's by providing extra nourishment. This extra work must not be carried to the point of exhaustion, or the member may become weakened or diseased.

The habit of life and the work performed play important parts in producing change and variation in individuals, even in so short a period as a life-time. Take two brothers of nearly the same age, similar in looks and characteristics, and approaching their majority, and let one lead an easy, sedentary life, largely within doors, while the other exposes himself to the sun, storms and cold, while employed in laborious toil. When these brothers have reached the age of sixty, they will be so unlike as to suggest that they might belong to distinct races. If the fast-stepping trotter spends his life in drawing heavy loads at a slow pace, and is kept fat in order to secure weight, he becomes to all intents and purposes a draft-horse. He may preserve his fine head and his smallish feet, but in weight and movement he will illustrate what marked changes are wrought in a half-score of years of use. Or allow the well-bred dairy cow to nurse her own calf for a half-year, so that she becomes nearly dry at the end of six months, in subsequent years she will fall short of her normal production; whereas, if the calf had been removed and she had been regularly milked, the flow of milk would not only have been more abundant, but it would have continued much 
longer and the normal flow of milk have been maintained the following year. The family horse, overfed and under-used, soon becomes slow and logy, although at first he was spirited and active.

It can be readily understood that, in order to preserve the inherited characteristics of a breed or an individual, the animals must not only be placed under similar conditions as to food and climate, but must retain similar habits and do similar work to that performed by the ancestors from which they sprung.

It is difficult to discover certainly the character of the ancestors by an inspection of an animal; it is easy to determine the uses to which they have been put and the abuses which they have suffered. Full use, without abuse, and appropriate work tend to produce variation for the better and to preserve and increase the efficiency of specialized qualities, as well as to make them permanent in time and capable of being transmitted to succeeding generations.

\section{SELECTION}

It is self-evident that variation is constantly taking place,- sometimes for the better, sometimes for the worse, and that changes sometimes appear which do not affect intrinsic value. Most of the causes which produce variation are known, but the causes may not produce immediate noticeable changes. It may take several generations before the accumulated effects become marked. The careless breeder does not note these causes and their effects until degeneracy has gone so far as to make it advisable to introduce new blood, 
rather than make the attempt to correct the mistake by using the animals which have been varying for the worse.

It is not easy to determine by the subsequent effects the exact causes of slight variations or the exact time when they are introduced. There is one safe ruleendeavor to make all of the conditions of the animal superior to those which formerly prevailed; then when variations appear they are likely to be for the better. The reverse of this is equally true. Inferior conditions produce variations for the worse.

Keeping these facts in mind, the breeder is ready to begin his selection; provided, however, he has good judgment and a clear-cut mental photograph of the animal he seeks to produce. Selecting an animal does not improve it. The breeder simply takes advantage of the variations for the better due to causes which antedate his choice. By selection, he seeks to eliminate the influence of those individuals which have varied for the worse or have not risen, on the whole, above the average. By selection, he may progress faster than he would if he attempted to raise the progeny of all the herd to a higher average level without selection.

A herd of bison, if changed from bad conditions and scanty pasturage to improved conditions and abundant food, will, in the course of a few generations, vary for the better; although natural elimination is likely to be more active under bad than under good conditions. It is, then, not natural selection, but improved food and environment, that have produced the variations for the better. 
The farmer is usually advised to purchase the best male he can find and then practice rigid selection, if he desires to improve his herd or flock. There is either too much or too little in this brief recipe. The stream cannot rise above its fountain-head. While the introduction of a superior male into the herd may improve it for a short time, eventually the average of the herd will represent the powers for growth, development and production which are found in the food, coupled with environment, use and abuse. More than this,-the herd, in time, may actually fall below its environment and food-supply, because of the introduction of the improved blood; since it may take several generations before the improved blood adapts itself to conditions less congenial than were those in which it was produced. In earlier years, many a farmer did introduce an improved male into his herd, but did not improve the food and environment, and after a time found that no permanent advance had been made. Not seeing the cause of his failure, he condemned the breed to which the male introduced belonged, by saying that it was a pampered, tender breed for which he had no use.

If the farmers who desired to improve their herds had been told to select a male superior to the animals already possessed, and to mingle his blood with selected females, simultaneously improving food, care and environment, and then to select from the offspring, permanent betterment would have been secured. After having learned something in the school of experience of the methods which must be followed to secure improvement, the breeder would naturally seek to make use of a still 
better and presumably a higher-priced male, since he had learned to progressively and logically unite better blood, better food, better quarters, kindness and selection, harmoniously, giving to each factor its appropriate place and value. Evolution does not go forward by leaps and bounds, but by slow, almost imperceptible changes from generation to generation. The breeder of domestic animals would do well to follow Nature's modes of action.

So far, the selection from the offspring has been discussed, but of quite as much importance is the selection of the parents through which, in part, the betterment of the offspring is to be secured. If it is desired to secure offspring which when mature will reach sixteen hands, the result would be reached far more certainly by breeding a female of fifteen and a half hands to a male sixteen and one-fourth hands high, than by breeding a female of fourteen hands to a male seventeen hands high. The progeny of animals radically different is seldom satisfactory. It is better to take two or three generations in which to attain the standard than to attempt to reach it at once by breeding very small and very large animals together. At the beginning, judicious selection is of prime importance. The one great mistake in horse-breeding is that of breeding large stallions to small mares; that is, little pains is taken to select such females as give promise of uniting harmoniously in the offspring with the blood of the male to which they are bred. It all comes to this, - that moderate variations through generations produce qualities which are likely to be permanent and potent. 


\section{RELATIVE INFLUENCE OF SIRE AND DAM}

Much has been written as to the relative influence on the offspring of sire and dam. When both parents have characteristics in common, there appears in the offspring little to indicate that one parent is more prepotent than the other, or that one transmits in a greater degree than the other special organs or specialized characteristics. But when animals of the same genus, but of extremely divergent characteristics, are crossed,- as the horse (Equus Caballus) and the ass (Equus Asinus)-most interesting results are secured. When the horse is used as the sire, the produce - the "hinny" - takes on, it is said, more of the outward characteristics of the sire than of the dain. Its ears are smallish, the mane and tail fairly abundant, the foot rounded like that of the horse, and it neighs. The viscera and interal organs appear to be largely inherited from the dam. She is small, so is the hinny, the outward structure adapting itself to the internal organs. If the cross is reversed - the jack bred to the mare - a mule is the product. Its outward markings and characteristics are like its sire's - long ears, short and stubby hair on mane and tail, a stripe over the shoulders, a narrow foot and the sonorous voice of its sire. The outward characteristics of this hybrid are largely from its paternal ancestors; while the internal organs are large, like those of its maternal parent. This being so, the mule is larger than the hinny. In such violent crosses, it is certain that the sire transmits his external organs to the offspring more largely than does the dam; and the dam the internal organs, at least as to 
size, more largely than does the sire. When animals which are similar are united, it is probable that the same principle holds true to a limited extent. Then it would seem wise to select, when possible, dams of good size - those of large lungs, heart and viscera capacity - even though they may not be as close-made or of as fine outward form as is desired in the offspring. It may be confidently expected that, if a smooth, symmetrical, moderate-sized stallion be united with such a mare, the progeny will be far better as to endurance, beauty and poteney than if the characteristics of the sire and dam were reversed. The practice of breeding large, even mammoth stallions, to small, unsymmetrical, unsound mares or to "any old thing," has done more to arrest improvement which should have been secured from the many good, home-bred and imported stallions than any other one thing,-- possibly than all other adverse causes combined.

\section{THE GOVERNING OF SEX}

The facts observed by many reputable breeders of domestic animals lead to the following conclusion,that the most vigorous, the most prepotent parent at the time of conception is more likely to govern the sex of the offspring than the less vigorous parent. This is only saying that the stronger is superior to the weaker; but this general law can be discovered only by being put to an extensive test,- - such as when a large number of animals are bred under similar conditions. Some extended experiments in France indicate that, when 
sheep were observed, the first lambs were largely males. As the yeaning season progressed, the number of male and of female lambs were about equal, while at the close of the lambing season the female lambs greatly predominated. In my own experience with five hundred American Merino ewes, I found that about nine-tenths of the first quarter of the total crop of lambs were males. Then the sexes began to even up, while, in almost every case, the last quarter of the lambs dropped were largely females. Where large flocks of sheep are kept, it is usual to separate the rams from the flock for three or four months preceding the rutting period. They are fed liberally with such foods as experience has shown will produce unusual vigor. At the same time the ewes are kept under normal conditions or those somewhat less productive of vigor, since the flock is usually large and the pasturage and food somewhat limited. It is evident that under these circumstances the males, when first turned into the flock, will be more vigorous than the females. As the season advances, there being but few of the males, they become depleted in vigor so far as to fall below the vigor of the ewes. Many instances of like experience with flocks of sheep could be cited.

My friend who owns an island off the coast of South Carolina which is stocked with cattle and swine that roam at will, with no care from the owners, states that they show marked sex-variations in different seasons. After a hard winter and scarcity of food, male pigs predominated. As they were hunted for food during encampment on the island, it was seldom that a female pig could be secured. The males, not being depleted by 
nourishing young the year before, passed through the winter with powers less impaired than the female. This is the explanation that he gave me for the facts observed. When food became abundant in other years and conditions were improved, the sex of those pigs which were slaughtered was about evenly divided. Were it appropriate, many facts could be cited to substantiate this theory in the human family.

However, before leaving this subject, it should be said that either the male or the female may be propotent in color alone or some other characteristic and not prepotent in sex characteristics, or either one may be prepotent in sex characteristies alone. We are acquainted with many animals which per'sist in bearing offspring of one sex though bred to different males, and with some that persist in producing one sex as long as mated with the same male, but when another male is used the sex of the offspring is changed.

Many theories have been advanced which sometimes have appeared to indicate a law; but as yet no law has been discovered for governing the sex of offspring which holds uniformly true or which is workable. We may sometimes change conditions or change the mating of the animals and arrest the prepotent factor of sex or any other potent factor, and at other times no change of food or mating accomplishes the desired result. We conclude then that the stronger characteristic, whatever it may be, is superior to the weaker. The difficulty consists in determining them. If any one had discovered a method of controlling sex, he would have taken out letters patent on it long ere this. 
ATAVISM

Atavism is the recurrence, or tendency to recur, to an ancestral type, peculiarity, or disease after its disappearance for one or more generations. It is intermittent heredity ; reversion; "dating back."

The offspring may be affected by physical conditions of parents at the time of copulation, and also by the condition of the parent during pregnancy. It is believed that the first fruitful connection may sometimes have a marked influence on subsequent offspring. It is contended by a few that, if a full-blooded animal has been fruitful by reason of connection with a mongrel, thereafter the blood of the dam is vitiated and she becomes incapable of producing full-blood offspring when united with a full-blood male of her own breed.

The relative age and vigor of parents may have a marked influence on the offspring. Animals which are overfat tend to lose somewhat the power of transmitting their highly specialized qualities and full vigor. In fact, animals overfat may be said to be on the verge of disease. Exercise, or the lack of it, in the parents may be a potent factor for good or evil, in reproduction.

In highly organized animals, mental impressions at time of copulation, and for some time afterwards, may have a marked influence on the offspring. In most cases, however, mental impressions play little or no part in.the breeding of domestic animals. 


\section{CHAPTER XIV}

\section{PLAN OF BREEDING}

A GENERAL plan should be carefully thought out before the farmer makes the attempt to breed few or many horses. As the work of breeding progresses, many questions of detail will arise which can be most successfully solved as they occur. One detail has a bearing on others, changes are constantly taking place in surroundings - food available, supply of and demand for horses, and fashion. After the general plan is outlined, he is most likely to succed who adjusts the details most skilfully to the general plan, to the environment and to the proposed results.

First, the man should take account of his likes and dislikes. He may admire the light, active horse. If his farm is rolling, the soil easily tilled, he may gratify his tastes; but he would almost certainly fail if he attempted to breed draft-horses. On the other hand, the man who occupies a stiff-clay wheat farm, and who from this fact may have learned to admire a powerful, large horse, would be foolish if he attempted to breed roadsters. He succeeds best who unites with his knowledge of horse-breeding a genuine love for the breed which he cultivates. Before beginning, call a meeting of the stockliolders of the enterprise - the wife and children; their wishes should be respected, and they 
may be able to give wise counsel. "In the multitude of counselors there is safety."

The market should also be studied. Draft animals sell well at the end of the halter tail. Roadsters and coachers should receive some training, if mature, before they are marketed, if full values are received for them. The amount of money and time that may be available for doing this training should be considered before it is undertaken. The beginner should start in a small way, carefully:

"Smaller boats should keep near shore, Larger ones may venture more."

To get the most out of breeding horses, one should know something of how to buy, sell and trade,-in other words, acquire some knowledge of the business. Some men are born with horse instinct, and these acquire a knowledge of horses quickly. Some tuition will have to be paid for this knowledge, if it is not possessed at the start. In the long run, honesty will be very much the best policy. This is especially the case in dealing in horses. Once a reputation is made for strict honesty, and the market for your horses is established. A sharp distinction should be made between differences in judgment and misstatements of facts. It is surprising how quickly the honest horseman is known and appreciated by purchasers in the horse market, although the judgment of the buyer as to value may not be in accord with that of the seller. Every honest transaction increases the selling price of every unsold horse in the stable, while every dishonest one not only depresses 
the price of the whole stock, but diminishes the number of customer's. Having decided on the breed,- I cannot decide for you,- hold honestly to it. If it is not the best one, make it the best, if possible. Do not attempt to breed a draft-trotting-coach-horse. You will be fortunate if you do not make enough mistakes, when breeding with a definite object in view, to furnish all of this class of horses which the market will take. The most difficult task of all will be to get together a half-dozen or a dozen good brood-mares, - but without them failure is predetermined. It is assumed that my reader lacks the means to purchase these animals outright. Even if he had, he would then, with the horses already possessed, have too many work-animals; for the mares will be able to do the summer's work, although they may be put to raising colts in the winter. One of two methods may be used to dispose of the geldings, unsuitable mares, the old and unsound of both sexes. From time to time, quietly trade or sell one of the undesirable animals. Give "boot" if necessary - money or a cow or a wagon,- but trade if a good and tried brood-mare is offered; or trade for other live stock - cows and sheep. Then trade these for the brood-mare, or sell outright and take a good promise to pay. Put the notes in the bank as collateral security and borrow enough money to pay for the brood-mares. Such transactions -will result in developing the judgment and in increasing confidence in one's ability to do business. If the trader is a young man, he will soon acquire good "horse-sense." There will be some tuition bills to pay, but we seldom 
secure knowledge of any kind without paying the score.

Many good brood-mares have been sent to the cities. They have been there on the hard pavement

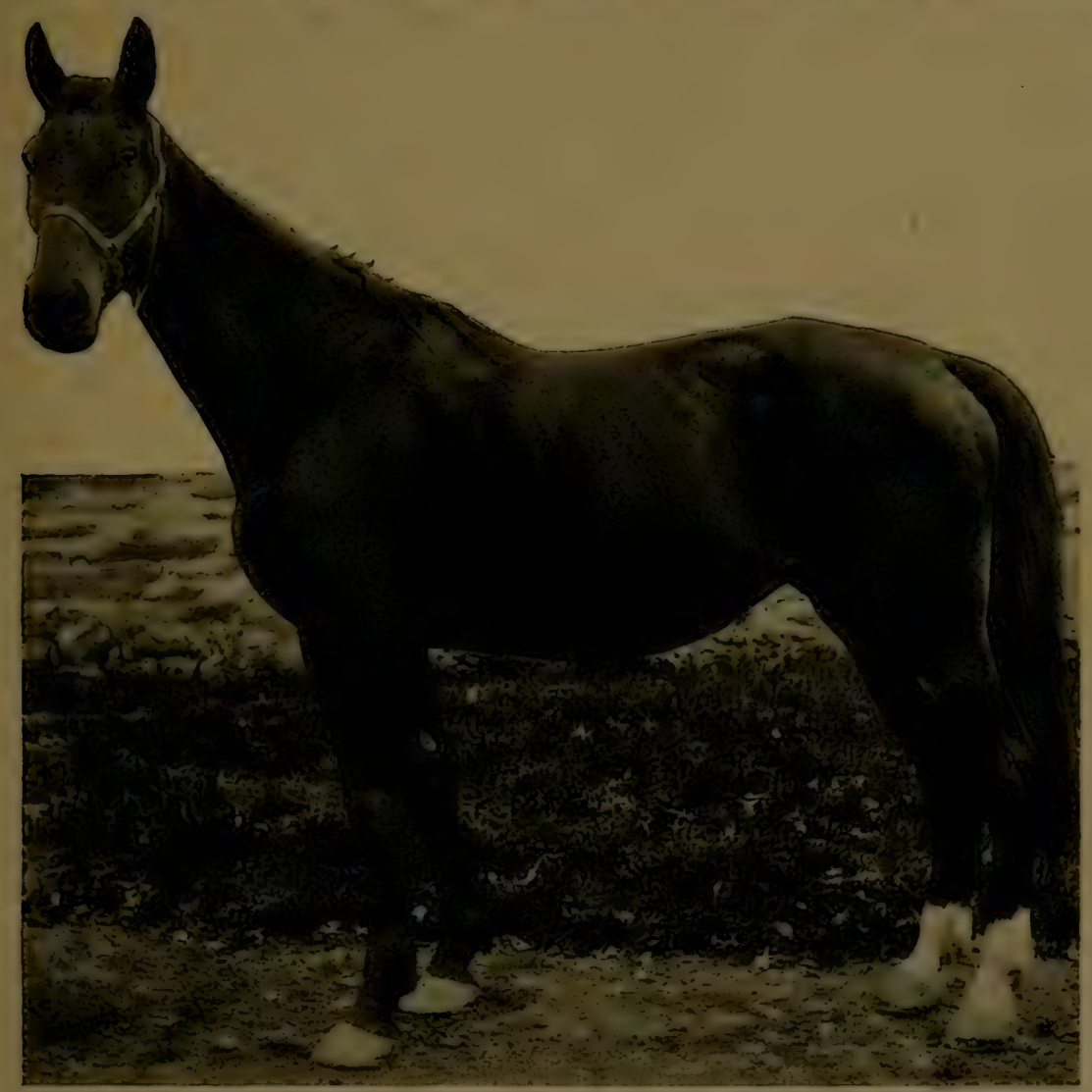

FiG. 48. A desirable conch brood-mare of gond action and high spirits. Notideal in form, but when tested for breeding purposes has proved to be superior.

quite long enough. Their feet would be benefited by the soft earth of the field. Trade a gelding for the mare and yet "boot." She may not be quite what you want, because she was not set at her life-work when 
young. Nevertheless, she may be good. There arc many good brood-mares on the farms which have never been used for breeding purposes. There are a multitud of ways to change the heterogenous workstock of the farm for at least fairly good, sometimes superior brood animals. One of the latter may be worth twenty-five to thirty cents per pound, or six times the price of beef on foot. My friend owns a mare which has performed regular and full work in the summer, and produced colts which, in the aggegate, have been sold when fairly mature for $\$ 1,700$, or nearly $\$ 200$ each. A plain grain farmer and a plain appearing mare; the latter suited to a distinct purpose, the former with acumen sufficient to make good use of his opportunity. (Figs. 48 and 49).

Description of a Brood-mare.-It is impossible to secure a clear mental photograph of a good or superior brood-mare by illustrations or printed descriptions. The living animal must be studied long, carefully, patiently, if one is to become an expert judge. However, some help may be secured by means of pictures and descriptions. The brood-mare should be of good size, considered from the standpoint of variety or breed to which she belongs and the size of the progeny desired. Her body conformation should be rather open, or the reverse of pony-build. She may be, and often is, a shade too long in body and slightly too coarse. But these defects, if they are defects, may be corrected in the offspring through the sire. The eyes should be prominent, bright and well-set; the head fine, for the breed; neck inclined to be, if anything, 
too thin, provided it be well set on the shoulders. Short, thick-necked brood-mares are too often disappointing. The shoulders should be rather thin, moderately oblique, and withers high rather than low.

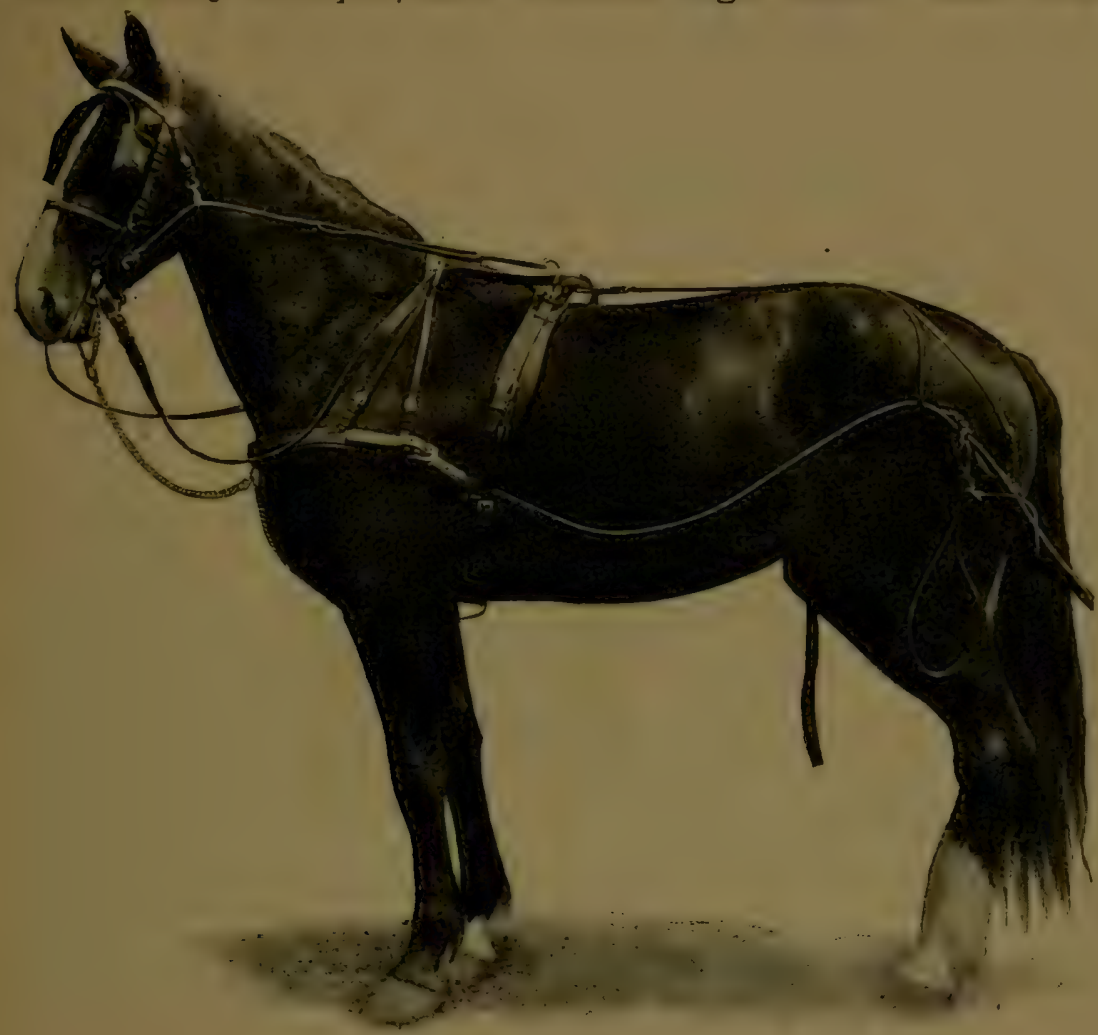

FIG. 49. A three-year-old fresh from pasiure

The back (top line) may be a trifle long if the bottom line is correspondingly long, though a short top line coupled with a long bottom line is best. The hindquarters should be broad and deep, neither steep nor flat, with hips thrown well forward. The hips and short ribs should not approach each other too closely. A 
brood-mare that is a little open-ribbed is preferable to one that is too close-ribbed. Such a structure usually accompanies a symmetrically set tail, a broad pelvis and well-developed mammary glands. Symmetrical, clean, well-knit legs, - a little short rather than a little too long, according to breed,-placed rather well under the body, instead of on the "corners" of the horse, should, if provided with good feet and nerve power, carry the dam safely through ten to fifteen vears of strenuous life, while imparting to her offspring her own characteristics.

Some horses have feet too large, some too small. Some have feet that are too low, flat and open at the heel. Others have too high feet with too narrow heels. If a happy medium can be secured, and the feet are dark colored, tough and close of texture, they will not only be good, but will indicate that the balance of the body structure is also tough and fine-grained. The color, as has already been said, should, when possible, be of some shade of bay or brown, while the hair should be thick, short and soft.

Having good mares, it is comparatively easy to select the male to which they are to be bred. The male should be masculine in appearance, fine, and larger and smoother than the female; for this is natural and logical if the reasoning which has already been given in Chapter XIII is correct. In any case, whether the purpose is to enlarge the progeny as compared with its smallest parent or to reduce size as compared with the largest ancestor, the change should be gradual. Full success may not be secured from breeding large 
males to small females, or small males to large females, nor when one or both of the parents are enfeebled by old age or by abuse and over-work or over-feeding. Animals which are markedly immature should not be

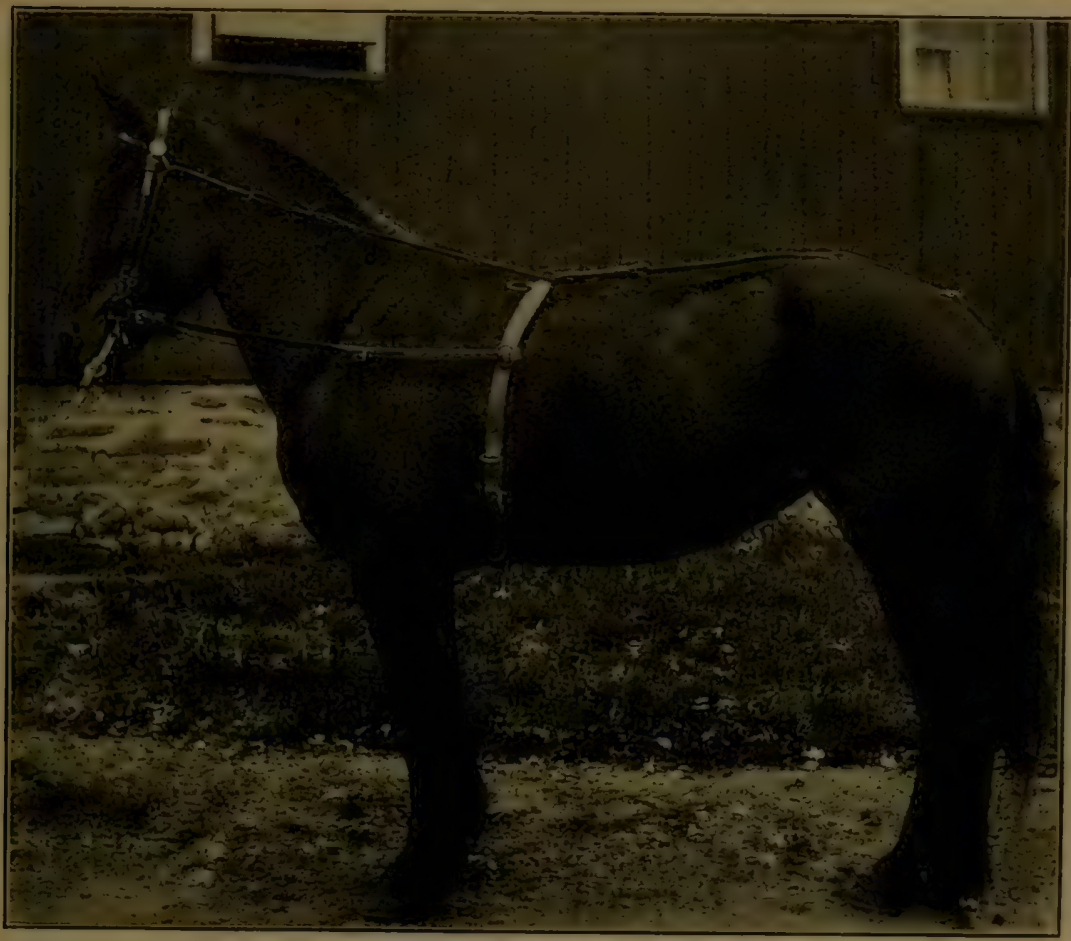

FIG. 50. The draft-colt's first lesson

Waist too small, rump a little too steep. When in good flesh and mature, these defects will largely disappear

used for breeding purposes unless the object is primarily to direct the energies into certain specific channels other than reproduction, as in the case of dairy cows, or as may be the case when it is the purpose to produce a superior, heavy-milking, broodanimal. (See "When and How to Breed.") 


\section{FALL VERSUS SPRING COLTS}

In the fruit and dairy districts the pressing work ceases in September; in the grain-raising sections it is October before the farm-horse gets relief. If fall or winter colts are to be raised, it is evident that the foals should not appear until October or November in the former case, and November and December in the latter, unless there are enough animals on the farm to permit of diminishing the work of those which are in foal. However, cireumstances will to a great extent govern this and other details. Wherever the fall work will permit, the time of breeding might well be advanced two or three months; provided, however, the foal does not appear when flies are cruelly annoying.

The female is not as likely to be amorous in the fall and winter, as in the spring. Usually, she is rather thin in flesh after the summer's work. If so, the task of securing the desired results will be the easier. By increasing the food, especially the grain ration, by giving regular but somewhat moderate exercise, and by double or single blanketing, conditions will be produced similar to those which prevail in the spring. Meantime the bowels should be kept free from constipation by feeding moderate amounts of succulent foods.

It is often asserted that fall colts do not shed their hair as freely and as perfectly as do spring colts. It is doubtful whether this is so.

Colts usually shed their incisor teeth about three months in advance of their third, fourth and fifth 
birthdays. Fall colts shed their teeth when grass is ret abundant; spring colts when on dry, winter food. Dentition proceeds more satisfactorily when the animals are at grass than when fed on dry food.

\section{PLAN FOR REARING WINTER COLTS}

Let it be supposed that a farm requires the labor of four horses. It may also be assumed that the usual number kept is seldom sufficient for performing the work promptly and satisfactorily in the spring. Such a farm should be equipped with at least five workanimals, four good brood-mares and one animal suitable for the carriage and family use and for emergencies: it may take two or three years to secure them. If four brood-mares are regularly bred, two or three colts may be raised each year, on an average.

Until the colts are large enough to do light work, the carriage-horse may be used for farm work in emergencies. When the colts reach from two and a half to three and a half years of age, they should be taught to do light work.

One weakness of the horse-breeder is his apparent inability to sell his colts and horses as rapidly as he should. A good way to advertise the fact that you have good, young horses for sale, is to drive them into town once or twice each week after the five o'clock supper. Get on a clean shirt, get the mail, and earn a dollar, more or less, by driving the colts; thereby enhancing their value by making them familiar with city sights and sounds. You dare not tie them in town, 
and therefore will have no opportunity to get a glass of beer. If the farmer is breeding roadsters, not infrequently he will place such exorbitant prices on his colts as to effectually prevent the sale of them. He may ask three or four hundred dollars for a single untrained colt, while, at the same time, he may have reared a calf to the same age and offer it for $\$ 25$; notwithstanding the fact that the calf has probably cost him one-half as much to produce as the colt. Ability to sell is quite as necessary as ability to produce. Lack of either handicaps the farmer, especially the breeder of live stock.

The intelligence of the farmer is augmented if he raises such products as require skill and judgment in their production and sale. The fruit-growers are usually intelligent and broad men, because it requires high intelligence to produce good fruits and to sell them to the best advantage.

If the number of colts which may be produced from four mares and their female progeny in ten years is computed, it will readily be seen that unless many sales are made this kind of horse-breeding will ruin the breeder. Just here is where many men who have added horse-breeding to their other activities have failed. A man will milk cows semi-daily for eight months of the vear and secure from them from five to ten per cent profit; but when he offers a colt or a young horse for sale he will put a price on it which includes cost and fifty to one hundred per cent profit. Failing to sell, the animal continues to eat until it "eats up the owner." 
If the colts or undesirable brood-mares become too numerous and the pastures too short, trade in August for a pair of bob-sleds, and get "boot." They will, at least, not "eat their heads off." The next winter some one will want the sleds. Or trade for hogs, cattle or sheep. These may be killed and disposed of, and the apparently endless chain is broken. The thrift of the New Englander is due, it is said, to his skill in swapping jack-knives. It is even recorded that a family of boys traded watches among themselves one entire winter and each made not less than five dollars. There is always a person somewhere who wants the very thing you have,-find him.

The two-year-old fillies which have the promise of developing into good brood-mares should be bred at about two years of age, and again at three years old. They may produce two foals each in this time, and a fair test will have been made of their breeding qualities. It is probable that their offspring will not be quite so good as it would have been had they been older; but it is of the utmost importance that they be set at their life-work when young if they are to be developed into superior brood-mares. The same principle should be observed with brood-mares as in the production of dairy-cows. After the second foal is weaned they may be trained for work.

If they prove unsatisfactory as mothers, by proper feeding they may be made to take the general form of mares which have not produced, when they may be sold or exchanged, being yet in the fifth year and quite young enongh for city use. 
All this plan may appear to the young reader easy of execution, but it is not,-it is difficult. Difficult undertakings, if successful, produce liberal rewards; easy ones, meager compensation. Failures will be met with, you may get cheated in trading horses; if so, that will stimulate your intelligence and after a time the increased knowledge, the valuable business experience and training, and the profits will be ample reward. Good horses are scarce and high priced. Milk is cheap. Then why not reduce the cow dairy and add a winter horse dairy and let the colts do the milking?

FEEDING THE BROOD-MIARE AND FOAL

When the mare is at severe work during the summer months, the ration should be wide,- one to seven or one to eight. ${ }^{1}$ As the work lightens and time of parturition approaches, the ration may be narrowed; about one to six is appropriate. The bowels should not be allowed to become constipated, neither should they be lax. The system should be kept free from fever and the muscles fully supplied with water by feeding some succulent foods and those which tend to cool the system and soften the striated muscles. For one or two months previous to parturition, the mare

${ }^{1} \mathrm{~A}$ ration is said to be wide when the heat and energy constituents of the food exceed the muscle-sustaining constituents more than seven times; when less than five times, it may be termed a narrow ration. These figures are not arbitrary. Nutritive ratio means the proportion which the proteids, muscle-sustainers, bear to the heatand energy-producers. (See Appendix III.) 
should never be allowed to work on soft plowed ground or on muddy roads or be driven at a rapid pace, nor should she be used for heavy draft work. Unless she be free in the pasture, she will be benefited by regular, light work.

Brood-mares, when nursing their foals, should be fed much as dairy cows are, - that is, for the production of milk. Timothy hay and corn are not good and economical milk-producing foods when fed alone. (See Appendix III.) The ration of brood-mares and colts should be narrow, about one to five if the stables are comfortable. If the temperature in the stable remains down to zero or below for considerable periods of time, then the ration should be widened to one to seven, or even one to eight, by adding concentrated carbonaceous foods. Rather wide rations should be fed in the stables which are over-ventilated-draughty. It is wise to feed some succulent food (carrots are best), even if the mare is not giving milk. Matured apples, potatoes and good corn silage may be fed in limited quantities. Bright mixed clover and timothy hay, if fed with judgment, should provide all the needed roughage. Better feed bright straw with nitrogenous grain rations to balance it than to feed overripe or musty and dirty hay.

For a mare of 1,100 pounds, nursing a foal, the following would constitute a good and sufficient daily ration as long as the foal subsists entirely on its mother's milk: (When it has passed that period, it should be tied during feeding time and fed in a separate manger.) 
Mixed hay ........... . . 15 pounds. Wheat bran (or its equivalent) .....5 pounds. Oats ............. 5 pounds. Carrots ............. 8 pounds.

This ration should be increased or diminished as the condition of dam and foal seems to demand. If the hay has a large proportion of bright clover, it is all the better, and, in this case, cracked corn may well be substituted for part of the oats. Roots are desirable in this ration, both because they tend to stimulate the flow of milk and because they are conducive to good health in dam and foal.

The colt, up to the time it is called on to perform service, should receive a narrow ration,-one of about one to five or one to five and a half.

There are two critical periods in the life of the foal, - the transition period when its food is being changed from the mother's milk to a partial or entire ration of solid food, and the time when it changes its milk-teeth for permanent ones.

If the dam becomes pregnant on the ninth day after she has brought forth young, or soon after, her milk will decrease, as time goes on, more rapidly than it would if she had not become so. Therefore, if the dam becomes pregnant, the foal should have its milk supply of food supplemented by an extra portion of palatable, easily digested, green and dry food. The foal should be weaned when it is three to four months old, if the dam is pregnant; if she is not, it may nurse somewhat longer. If, for any reason, the colt begins life in the spring, then the time for weaning 
it will be when the flies are most annoying, the sun fiercest, pastures scant, the grasses dry and more or less innutritious. It is cruel to separate the young things from their dams and turn them out at this time of the year to fight for their lives. Far better, place them in darkened box-stalls until the flies have departed.

Water should be offered in the winter twice and in summer thrice daily. The drinking water in the winter will be most acceptable if raised to a temperature of 98 degrees Fahr., though this is not imperative.

A roomy box-stall should be provided for the mare and foal; one ten by fifteen feet in the clear will suffice, except for large draft-mares. When the foal is a few days old, its dam may be led out of the stall daily. At first she should not be separated from her offspring but for a few minutes at a time; the time of each successive separation may be increased until it will be safe to use the mare for two or three hours at a time. The blood of the mare should not be overheated, nor should the foal be allowed to nurse when the mare is over-warm. A good plan is to allow the mare a liberal breathing spell at the far end of the field, with her head away from the barn, a half-hour or so before she comes to the stable. If this does not result in her cooling off, then it will be better to relieve the udder of some of the milk before returning her to the stable and her foal.

The foal should not be allowed to follow its dam when she is at work. The mare and foal would better be turned into a field or paddock during the pleasant weather a few hours each day in the winter, and at 
night in the summer after having eaten their usual grain ration in the stable. Mr. F. S. Peer, in his interesting book on "Soiling, Ensilage and Stable Construction," recommends soiling brood-mares and foals during fly time and turning both out at night. He recommends feeding oats and peas, also alfalfa.

In summer, darken the stables and exclude the flies as far as possible. Preserve the rotund appearance and the "colt flesh" of the foal until it disappears naturally, when eight to nine months of age. A stunted colt means a handicapped horse.

The fall colt.-By the middle of May, or before, will have been weaned, will have all of its incisor milk teeth, and will make rapid growth without concentrated food when turned out to pasture.

We may now sum up the transaction: The broodmare has earned by her work her own and her foal's food and, in addition, enough to pay an ordinary bill for services of stallion. The value of the colt, when weaned, will usually range somewhere between thirty and one hundred dollars, the larger part of which will be profit. After the foal has been turned to pasture, it will require but little attention $\mathrm{or}^{\circ}$ grain, either summer or winter. The cost of its food will usually be between fifteen and twenty-five dollars per year. The colt, unless thoroughbred or trotter, may be made to earn its keep after it is three years of age.

NотE. Colt - the male offspring of the mare when less than five years old. At five, the name changes to gelding or stallion. Filly - the female offspring up to five years of age or less, afterward a mare. The word colt is also used generically for a male or female, under five years of age. Foal - a young colt of either sex. 


\section{PERIOD OF GESTATION AND PARTURITION}

The normal period of gestation may be placed at three hundred and forty days, though it varies in horses as it does in all other species of mammals. Veterinary writers usually place the minimum period at three hundred, and the maximum at four hundred days, for mares. Some breeder's believe that if the normal period of gestation is exceeded it indicates the probability of a male colt.

If there is more than one mare to be bred, the stinting of them as near together as possible will diminish the work of the care-taker at foaling time. As the time of parturition approaches, an attendant should be close at hand, both day and night; and several foals and mares can thus be cared for with the minimum of extra attention.

The period of gestation being variable, the mare should be closely watched as her normal time of bringing forth young approaches. There are signs of the near approach of parturition which, though not infallible, give indication of near delivery. The udder may become greatly distended, especially in the morning, but exercise usually reduces it. The teats seldom become large and plump more than two or three days before the foal is dropped. A large udder does not necessarily imply near approach to delivery. The waxy substance which closes the ends of the teats usually loosens and allows the milk to escape about one day prior to the birth of the foal. Sometimes the foal is born before there is sufficient flow of milk to sustain 
it, in which case resort must be had to the nursingbottle. About one week before parturition occurs, a shrinking and falling away of the muscles of the buttock near the root of the tail takes place.

The mare's milk is relatively poor in fat and protein and rich in sugar. If cow's milk must, for a time, be substituted for the mare's, in part or in whole, that of a fresh young cow should be used. It may be modified by adding a little water to reduce the per cent of fat and protein, and a little sugar that the modified milk may be similar in constituents to the dam's. The temperature of the milk, when fed, should be $98^{\circ}$ to $100^{\circ}$ Fahr. In cold weather there is danger that the milk, while being used, will fall below the proper temperature. To obviate this, wrap thick, hot, woollen cloths around the bottle. About one-fourth to one-third of a pint of the modified milk may be given every two hours, gradually reducing it as the mother's milk becomes available.

The colostrum, or first milk after parturition, as already shown, tends to move the foal's bowels, which is beneficial. The modified milk, on the other hand, tends toward constipation; therefore the bottle-fed foal should be given a mild physic.

The bowels of foals which nurse their mothers may be moved by administering to them two to four ounces of unboiled linseed oil or the same quantity of castor oil, or by an injection of water at a temperature of $100^{\circ} \mathrm{F}$; or administer to the dam one pint of either of the above-named oils. The feeding of succulent foods tends to hasten the flow of milk after parturition; 
dry, carbonaceous foods, to delay the milk flow. (For teething, see Chapter XV.)

The foal should not be petted, but kindness and firmness should be used in handling it. Sometimes the attempt is made to educate the foal beyond its ability to receive instruction. It is a mistake to attempt to educate either boys or foals above their capacity. The colt trained to all the ways of mature horses is sure to be put to horse-work too young. Let the boy be a boy, and the colt a colt. While the foal is yet with its dam, it should be taught to lead and to allow its feet to be handled. The paramount object in all kindergarten work with the foal is to teach it prompt obedience and to inspire it with courage and confidence. It should be taught to follow unhesitatingly when it is led. It should not be allowed to get its legs entangled in stable floors, bridges or fences, and it should never be purposely frightened. The colt and the filly, as well as mature animals, discern quickly a timid, hesitaing or incompetent attendant or driver. As the attendant is, so is the future mature animal likely to be. Teach the foal but little; but what little education it does receive should be so thorough that it will be retained through life. Young colts are nervous; endeavor to strengthen their nerves by implanting confidence, which tends to allay nervousness.

Much space has been given to the brood-mare and her offspring, because these are the foundations upon which success or failure rests. But it will be necessary to add something by way of suggestion as to the business of breeding horses, selecting breeds to suit 
environment and use, and how to dovetail the breeding and rearing of a few colts with the manifold activities of a diversified agriculture, carried on in a diversified climate on radically different soils.

\section{SUGGESTIONS FOR THE BEGINNER}

A clearly defined plan of what is desired to accomplish should first be made. To do this, a good knowledge of the horse and horse-breeding should be secured from all available sources. Breeding establishments should be visited, and the successes and failures noted. The beginner should become acquainted with successful and distinguished horse-breeders, - in fact, become a pupil for a few hours or a few days, of those men who, above all others, are able to teach. All of this preparation and more is desirable, even if but a few colts are to be bred yearly on the farm devoted to mixed husbandry.

It should be clearly kept in mind that, from this time on, none but superior horses will sell at remunerative prices. The man who is able prefers his own carriage to the street-car; but everybody prefers the street-car to a carriage drawn by a "lame, woolly horse." Do the best we can, there will always be enough mistakes in horse-breeding to supply the demand for cheap hack-about animals. I doubt if the market will ever be overstocked with superior animals - roadsters, coach-, saddle- and draft-horses.

For all except the few professional horse-breeders, who should confine themselves to the production of 
thoroughbreds, full-bloods and standard-bred animals, - the following suggestions may be of value:

Care should be taken to select the breed which best suits the farm, the local markets and the tastes of the breeder. Roadsters naturally belong on land devoted to grass and the dairy industry. Here but little plowing and other hard work will be required, and the necessity of reaching the market town, the station or the creamery, daily, indicates that a light, quickmoving horse, especially if the country is rolling, would be best.

The coach-horse may well be bred on farms which require a somewhat larger horse than the dairy farm, but not so large as the grain farm. Coachers are well adapted to the fruit farm, with one exception, - they are too tall to be used to the best advantage in the tillage of orchards.

Farms devoted largely to grain-raising, unless the land is light in character, call for heavy horses. Here the draft-horse finds his true place while he is acquiring age and solidity before he reaches his final destination - the busy city. Mature horses are for the city, young horses for the farm.

The blood-horse is not well adapted to farm labor. Few of them are required; therefore, the farmer carrying on several lines of activity should not attempt to breed this high-mettled horse, even if he is beautiful.

The rearing of horses for the purpose of securing the highest class of animals - those which are to be used largely for recreation - should always be in the hands of a comparatively few skilled horsemen. If the 
farmer engaged in many enterprises has use for a wellbred roadster, or one with a long line of distinguished ancestors, he will find it cheaper in the end to purchase such a horse than to attempt to breed and rear it.

Should the farmer engaged in a more or less mixed agriculture attempt to breed and raise horses? Should many of the dairymen part with a few of the poorer cows and in time breed colts to take their places in the stalls? Would it be wise for most grain farmers to replenish their work-stock and have one or more spans of horses to sell each year? To all these questions the answer is emphatically, yes. Some farmer's appear to have but one idea, viz, that the town or city is the place to buy things, even horses; when cities and vil. lages should be looked upon by the farmer as places to sell things, and to buy only what cannot well be produced at home.

It is said that the horse is to be supplanted by mechanical contrivances, which will take his place in the street, the field and for recreation. It is also contended that horses are too expensive, in that they require feed and care when not at work; while the bicycle, the automobile and the street-car require no care when not in use. The last argument may be met with the fact that nearly all classes of machinery and appliances rust out and depreciate when not in use faster than when they are constantly employed.

Formerly, horses were used extensively during the winter months. Cord-wood, logs and various obstructions to tillage had to be removed. They were also 
used extensively for freighting and for travel. All these primitive conditions are passing away and most of the farm-horses are now idle for nearly half of the year. To economize, they are kept on coarse and innutritious foods and have little or no exereise. All this results in soft muscles, weakened vitality, soft and distorted feet; and in all ways the horse becomes, during the winter, more or less incapacitated for the difficult spring work. Can these conditions be improved? I think they can; and the following somewhat specific directions, if carried out, will, it is believed, materially increase profits and better conditions.

Brood-mares should be kept on the farms to a much greater extent than they are, and fewer mares should go to the eity. None but mature horses of not less than six to seven years of age should be used on pavements; while the brood-mares and the young animals, with their immature and soft bones and muscles, find a congenial home in the green pastures and on the soft, moist earth of the plowed field.

We believe that the breeding and rearing of horses by farmers who are engaged in mixed farming, where three or more farm- and driving-animals are kept for each one hundred acres of land, can be made profitable. It costs about fifteen to twenty-five dollars more to breed and rear a colt up to the age of three years than it does to rear a heifer to the same age. The colt may sell for seventy-five to one hundred dollars, while the heifer, unless she be pure and highly bred, may bring thirty-five dollars. The farmer whose time is 
occupied in carrying on several lines of activity, such as grain, fruit and berry industries, would better not attempt to breed the larger varieties of pure-blooded animals. For him the breeding of grade cattle, sheep and horses is likely to be more remunerative than the purchasing of them when wanted, or the breeding of pure animals, which necessitates large expenditures for foundation stock. Most farmers would better master the art of successful live-stock breeding by the production of grades. If eminently successful in this, it is easy to change to the breeding of pure-blooded animals when the principles and practices of breeding are mastered. The breeding of superior grades presupposes that the dams are selected with a specific purpose in view, and that their sires are pure-blooded animals selected from the stables of those whose chief business is to breed and rear superior pure-blooded animals endowed with strong, specialized characteristics. It is no uncommon thing to see horses with draft bodies and roadster limbs and feet, or with these characteristics reversed. Some have large, ill-shaped heads and legs and beefy shoulders, with the trotter's loins and hindquarters. Too often, the feet and limbs are not well adapted to the body-weight or the work which the horses are called on to do. In pioneer days, oxen were largely used for farm work; but, when the forests were cleared away and the country lad had outgrown his homespun suit, he longed for more rapid transit than could be secured even from his yoke of frisky steers.

As yet the true draft-horse was not thought of. 
The desire was to secure a quick-moving, pleasuregiving, saddle- and road-horse. In New England, the Morgan horse came to supply a long-felt want of bright farm boys. But the fitness of the horse of that period for agricultural work was not entirely lost sight of. The boys were looking for a horse that could outtrot, out-run, out-jump any other horse, and could pull anything that had one end loose. The Morgan horse came nearer to fulfilling these requirements than any other horse of that period. In most sections of the country there were few well-bred, prepotent horses, like the Norgans, for improving the nondescript farmhorse. It is only within the last part of the nineteenth century that an intelligent grasp of the fundamental principles of breeding has been secured by a few; and a fairly clear comprehension of the reproduction and improvement of domestic animals has not yet been secured by the great majority of breeders, although many farmers are breeders of horses. The lack of adequate knowledge of the principles which shonld govern in the breeding and rearing of horses is apparent in the multitude of unsymmetrical, inefficient horses seen alike in country and city. Had not progressive, far-seeing horsemen imported numbers of the best animals of Europe, the horses of America would be more inferior than they are-perhaps as poor as are those of China.

It is only in the last decade that the farm-boy has had any opportunity for securing instruction in the science of breeding good horses. As ret, but few have availed themselves of even the meager provisions which 
are offered. The wonder is that the horses are as good as they are. The native ability of the American boy, the abundance of suitable food and a propitious climate have done much to arrest deterioration of the horse when in the hands of careless owners.

In some localities, the combined influences of food, climate and skill of the breeder, have improved the horses, without the aid of a liberal admixture of imported animals of acknowledged superior qualities. Under the best conditions, many superior horses have been bred from animals of mixed blood,-that is, from those whose ancestry may be traced to several breeds or to no breed. While this careless mating of animals of quite different characteristics is not to be recommended, yet it must be said that many fine horses have been produced by this effort to breed a general-purpose horse. In older countries, the various breeds of horses are soon adjusted to the localities and conditions best suited to their specialized qualities. In a new country, like America, too often the heavy horse is found in the rough dairy districts and the light one on the tenacious, heavy-clay grain farms. In time, horses will be bred not only for special purposes but to suit the climate, soil and local conditions. True, no hard-and-fast lines can be drawn, but the time will come when the light roadster will find no place on the heavy grain lands, nor will the draft animals be used for carriage and road work.

During the last twenty-five years, the increasing heavy traffic of our numerous cities and villages has demanded more and heavier horses than were formerly 
required. This demand has been met by the importation and breeding of large numbers of Clydesdales and Percherons and a few others of less-known draftbreeds from Europe and Canada. The growing commercial cities of the West, especially Chicago, have also furnished a good and increasing demand for heavy horses, until within the last few years. The breeders of Illinois responded quickly, and for a time this single commonwealth contained nearly onetenth of all of the horses of the United States. Notwithstanding the large numbers bred and imported, prices for good horses remained steady and remunerative for a long time. Recently, the great production of horses on the prairies and the introduction of electricity and steam-power, both being utilized for the transportation of goods and passengers, have resulted in checking the demand and in lowering prices. In extreme cases, horses were sold at ruinous prices or slaughtered from humanitarian reasons. In some cases the slaughtered animals were packed and marketed for food.

At the present time, the demand has overtaken the supply, and good horses, bred for special purposes, again bring remunerative prices. In the future, not so many horses per thousand inhabitants will be required as formerly, but there will always be a large place in America for the horse. Nothing can drive him from the streets of the city or the fields of the rural districts. But, from this on, purchasers will be more eritical than formerly, and hence a better class of horses and those of specialized characteristics will be demanded. 
Something of the history of the horse and the conditions in America which have tended to produce large numbers of varied characteristics have been discussed. It is ascertained that no native horses were found on the continent and that a large number of horses of varied qualities have been imported; that these have been bred, in many cases, with little care and judgment. As might have been predicted, our horses at the present time have many characteristics. Few of them are homogeneous, - that is, little care has been taken until recently to breed for special purposes and for uniform characteristics; hence, most of the horses are not likely to produce uniform offspring when bred together. However, when coupled with pure-bred and full-blood horses more uniform characteristics are likely to appear. There are some compensations for this unstable blood, for it can be easily molded and directed into well-defined lines by the admixture of well-bred horses of prepotent qualities. Happily, we already have large numbers of most excellent thoroughbred and full-blood sires. From these, selections can easily be made. It will not be necessary to import large numbers of foreign horses, to secure those worthy of a place at the head of the breeding establishments.

In selecting a stallion, the beginner should be careful and not be led astray by a fragmentary pedigree with one or two high-sounding names, five or six generations removed. Sometimes the name of a noted horse, as Flying Childers, appears at the end of a pedigree. The blood of a noted horse is supposed to impart great value to the animal whose pedigree in the fourth or fifth 
generation groes back to one or two more or less noted ancestors. If the distinguished blood has not been fortified by some inbreeding, by the tenth generation the offspring would contain but one part of the distinguished blood to 1,023 parts of blood from other sources. Surely, but few valuable qualities of a single remote distinguished ancestor would be likely to appear in the offspring. It is not wise to lay too much stress on the value of the blood of remote ancestors, which has been diluted many times. The improvement of the horse, where he has been improved, has been due largely to three principal causes: improved food, better environment and more rational use and training, and the infusion of new and better blood.

A man who wished to stint his mare was asked if he wanted to inspect the stallion. "No," he said, "I have inspected his colts." So the beginner should inspect the get of a horse, if possible, before he patronizes him. 


\section{CHAPTER XV}

\section{JUDGING HORSES}

THE purchaser should know something of the ancestors of the animal under consideration, as a horse may have inherited characteristics and specialized qualities which canuot be discovered until the animal has been used for some time. Only in rare cases has the purchaser an opportunity before buying to drive the horse enough to discover all of its desirable or undesirable qualities, or its probable future development. Therefore, the breedng of the animal, or, in other words, the pedigree, written or unwritten, should be fairly well known, when possible.

The selling of horses gives the owner great opportunity to indulge in exaggerated statements, even to misrepresent and to skilfully conceal defects and the true age of the horse without becoming legally liable. The seller may offer to guarantee the animal to be sound and free from viciors habits; but even then there are usually loopholes left in the guarantee through which the seller may crawl by the aid of a lawyer, if he leave his conscience behind. It is often wise first to investigate the pedigree of the man offering a horse for sale before looking up the history and pedigree of the horse, especially if he has bred and raised the animal under consideration. 
If the animal has passed through many hands, remaining with no owner any considerable length of time, it is safe to conclude that there is some radical fault or blemish which is not easily discoverable. If a horse is purchased of a thoroughly reliable dealer or breeder, it is only fair that something of the price of the animal be considered as representing the reputation of the seller. One can afford to pay more for a purchase from a well-known, reputable horseman than from a stranger.

The horse should be led out of the stable slowly. While this is being done, stand at some little distance in front of the animal. Little defects, such as slight lameness, may be detected if the animal is not excited. Some horsemen make it a practice to excite their horses, even when standing in the stalls, by sharp words and a liberal use of the whip. All this tends to make the horse hold his head high, to forget for the time the pain in an unsound foot or limb, and to appear alert, spirited and beautiful. These little tricks of the trade are sometimes seen at professional horse sales.

In judging horses, four ideas are paramount: ability to perform the service desired, reliability, endurance, and symmetry and beauty of form. True service consists in using energy economically, that it may give satisfaction to the owner, whether the energy be expended in moving heavy loads or in covering the greatest distance in the shortest possible time. Horses, then, should be selected with the view of securing the results desired in the most economical manner. Since they are put to a variety of uses and are placed under 
greatly varying conditions, it follows that they should have widely different characteristics if they perform the different kinds of service satisfactorily. The horse should, therefore, not only be good but also be suited to the service he is called upon to perform. He should be trustworthy, that is, free from vicious habits. Utility is not all, however; beanty in the horse counts for much. Many horses are kept neither for laborious work nor for fast driving. The family horse is the most conspicuous type of this class. A large number of horses besides the true family horse are not called on for either laborions work or for rapid driving. Beauty or symmetry of form in all this class counts for more than either superior strength or speed if they be trustworthy. But what is beauty? On a true roadster a neck with straight or concave top line would be appropriate, and, because appropriate, beantiful; but such a shaped neck on a draft-horse would not only offend the eye but be incongruous. Beauty, then, may, be of two kinds-that which is beantiful because appropriate, and that which exhibits the blending of forms or lines or colors so harmoniously that the thought of abstract beauty is emphasized above the idea of mere utility. So the horse may be valued for the highest beauty consistent with greatest usefulness, or for attractiveness in form, color and action. Fortunately, beautiful, useful and appropriate qualities may be combined to a large degree in a single animal; becanse, where all parts of the horse are symmetrical and adjusted to serve in the best manner the purposes for which the horse is maintained, many lines of beauty 
will necessarily be present. A good draft-horse may be beautiful, though not so beantiful as a Kentucky saddle-horse.

Advancing civilization demands not only a useful, but a beautiful horse, and the breeder is wise who now pays much attention to the quality of beauty, even if the horses he is raising are designed to do laborious work. The color of the hair and its texture, as well as symmetry and temper (for a horse may have a "beautiful" temper), may add to or detract from the beauty of the animal and its value and selling price, whether draft-horse or roadster. All that has been said is to emphasize the need of producing in the future not only better, but more beautiful horses.

The colors of horses may be either beautiful or striking. The calico, or piebald horses, when seen on the street or under a circus tent, certainly attract attention; but persons of good taste usually select horses of solid colors. Only in rare cases are unusual colors preferred, and then for the purpose of advertising or attracting business, or for the delectation of children. Bright bay, seal-brown and dark chestnut are the colors preferred, because they are not only beautiful but usually do not fade in hot weather. Horses of these colors are more easily kept presentable than light-colored ones, and in old age their coats do not become unsightly,that is stained, "flea-bitten" or rusty. Black horses seldom retain the full brilliancy of their coat; when exposed to the sun, the black often changes to a dirty, unsightly brown. It is believed that darkish skin, hair and hoofs have the power to resist some of the skin, 
leg and hoof troubles to a greater degree than those of light colors. Many think that dark-colored animals, like brown men, are able to withstand adverse conditions better than those of light color. Be this as it may, it is safest to select animals of strong colors with dark points.

The size of the horse is sometimes an important factor in determining price, or rather the amount which can be realized for him. Large horses, other things being equal, usually command a higher price than those of medium size, and those of medium size more than small ones. But the largest types of horses, be they draft, coach or roadster, are more difficult to produce, and when produced are more in danger of becoming unsound than medium-sized ones. As these pages are for the farmer, and not for the professional breeder, the advice is not to attempt to produce monstrosities or even the largest types of any class of domesticated animals. Good profits are seldom secured by rearing horses which weigh a ton, or cows which tip the scales at sixteen hundred pounds, or pigs which weigh half as much as horses do. One escapes a multitude of disappointments by holding on to a little good "horse-sense."

It might be thought that judging and selecting horses would be an easy task, since, unlike the cow and sheep, the horse is prized largely for his stored energy; but the conditions under which he must exert his powers are so varied; the first cost and the keep of a horse are so great; he is so liable to become unsound, so utterly useless when incapacitated for work, so disappointing if bad tempered or without 
temper; that the judging of horses becomes exceedingly difficult. It seems that some directions "as to how one may be least cheated when purchasing a horse" should be given.

Horses naturally fall into a few groups. The drafthorse of laborious work, the coacher, the roadster, the runner (thoroughbred), the saddle-horse and the children's horse or pony. Some of these groups overlap each other, and, while a good roadster or thoroughbred may make a tolerable saddle-horse, they cannot be first-class in their own group and also first-class in another group. There is still another class of horses, which does not belong to any group. They are nondescripts, that is a mixture of unknown blood or mixed blood in unknown quantities; careless breeding seldom produces valuable animals. An animal with no marked or striking characteristics in any direction never attracts a good horseman.

In judging a horse, one should first classify himthat is, think of him as belonging to some one of the groups; for an animal may be good if used for one purpose and very poor if used for another. However, there are some characteristics which all horses should have in common; therefore our first discussion may be along general lines.

It is desirable that all horses should have good eyes, sound limbs and feet, good temper, and be free from serious blemishes and vicious habits.

It is far easier to detect some blemishes and some objectionable traits if the animal be examined when he is quiet. First notice the horse in the stable. If 
he stands with one front foot at ease, that is, pointed to the front, he is unsound somewhere in his front limbs or shoulders, or in both.

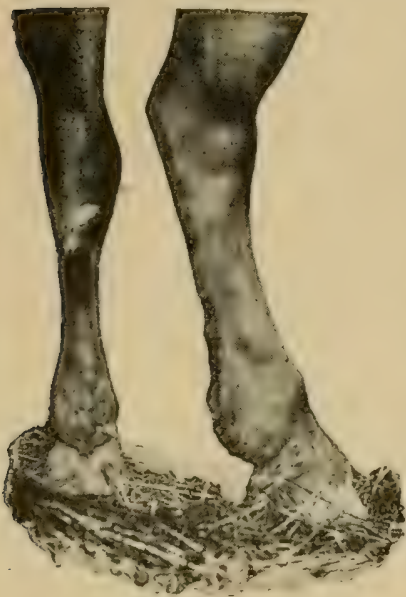

Fig. 51. Cow hocked. Sound horses invariably stand with their front feet in such positions that the weight will be borne equally, or nearly so, on both feet. Not so with the hind limbs; for a horse often stands with nearly all his posterior weight thrown on one leg while resting the other, and, while he may be unsound, such habit is usually not proof of it. A horse may be sound and yet be so awkwardly put together as to greatly reduce value and price.

The purchaser, after having examined the horse in the stable, should have him led out quietly into an open space. Here the eyes should be critically examined. If the sunlight is bright, the hat may be held above the eye to cut off the dazzling rays of the sun while the eye is being observed. It is usual to wave the hand in front of the eye as an additional test; but the rapid movement of air in front of the

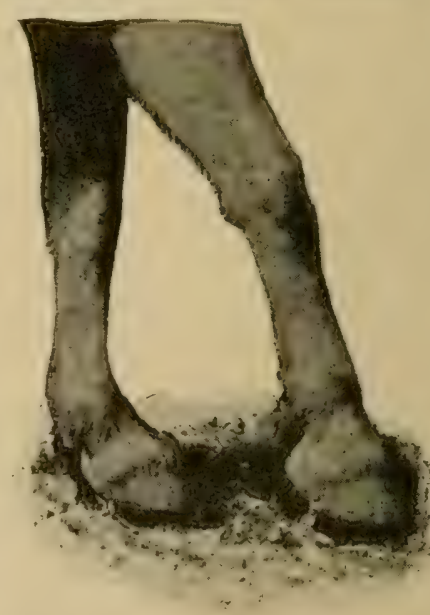

FIG.52. A pointer. hand may cause even a blind horse to wink. A better method is to approach the eye with the hand, in a nearly 
horizontal position, and with all the fingers, except the index finger, closed.

Before proceeding farther, it may be stated that defects and blemishes should be classified as major and minor. Many little imperfections are to be found in even the best of horses, but these may not seriously reduce values or usefulness. The ear may be a shade too large, the forehead a little too narrow or the nostrils not so thin and open as desired; but these all sink into insignificance beside curby legs, calf hocks and poor feet. A slight thickening of the skin, small round puffs and even more pronounced blemishes may be ignored, if they are not located at dangerous points and have the appearance of being

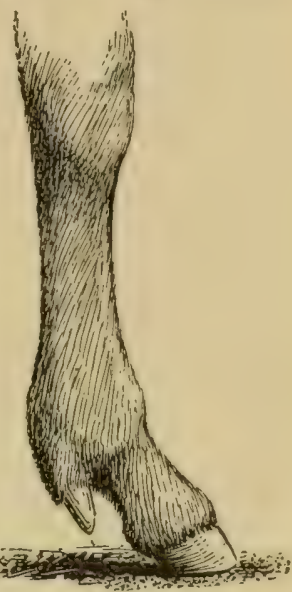

Fig. 53. Reversion to original type. quiescent. While a critical examination of all parts of the holse should be made before purchasing, it is believed that even the boy on the farm will be able to distinguish between major and minor defects, now that attention has been called to them.

Hazel-colored eyes are believed to be better than dark ones. Bright, prominent open eyes are better than those which appear flattish and dull. If the opening for the eye has the appearance of a narrow slit ent bias, the horse is said to be pig-eyed. If, in in addition, the eyes be set too near the butt of the ear and too near together by reason of a narrow forehead, the horse is likely to be an untrustworthy 
"lunkhead." Though technically sound, horses that have the appearance of the photos, Figs. 54 and 55, are to be avoided, as it would be safer to walk than to ride behind them.

The ears and their position on the head may serve to assist in determining the disposition and some other qualities. They should be neither too close nor too far apart, neither lopped nor too sharply pointed backward.

A disproportionately large head is always objectionable, and especially so when found on horses designed for speed

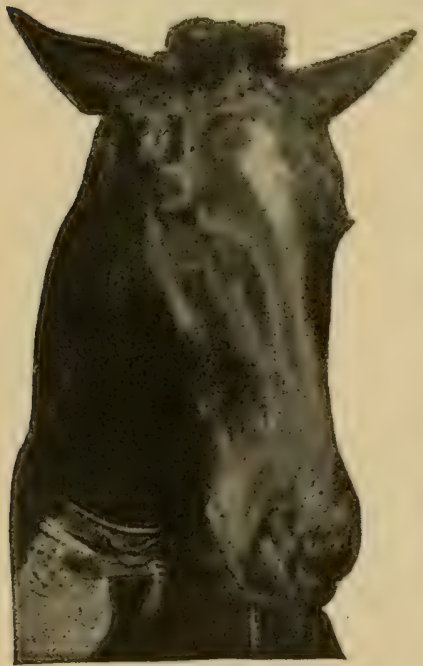

- FIg. 55.

From a photograph. Such ears would condemn any horse.

or for uses where beauty counts for much. The head, as seen from the front, should look

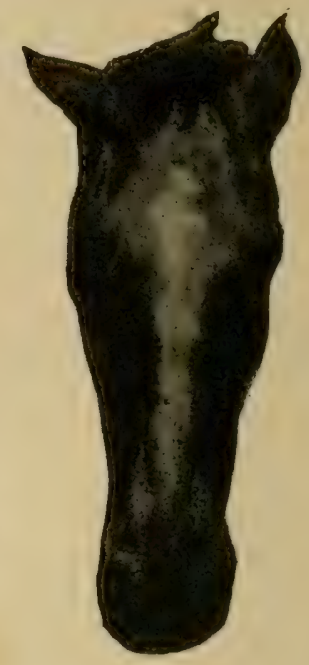

FIG. 54 .

From a photograph. This shows bad hreeding. broad between the eyes, rise rather high at the top between the ears, and have the appearance of being cut away below the eyes and along the nose; that is, the head should be free from flesh, and loose, thick skin, and shouid have a fine-boned framework.

A fine head necessarily implies a flexible ear; bright, alert eyes; open, thin-skinned nostrils, and an under jaw narrow where connected at the lower end. A jaw wide at the upper end gives ample room for the windpipe. 
Next, the horse should be viewed frou the side. The symmetry, general outlines, length of limbs, their setting on, their curvatures, length and appearance of the middle and the harmony or lack of harmony of each part with the other, may be discovered best from

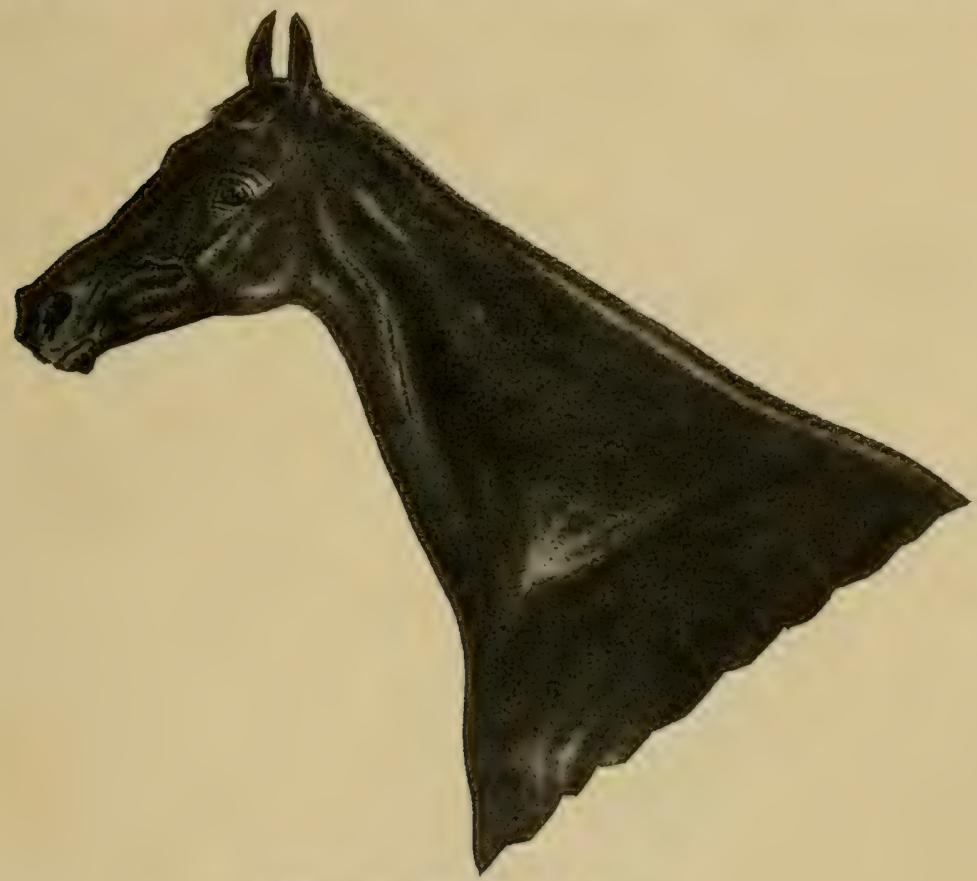

FIG. 56. Goldsmith Maid.

this position. From the front and side views correct general impressions may be secured. These, supplemented by a eritical inspection of each part, should result in a good understanding of the make-up of the horse, his value and adaptation to the uses contemplated.

If the neck be thin vertically at the setting on of the head, the animal should be a pleasanter and safer 
driver than if the neck at the throat-latch be thick. The head should not be set on to the neck of the animal like that of a pig, or the animal will be likely to "hog the bit," that is, take the bit in his teeth, thrust his nose straight out ahead, and be as unman-

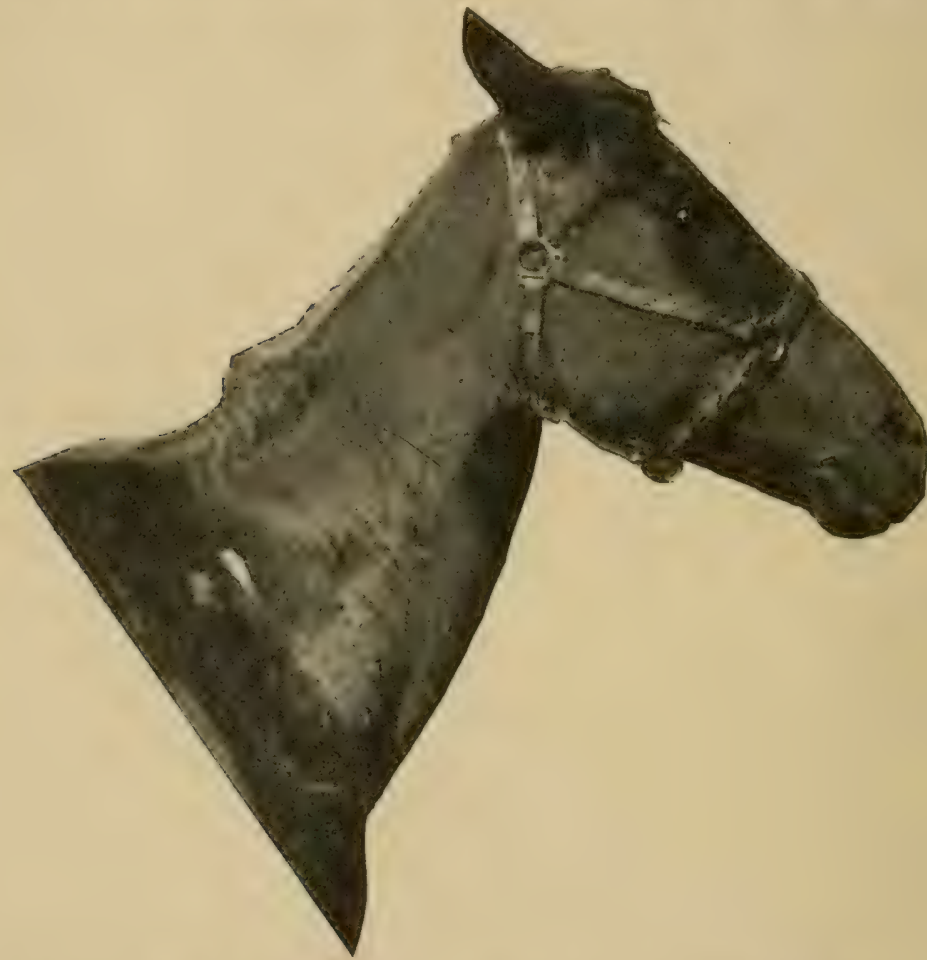

FIG. 57. From a photograph. Beauty of form counts for much.

Who could admire such a neck and head?

ageable and as contrary as the animal whose neck is of the same style. If the horse is designed for fast work, his neek should be thin and rather light, with little or no crest.

Beauty of form counts for so much that, in most cases, the ewe-neck should be avoided. For most pur- 
poses, the neck should be a trifle long, but all-embracing where it joins the body. It should be set on the body at an angle of about thirty degrees above the horizontal; or, as the horsemen would say, on the corner, and not on the end of the body. The allembracing neck, well set on, is not only beautiful but is indicative of strength, vigor and endurance. The above thought should be somewhat modified when the pony and the draft-horse are considered. The word pony usually implies a short, compact, small animal, and of necessity this build requires a rather plain, short neck. A good draft-horse may be said to be an enlarged, modified pony. Some of the better breeds of

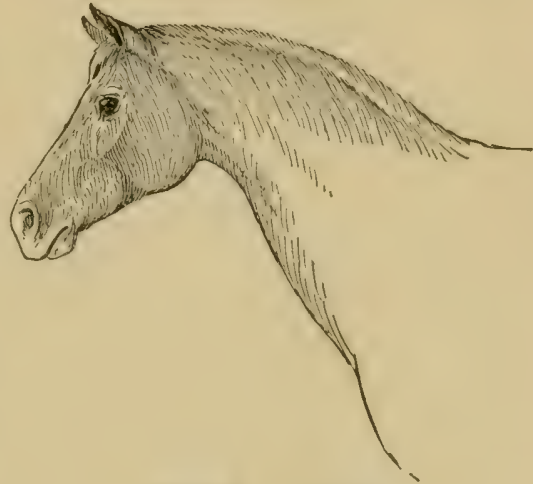

Fig. 58. Hassan. An all-embracing neck. draft-horses show unmistakable signs of having had some admixture (probably mostly through their dams) of the warm blood of the east, which blood has done much to give symmetry of form and courage to many varieties of horses. If the shoulders of the drafthorse be too oblique, as they sometimes are, the collar tends to rise under great pressure, and this may result in seriously obstructing free respiration.

The hollow or protruding breast, the bend of the back, the length of bottom and top body lines, the length and slope of the hind quarters, the curby leg, the thorough-pin, the length and direction of the legs 
between the fetlock joint and the hoof, can all be seen easily from the side when the horse is viewed by the trained eye. If in this general inspection the horse is not condemned for the purposes desired, a more critical inspection should next be made of the legs and feet. By bending down while standing in front of the horse, one may see clearly the contour of the inside of all the legs. Splints, spavins, wind-galls, ring- and sidebones, if of any considerable size, are immediately discovered. In this position comparison is easy, since, if one limb is enlarged at any point, the other serves to call attention to it. Only in rare cases is more than one limb affected in the same way and to the same extent. Not infrequently a blemish may be incipient and slight, and hence likely to escape detection; therefore the limb should be examined by passing the hands downward over two legs at a time, pressing hard and keeping the hands opposite to each other. A blemish which could not be seen may be discovered by the sense of touch. A horse may pass all of these examinations successfully and yet be unsound; therefore, if any doubt remains, other tests should be made. Standing in front of the horse, force him to move backward slowly and quietly. If he picks up his forefeet and steps backward without dragging the toe of the foot, he may be pronounced sound in the shoulders; but if the foot, instead of being lifted fairly clear of the floor, is moved back with a dragging motion, the horse is not normal. (For practice, observe a horse when backed that is known to be unsound.)

If not fully satisfied with the inspection already 
made, force the horse back by the bits and then turn him to the right or left quickly. This will throw extra weight on the rear legs, and the twisting motion given to them by the turning will cause the animal to flinch in case of an incipient spavin.

The feet should be observed with the greatest care, keeping in mind the work the horse will be called on to perform. Feet which might not be seriously objectionable if the horse is to be used at slow work in the soft fields might be totally unsuited to fast work on pavements.

Horses which have a strong infusion of warm blood frequently have naturally erect hoofs and rather high heels. If this feature of the hoof be accentuated by bad shoeing and previous fast road work, the foot may be in langer of becoming so contracted as to produce lameness, although the foot at the time of the examination appears normal. On the other hand, feet may be so flat and open at the heel and the shell of the hoof so weak as to endanger the usefulness of the horse, and yet be technically sound. This class of feet is most often found on horses of the draft type. There is a happy medium between feet which are too narrow at the heel and too erect and those which are too open at the heel, too flat and deficient in bony structure. The open flat foot often becomes injured by the frog coming into too violent and intimate contact with hard earth and stones, while the narrowheeled foot is more likely to be associated with navicular troubles. 


\section{\&.}

THE HORSE'S TEETH

So far nothing has been said about determining the age of horses. A discussion of this subject has been purposely deferred until the limbs, and particularly the feet, have been examined. If these indicate that, in general, the bony struture is softish and of open texture, then it may be concluded that the teeth are of the same general character. The teeth rif horses which have bones of somewhat open structure are likely to indicate that they are slightly older than they really are; while the teeth of horses whose bones, as indicated by legs and hoofs, are of fine and close texture may indicate them to be younger than they really are. All this applies to horses which hare passed their eighth year, there being certain characteristics and changes in the teeth up to about the eighth year by which the age within a few months may be accurately determined. After the horse has passed the eighth year, it is sometimes difficult, to determine his true age by the teeth. Experts may come within a year or two of it until the horse becomes quite aged, when he may be said to be sixteen past or eighteen past, and the like; but how much past may not certainly be known from the appearance of his teeth. The texture of the bone, the breeding, the kind of food the horse has eaten, and other conditions, have more or less influence on the teeth; therefore in the old horse the teeth serve to indicate age only in a general way.

The horse when full-grown has forty teeth- 
incisors $\frac{6}{6}$, canines (incipient in the females), $\frac{2}{2}$, molar's $\frac{6}{6}, \frac{6}{6}=\frac{20}{20}=40$. As the incisor teeth only are usually inspected when the age of the horse is to be determined, they alone will be discussed here. The colt is provided, before the end of the first year, with twelve temporary incisor or milk-teeth. The difference in size of the jaw-bone of the foal and the horse makes a change from milk to permanent teeth necessary.

Usually from one to two weeks after the foal is born, two center nippers in each jaw are plainly visible and appear as shown in Fig. 59. It will be noticed that these teeth are long from right to left and have well-defined cups, or "marks," and that they show little or no wear. These characteristics should be noted carefully, for all temporary and permanent teeth when new have pronounced distinguishing marks. If the age of the colt and horse is to be determined with any degree of accuracy, not only the number but the shape,

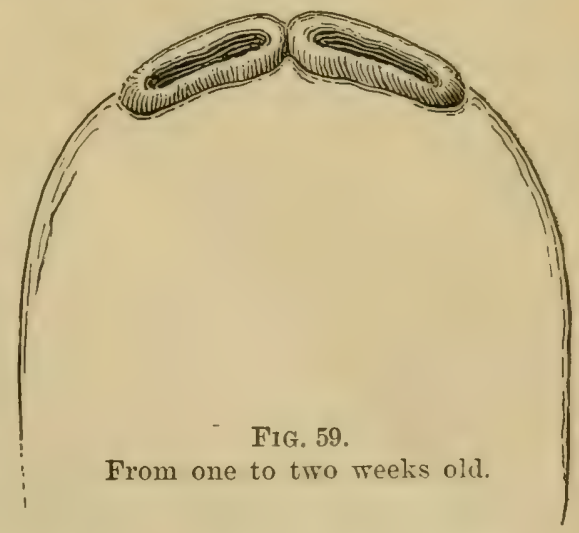
character and various changes, as the teeth progress in age, should be most carefully noted.

At from four to six weeks of age, by reason of use the first pairs of nippers will have been worn down level, that is, the inside of the teeth will show level with the outside. The outside edges of new teeth are 
always more forward than the inside edges. It should also be noted that these new teeth are fully twice as long laterally as they are thick. In Fig. 60 are shown the lower nippers when the colt is from four to six weeks of age. The central pair of nippers shows wear and the lateral pair is through, but the inside and the posterior corners are not fully up and show clearly that they have not been in wear. The per-

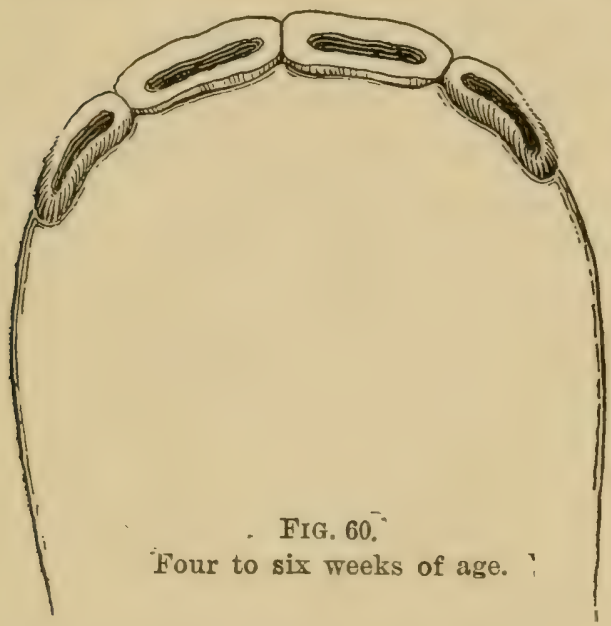
manent teeth show the s a m e characteristics when new; that is, the inside and the posterior corners do not come up nor come in wear as soon as do the outside and the anterior corners. Note that the cups, or marks, in the central pair are not quite so deep nor so long as they were when coming into wear, as shown in Fig. 59.

When the colt reaches eight to ten months of age, the teeth will appear as shown in Fig. 61. The corner nippers are up but not fully in wear on the inside and the posterior corners. The posterior corner's of the last pair of nippers, both in the colt and horse, come up and get in wear more slowly than do the posterior corners of lateral nippers. Note, too, the changes which have taken place in the cups and in the shape of both the central and the lateral nippers. 
It would be well, before proceeding further, to turn to Figs. 74 and 78 and notice how the wear from year to year results in a change of the form of the tooth and, in time, in obliterating the cups, or marks.

Note also the difference in the shape of the root of the permanent tooth, Fig. 74, and the temporary tooth, Fig. 62. The root of the latter is much smaller and shorter than the former. It also has a distinct

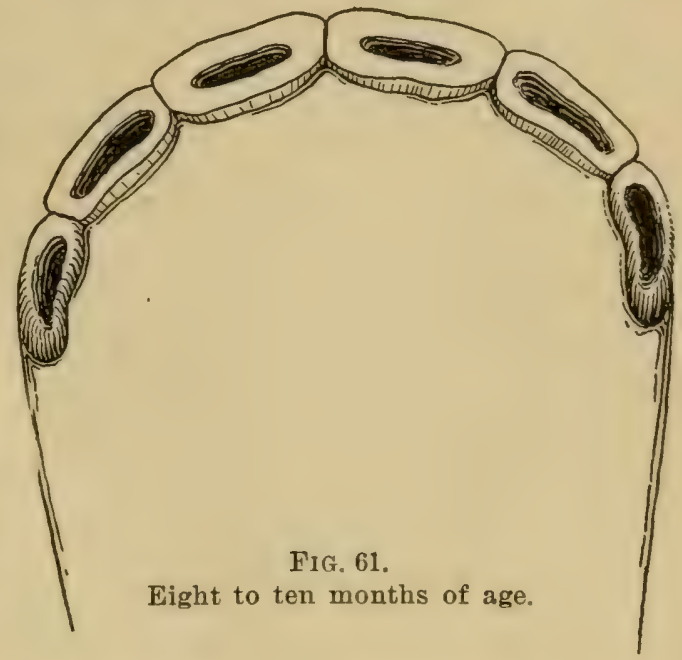
neck, which, however, is not easily discovered at first, as the gums partially cover the neck. As the milk-

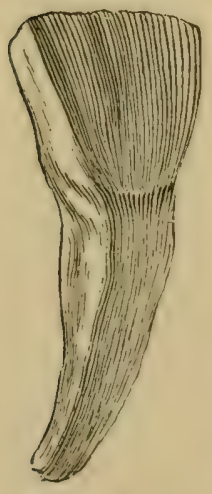

Fig. 62.

A temporary, or milk tooth. tooth approaches three years of age, its roots are absorbed rapidly and the neck is easily discovered. By the time the permanent tooth is ready to appear, the root of the temporary tooth is nearly absorbed and little remains besides that portion which is above the neck. The temporary teeth not only have a distinct neck but are smaller, smoother and lighter colored than the permanent teeth. These differences may assist the beginner in distinguishing the two kinds of teeth and in determining age. 
At the full age of one year, the marks in the central nippers will be much shorter and fainter than they were at first. The lateral nippers will show wear, the marks will be longer and more pronounced than in the central nippers, but they will be shorter and less indented than in the younger corner teeth. All of the nippers will be up and the corner ones will be worn level; that is, their posterior corners will be fully up but not worn quite as much as shown in Fig. 63. It requires some care to determine accurately the age of the colt when it has passed its first year and up to the time the central nippers are

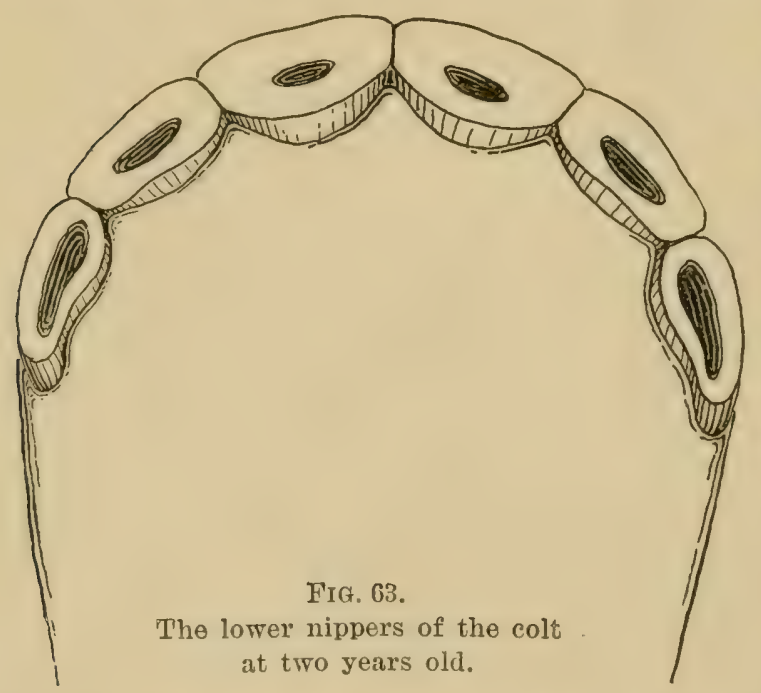
replaced by permanent ones. It may be said, however, that the teeth show wear and have something of the appearance of a six-year-old mouth in miniature; but, with careful inspection, man $\mathrm{y}$ minor d iffer ences can be observed. The teeth are shorter, that is, show less above the gums, are smaller than those of the six-year-old animal and have a distinct neck. They are lighter colored than are those of the horse of six rears of age. If tho teeth of the two-rear-old 
colt (Fig. 63) be compared with those of the one nearly a year old (Fig. 61), it is seen that the cups, "marks," of the central nippers of the two-year-old have nearly or quite disappeared, althongh a little discoloration usually remains in the center of the teeth. There is still a slight mark in the laterals, and the marks in the corner nippers are fairly deep,

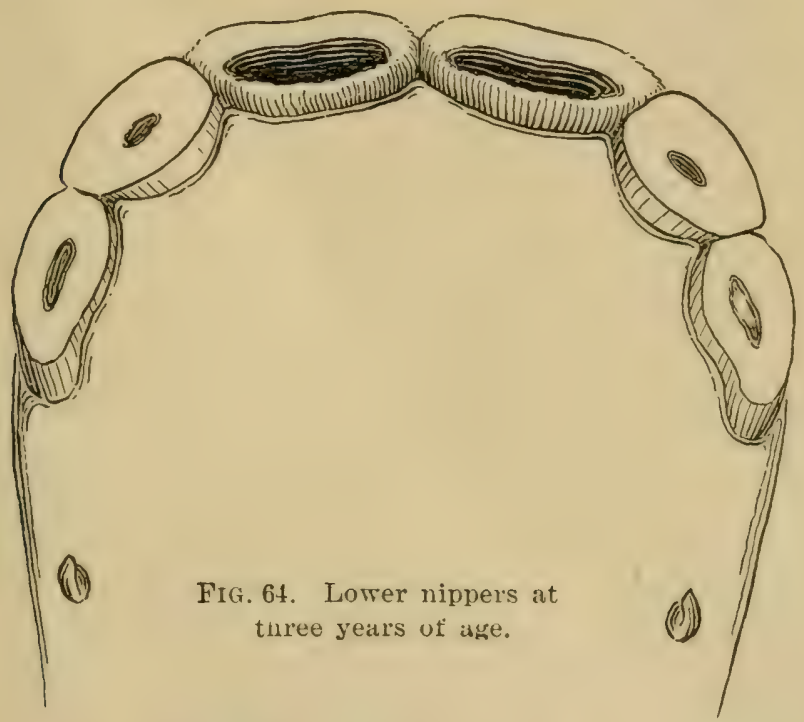

It may be said that they are much deeper in the corner teeth when the colt is but a little past two years than they are when the colt approaches three years of age

When the colt reaches the age of about two rears, nine months, the roots of the central nippers are usually nearly absorbed and the permanent central nippers, if not already in evidence, will soon make their appearance.

When the colt is shedding teeth its mouth should 
be watched and, if the milk-teeth have not disappeared when the permanent ones have pushed through, they should be removed, as they only serve to irritate the gums and to prevent the animal from consuming the

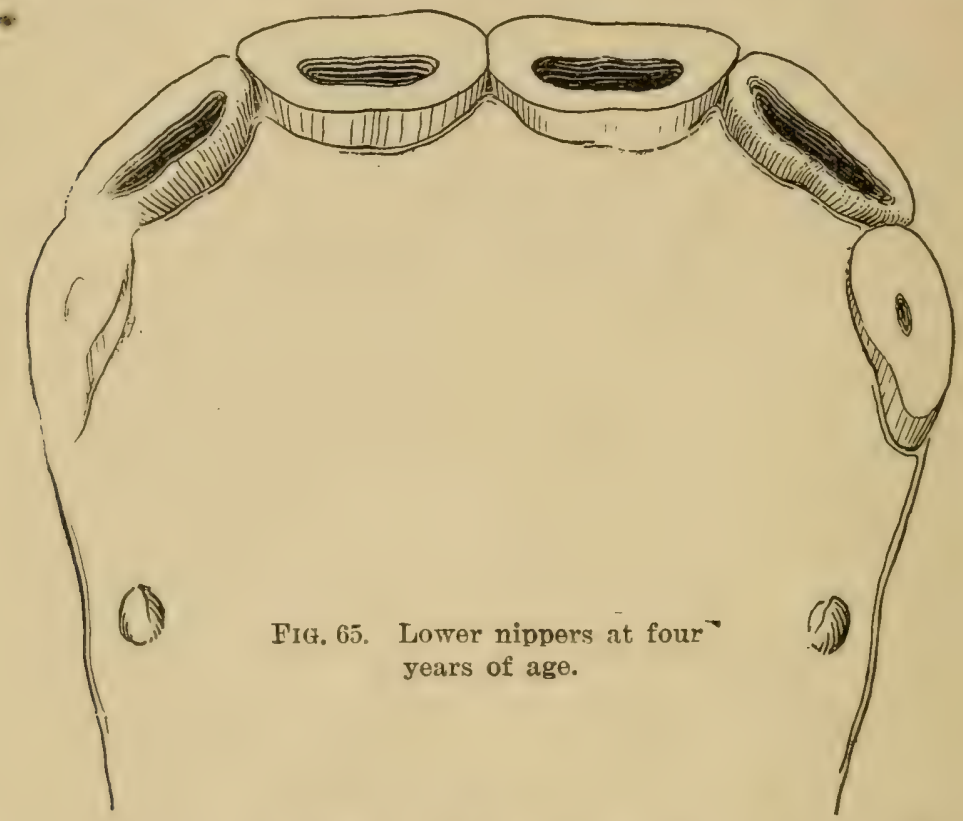

usual amount of feed. A little extra feed and care should be given the colt while it is substituting permanent for temporary nippers.

At about two years and nine months to two years and eleven months the center permanent nippers will appear, and at full three rears of age the outer portion of the teeth and sometimes the inner also will be up and in wear. (Fig. 64.) These teeth are larger every way than were those which were supplanted. The lateral temporary nippers have changed 
shape and have lost all or nearly all their eups. The slight black indentations can hardly be called cups. The cups in the corner teeth are greatly reduced. If the colt be a male, small tusks are likely to be present or in process of coming through the skin of the jaw.

At about three years, nine months, the permanent lateral nippers appear. At four years of age they are fully up and in wear on the outside and sometimes on the inside. (Fig. 65.) The central nippers show a year's wear, and the cups are not so deep as they were when the colt was three years of age. The cups, or marks, have nearly or quite disappeared from the corner (milk) teeth, often nothing but a slight dark indentation being left. The tusks have enlarged, but are still sharp at their points and flattish on the inside. A side view of a four-year-old mouth is shown in Fig. 66. The crowns of the two temporary, or milk-teeth, one upper and one lower, come together closely over their entire surface, while the two permanent teeth do not yet meet at their posterior corners.

When the colt reaches the age of four years and nine months, the corner nippers make their appearance. When he reaches the full age of five years, the outer Frg. 66. Side view of the teeth anterior portions of these teeth

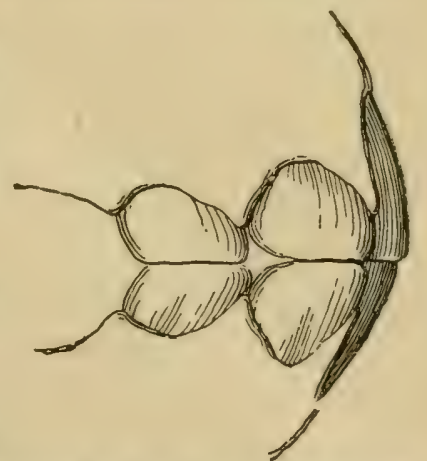
meet. (See side view of a five-year-old mouth, Fig. 68.) Abont one year of wear must take place before the corner teeth are worn level throughout their entire surfaces, - 
the corner teeth when worn off level are one of the distinguishing marks of a six-year-old horse. At five years the central nippers have had two years' wear, and one more will virtually destroy the cups. They are also changing slightly in shape; they have become rounder on the inside and slightly shorter in their longest dimen-

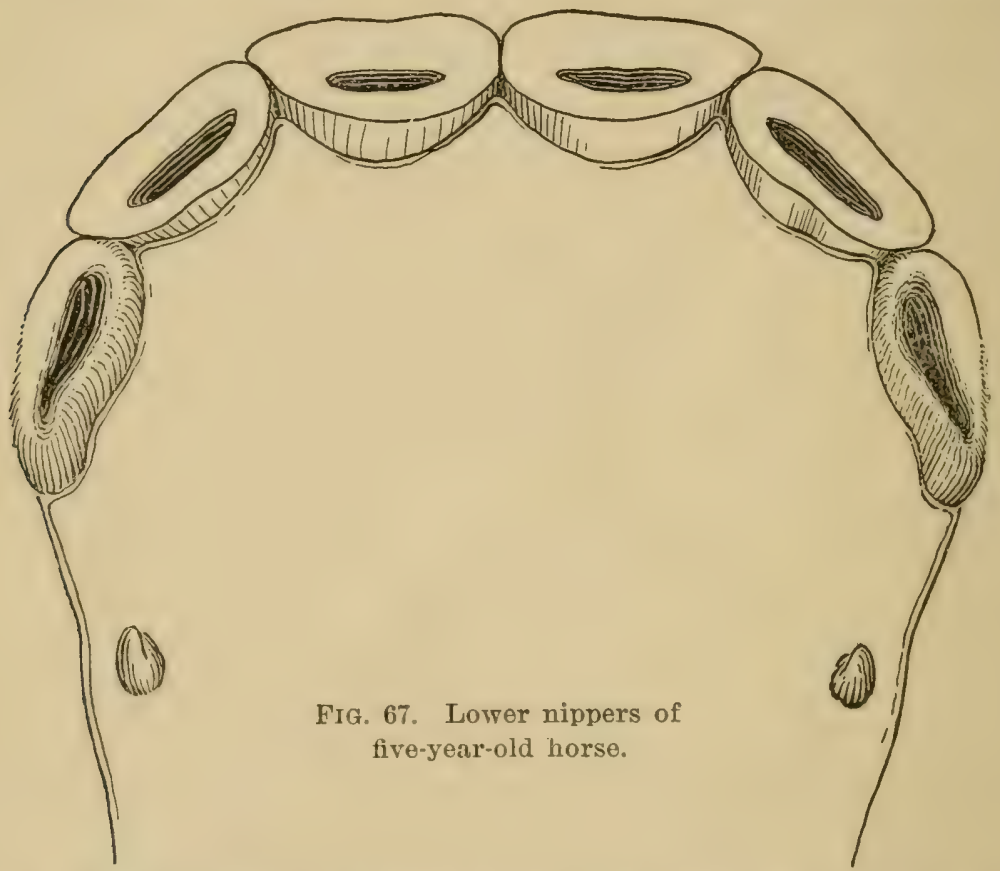

sions. The lateral nippers have also changed. They have been in use nearly one year. In about two years more the cups will have nearly disappeared. The corner teeth are longish from front to rear, and do not show change of form or indications of rounding up on the inside as do the older central nippers. The cups are deep and fresh, the corners are deficient, and in every way they show unmistakably that they are young teeth which 
have been subjected to little wear. The tusks have enlarged, but are not yet blunt, and prominently rounded on the inside, as they will be when the horse approaches his "teens." The permanent teeth are roughish, that is, have slight corrugations, while the temporary teeth are smooth on the outer surfaces:

The colt at five has a "full" mouth, and, with it, his name is changed to that of "horse." The female

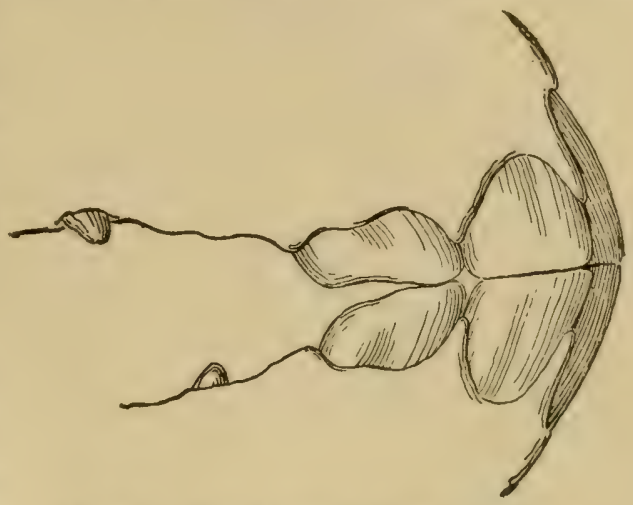

Fig. 68. Side riew of the teeth of a five-year-old horse.

is no longer called a filley, but a mare, and the "entire" horse a stallion.

Sometimes horses have shelly teeth, in which case the inside of the corner teeth may not be up and in wear, in fact may never come up, and always have the appearance of a corner tooth that is not fully up. At rare intervals horses have what is known as "hawlbill" mouths, that is, the upper incisors extend over the under ones; in which case it is difficult to determine the age after the horse has reached his sixth year. However, in horses, malformed teeth are rare.

Fig. 69 shows the teeth of the lower jaw when the horse reaches his sixth year. The marks, or cups, have disappeared, or nearly so, from the front nippers, have become shallower and smaller in the laterals, and the corner teeth are up on the inside and posterior corners. 


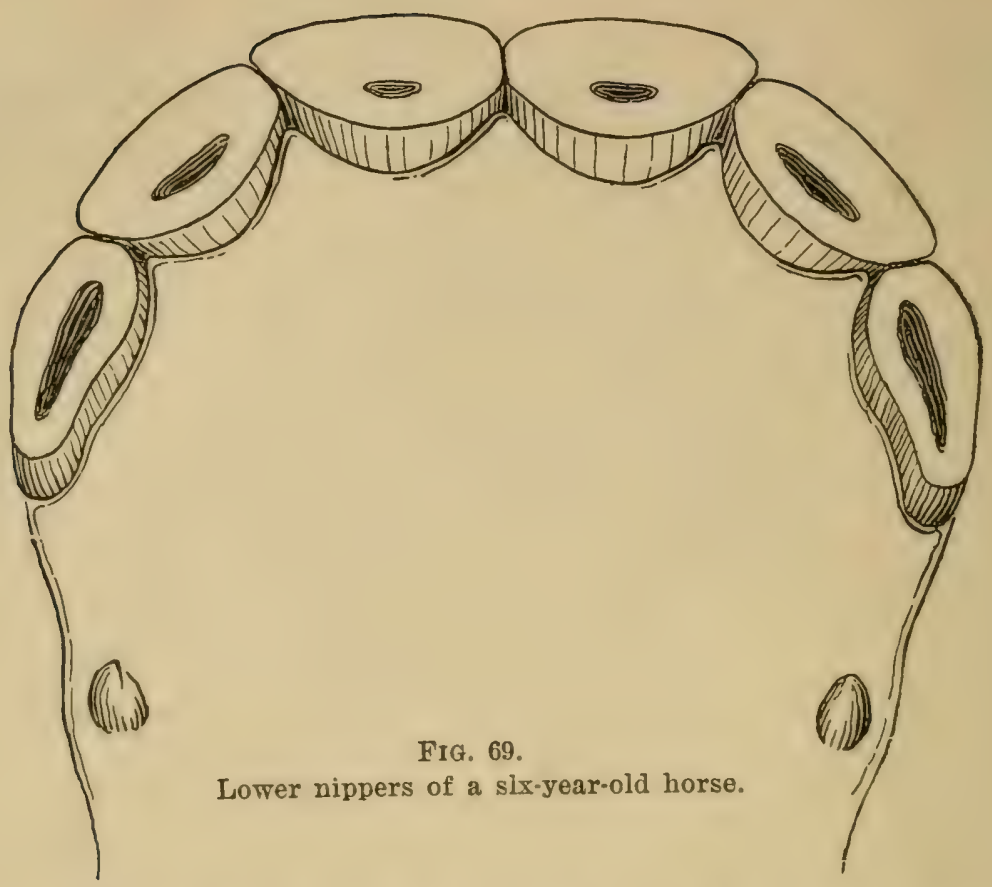

No notches will yet be found in the upper corner incisors. The corner teeth are somewhat smaller than the laterals or the front teeth.

At six years of age, the wearing surfaces of these

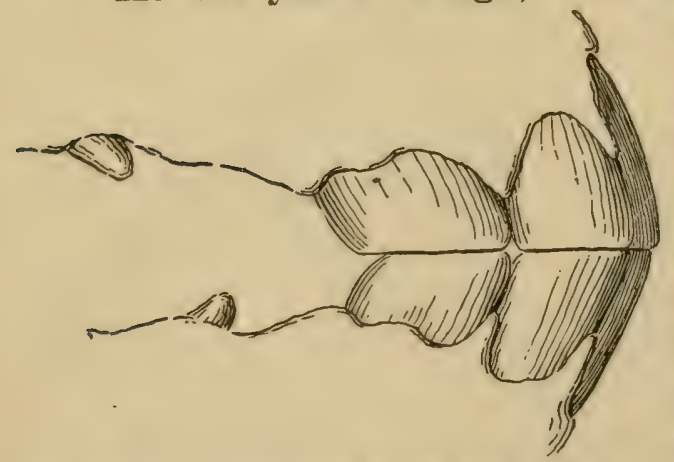

corner teeth come together throughout their entire length. The central teeth have made marked changes in shape,-they are becoming quite roundish on the inside, and the laterals are also somewhat

FIG. 70. Side vier of the teeth of a six-year-old horse. modified, while the 
corner teeth are but slightly changed in general contour. During the year from five to six, the tusks have become slightly larger, rounder and blunter. If the horse's lips be parted, and the mouth viewed from the front, the teeth, especially the central ones, will appear

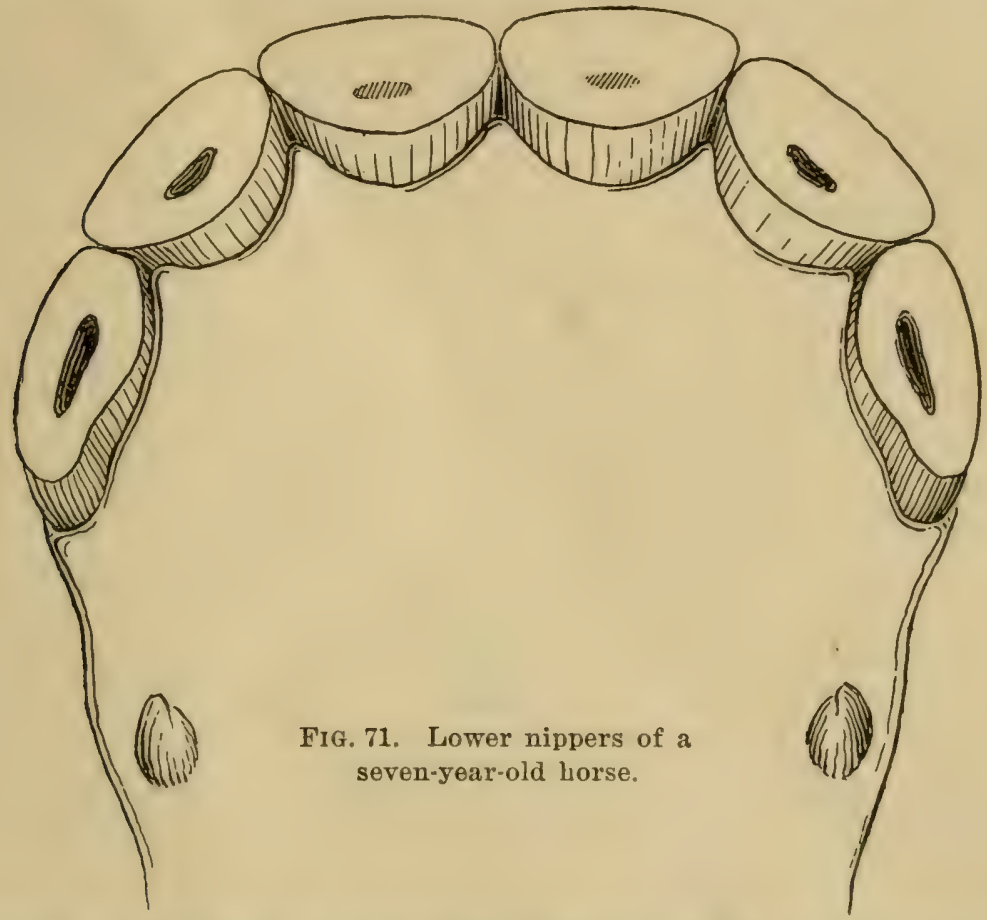

darker colored and longer than they did a year or two years previous, due to shrinking or receding of the gums. Compare Figs. 64, 65, 67.

When the horse reaches seven years of age, the cups have not only disappeared from the central nippers, although small, darkish spots may be seen, but they have nearly or quite disappeared from the laterals as well. The corner teeth still retain the cups, though 
they are shallow, which is evidence that the teeth have been in wear two years, and that in another year the cups will have nearly or quite disappeared. (Fig. 71.) It will be noticed that, from the time when the teeth in the lower jaw are well up and in wear to the time the cups have virtually disanpeared in the lower jaw, is three years. It is well to keep this in mind. The teeth in the upper jaw retain their cups for a longer period.

A side view of a seven-year-old mouth shows one marked characteristic. (Fig. 72.) The lower corner

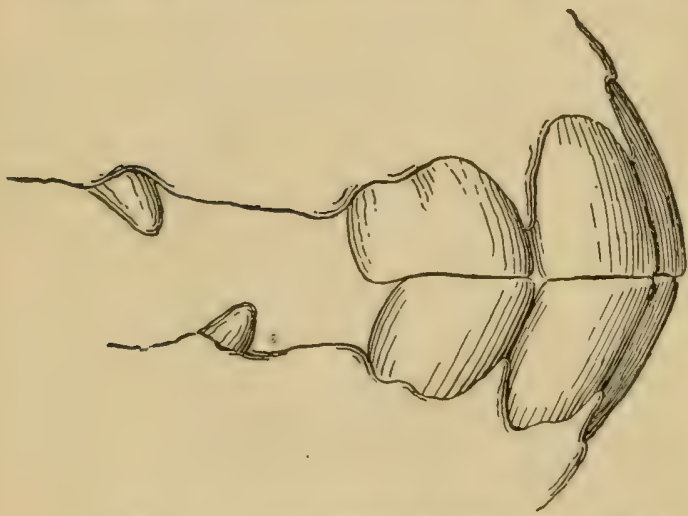

FIG. 72. Side view of the nippers of a seven-year-old horse. teeth seldom extend as far backward as the upper ones do. Only in very rare cases do all of the four corner teeth meet at the corners accurately; in which case the posterior corners of the upper incisors are not worn down level with the rest of the teeth.

The result is, the face of the tooth in wear recedes, while that part of the tooth not in wear projects downward, forming more or less of a "notch." Sometimes no distinct noteh is apparent. However, by close inspection, it can be seen that the face of the upper corner tooth, where it meets the lower one, is not straight, as it was when the horse was six years of age, but slightly concave. If the teeth should chance to meet 
at the corner's more accurately than shown in Fig. 72, then no notch will be formed; nevertheless the upper corner tooth will be slightly concave, though not so marked as shown in the above figure. However, it is seldom that this distinguishing notch is not forming $\mathrm{Ol}^{\circ}$

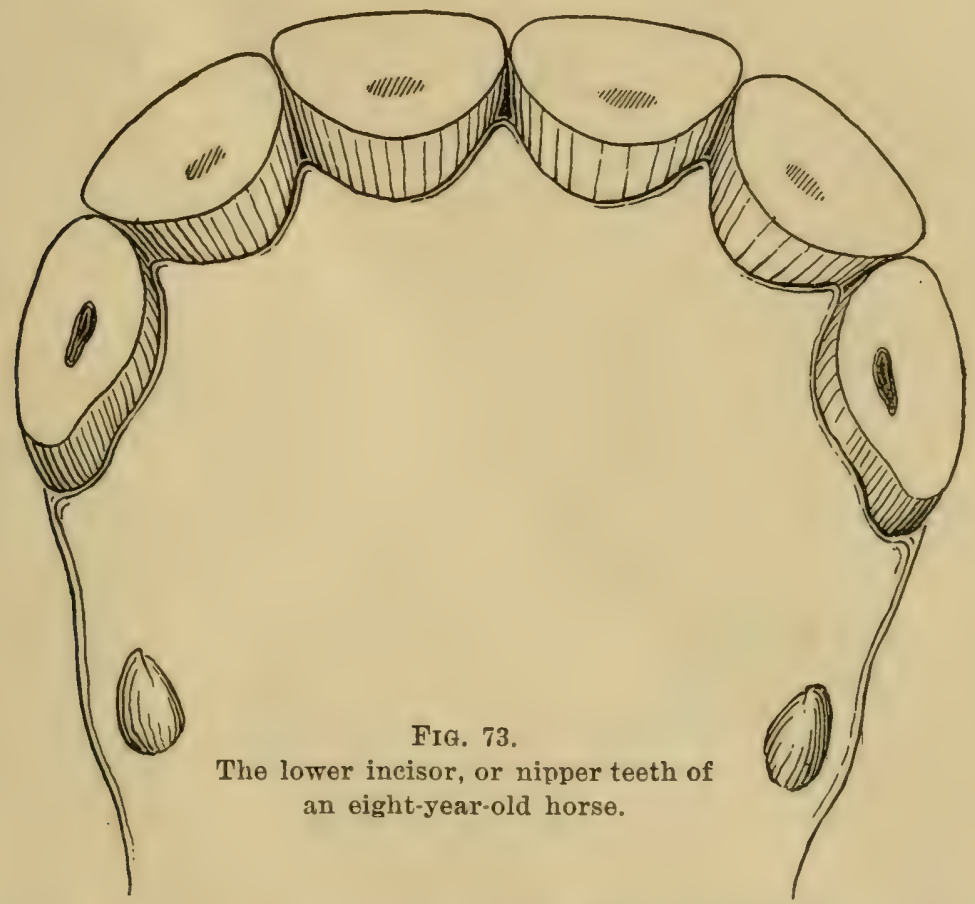

formed on one or the other of the upper corner teeth at the age of seven years.

At eight years of age, the marks or cups have disappeared from the teeth of the lower jaw. However, slight dark-colored indentations are still present in the corner teeth, but they are not pronounced enough to be called cups. (Fig. 73.) The shape of the teeth has 
radically changed. Turn to Fig. 74 , and note the crosssection of a front incisor tooth when it has been in wear five years, - that is, when the horse is eight years old, as compared with the teeth of a five-year-old horse. At eight years of age there are indications that the bones of the jaw and the teeth have already ceased to enlarg. In some cases they show a slight shrinkage

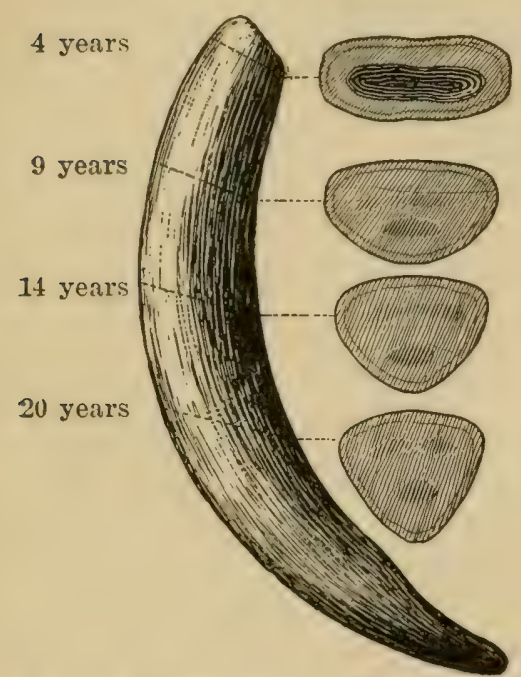

FIG. 74. Cross section of an incisor tooth, showing how the shape changes with advancing years. and the contour of the lower jaw has become less rounded. Compare Fig. 73 with Fig. 65. Finding that the cups have nearly or quite disappeared from the lower jaw, we proceed to examine the upper nippers. It is not easy to get a clear view of the upper nipper teeth of a restless animal. If the horse is eight years old the cups will still be present in the upper center nippers, but they will not be deep. If the teeth be viewed from the side, Fig. 75, they will appear somewhat long, and will meet at a sharper angle than they did when the horse was but four years old. As the years go by, the angle of the teeth increases. At four years of age, the upper and lower teeth meet nearly vertically with each other, at twenty at an angle of nearly forty-five degrees. The tusks are becoming constantly larger, rounder and blunter as the years advance. Compare Fig. 75 with 
Fig. 66, and the notches in the corner teeth have become pronounced.

At nine years of age, the cups will have disappeared from the upper center incisors, and will be shallow in the laterals but fairly deep in the corner teeth. The cups do not disappear at such regular intervals in the upper teeth as they do in the lower ones. Therefore, it is not always possible to tell the age of a horse within a year or two, after he has passed his eighth year. However, the character, shape and angle of meeting of the incisor teeth may all be used to assist the judgment in determining age. As has been formerly stated, horses having dense, hard bones and hoofs are likely to be rated younger than they are,

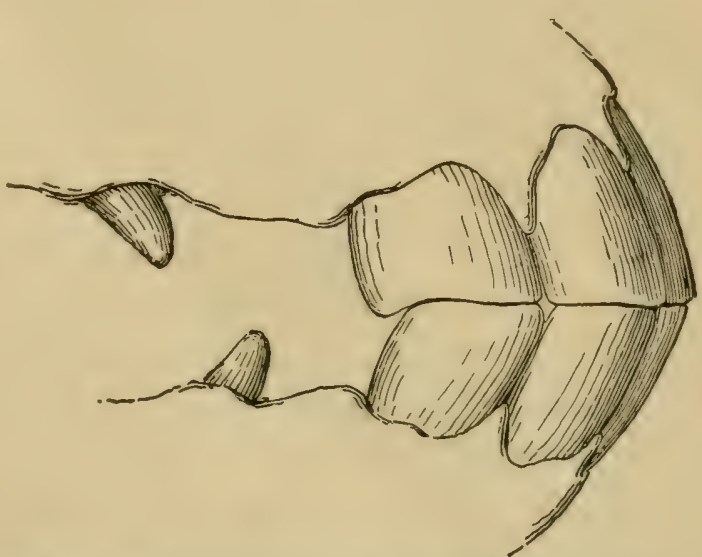

FIG. 75. The incisor teeth of an eight-year-old horse after eight years of age, when judged by the teeth alone; while horses of softer bony structure are likely to be judged older than they are.

At ten years, the cups have disappeared from the upper lateral teeth, the notches in the corner upper incisors have become enlarged, and all the signs of advancing age, as described above, are becoming marked. 
Usually, when the horse reaches his eleventh year, all the cups have disappeared; though it is not uncommon to find shallow cups in the upper corner teeth of smallish dense-boned horses up to thirteen or even fourteen years of age. However, the shape and the angle of the incisor's prevent a close judge from being much deceived. After the horse has passed his twelfth year, the matter of two or three years counts for but little; since all horses have then passed their prime, and, while they may, for certain purposes, be as efficient as they were when young, the time is fast approaching when the capital invested in the horse will be lost. The value of a horse is modified by the number of years which is likely to elapse before his value reaches the zero point. For instance, a tenyear-old horse may be, and usually is, able to perform more service than a five-year-old; but the fiveyear-old may be able to perform twelve years of efficient service, while, if a horse be ten years old, there would be but seven years of service before the capital stock invested would be sunk. Then, too, old horses are likely to be more sluggish than young ones. All things considered, it is seldom wise to purchase an old horse unless the price is low; in which case it matters little whether the horse is fourteen, fifteen or sixteen years of age. One's judgment of the value of a horse at these ages should be founded on general appearances and on activity shown, rather than on age, which cannot be accurately determined by an examination of the teeth. One may distinguish between a horse moderately old and one that is very 
old; but after the horse reaches his twelfth year the teeth do not accurately indicate the age.

Figs. 76 and 77 graphically illustrate the appearance of the teeth of an old horse. The incisor teeth have become nearly triangular and they show long

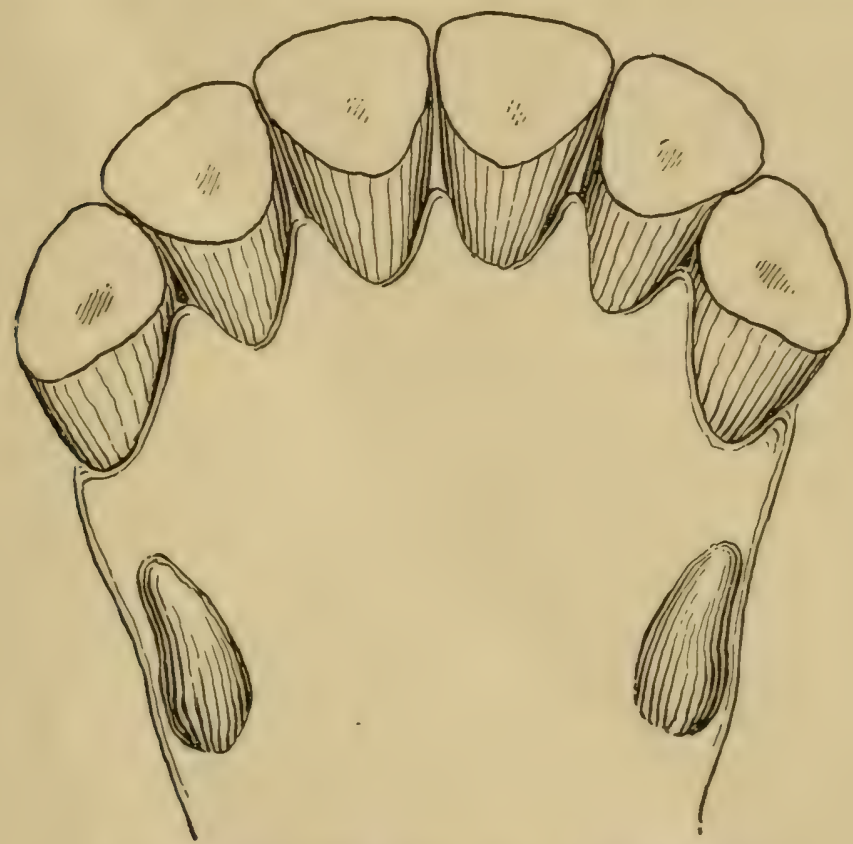

Fig. 76. The lower incisor teeth of an old horse. Note the shape and length of them.

wear. The tusks are large, blunt and round; the notches in the corner teeth, long and deep; the front ends of the teeth have been broken off, and they meet at an acute angle. They may have grown out so long as to prevent the double teeth from meeting; in which case the horse will spit out his food after he has extracted some oî its juices by imperfect mastica- 
tion. If the incisor teeth be rasped off on their posterior edges, the grinders will then meet and life will be somewhat prolonged. It is humane either to do this or to destroy the animal, rather than to let it die by slow starvation.

Having given somewhat lengthy and detailed instructions for determining the age of horses by an inspection of their teeth, it will assist materially in

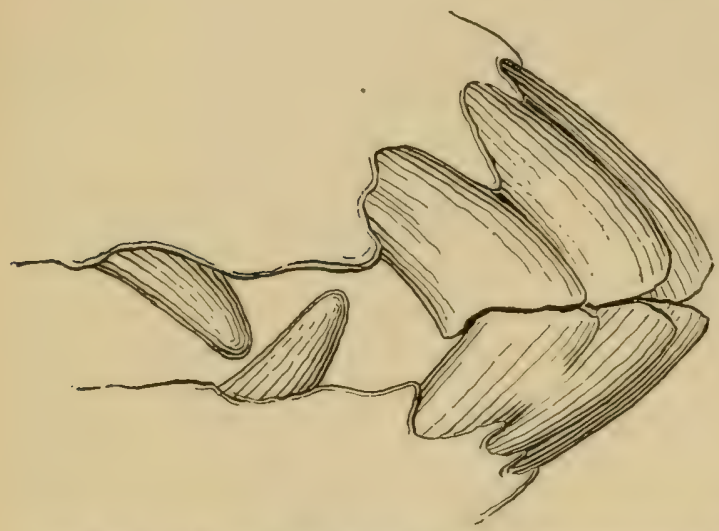

FIG. 77. A side view from life of the nippers of an old timer. understanding the instructions if the teeth be studied in a different way. Fig. 78 shows an entire permanent incisor tooth. It will be observed in the left-hand cut, that the face of the tooth has not yet been in wear and that the inside of it is not fully up. The cup is about three-eighths of an inch deep. It is of such a curvature that when the opposite tooth meets it they will come together much as the jaws of an ordinary pair of pincers do, and not like the jaws of a pair of tongs.

In the second cut from the left is shown the same tooth, the cross line indicating how much of the tooth has been worn away by one year's wear. Nearly or quite one-third and the broadest part of the cup is gone. In the third cut from the left, the cross line 
shows how much of the tooth will be worn away when it has been in wear two years. The fourth cut from the left shows a front incisor which came up at three years of age and has been in wear three years. The cup has nearly or quite disappeared, which occur's at six years of age. When the horse reaches nine years of age, the cut shows that about three-eighths of an inch of the

At 3 years. 4 years. 5 years. 6 years. 9 years. 20 years.

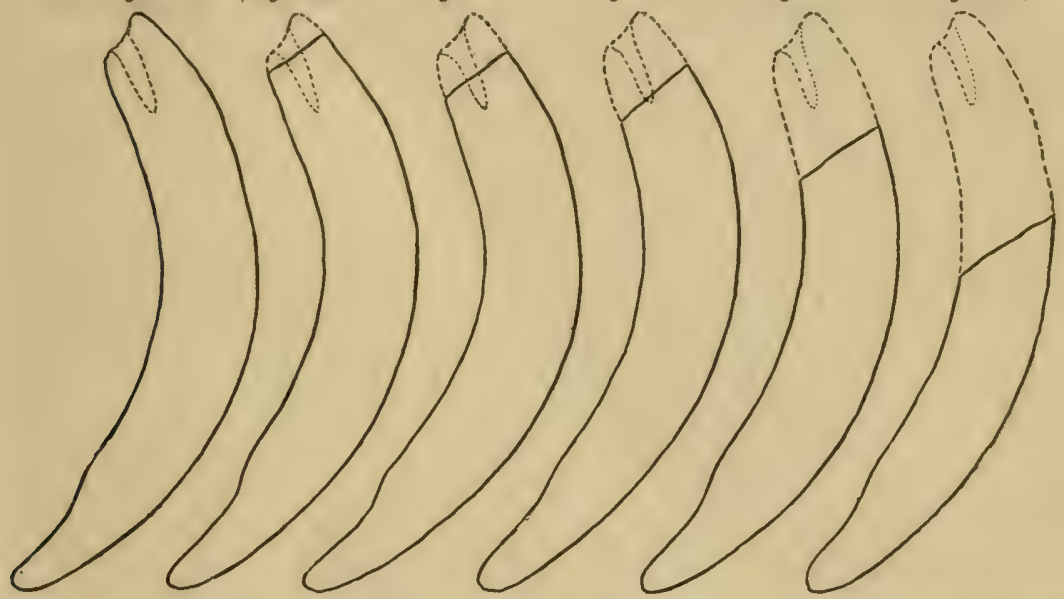

Fig. 78. Shows the wear of an incisor tooth and why the eups, or marks, disappear as age advances. The lower nippers wear away about one-eighth of an inch each year. The upper incisors wear away more slowly.

tooth has been worn away below the cup. At twenty years, the tooth shows much wear. The direction of wear, as shown by the cross line, has changed. Note the angle and how different it is from the visible angle of the teeth of a young horse.

Turn back to Fig. 74, as it will assist the eye and the judgment in distinguishing between a tooth which has just come in wear and one that has been in wear 
four, eight, fourteen and twenty years, respectively, as shown by the dotted lines. It also shows clearly the marked changes which occur in the shape of the teeth when viewed in cross section. At from eleven to thirteen years, as has been stated, all the cups disappear from the upper incisors, after which there is difficulty in accurately determining the age. However, if the shape of the teeth is observed critically (Fig. 74), it will not be at all difficult for a novice to distinguish between a horse just past his prime, an old horse and a very old horse.

NотE-Throughout this chapter the terms "temporary teeth" and "milk teeth," also the words "incisors" and "nippers" have been used synonomously. This is in recognition of the fact that these terms are so used by many good horsemen. 


\section{CHAP'TER XVI}

\section{BREEDING HORSES}

The breeders of horses may be divided roughly into two classes - the professional and wealthy amateur, and the commoner. The former usually has means sufficient to secure as foundation stock expensive and superior animals. He may expect profits, but does not always realize them. The business is not infrequently carried on for the enjoyment which is secured from rearing, handling and driving fine horses. While the undertaking may yield no profit to the proprietor, it seldom fails to be of great value to the horse interests. The commoner learns much from observing the successes and failures of the professional and the amateur in their expensive efforts to make advancement. Then, too, the commoner may reap great benefit from having near at hand tested stallions, the services of which may usually be secured at reasonable terms. Although the commoner has to follow a long way behind the professional, he should not, by reason of prejudice, fail to make use of the many valuable facts secured by the liberal expenditures of the professional. It would be gratifying if the wealthy breeders would take more interest in improving the horses in the hands of the farmers and less in conspicuous display.

However, it is the commoner we are seeking to 
benefit; since the wealthy breeder usually has the lesson of breeding fairly well learned, and, in case he has not, is amply able to employ experienced and trained foremen. The wealthy breeder often goes so fast and so far that the commoner loses contact and hesitates to follow.

The farmer carrying on mixed husbandry has constant use for horses during a part of the year. For about six months they are often overworked; during the balance of the year the cost of maintenance exceeds the value of their services. To minimize this expense, the grain ration is much reduced or entirely dispensed with. The coarse and innutritious roughage, which cannot be readily disposed of in the market, is used to furnish a ration which sometimes falls short of the maintenance standard. In the spring, the horses are soft and inefficient, and when put to severe work are often permanently injured. Usually the animals are too light for the service required; in rare cases, too heavy. Many are "weedy" and weak, when the highest endurance should be possessed to carry the farm-horse through the rush of spring seeding and harvest. In the following chapter something is said as to adapting the breed to the work to be performed and as to the details of raising winter colts. Here, it is proposed to speak to that large number of farmers who pay little or no attention to breeding horses and give but scant care to the horses already possessed. When one is worn out another is purchased, or the attempt is made to farm with too few work-animals. All this results in slovenly 
and often unprofitable husbandry. The stocks and bonds of a railway that owns too few, inefficient and poorly cared-for locomotives never sell at par or earn satisfactory dividends.

It will not require a large fund of knowledge $\mathrm{Or}^{\circ}$ long experience to fit even a man who has little taste for horses to intelligently select a good brood-mare, and the experience of his neighbors will indicate the stallion to be used which will most likely beget offspring suited to the soil and the work to be performed. Once the work of breeding is entered upon, even the novice will soon learn enough of the fundamental principles of breeding to produce animals which are likely to be far superior to those purchased at random under the stress of necessity and paid for by a promise to be fulfilled in the future.

Farmers' boys without colts are as unhappy as married people without children. Our experience leads to the conclusion that, after keeping an account of the value of the food consumed by colts, there is a profit of from thirty to fifty per cent in raising colts up to three years of age, provided they are worth one hundred dollars at that time, and allowing that the value of the manure produced equals the trouble of caring for them. ${ }^{1}$ In other words, in the middle and eastern states, horse-raising at present is likely to produce double the profit that can be realized in most other branches of mixed agriculture; and this, too, by the man who is unskilled, and whose chief energies

${ }^{1}$ See "Fertility of the Land," for quantity and value of manure produced by horses. 
may be devoted to the production of grain or hay or dairy products.

To secure one hundred dollars, more than 10,000 pounds of milk must ordinarily be produced. Perhaps I am spending too much time in trying to energize those who stand lowest in the art of horse-breeding, and who find it easier to give promissory notes for an unacclimated horse of comparatively little value for a year, and which may prove to be vicious or unsound, rather than to "bother with a colt." But I have a great interest in, and really affection for this man, who had no opportunity in youth to acquire even a smattering of the principles which underlie his profession, - who has worked so hard and long, as boy and man, that he has become unresponsive, soured and often egotistical. Under the circumstances, it is difficult for him to receive and adopt new methods which require additional knowledge and foresight. He is often so cramped in means that he hesitates to undertake anything which does not give promise of quick returns, although the undertaking may offer satisfactory rewards. These are the men who set no orchards, drain no lands, repair no buildings. They are to be pitied, not blamed. It has seemed to me that this class of farmers should find a friend and an adviser somewhere. Such cases cannot be dismissed by simply saying, "Why don't you do better" " Why not raise cows that will bring fifty dollars each, instead of twentyfive dollars? Why not raise horses at forty dollars profit each, instead of raising wheat and oats at a 
positive loss? Or why not raise hothouse lambs and get ten dollars per head for them at eight weeks of age? But how can they do better until they have more knowledge and skill?

I have suggested that raising one or more colts yearly would be practicable; since horses must be maintained to do the work of the farm, and since men and teams, in many cases, spend four to five months of the year in comparative idleness. Often a fairly good brood-mare is already at hand; and what better use can she be put to during the winter than nursing a colt, and what better and pleasanter work for the boys than caring for and "breaking" colts?

One illustration of the results which followed acceptance of advice similar to the above may be given. A young farmer living from "hand-to-mouth" secured a mare which had many of the characteristics of motherhood. She was bred four successive years to a smallish, symmetrical, dark-colored Percheron stallion. The result was four colts. Being large, symmetrical and strong, they were used at light work as soon as they had passed the age of two years. One pair was sold when the colts were nearly four and five years of age for three hundred dollars cash at the farm. The next day after the sale the two younger colts were harnessed, and in a week they were doing the work of the pair sold. Here, with no great effort or expense, nearly six hundred dollar's' worth of horses had been produced in five year's, and the net profits realized were more than the net profits on all other products of the little farm for that period. This man 
dropped his hoe and leaped into the saddle, and ever after was a more intelligent and a broader man.

But the profits are by no means the chief consideration in such an enterprise. There are boys on the farm, or should be, who have paramount claims. John will not remain contented between the plow handles many rear's if he has no colt upon which to try his courage and skill. Unless some means are provided for recreation and an outlet for his restless energs, and opportunity for gratifying his desire to exhibit his courage and skill, do not be surprised if some day you find the plow standing idle in the furrow and the boy standing on the front platiorm of an electric car, uniformed and numbered. These unknown and unappreciated farm lads, with their nascent pride and repressed nervous energy, are humiliated, shamed, when seen in public with that rough, old, overworked farm-horse hitched to the carriage. Nearly every farm boy now has a carriage - and a best girl. Deprive him of a good young horse,-one which has spring and mettle, one which it takes both hands to manage, - and he will take to the bicycle and the town and leave the farm, carriage and the girl behind,- and leaving the girl behind is the worst of all. When his hands have become soft and white in town, he may be ashamed of the virtuous, natural, nut-brown girl in the farm home. If he could remain on the farm a little longer, his better and riper judgment would enable him to discriminate between solid and enduring, and showy characteristics which fade when tested under the strenuous conditions which sooner or 
later always come, both in city and country life. The strength, courage and patience which come from rural life will then be worth more than the lily-white complexion.

The wood, with its multitude of wild animals to hunt and trap, is no more; the evening social function at schoolhouse and farmhouse has passed into dim remembrance; even the inspiring winter revivals in the country church have gone out of fashion. If he has no colt to drive, there seems no place nor time left for the farmer's boy to secure relaxation and recreation but to find it by scouring the country on the Sabbath days by means of back-breaking, bowelcurling bicycles. The boy does secure a change by his Sunday wanderings; but he is likely to secure much else in country inns, fruit plantations, and association, in too many instances, with those whose character's are the reverse of the girl's he has left at home.

It will be seen by the most casual reader that my objective point is the boys and girls on the farm, while the horse is treated as a means to an end. Only yesterday I saw this boy and girl, as I stopped at their home to get a drink of milk. Large-headed, muscular, clear of eye, alert and hanging on every word from the outside world. Already a little ashamed of their work-day clothes, and already, for want of opportunity and experience, imbibing something of the false notion that fine clothes and soft hands are sure indexes of respectability, virtue and learning. The three things most prized by the children in this faraway, semi-mountain home, were the colts, the flowers 
and the chickens. I stopped long enough to look them all over, and received instruction.

The old custom of presenting each son with a colt or young horse on arriving at his majority was most excellent, and might well be revived. If father will not present you with a colt, raise one for yourself; if he confiscates it, raise two more, but raise good ones. A poor horse may be made to increase your efficiency in production five-fold, but a good one not only gives pleasure but may be made to increase your productive power more than ten-fiold. Then, too, a good horse may be one of the truest, most helpful and appreciative friends you will have in your boyhood. No boy can be said to be ignorant who has learned how to breed, rear, feed and drive a good horse.

My young lads and lasses, I have laid aside for a time the discussion of scientific and practical horsebreeding for the pleasure of having a familiar chat with you; and if you believe the half of what I have said as to the beneficial influences, pleasures and profits which may be derived from a love for and the breeding of the horse, you will read the next chapter, which gives directions somewhat in detail, as well as some of the principles which should be observed, if the breeding and rearing of horses is to be added to the general farm operations already established. 


\section{CHAPTER XVII}

\section{EDUCATION AND CARE OF ROADSTERS AND OTHER LIGHT HORSES}

NEARLY all the ailments of horses are due not so much to bad breeding as to faulty training, ignorant, brutal driving, overwork, carelessness in feeding and watering, and thoughtlessness and ignorance with regard to the kind and amount of work which should be demanded of a horse under given circumstances. This being the case, the subject of driving, feeding and management is set forth in this and the following chapter with painstaking minuteness.

\section{EDUCATION}

The colt, it will be remembered, was taught, while yet with its dam, to obey simple commands and to acquire confidence in its master and in the myriad of frightful objects of the new world in which it first found itself a timid, ignorant stranger. It has had a happy, unrestrained life so far, and has learned much of men and things during its three years of growing, joyous, bounding life. Its freedom has given it powel and courage,- both of which we shall discover when an attempt is made to get dominion over it. Without this bounding energy and courage, it would be a disappointment - simply an ass. 
The modern colt is easily educated, for, through many generations of domestication, it has inherited the capacity to acquire an education readily. On the plains, it was once necessary to "break" and tame colts as we do lions, by harsh methods, and in a few cases it is still so.

With rare exceptions, the colt on the farm is made usable if, for a few hours each day for a week, he is subjected to the restraints of a bitting harness in the open paddock. (Fig. 79.) The check- and side-rein should be left slack at first. Gradually, from day to day, the reins may be shortened; provided, however, they are never made so short as to place the head in an uncomfortable position or draw the bit so tightly into the corners of his mouth as to make them sore. After the bitting, the colt may wear the harness and be driven with lines in the open field, without being attached to a vehicle. The next step is to drive him for a few hours each day, by the side of a good-sized, staid, mature horse attached to a farm-wagon, which should be furnished with a brake, first in the open field, until he learns what is wanted of him. The colt is now ready for light work. The education should be continuous, not spasmodic, and the after work should be continuous but light. The way not to train a colt is to give him one lesson a week or a month, which he forgets before he receives his second lesson, and then the first lesson has to be relearned. As the colt is put to light work, the grain ration should be increased, governed, however, by the exhaustiveness of the service. If the work is light and the grain ration 


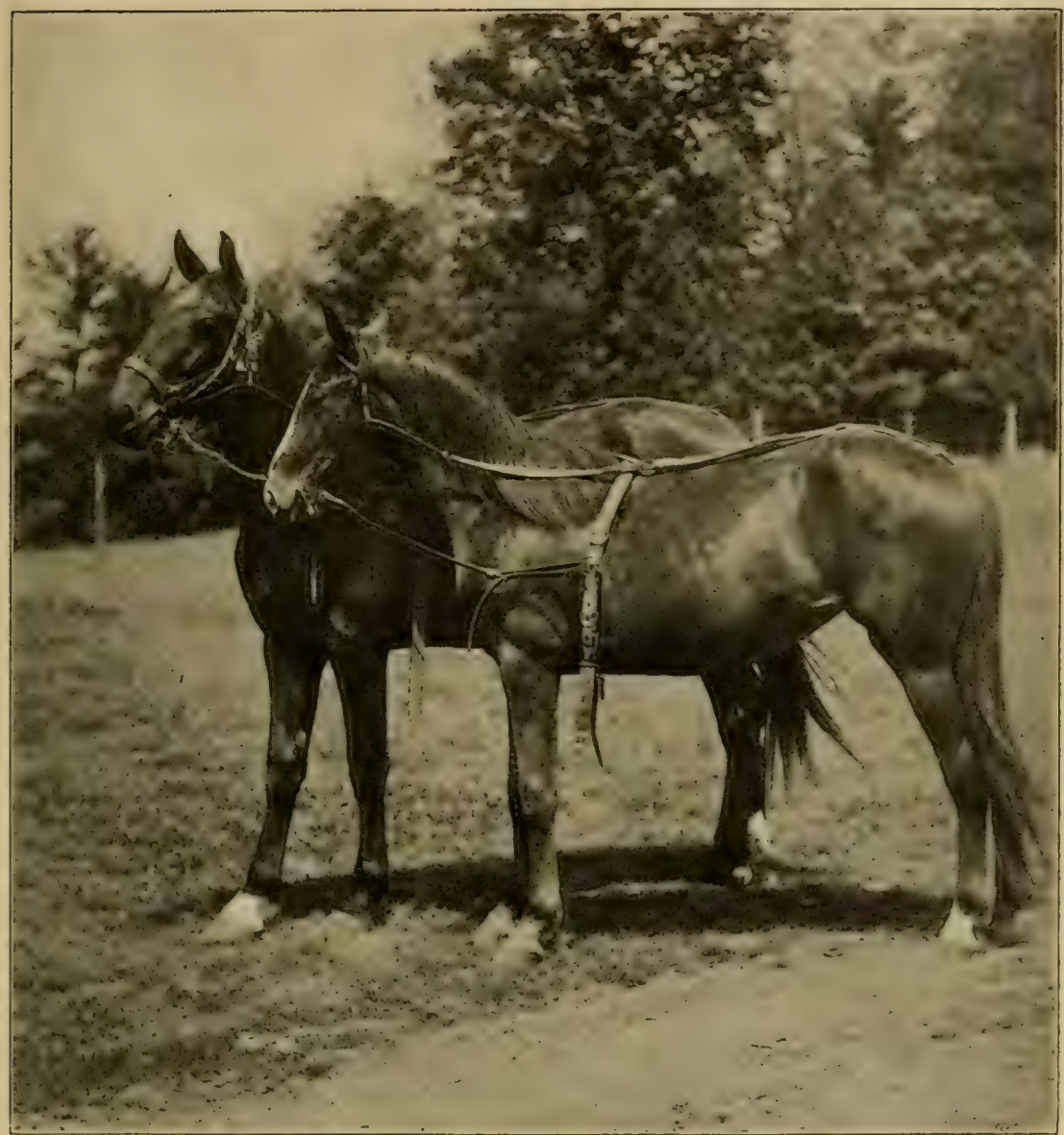

FIG. 79. Receiving their first lesson.

liberal, the colt is likely to attempt to play in the harness, get into trouble and become frightened. It is, therefore, not wise to keep the colt in too high spirits until he acquires staid horse-sense. On the other hand, his spirit should not be broken, or he may be a dullard all the rest of his life.

All of this preliminary education is not always 


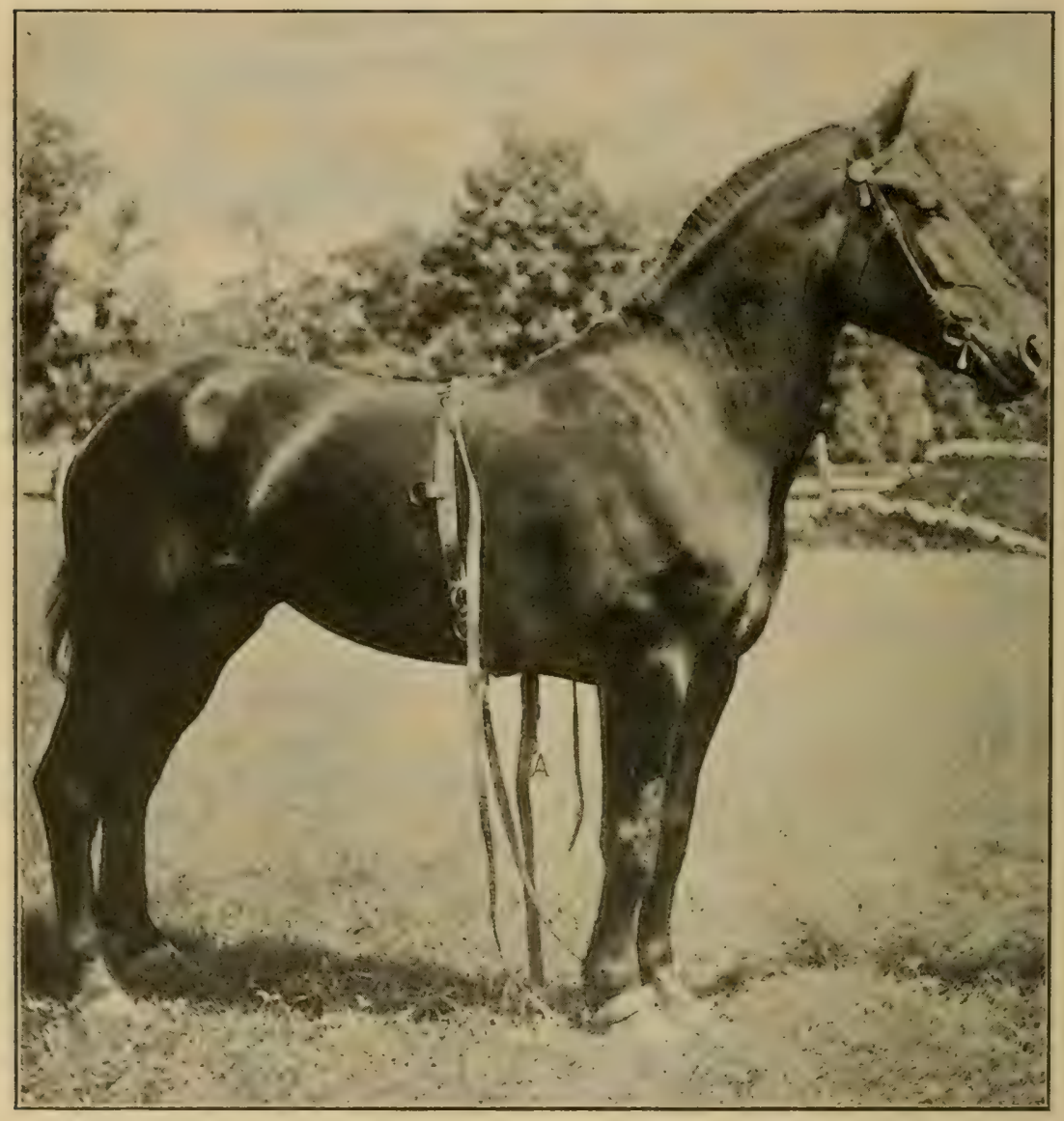

Fig. 80. Ready for the second lesson.

necessary. Colts of the draft-breeds are not so sensitive as are those of the warm-blooded breeds. Since the colt receives his education largely through the sense of tonch, and since this sense varies widely in indiriduals and breeds, no hard-and-fast rule can be given for the training of colts. Only occasionally is it difficult to get the colt to receive his lessous kindly. 
When these exceptional cases are met with, I know of no better way to get dominion over him than to throw the colt, "Rarry him." The bitting rig serves well for this purpose. Horse ready, Fig. 80. The right fore foot is strapped up, and a strap is also

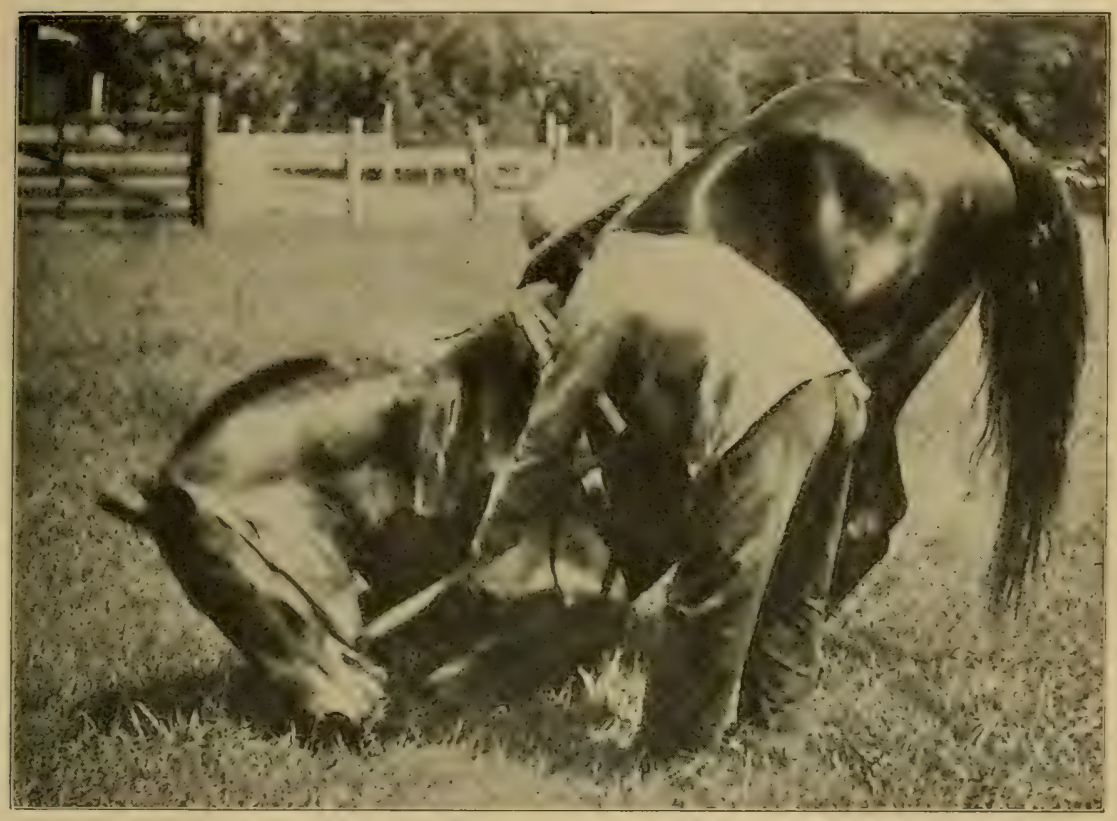

FIG. 81. The work half done.

attached to the left fore foot below the fetlock. Standing on the left side, the colt's neck is turned sharply to the right side and he is made to take a step with his free foot. As he raises it, the operator brings it sharply up to the body. This results in bringing the colt to his knees. Fig. 81. If the neck is kept well bent, as it should be, the colt can make but feeble efforts to rise, although he may do some 
plunging. The operator remains close to the colt's side, with one elbow over his back. This is a most humiliating and uncomfortable position for the colt. He soon yields and lies down, usually on the left side. This brings his feet away from the operator. If the

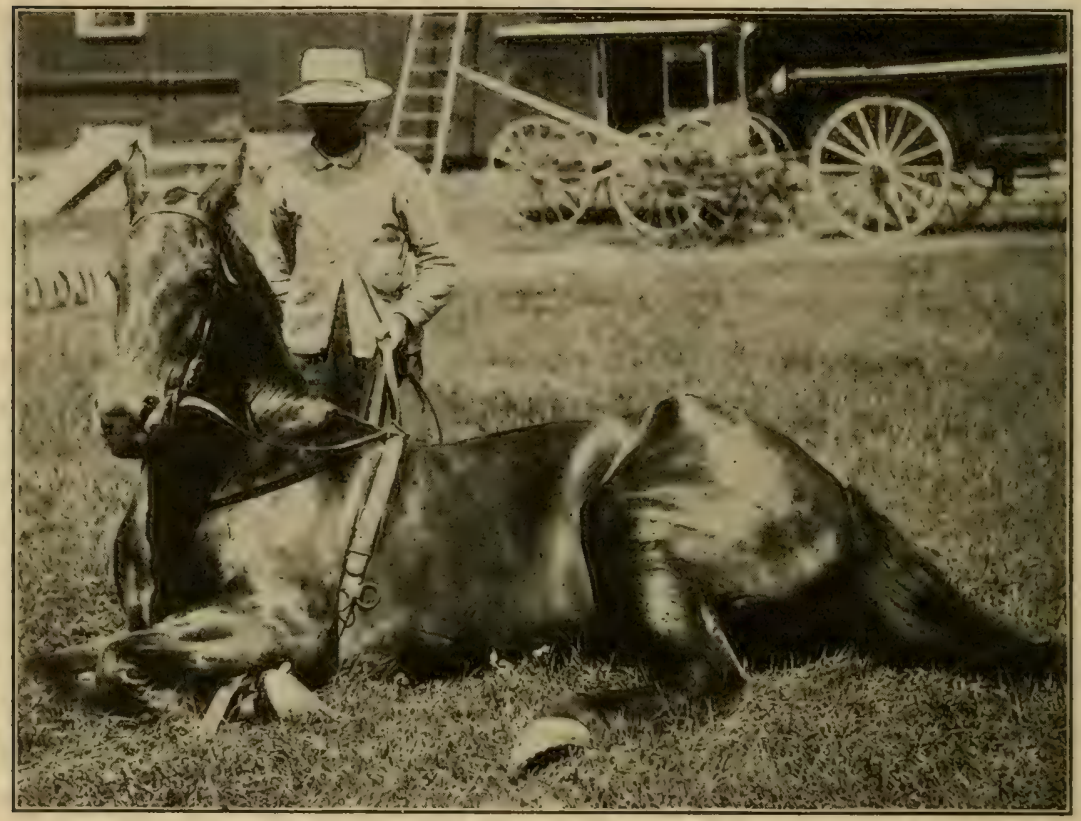

FIG. 82. Brains versus brute force.

front legs are kept up to the body and the neck slightly bent to the right, the animal cannot rise. (Fig. 82.) Now almost anything, such as opening and closing an umbrella, jingling bells, ete., may be done. The colt quickly learns that these do not harm him. If he be laid down several times and afterwards be driven with lines, with one leg tied up and the other ready to be taken up at the slightest indication of 
self-assertion, much will have been accomplished to convince a vicious colt that the intellect of man is superiol to the intellect of a colt, even though associated with powerful muscles.

\section{FEEDING}

Driving-hor'ses, especially those used at fast work, should be fed with great care. They should have relatively a greater proportion of concentrates and a less proportion of roughage than those used for heavy, slow work. Horses designed for fast work should not have their bowels distended with coarse foods. Some roughage is always necessary to float and divide the concentrates in the stomach, otherwise the grain and meal become somewhat compacted, and then are not easily attacked by the digestive juices. There is always some danger of feeding so likerally as to produce overfatness. Fat horses, to the untrained eye, appear more beautiful than lean ones, and hence the danger of sacrificing highest usefulness for beauty. Any unnecessary weight on the legs reduces to some extent their efficiency, and also tends to make the horse sluggish. The family horse may be kept much plumper than the roadster, for he is not driven so fast and far, and, by reason of the extra flesh, in time he becomes safer and less nervous. If the food of the horse thin in flesh be increased, his spirit is likely to increase for a time, and a horse considered safe when thin may become so energetic and frisky when putting on flesh as to injure his reliability as a family horse. Having 
once arrived at the maximum of flesh, he will soon tend to become as trusty as at first. Having been fat for some time, the tendency is for him to grow sluggish.

\section{FOODS}

Roughage and Concentrates. - Timothy and wild prairie hays form excellent roughage for feeding roadsters. While the roadster may be fed hay from grasses mixed with clover, and even bright clover alone without injury if the quantity is sharply restricted, yet there is always some danger of injuring the wind of the horse by so doing. Timothy and prairie hays are less palatable, and more carbonaceous than hays mixed with clover, which are more relished; and hence the tendency is for the horse to eat too much of the latter unless the feeder limits the ration. Mixed and clover hays are admirably adapted for feeding colts and other young stock. Such hay has a nutritive ratio of about 1:5.8 (one to five and eight-tenths. See Appendix III), while timothy hay has a ratio of about 1:16. The chief reasons for not feeding clover hay to driving horses are two: It is always more or less dusty, and it is too proteinaceous, and hence tends to loosen the bowels when the animal is put at hard, fast work. However, if clover hay be mixed with bright straw, and the mass be dampened, a satisfactory roughage ration will be secured for all but fast drivers.

Oats and corn are the two standard concentrates. The former is best adapted to driving-horses, while the latter mixed, or even unmixed with oats, serves 
well for horses which are kept daily at work which calls for large expenditures of energy, if the roughage is not also rich in carbohydrates. Bran may also be used but to a limited extent; for it is not sufficiently concentrated to furnish nutrients to satisfactorily sustain either driving- or work-horses when put to fatiguing work. If fed liberally, it tends to keep the bowels too lax. When scalded it is not infrequently fed to relieve constipation in horses. About four quarts of bran may be thoroughly moistened with boiling water, covered up, and left until the next feeding time, when it should be diluted and fed warm. A gill of linseed meal per day, mixed with other concentrates, serves to keep the bowels in good condition, and to brighten and soften the hair. Barley and rye are also used as concentrates to a limited extent. Both are much improved if ground and mixed with other concentrates. Wheat is sometimes used for feeding horses, but it is the least satisfactory of all the foods mentioned. Before it is fed, it should be mixed. with other grains and ground into meal. Cottonseed meal, a valuable concentrate for feeding cattle and sheep, is not relished by horses.

In closing this discussion on feeds and feeding, it may be said that regularity in feeding and watering, judgment in withholding a part of, or adding to the ration, and in the kinds of food to be used under any particular condition, all play important parts. With mows and bins full of good foods, some horsemen are unable to keep their horses up to a high state of efficiency. They appear to acquire the habit of caring 
for their horses in the wrong way or at the wrong time, or both. The very breath of such an attendant seems to be poison to the horse. Horses should be used but moderately for a short time after they have partaken of a full meal. Horses kept in cold stables should receive wider rations than those kept in warm stables. "The skill of the groom is half the ration." For a more extended discussion of this subject see "Feeds and Feeding," by Director William Arnon Henry, Madison, Wis.

\section{HARNESS}

Care should be taken to fit and adjust the harness to the horse. This is particularly true of the young horse when he is first put at work. His shoulders and mouth, the places likely to first show abrasion, are tender. Then, too, if he be somewhat fleshy when put to severe work, the collar, which was none too large at first, becomes too large for the neck after a few weeks.

In this chapter, the care, management, etc., of moderate-sized horses put to light work is treated; in Chapter XIX, the driving and care of draft-and plow-horses will receive attention.

After the collar, the bridle is of next importance. First, the length of the headstall should be so adjusted as to bring the bit in mild contact with the bars of the mouth, so that there may be quick response to the slightest pressure of the driving reins. If the headstall of the bridle is too short, the bars 
of the mouth soon become sore and finally unresponsive; if too long, the horse becomes careless of the driver's wishes.

A good-sized straight bit, covered with leather, if the mouth is tender, cannot be improved upon except in a few special cases when a more severe one may be required. "Pullers" are frequently cured of their disagreeable habit when the change is made from a severe bit to a straight, mild one. With the severe bit, the horse was in constant pain and hence nervous and excited. Being excited, his only desire was to go. With a bit that gives pain and a driver a little afraid of his horse, it is no wonder that the horse pulls. The horse, at one end of the lines, soon discovers the qualities of the man at the other end.

The crupper becomes necessary if no breeching is used on the harness. The modern fad of driving without breeching is to be condemned. If the horse is reined high, the crupper is almost indispensable. But horses should not be reined high. If the crupper is used, care should be taken to have it fit and to keep it clean, lest it abraid the tail and produce a disagreeable, if not a vicious horse. Last of all comes the check-rein, with or without the over-draw attachment. Two radically different practices prevail in the use of the check-rein. Some drivers over-use it; some do not use it at all. Is not a happy medium between these two practices best? The over-draw rein, if worn tight, is nothing less than cruel. (Fig. 83.) It makes the horse hold his head, not only in an uncomfortable, but in an unsightly position. If no 
check-rein is used, most horses become slovenly and careless in their habits, and, when not moving, the temptation to eat grass or earth becomes too great to be resisted. The feet, too, may get entangled in the lines and the collar fall half-way down the neck.

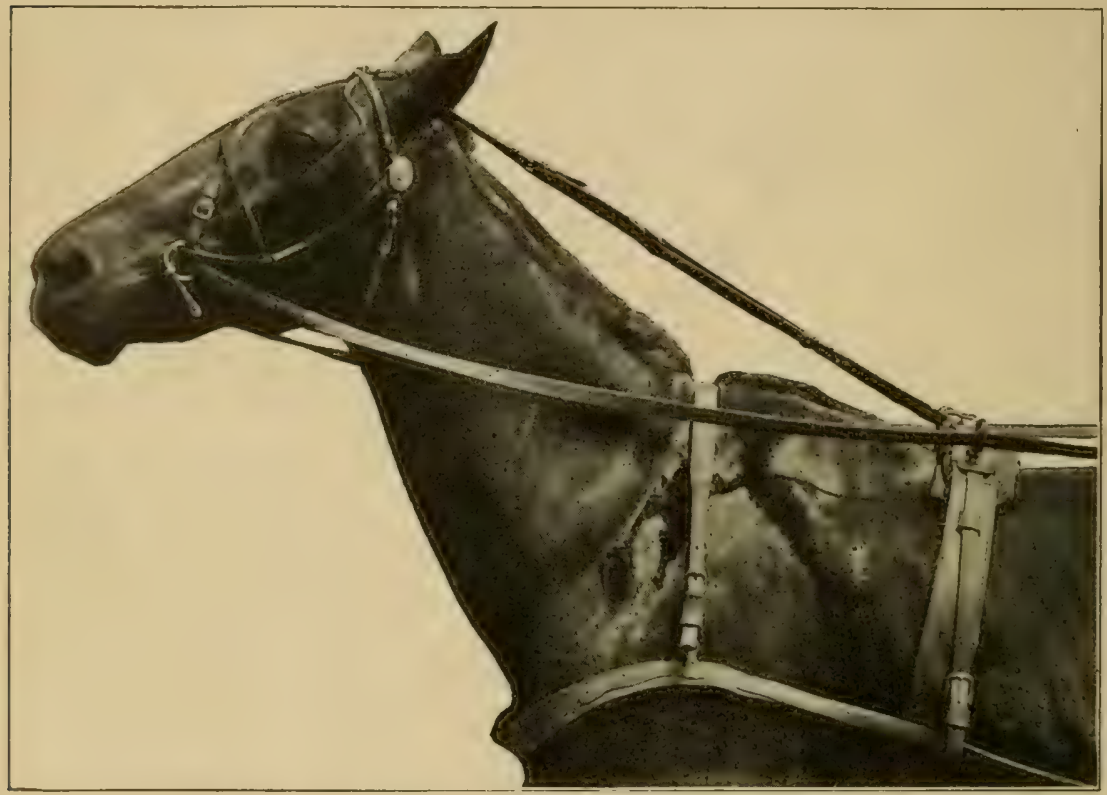

FIG. 83. A rein eruelly used. (Also see page 298.)

It is the abuse of the check-rein, not the use of it, which is to be deplored. Horses should always be checked up mildly, for it is the business of the horse when in harness to attend strictly to his duties. Without a check-rein he seldom does. I imagine that a check-rein on some people who walk with heads bent low and rounded shoulders, or sit on their backs instead of their buttocks, would be beneficial. Happily, many of our young ladies are learning to walk 
erect and keep their heads perpendicular to their spinal column. Perhaps the high, stiff collars have had something to do with this improvement.

Shall, or shall not, blinders be used? Again we have a wide diversity of opinion. Here, too, as with the check-rein, extremes should be avoided. A horse should be directed by contact with his nerves of sensation and by spoken words. He has no business to be looking backwards for orders. If he does, he soon imagines that he is "bossing" the job himself. Strict and prompt obedience is best secured when the highest intelligence directs. A small projection, not a blind, attached to the headstall of the bridle, does not keep the eye hot nor obstruct the side or front vision, while it does prevent the horse from looking backward, thereby conserving his vision and attention for the objects in his pathway. The breast collar is admissable when the load is light.

\section{DRIVING}

The art of driving a horse or a locomotive must be learned largely by practice, as both are complex machines. The former differs from the latter in that he is a highly organized living thing and therefore may attempt at any time to act on volition, while the locomotive must be acted upon. While the horse may and should, within narrow limitations, act without directions, he is largely like a machine under the hand of a master. His mental powers should be trained to willing obedience rather than toward originality. Since 
a well-bred horse has a will of his own, it will require more skill to drive him efficiently and safely than to drive the locomotive.

Horses are usually badly driven and waste much of their power and flesh to little or no purpose. Perhaps some suggestions as to driving may result in easing the burdens of the horse and in making him more efficient. Constant nagging with words or whip soon ruins courage and spirit. The driver is almost certain to get into the habit of nagging when the horse is continuously required to do more than he should. Constant repetition of word and whip, it is true, is the only way to get more service out of an animal than it should perform. Even a horse of high courage will at last fail to resent the cruel treatment of its driver. He soon learns that "It is hard to kick against the pricks."

In ancient times oxen were driven by means of a long stick, or goad, one end of which was provided with a piece of sharpened metal. The animals soon learned that, if they kicked against the pricks, it not only increased their punishment but resulted in being pricked again for kicking. Some modern drivers act on the principle of ancient ox-drivers.

If the horse's spirit has not been broken and his powers have been sustained and he has not been overworked, and yet he is not responsive and obedient, what is to be done? There is no way but to energize him now and then with a sharp switch. If this hurts your feelings more than it does the horse, get clear of him and breed one that has more courage and spirit. 
Hor'ses become discouraged and disobedient when they are punished for they know not what or are given double commands, as, for instance, "Whoa, back." They get disgusted,-I suppose a horse can get disgusted, - and finally mad when required to back a load several times, when if the driver had cramped or directed the front part of the vehicle at the right angle, it would have been in the position desired by a single effort.

Horses, like men, should receive punishment for disobedience; but, unlike men, they should receive theirs here, and when the offense is committed, or they may escape. There is often great cruelty shown to horses, which is justly condemned. On the other hand, there is much "namby pamby" literature on the subject of kindness to horses. One of the things desired in horses is strict and prompt obedience; failing to obtain this by kind means, intelligently applied, then punishment for disobedience should fall quickly. With brutal drivers, the punishment for disobedience or non-performance of duty is always excessive. Excessive punishment tends to produce viciousness and lack of confidence, and, above all, it is cruel. A single stroke with a light, stinging whip will do more to prevent future disobedience than swear-words and many blows with whip and club.

If the driver is careless and lazy, so will the horse soon become. The light touch on the reins and the firm, kind, cheery voice do much to inspire the horse with courage and obedience. Some men, even young men, are so constituted that they should never be set at 
driving horses. These I do not expect to reach and benefit. But, discarding this class and do the best we may in educating the youths of the land, there always will be the unenergized and unskilful horseman. Unless one is proud, not vain, of his horse, he can not aequire the nice judgment which tells him when to drive fast, when slow, and when the horse has done enough. Listen to the horse-

Up hill bear me;

Down hill spare me;

On the level spare me not,

But cool me when I'm hot.

Proud enough to drive so that the wheels of the vehicle will be kept in the beaten track and direeted away from stones and holes, - which can be accomplished only by watchfulness and by being constantly in touch, through the reins, with the horse. The horse at farm-work requires comparatively little direction; and but little skill, if applied at the right moment, is needed to direct his energies along the most efficient lines, when at slow work.

\section{WATERING}

Horses that are used for driving and for light work are usually in higher physical condition, not necessarily fatter, than farm- and draft-horses. Since their hours of labor are usually not so many nor their work so exhausting, they do not require so much water as farm-horses, but they are likely to be injured by drinking large amounts of water at one time. Horses which are driven long distances may perspire freely for 
eight to ten hours per day, and they are apt to come to the stable at night not only depleted of vitality but over-thirsty as well; in which ease great care should be exercised in restricting the amount of water until the animal has recovered some of its normal vitality. Under the conditions described, the horse should first of all be given a small amount of thin oatmeal gruel. If this be fed at from $90^{\circ}$ to $100^{\circ} \mathrm{Fahr}$, so much the better. It is not so much the amount of water nor its temperature as the amount of vigor which the horse possesses when he is watered that governs the result.

The horse, like the man, has far less resisting power on some days than on others, - that is, he is not always at his best. The careless driver fails to discover this, and, when the horse shows weariness, it is accounted to him as laziness and the whip is used to stimulate his flagging energies. When he arrives at the stable, he may be in just the right condition to be injured by even a single pail of cold water. Horses which are fed all they will eat of hay that is dirty or that contains a large per cent of clover desire much water. In time they get into the habit of eating and drinking too much. This results in large and unsightly abdomens, difficult breathing, and general sluggishness, and is likely to result in the horse's having the "heaves." The animal becomes inefficient, not because of its breeding, but through the ignorance or carelessness of the driver. The horse that is driven four to six hours continuously should be watered midway on his journey; though he be quite warm, no harm will result therefrom. However, he should be driven somewhat slowly for the first 
few minutes after he has drunk. No horse should be called on for his highest effort immediately after eating or drinking heartily. It will do no harm to again emphasize the need of furnishing the horse a full and frequent supply of water, if he is healthy, and it is desired to keep him so.

\section{GROOMING}

The grooming of the horse, under certain circumstances, becomes an important factor in efficiency of performance. Those called on for rapid work for short periods can hardly be groomed too much. Relatively, too much attention is usually given to the body and too little to the legs. The groom has pride in the "shine;" the driver has more interest in having the legs hard and limber. The legs of a horse should always receive first and largest attention: often they receive the last and least. Much of the body-grooming of the horse may be dispensed with if blankets are judiciously used.

The proper use of blankets requires some skill. If the horse is allowed to stand on the street in cold or windy weather, he should be covered with a heavy, large blanket imrnediately upon stopping, although he may be sweating. But if the horse arrives at the stable sweaty, where he is measurably protected, he should not be blanketed until he has ceased to steam. For, if he be covered at once, little opportunity is given for him to dry off, and the blanket will become damp and the hair may remain so all night. True, this diff- 
culty may be partly obviated by substituting a dry blanket one or two hours later. If the blanket is not used until the steam and surface heat have measurably subsided,- which it usually does in from fifteen to twenty minutes, - the hair will be dry and smooth the following morning, when the scurff may be removed easily by the use of a stiff brush. The use of a stable blanket, as well as one for the street, cannot be recommended too highly. The former should be of light material, and not so large as the latter. A blanket of some loosely woven cheap material may be used from June to September, and the ordinary light winter stable blanket for the rest of the year. Stable blankets may be dispensed with in hot weather if flies are excluded by screens or by darkening the stables by the use of curtains; but they should be used in the fall, as soon as the nights become cool. Such early use will arrest, too, in a marked degree, the growth of hair both in length and density. The coat of hair being kept short and comparatively thin, the horse does not sweat so profusely, when driven, as he would if the stable blanket is not used until the beginning of winter. The early use of stable blankets usually obviates the need of clipping the horse. However, some horses have such dense and long coats of hair that health and ease of grooming require that the clipping be performed, but such woolly horses are rare. In any case, the clipping should be done before midwinter, not in March, the most trying month in the year for a driving-horse. For some time after the horse is clipped, both stable and street blanket should be 
doubled, or those of greater weight and warmth, secured around the abdomen with safety pins, should be substituted for the light ones. In warm weather the horse enjoys a sponge bath, and the skin is cleaned and hair benefited thereby. Much space has been given to the use of blankets, with the view of keeping the horse comfortable and the skin and hair pliable and presentable, with the minimum of body grooming, an excess of which tends to keep the skin too sensitive for our erratic climate.

The care of the legs is really of more importance than the care of the body. They are subjected to severe concussion and strain; often covered with mud or ice, or both, or soaked with water the entire work day. It is little wouder, then, that they become unsound, sometimes useless. Added to mud and ice in the winter, is the ever-present dust in the summer, which fills the hair and pores of the legs far more than of the body. All these necessarily adverse conditions tend to injure the legs in time; hence they should be cared for promptly and with skill and judgment.

When the horse comes to the stable with muddy legs, they should be roughly cleaned by using a halfworn common broom. In an hour, or when the legs have dried off, they should be rubbed and brushed until they are quite dry and clean. Then, too, such rubbing will restore circulation, and the following morning the horse will be supple and ready for work, even if his legs receive but little attention just before going to his task. In other words, fifteen minutes' time 
spent in cleaning and rubbing the legs at night is more efficient in promoting sound, strong legs than a half-hour's time spent on them in the morning. It all comes to this,- - horses are usually kept at work so late in the day that time is not allowed for properly cleaning and caring for them after their day's work is done. That which should be done promptly at night is put off until the morning, when the desire is to get to work early; thus cutting short the time which should be given to caring for the legs, and finally they are not cared for at all. For what is the use in cleaning them at six-thirty, when at seven they will be as muddy as ever? When the weather is warm, the legs should be washed and afterwards rubbed dry. Nothing contributes more toward producing diseased limbs than allowing the horse to remain all night with damp legs covered with mud, especially in damp or cold stables. Depletion of flesh produced by neglect can easily be remedied, but injury to the legs from the same cause is often irreparable. Wherever wheat or rye straw is used for bedding, the very best possible material will be at hand for cleaning and invigorating the legs. A willing groom with a wisp of clean straw in each hand are all the appliances necessary for putting the legs in splendid condition. The old fashioned iron currycomb is not well adapted to cleaning the horse's body much less to cleaning his legs.

Horses sleep but little - from three to four hours out of the twenty-four; hence the more need of making them comfortable at night. Narrow stalls, insufficient bedding and stiffened joints on rising, all 
discourage the horse from lying down as much as he should, or from lying down at all. All these conditions should be remedied, because such change would be both profitable and humane. Stalls should be wide and well bedded. However, ample space and a comfortable bed may not only induce the horse to rest by lying down, but to roll also, even to roll over, in which case he is likely to get cast, that is, get his feet higher than his back and against the side of the stall. If so he suffers, may even die, if not promptly relieved.

To prevent the horse from rolling over, fasten a small pulley to the ceiling over the horse's head, and a second one nearly over the side of the stall. Attach a ring to the top of the halter, to which fasten a small rope, pass the rope through both pulleys, and fasten the end to a weight of one or two pounds. The length of the rope should be so adjusted as to cause the weight to strike the pulley when the nose of the horse is from six to eight inches from the floor when he is lying down. A horse cannot roll if he is prevented from getting his head flat on the floor or ground, 


\section{CHAPTER XVIII}

\section{"HANDS" IN DRIVING \\ By F. S. PeER}

Attention has already been called to the necessity of preserving the sensitiveness of a colt's mouth, when educating him, by the use of a bit covered with leather; when he is having his first lessons with the bit and dumm-jockey, such lessons are commonly known as "mouthing" and are of the greatest importance. When we consider that our every wish or command is to be communicated to a horse along the lines to a bit in his mouth and further, - when we take into account that mere strength with us is as nothing compared with the strength of a horse, - the necessity of preserving a horse's mouth as sensitive as possible is apparent.

Americans, as a rule, are fairly good at anything they undertake, but in the question of "mouthing" colts, and "hands" in driving, they are about as bad as possible. We may be pardoned for dwelling a little on this point, for the want of "good hands" is one of the most universal and most glaring defects in American horsemanship.

By good hands in driving is meant that delicacy of touch that never pulls at a horse's mouth more than is necessary, and never, on any account, when it is not necessary. The reason why Americans have such bad 
hands is because they do not hold the reins properly when driving. It is a pity that, when we inherited from our English, Scotch and Irish ancestors a love for horses, we left behind us their perfect hands for driving them. Everywhere in Great Britain one sees horses being driven with perfect hands,--farm boys, lads on delivery wagons, cab-drivers, teamsters, everybody; while in America, with the exception of a few coachmen in cities and an occasional gentleman-owner who has been properly instructed, we are about the worst lot of reinsmen to be found in any civilized country. I am well aware that this will possibly be challenged or looked upon as a very severe criticism. The trouble is, our training has been wrong from the start, and as we are, generally speaking, all wrong, we do not know how bad we are.

The American style of holding the reins is distinctly our own; we have neither inherited it nor borrowed it from any other nation. How, then, did we come to possess it? By copying after the style of jockies, sitting in a sulky driving on a race-track. Nor is "hands" the only thing we have copied from the trotting track to no purpose. I refer to the overdraw check. This instrument of torture, as well as the method of holding the reins, has a purpose on the track, but off of it they are alike abominable.

The sole purpose of the overdraw is to extend the nose of a trotter so as to give him a straighter air passage from nose to lungs, which, in races where the fraction of a second wins, is undoubtedly useful, as the volume of air to be pumped in and out under such terri- 
ble pressure needs the greatest possible freedom. Thus the overdraw has its legitimate use. To use it for any other purpose is to abuse it. A trotting-horse can stand it during a race lasting a few minutes; but, when a poor dumb brute is made to carry his head out of a natural position for hours, it becomes a torture. So universal has the fashion for overdraws become that, unless it is especially ordered, you can hardly find anything else on a ready-made single harness. It is, as above stated, from this same source, and with no more reason, that Americans have copied the prevailing style in this country of holding the reins when driving.

The proper way of holding the reins when driving is to take them in the left hand; the nigh, or left rein coming into the hand over the forefinger, the off, or right rein coming into the hand between the middle and ring finger. The left hand holds the reins; the driving or guiding is to be done by the right hand, which carries the whip and manipulates the reins. The arm of the driver from shoulder to elbow hangs naturally, the forearm nearly at right angles to the same; the hands nearly meet in front of the body in a perfectly natural position, thumbs uppermost. This position of the hands and reins gives to the driver the best possible control of the lines, at the same time enabling him to keep at all times a light touch on the horse's mouth, which is not only the proper way but the way all horses prefer to be driven. A horse properly bitted or mouthed as a colt, and the sensitiveness of the mouth preserved, the slightest touch of either rein with the pressure of a finger will be quite sufficient to quiet him. 
The American, or jockey style of holding the reins is not only bad in form but ruinous to a horse's mouth; because, with the arms extended and a grasp of each line in separate hands, the weight of the arms and hands is constantly resting against the horse's mouth. Pulling hands make pulling horses, because, when a man takes hold of the lines with extended hand, although he is not conscious of pulling at his horse's mouth and is not in reality doing so by a muscular effort, the weight of his hands and arms resting on the reins amounts to the same thing. So much for the constant pulling on a horse's mouth; that of necessity makes it calloused or so hardened as to be insensible to pressure, until the driver has simply to pull his head about by main force to let him know what is required. When the driver pulls at a horse's mouth, it hurts. He finds, however, that if he gives in to it he is touched with the whip to make him, as we say, "drive up to the bit,"-so we will have something to rest the weight of our arms and hands against. The horse soon learns, also, that the harder he makes the driver pull at his mouth, the less painful it is; because, when the pressure is great enongh, it shuts off the circulation and the parts become numb or deadened to the pain. Thus it comes about that pulling hands make pulling horses.

On the plow, we see horses dragging along a plowman who has the reins about his body; again, with a pair of hands as heavy as lead, arms extended, the horses are made to pull the driver along in addition to the harrow, and the driver is by far the most fatiguing pull of the two. You may say that he has 
to do it, - can't hold them: then it is the fault of their early training. All you can do in such a case is to drop the bit into a new place and make the best of it. Sometimes the change to a large, smooth rubber curved bit will stop a horse's pulling. The proper mouthing or bitting of a young horse is not half appreciated, and less understood or practiced in this country than in Europe. Anything and everything you can do to preserve the sensitiveness of his mouth should be done.

While there is some excuse for holding on to a horse that is already a puller, there is no excuse whatever for driving him with a slack rein when he comes to a walk. In this way, we teach him that when we pull back we want him to go fast, and when we let up entirely he is to walk, - which is just contrary to what we really intend. Never pull at a horse's mouth an ounce more than is necessary, and never drive him for a rod without a light touch of the reins so you can just feel the bit. You can easily do this, when your hand is in the position recommended (thumbs up), by permitting the wrist to give and take to the forward and backward oscillation of a horse's head when moving.

As to hands in driving, we are the laughing stock of the world. ${ }^{1}$ No system or form could be devised that could be worse than the American style. It is simply ruinous to a horse's mouth. It is a most difficult thing to find in America a horse of any natural

1 See "Cross Country With Horse and Hound," by F. Sherman Peer. 
spirit which has not had his mouth damaged, if not ruined, by heavy hands. It is our one common fault, which accounts for the special emphasis placed upon it in this chapter.

In teaching a colt to rein, his first lesson,- after a week or two of bitting, - should be with long reins on the barn floor or some other small enclosure. In addition to the reins and a soft, easy, smooth, straight bar-bit, place a non-shurring loop about his under jaw, and pass the rope about his head and down through the loop in his mouth. When he attempts to run or get away, take him in hand by the rope, leaving the reins principally for guiding purposes. This will teach him the lesson you wish to impart, without endangering the sensitiveness of his mouth where the bit naturally comes. 


\section{CHAPTER XIX}

CARE OF DRAFT-HORSES AND FARM-HORSES

DRAFT-HORSES, in this connection, include all horses used for slow or comparatively slow and exhausting work, especially farm-horses used for tilling the land. Horses in a wild state graze largely at night, while cattle feed largely in day time. The horse's stomach is relatively small, implying that he should be fed more often than cattle, and less at a time. Horses do not eat so fast as cattle, and do not remasticate their food, as do cattle and sheep. Horses may be fed three or four times daily, while cattle and sheep do well when fed but twice. The morning ration of the horse should contain about one-fourth of his total daily ration, and it should be given him some little time before being put to hard work. Another fourth of his food may be fed at noon. On the farm, one hour's nooning instead of two, as of yore, is best. The hour saved will shorten the work-day one hour at night. This will give time for the horse to cool off before the dampness and falling temperature of the evening occur, which tend to produce that disagreeable and dangerous condition which a person feels in the evening whose shirt is saturated with the prespiration of the day. Horses, and especially oxen, if perspiring freely, 
and worked late, are frequently found in the morning with the hair and skin damp, and in a condition of lassitude which unfits them for entering upon the day's labor with vigor. 'Ten hours of faithful work per day is quite enough for either man or beast; and such work would better be accomplished by starting early than by continuing late. If the horses are brought to the stable early, they have time to eat hay and to rest, after which one-fourth of the grain ration is fed. Just before the attendant retires, the last fourth of the day's ration may be given. Or, if this is too much trouble, the horses may be left to eat hay for an hour while the teamster is eating supper; after which the legs are cleaned, and then one half of the day's ration of grain may be fed. The hay ration should be fed about the time and in about the same proportion as the grain is fed. How much grain and how much hay should suffice for each horse it is impossible to say; since the size of the hor'se, his ability to digest and assimilate food, the kind of food consumed, and the work performed vary widely. When horses are put to unusually severe tasks for a month or two, when work is pressing, as they usually are on a farm, it is better to increase their grain than their hay ration. Quite a large part of the energy in food, especially if it is coarse food, is used for preparing the ration for assimilation. Coarse and unconcentrated foods are frequently more expensive per unit of net avalable energy than concentrated ones. It is not the total energy of the food so much as the available energy over and above that required to masticate and digest it that gov- 
erns value. Dr. H. P. Armsby's experiments show the following results: "Of the totsh or 'gross' energy of hay, about $4 t$ per cent was capahle of conversion into the kinetic form in the animal, while the remaining 56 per cent was found as potential energy in the excreta. Of the 44 per cent which I have called metabolizable energy, about 63 per cent, equivalent to 27.72 per cent of the gross energy of the hay, was found to be available for the maintenance of the animal, while the remaining 37 per cent of the metabolizable energy, under our conditions of experiment, simply went to increase the heat-production of the animal. This 37 per cent of the metabolizable energy seems to represent the expenditure of energy which is involved in making the remaining 63 per cent available for the actual uses of the organism. The above results represent the average of four experiments only, on a single animal, and of course should be generalized from very cautiously."

The more concentrated the food is, within proper limits, the less per cent of energy is needed to make it available. This fact explains in part why animals cannot be sustained and produce sufficient energy for growth and work on unconcentrated food, difficult to masticate and prepare for assimilation. It is because too great a per cent of the energy of the food is used in its preparation by the stomach, hence the net energy is small.

When horses are doing light work or are idle, not only will less food suffice, but the proportion of rough, cheap food to the concentrated may be increased. 
Horses should be fed slightly less on idle days than when employed. Much of the trouble, particularly bowel-complaints, on Mondays is due to over-eating on Sundays. When a record was kept with farm-work horses, it was found that there were more than twice as many indisposed horses on Monday as on any other day. When the Sunday's ration was slightly reduced, the health was equally good on all days. When practicable, work-horses should have some exercise every day. This can most easily be secured by turning them out for a few hours in a paddock, on idle days. If the horses are at severe work, they do better on dry food than on green grasses and clover. If horses are allowed all the green food they desire at night, bowel trouble may occur the next day if the weather is warm and the work hard.

Not infrequently the hay runs short in late spring and grass is fed in the stables as a substitute. This is all very well if the work is light. New hay, while still heating in the mow, is always dangerous. The health of a horse at hard work is governed largely by the food he consumes. A little grass mixed with old, dry hay may be fed safely, but new hay passing through a sweat should never be used. In hot weather, horses at severe work in the fierce sun do best if they are kept in comfortable stables at night and are fed on roughage and concentrates of the previous year's growth. Some horsemen understand this, and will pay more for old than for new oats or hay. So the haybuyer does not bale hay for the city until it has gone through the "sweat" in the mow or stack. 
Neither green sheaf oats, nor threshed oats which have not been seasoned for three months or more, should be fed,- especially to fast drivers and hardworked draft-animals.

So far, the feeding of horses used for draft and severe continuous farm work has been discussed; but there are many horses on farms which have light, intermittent work, in which case quite different methods of feeding may be practiced. If pastures are abundant, the horses may be turned out at night, and in the day-time when not in use. They may receive less than one-half as much concentrated food as the horse at severe toil. A good practice is to bring the horses to the stables in the morning, that they may be quickly available if wanted. A little hay and grain may serve for their noon feed. If the pastures are satisfactory, the horses may be turned out in the early evening without having received any food whatever in the stables, even if they have been at moderate work.

Little or no grain food or grooming or care will be necessary, provided the horse's work is not hard or continued for too many hours a day. If the outside covering of the horse does look a little unkempt, it will correspond with the clothes of the driver, both being suited to their work. The horse which is used for purely utilitarian purposes should be the servant of man; not man the servant of the horse, as is sometimes the case when the owner waits on his pet horse more than he does on his wife. This may be appropriate if the horse is kept for conspicuous display and the wife for work. 
In America, food is so abundant and varied that the horseman has opportunity of wide choice. Hay, bright straw, coru-stalks aud even silage serve well for roughage. Usually all of these fodders have a wide nutritive ratio and therefore require that the grain ration be narrow. The reader will have no difficulty in compounding a suitable ration after studying Appendix III. (See Chapter XVII for feeding driving-horses and those employed at other light, quick work.) Farm-horses when at moderate work, and especially mares with foal at foot, may wholly or in part be soiled - fed in the stables on green food - especially if their grain ration be abundant and well seasoned. Grass, clover oats and peas are good for summer soiling. See "Soiling." by F. S. Peer.

\section{WATERING}

In warm weather, horses which are working hard enjoy a sip of water before partaking of their morning meal, and even in cool weather some horses relish a drink before breakfast. All horses can be trained to this habit, and it is probable that such habit promotes healthfulness, since, if watered before they are fed, they are not likely to drink much after their morning meal. Large quantities of cold water taken into the stomach immediately after a meal tend to arrest digestion. It may also cause serious irritation of the intestines by washing undigested food into the alimentary canal. If provision could be made on the farm without too great expense for watering horses when at work, in warm weather, in the middle of the fore-and afternoon, 
it would be both profitable and humane,- for without water they often suffer when sweating profusely. Horses naturally drink when they come from their labors to the stable, and this is well if they do not drink too much; for water taken when the animal is thirsty, before eating, quickly passes into the circulation, whereas the same amount of water taken after a hearty meal would tend, as before stated, to arrest digestion. Cold water taken in large quantities, when the horse is unusually depressed or when over-warm, may chill the stomach to the point where it reacts but slowly, in which case colic or founder may result. If reaction comes promptly, as it should when a coldwater internal bath is taken, the stomach is stimulated instead of being depressed. If horses are thirsty when fed, they do not relish their food. A full supply of water in the system is quite as necessary as a full supply of food. It should never be forgotten that water is the great vehicle which carries food into, and most of the refuse material out of, circulation.

Heating water for cattle has been tried to some extent, but the practice has been largely abandoned, the reason for which I think is explainable. First, no suitable appliances were at hand when the attempt was made to heat the water, and the temperature was not raised above lukewarm. Lukewarm water is not only less palatable than cool or hot water brit may be positively nauseating. Water raised to $98^{\circ}$ or $100^{\circ}$ Fabr. is highly relished by both cattle and horses in cold weather. Hot water saves food, promotes health and digestion, and may, under certain conditions, prevent 
chills and founder in severely worked horses. The only reason for not providing it is that it is not usually convenient to do so. In a few cases, steam is in the barn or can be generated easily and cheaply, in which case it is wise and profitable to heat the water for both cattle and horses, in cold weather. Horses cousume less water than cows in milk. The average for horses at work is not far from forty pounds and for cattle in milk sixty pounds daily. The taking into the system of such large quantities of water often at or near the freezing point, is not conducive to economy or health; for this water must be raised by the use of food to blood-heat, quickly. Since it takes more units of heat to raise a mnit of water one degree in temperature than any other food substance, it can easily be understood that a considerable part of the ration of the animal must be used in raising the temperature of the water. However, the matter is largely a financial one. In some parts of our country roughage is cheaper than coal; in other sections, the reverse is true.

In the winter, horses are likely to become constipated. Their voidings should be watehed closely, for constipation is the mother of many ills. Carrots are much relished by horses kept on dry foods. Unsalable apples, if fairly ripe, or small potatoes, may be fed to advantage in small quantities, though they are of small nutritive value. Mangolds are fairly good and cheap of production, as twenty-five to forty tons per acre can be raised and the cost per bushel is not more than one-half as much as of carrots. A hot bran mash is a most excellent regulator of the bowels. However, a gill per day of 
oil-meal helps to narrow the almost invariably too wide ration, corrects constipation and tends to make the skin pliable and the hair soft. Nevertheless, it is seldom that the farmer can be persuaded to purchase even a single ton of oil-meal, or to feed it even in an experimental way. He has been feeding, for instance, four quarts of grain at a time, the measure full. If he adds a pound of oil-meal to the ration, the supply is soon exhansted. He has seen no marked beneficial results, since he has not observed closely enough to have seen the constant little changes for the better, day by day; and he comes to the conclusion that his twenty-five dollars which he paid for the ton of oil-meal has been thrown away, and, of course, purehases no more.

Draft- and farm-horses require more salt than do those put to less severe work. Salt should be accessible at all times in the stall. The common soft salt is to be preferred to rock salt, especially the cheap kinds, as the tong'ues of the animals may be irritated by licking it, notably of those requiring a liberal supply. Four horses on dry feed ate twenty-eight pounds of salt in fifty-six days, or two ounces per day per horse. In experiments with cows, at the end of forty-three days it was found that they consumed three and fifteen one hundredth ounces of salt per cow per day.

Horses relish a little hard-wood ashes, and it used to be a common practice among farmers to supply them with limited quantities, once each week. Horses, as well as pig's, when fed on dry food, appear to be benefited by small quantities of charcoal, if they do not have access to the ground. 


\section{BLANKETS}

What has been said in regard to the use of blankets, in Chapter XVII, is true with slight modification when applied to their use on draft-and farm-horses. Stable blankets when judiciously used promote health and economize labor, but, when used injudiciously or of too heavy weight, they tend to injure appetite and to make horses more sensitive to the many vicissitudes which they are called upon to pass through.

Fly-blankets to be used outside of the stables are not to be recommended; fly-nets are, under certain conditions. Farm-horses should always be supplied with a throat-latch cloth when the annoying bot-flies are present. Fly-blankets of strong enough material to last a reasonable length of time prevent the free radiation of heat and moisture from the body. Leather fly-nets are not objectionable. Fly-nets and fly-blankets are both annoying to the teamster, are more or less expensive, and should not be used if reliable material for spraying the horse can be secured. The "Eureka Fly-killer" and some others are fairly satisfactory when used twice daily; they largely protect the animal, and do not soil or injure the hair, and, all things considered, they are cheaper and more satisfactory outdoor flyprotectors than blankets. A little sprayer suitable for applying the material can be purchased at almost any hardware store for a dollar or less.

Even more pains should be taken in fitting the harness of draft- and farm-horses than of drivers. See Chapter XVII. 
Horses designed for heavy work should not only be of strong build, but of height suited to their weight. Here, as in all other productive enterprises, the best of judgment should be exercised to adapt the weight of the horse to his work, and the soil upon which he is kept, and the climate in which he is used. Most farmhorses are too light for the work required, a few are too heavy. Some soils are easily tilled, some farms are hilly, some farmers do little plowing or other laborions team work. Manifestly, under such conditions, a horse weighing sixteen hundred pounds would be out of place. On the other hand, the plowing of tenacions soils, and the hauling of large loads are most economically accomplished with horses of from twelve to sixteen hundred pounds' weight. It should be remembered, however, that a hor'se of twelve hundred pounds in good flesh may weigh but ten hundred pounds when thin in late summer, and the horse of sixteen hundred pounds may weigh but fourteen hundred pounds when called upon to draw the heaviest loads of the year. Finally, it may be said that, in general, the farmer has been mingling the trotting strains of blood too liberally with his nondescript mares, and sometimes with ruinous results.

\section{SIZE AND WEIGHT OF HORSES}

We make no plea for the light horse or for the heavy horse. What we do emphasize is the wisdom of breeding the horse which can perform the services required most effectively and economically under any 
given conditions. Horses of light weight are at a great disadvantage when used for heavy loads, especially on an ascending road and on slippery pavements; while horses of heavy weight are at a disadvantage if used at light work, or for harrowing on soft ground. In the former instance, there is not enough weight to secure adequate traction - adhesive friction, - in the latter, there is unnecessary traction due to unnecessary weight of team, for the work to be accomplished; hence the most economical expenditure of energy is not secured.

\section{DRIVING-, FARII- AND DRAFT-HORSES}

Of necessity these horses are driven slowly; hence full opportunity is given for avoiding obstructions without sharp and quick attention to the reins. Little or no display is required of the farm-horse; hence his check-rein may be loose, the driving reins fairly slack, and all his gear and movements arranged to perform service with the least possible expenditure of energy. This does not imply carelessness nor disobedience on the part of the horse. It does imply less guidance by rein, and more by words than would be suitable for a roadster. However, it keeps the draftand farm-horse up to their highest standard of efficiency, if occasionally, when they are not wearied, they are driven rapidly with tight rein for a short distance; it does them good to stir them up now and then. Such drives bring other muscles into play than those used at slow, heavy work, enliven the team, and in many ways are beneficial. 
The class of horses of which we are speaking are called upon to back frequently, often under most difficult conditions. To see energy expended for naught, watch a team backing after both man and team have lost their tempers. Back the horses come, saying as plainly as they can, "You fool driver"; then come loud words, a yanking of the reins, the sting of the lash, and back the load comes, but in the wrong place, and this may be repeated several times before the wagon is placed satisfactorily. No wonder there is need of a society for the prevention of cruelty to animals !

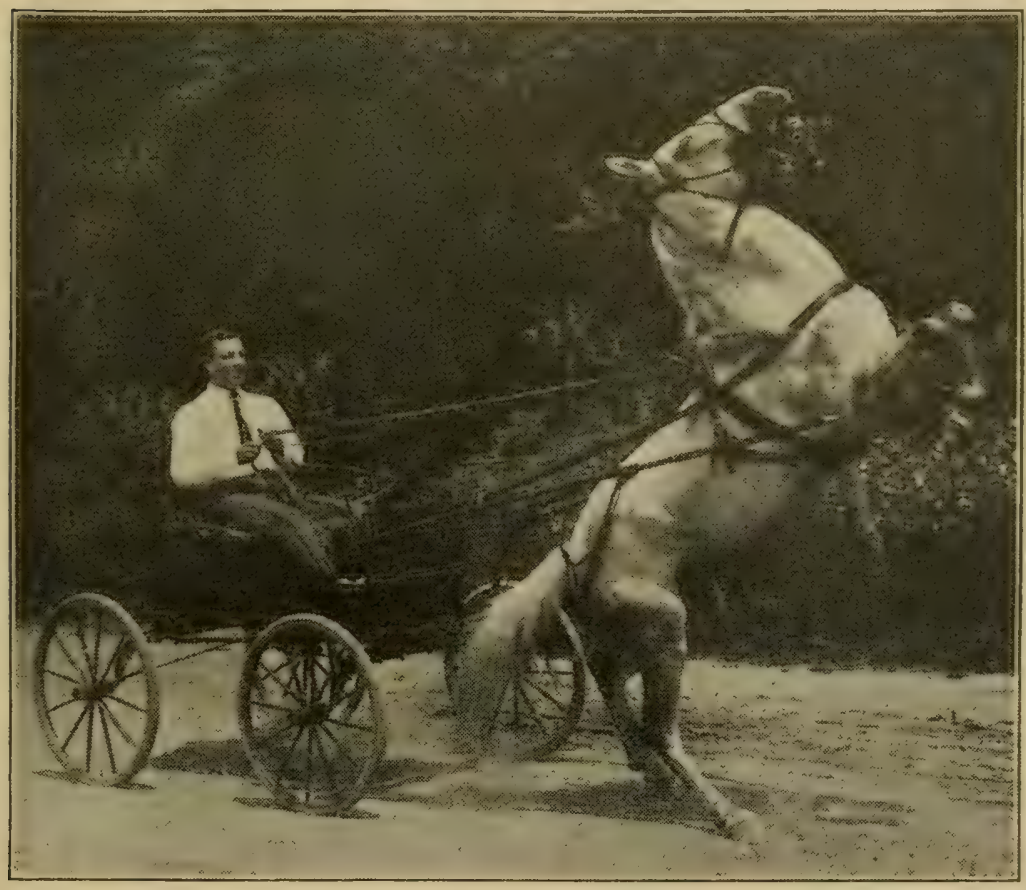

A trained horse with extraordinary development of muscle Orned by Dr. F. B. Howe, Ithaca, N. Y. 


\section{CHAPTER XX}

\section{THE HORSE'S FEET-SHOEING}

MucH has been written on shoeing horses, but it is seldom that any two authorities agree. The mechanic who does the shoeing has his notions; usually, they are nothing but notions, since he has no knowledge what ever of the anatomy of the foot, and little or no expe rience in the varied uses to which horses are put. The veterinarian is called on only when the feet have become abnormal or diseased. The owner of the horse, be he farmer, tradesman or a horse fancier, often knows even less as to when and how a horse should be shod than the blacksmith. These unfortunate conditions result in producing a multitude of opinions, some founded on wide observation and hence of value, a few on facts; but, in the main, the opinions are simply notions founded on a single observation, or, at best, but few.

Under the circumstances, what can be said which will assist the young farmer? We hesitate to write anything about the shoeing of horses; but we feel loath to leave the young men at the mercy of the untrained, country blacksmith, or to the loud opinions of some city mechanic who, becanse he has shod the horses of the Honorable Mr. Smithkins, imagines that he has nothing more to learn. 
The feet of the horse being a prime factor when value and usefulness are considered, it will be well if this factor be taken into account when the sire and dam are selected and mated; for like produces like, under like conditions. Good-footed parents tend to produce good-footed offspring. Horses with poor feet should never be used as progenitors of their species. Supposing that the colt is born right, that he is of good inheritance, still his feet should receive attention, especially in the spring of the year. Not infrequently he is kept in the stable for half of the rear, if so, the feet wear away but little; if he stands on manure from which ammonia is escaping, the growth of the hoofs is stimulated, the harder parts of the foot are softened, and the softer portion (the frog) develops an abnormal growth, which not infrequently leads to a diseased foot. Even if the colt is allowed to stand on manure from which ammonia is not escaping, the hoofs are still likely to make too much growth.

To avoid many, if not all of the ills produced by stable confinement, paddocks or large yards should be provided where the colts may spend a large part of each day. True, the hair will grow longer than it would if they were confined in warm stables, but this will not be so serious a matter as to have the hoofs grow long, soft and out of shape. But, in any case, the feet of colts shonld receive attention and be pared off whenever the growth much exceeds the wear. This attention is especially necessary in the spring of the year, just before they are turned to pasture.

If, then, the horse has good inheritance and has had 
proper attention during colthood, he should come to his life work with sound, normal-shaped, hard feet. From this on, use and breed should both be considered. The draft-horse with his large, comparatively flat foot, and the roadster, which sometimes has narrow heels, should have quite different foot treatment as to cutting away the surplus growth and as to the weight and shape of the shoe. When the comparatively low heel of the draft-horse and the comparatively high heel of the roadster are not too pronounced, both are well adapted to the work which these two classes of horses are usually called upon to perform. Climate, soil and use combined have resulted in producing, as a rule, the foot best adapted to all the conditions under which the breeds and varieties were formed. When it becomes necessary to place a breed under conditions differing from those in which the breed grew up, care should be taken to select those specimens which have varied, however slightly, toward the forms which will be best adapted to the changed conditions. Then climate, soil and use will soon accentuate the variations, and the breed will quickly become adapted to its changed conditions, instead of breaking down under them. To the heavy draft-horse, his large feet are to him what wide tires are to the freight wagon, when used on rough pavements or on soft ground. So, reasonably large feet and reasonably low heels are well suited to a heavy draft-horse. The great weight of the draft-horse makes it necessary to shoe him so as to bind and sustain the quarters of the foot and protect the frog as well. Hence, the shoes of the draft-horse should be rather 
wide of web and thick of substance. A shoe with a wide web at the heel will protect the frog of the foot, and a thick shoe will prevent the foot from spreading when called on to sustain heavy weights. If the web of the shoe be drawn in slightly at the heel, and if the shoe extends well back, the frog is usually safe from abrasious. It is only in rare cases that a sound foot is so wide and weak at the heel as to require a bar-shoe.

The foot of the light hor'se, particularly the roadster, is quite different from that of the draft-horse. Here the tendency is often toward contracted heels. Care should be taken to drive fast steppers with high heels slowly when going down hill. Even good shoeing cannot overcome the effects of injudicious driving. If shoes are allowed to remain on the front feet too long, a single day's hard and careless driving on paved roads or over a hilly country may lay the foundation for contracted feet or "jammed" shoulders, or both. After one of these injudicious drives, the horse comes out of the stable with less suppleness and less freedom of stride than before. If the abuse is continued, the stiffness of the shoulders and the tenderness of the feet increase rapidly; and then appropriate shoeing may somewhat alleviate the pain, but it will not cure the unsoundness. Manifestly, prevention is better than palliation.

The heels of horses designed for fast work are usually naturally bound together firmly and closely; a necessity if the horse is to be driven rapidly on hard roads. However, the heels of the front feet may be so 
high as to result in severe heel concussion, and so narrow as to restrict the elastic play of the frog, which normally greatly modifies and alleviates the concussion of the foot when the horse is in rapid motion. If this elastic cushion becomes hard and somewhat unresponsive, it will not be long before the other members of the foot will suffer. If the trouble is not alleviated quickly, the heel contracts and the non-sensitive envelope of the foot becomes too small for the internal sensitive portions. Horses with high, narrow heels should be shod frequently, and a liberal portion of the hoof should be pared away.

The foot may be but slightly affected, in which case a spirited horse will not limp when driven. It is not an uneommon thing for horsemen to dispose of their horses before the unsoundness can be detected by the inexperienced purchaser. However, even if the animal be but slightly affected, if it be left entirely quiet for a little time, it usually thrusts out one front foot ahead of the other, thus relieving the foot of some of its normal weight. If both feet are affected, the horse may ease first one and then the other.

In this work-a-day world, it matters little to the commoner whether a horse trots a mile in three minutes, or three minutes and forty and one-half seconds, but the character of the feet does matter. In addition to good inherited feet, see to it that the horse is not ignorantly driven, and that his feet receive appropriate attention in the stable. Having seen to all this, we may approach the blacksmith shop with a clear conscience. 
The feet of most horses kept for fast work are not pared away enough. The heels are left so high as to prevent the frog from coming into contact with the ground. If the frog does not perform its legitimate purpose of modifying concussion, then it soon becomes hard and inelastic. However much it may be necessary to reduce the horny portion, the buttress should seldom or never be used on the frog of the foot. Never cut away the rough and apparently dead Exterior of a sound foot, for this is as necessary as the semi-sensitive parts which are not and should not be exposed. So, the first instruction to the blacksmith should be, Do not use the buttress on the frog. He may lower the hard enveloping outer crust of the foot sufficiently to allow the frog to come into contact with the ground where the dirt is soft enough to allow the shoe, or the greater part of it, to sink into the ground. Or the rim of the foot may be cut away until the frog just escapes full contact with the smooth pavement, after the plates or the light shoes have been put on. If the frog is slightly higher than the face of the shoe, the inequalities in the pavement are enough to bring the frog in contact with the earth sufficiently to keep it in a healthy condition.

The long strides of the roadster result in the heel of the foot striking the ground much in the advance of the toe. It can readily be seen why the heels of roadsters tend to become feverish, and ultimately contracted. By paring down the heel as much as practicable without endangering the frog, some of the severe heel concussion may be avoided. The student shonld observe carefully how the fore feet of various classes of 
horses and of individual horses come in contact with the road, as it will help to determine how the feet should be pared and shod. The shoes of the horse of quick movement should be rather light and not so thick or broad of web as those of draft-horses. The narrow web exposes the frog to wear more than the wide one does. Some contact of the frog with the earth is desirable and really necessary. If the shoe be somewhat thin, especially near the toe-calk, it will permit the heel to expand slightly. Sometimes it is well to cut it in two in the middle, and make two half plates of it. This method of shoeing gives the greatest possible opportunity for expansion of the heel. Sometimes the ends of the shoe, after it is set, are slightly expanded by the use of a strong pair of tongs; but this practice is not to be recommended. It is seldom that the sound foot is benefited by the use of the bar-shoe. When the feet are abnormal, diseased or injured, do not trust your own or the blacksmith's opinion, but consult a veterinarian. In fact, all veterinarians should have facilities for shoeing horses that have imperfect or diseased feet.

A third instruction should be, Fit the shoe to the foot and not the foot to the shoe. Use the lightest nails that will hold the shoe in place a reasonable length of time. Some horses should be shod semi-monthly; others need not have their shoes removed more than once every twenty or thirty days. The character of the foot and the work performed should determine the length of time a shoe should be worn. And, lastly, give strict injunctions not to rasp or polish or beantify the outside of the hoof. Nature has provided not only a 
most beautiful outer coating for the hoof, but one that is nearly impervious to moisture. Destroy this by the use of the rasp, and the hoof becomes, first, too wet, then too dry and hard, and finally unhealthy. The natural oily protective covering of the foot is far superior to any concoction of tar, lampblack and linseed oil,- - even though it be perfumed and mixed according to some well-guarded formula. True, the clinches of the nails should be smoothed off lightly; otherwise, the outside of the hoof should not be rasped or filed, unless it is abnormal. If the foot is normal, it is not well to shorten the toe and then attempt to give form to the foot by using a rasp. Some one has said that the Lord put all the water in milk that it would bear. Nature's modes of action, undisturbed, produce a goodshaped foot; don't try to improve it. If the foot is good to start with, has been watched and cared for during its growth, has been judiciously used and properly protected by iron or steel, still some attention should be given it, because the horse, when standing in the stable, is placed in unnatural conditions; if standing on a hard floor, his fore feet, especially, become dry and unelastic. Suggestions have already been given as to caring for the legs. When this is being done, the feet should be examined that the condition of the shoes may be known, and, if extraneous dirt adheres to the sole of the foot, it should be removed.

Let it be supposed that the horse has been put to severe road-work for several days, and that this is followed by little or no driving for an equal period, and that the horse is left to stand on a dry plank 
floor; these conditions, especially in dry weather in mid-summer or in cold weather in winter, result in causing the feet to become over-dry, and, in fact, slightly contracted, while the horse is losing something of his suppleness. In a majority of cases, horses which are used only occasionally do not get regular exercise. Hence something should be done to modify the undesirable conditions. The floor of the stall should be kept slightly damp; sawdust may be spread at the front cnd of the stall, or, better still, use a moderate amount of clay slightly dampened, but not so damp as to soil the horse; or, best of all, provide boxstalls for horses which have intermittent work and which alternate between severe work and idleness. (See Chapter XXI.) There are several ways of preventing the front feet from becoming dry and hard when, of necessity, the horse is left to stand on a hard floor for periods of time varying from a few days to a few weeks. We hesitate to recommend packing the front feet with moistened linseed meal, because the tendency too often is to leave the packing in the foot too long, and not to cleanse the foot thoroughly when it is removed. Oil-meal is a highly nitrogenous product, and hence becomes offensive and even dangerous to the foot if the packing is not removed and the foot thoronghly cleansed often. The oil-meal packing is most excellent when properly used; the careless man would better use clay for packing. If the feet of horses used severely on hard roads are examined daily, and simple treatment given when necessary, one will soon discover if the foot has a tendency to become 
feverish and unsound, and then may call in a veterinarian in time for him to be of some use in saving the feet of a valuable horse. If the foot is neglected until it becomes badly diseased, even the expert cannot usually restore it to soundness. All that can be expected of him is to palliate the trouble.

Some horses overreach because of faulty form. The front quarters of such horses may have something of the draft conformation, while the hind quarters approach the trotting-horse build. In other words, the front feet cannot get out of the way of the hind ones, because of their hesitating motion, and the long, quick reach of the hind feet. If, by a slightly modified method of shoeing, the movement of the fore feet can be hastened, and that of the hind feet retarded by a fraction of a second, the overreach will be obviated. If the soles of the front feet be lowered at the toes and the toes slightly shortened, and the heels left rather high, the roll of the foot and the time of the heel's leaving the ground are hastened. On the other hand, if the heel of the hind foot be kept rather low, and the toe slightly longer and higher than the normal, the time of the hind foot leaving the ground will be slightly retarded. If, by reason of the lowered, shortened toe, the time when the front foot leaves the ground be hastened, and that of the hind foot retarded by reason of the slightly higher and longer toe, the fraction of a second needed to keep the hind foot from coming in contact with the front one is secured. The blacksmith usually reverses all this, - shoves the front shoe forward 
to get it out of the way of the hind one, and places the hind shoe back of its normal position, with the hope that it will not strike the front one. This method of shoeing does not accomplish the desired result. Taut lines and encouragement on the part of the driver materially assist the horse to overcome the habit of overreaching or stumbling.

Many patent shoes designed to save the front feet of horses, especially the frogs of the feet, are on the market. None of them are of much use to sound feet; some are a positive injury to the foot, as they cause the frog to become tender from non-use and, in time, to become diseased. When the foot becomes unsound, a padded shoe may palliate pain and prolong the usefulness of the animal; but all of these shoes which we have seen allow the dirt and filth to get under the protecting pad. By reason of the constant wet, dirty and unsanitary conditions of the frog and sole of the foot, due to the dirt under the pad, and the partial exclusion of the air, the foot inside of the hard outside covering tends to become soft, tender, bad-smelling and diseased. Patent horseshoes can, at best, only palliate the ills of the fcet due to bad breeding, over-driving, want of care and the insane desire to draw the largest possible load or to pass everything on the road. The ideal horseshoe is yet to be invented. The horse's foot really requires little attention, if the horse is bred right and used humanely and with judgment. We wonder if time is so precious and valuable, after all, as to justify the tearing up and down the country of droves of people at breakneck speed, in nervous haste to overtake and find rest and 
recreation, and a locality where there are two-minute horses and no Sabbath.

Fig. 84 represents the exact shape of the foot of a four-year-old three-fourths blood Percheron mare, weighing 1,450 pounds. A matrix of the foot was formed of clay, and the drawing was made from it. It is a fine foot for a draft-horse; the frog is reasonably $\mathrm{high}$ and the heel only moderately wide. The shoe measures seven inches from toe to heel, and is six and one-half

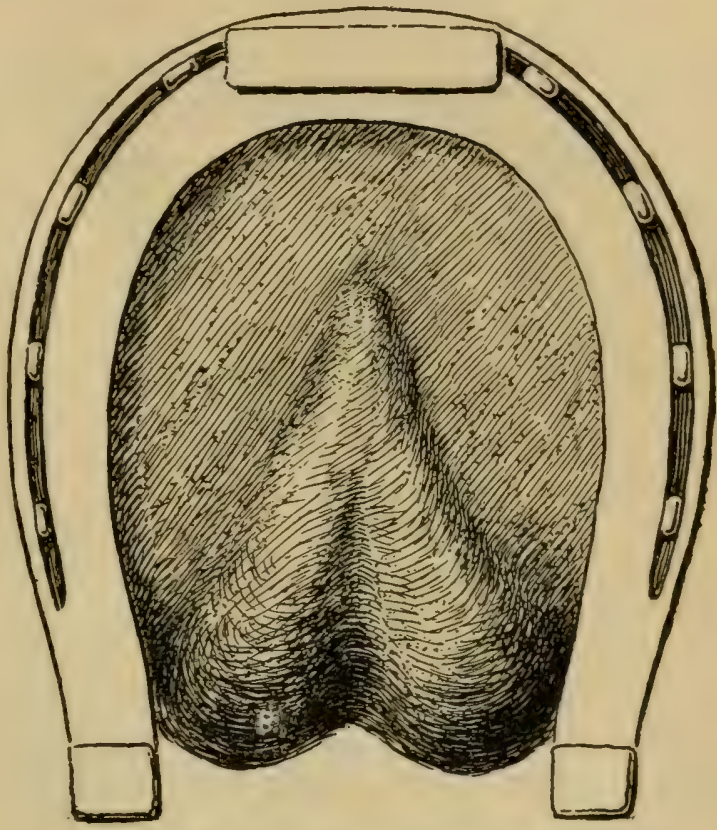

FrG. 84. A foot that will last through life inches wide, and embraces an area of a trifle more than thirty-seven square inches. Fig. 85, from a photograph, is a front view of both feet.

Fig. 86 was also drawn from a clay impression. This fore foot is most excellent in shape, and represents that of a mare sired by a trotting stallion out of a fairsized active farm-mare. The heel is proportionately narrower than that shown in Fig. 84, and the foot is more rotund and is almost an ideal foot. The shoe is 
five and one-half inches long and five and one-half inches wide, and embraces twenty-five and nine-tenths square inches of area.

The font of the horse frequently plays an important part in tillage. Not infrequently, the horses are driven

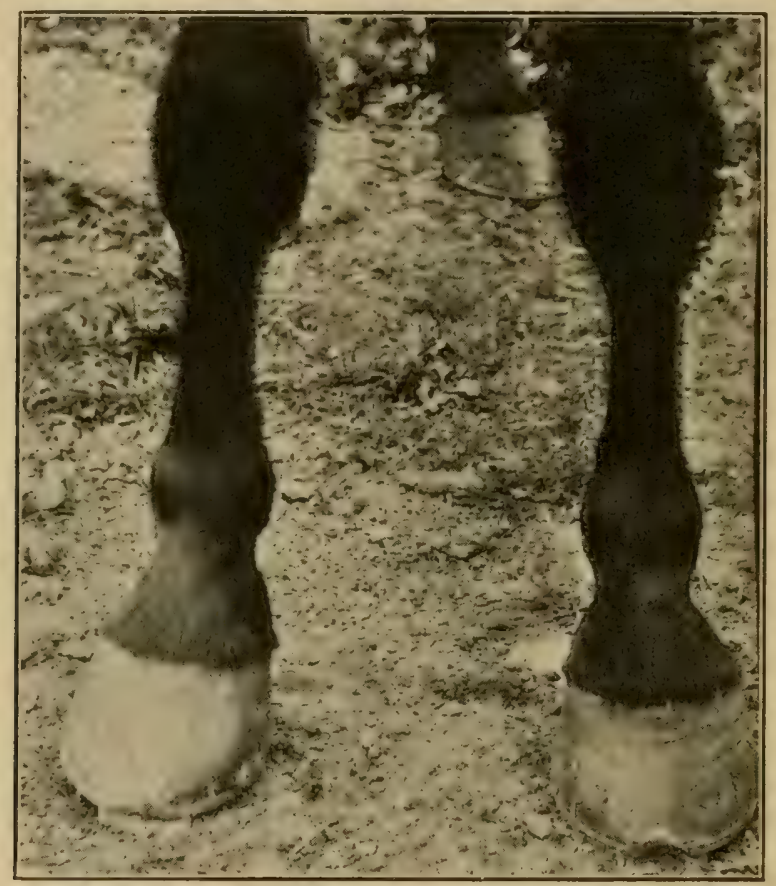

FIG. 85. Two good feet supporting a broud breast

over the field five times in preparing the ground and in covering the seed. Watching horses when at work plowing land, it was found that the average step was four feet three inches, and that most horses, when at this kind of work, set the hind feet down a little short of the track made by the front feet. Supposing this to be the case, and that each foot of the horse at each step 
covers and presses thirty-one and one-half square inches of surface, and that two horses be driven over the plowed ground five times, in the fitting and seeding of the land, and that the implement covers an average space of five feet at each passage, the feet will have compressed and fined approximately five-twelfths of the acre of land. However, some deduction may be made, for it is probable that the feet will occasionally tread in a former track. Usually, un-

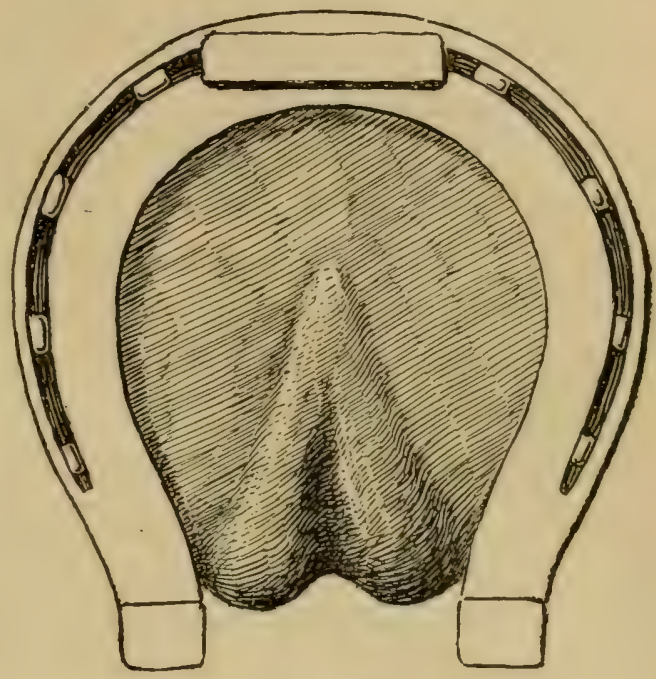

Frg. 86. Durable and beautiful

plowed ground is too compact and plowed ground too loose for the fullest growth of most plants, and the compacting and fining of the surface soil by the horse's feet is usually beneficial, as far as it goes. Then, too, many clods will fall into the depressed tracks made by the feet; as the harrow follows, the clods will be drawn into the depressions and crushed or covered; if covered, they become softened and are then fined by the roller or a second harrowing. Sometimes the beneficial effects of the compacting by the feet are marked. On the other hand, the tramping may be detrimental, as when the ground is moist and the crop to be raised does best in a loose soil. 


\section{SHOEING, TO IMPROVE ACTION}

In shoeing horses with a view to improving their action, the shoes for the fore feet are made especially heavy, and the toes are rounded off from the under side with the intention of enabling the horse to lift his feet as quickly and as easily as possible. When a horse thus shod feels the additional weight on his foot, he makes an increased effort to raise it and, not taking into account the greater ease with which the toe leaves the ground, he elevates the knee higher than he has been accustomed to do. Most horses are greatly benefited in height of knee action by heavy shoes with smooth, round toes. This plan works very well with some horses, possibly the majority, but with others it causes them to forge or overreach; because, as the toe begins to leave the ground, the toe of the smooth, rounded shoe slips backward and the horse forges, - not as in the case above referred to, where the hind foot strikes the iron of the front foot before the latter can get out of the way, but because the fore foot slips backward and in reality forges with the iron of the hind foot as it is going to its place.

Hock action in some horses is benefited by similar treatment, and, again, by the very opposite. Some horses, while they are improved in the mere act of raising or lifting the knees, are thrown out of balance by the fore legs moving too fast at the beginning of the stride; in which case they either shorten their gait or "point" or "dwell" with the action of the foot just before it reaches the ground. So much depends upon the perfect balancing of the animal, which may be slightly 
out of balance naturally to begin with, that the question of shoeing for the improvement of action must be largely one of cut and try, and adaptation to the individual horse.

Horses that "paddle" or "dish" the fore feet are animals that either toe in or do not stand properly on their legs, or whose legs are not straight. This winding motion is quite as objectionable as pointing or dwelling. It is also prevalent in broad-chested horses that usually have a rolling action of the body, and, again, in horses that for the same reason have the elbow-joint crammed at the beginning of the stride and suddenly liberated after the foot is well under way. Shoeing such horses, heavy on the inside of the foot and especially toward the heel, is in some cases very beneficial; in others, the additional weight seems to aggravate the cause. As a rule, it may be said that action follows weight; that is to say, if a horse follows too closely behind, so that he interferes, the weight on the outside of the shoe will make him step wider apart. If he travels too wide, weighted shoes on the inside would make him travel closer. This is the principle, but, like many other principles, it has many exceptions. Sometimes a hind shoe particularly long on the outside answers the purpose, but even then it may be owing more to the additional weight of the shoe than to the additional length. This subject has been treated somewhat in detail, with a view of calling attention to these matters and to enable the novice to solve the puzzling problem by his own study and observations. It may be said that nearly all the rules for shoeing, with the view of correcting faults of conformation and 
of improving action, are cousistent only in their unreliability. This is because horses dish, point, interfere and forge from many different causes; hence there are many men of many minds. When an artist of the anvil succeeds in making a horse stop interfering or forging, he thinks he has discovered the secret and will forever after shoe every horse identically the same for the same defect. The trouble is in the want of ability to discern the true causes which produce the defect.

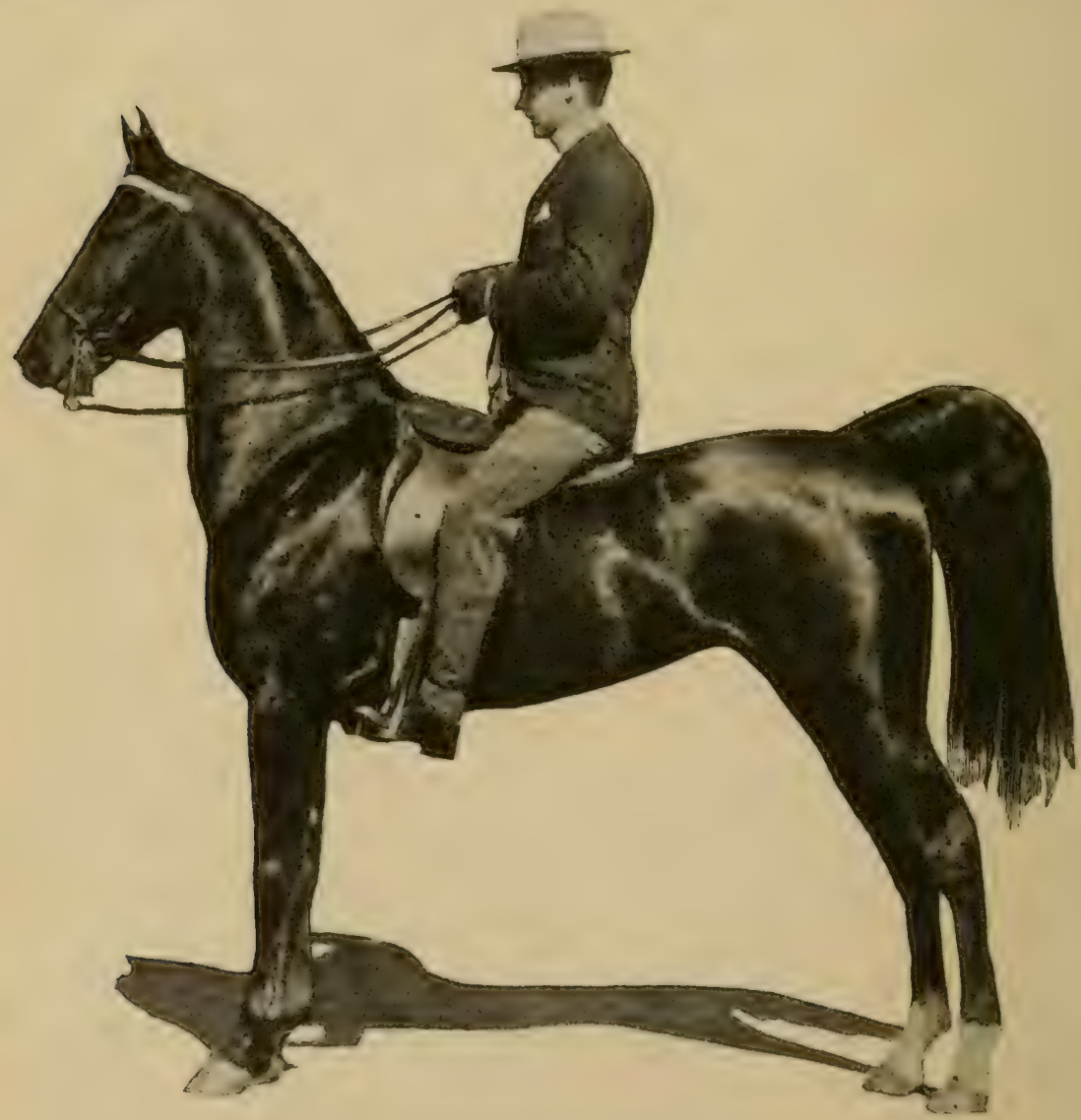

Gypsy Queen, a good saddler 


\section{CHAPTER XXI}

STABLES, SANITATION AND PADDOCAS

EAcH horse should be previded in the stable with at least two cubic feet of air-space for each pound of live weight. Cattle require about one-half as much air-space per unit of live weight. This difference arises in part from the fact that both the solid and the liquid voidings of horses begin to ferment much quicker than do those of eattle. Horse manure is hot and dry; cow manure, cold and wet. Horses are put to exhaustive work and require a full supply of oxygen in the stables, that the depleted energy may be quickly replenished.

High ceilings save floor space and are more satisfactory than low ones, as they give opportunity for lighting and ventilating. The horses' heads should be turned away from the light, and hence from the windows. Side lights are not so objectionable as are those placed in front of the horse. All windows should be arranged for lowering the top sash, as well as for raising the bottom one. Windows should be numerous and tall, if the ceiling permits; if it does not, sash hung near the middle may be made to serve for both light and ventilation. Fig. 87. The windows may be furnished with screens; but, if they are curtained and the light in the stable be reduced in the middle of the day, the flies will be largely excluded. 
It is seldom that tuo many windows are placed in the stable. All the light that is practicable to introduce will be needed morning and evening in cloudy weather and during the short days of winter. It is inexpensive to exclude some of the light in midsummer. Many windows assist in securing ventilation. True, windows increase the temperature in the daytime and serve to radiate heat at night. The worst possible position for a window in a stable is immediately in front of and on a level with or above that of the horse's head. If such windows be even partially opened, dangerous drafts of air strike the horses on their most vulnerable points - heads and eyes. I have known two high - priced spans of coachers to be seriously injured by drafts from such windows. When the stables were rearranged and the horses placed with their heads away from the

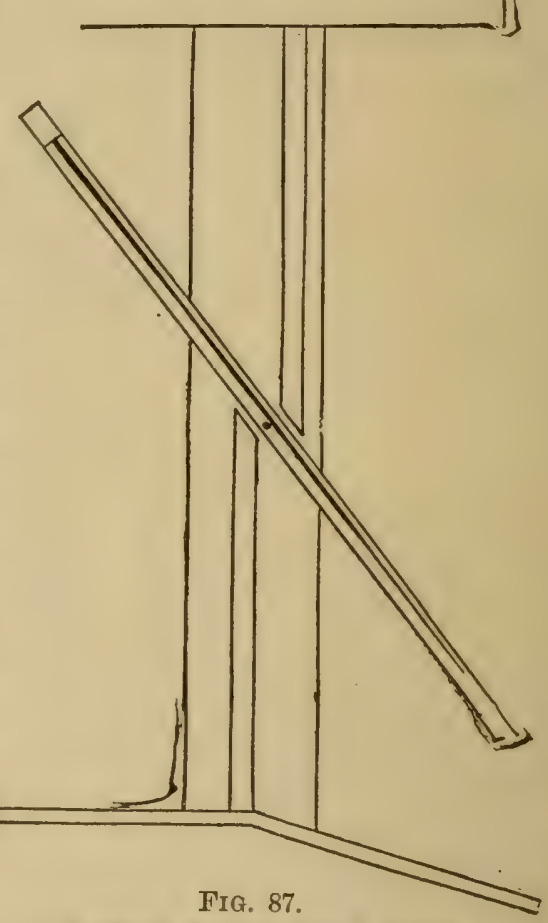

A swing window for a stable outside wall and light, the trouble ceased. Most sizable stables are arranged with a wide walk-way between two rows of horses, the two feed alleys being placed on the ontside. This arrangement is objectionable for several reasons. First, it places the horses' heads toward 
the light; then it masses all the voidings of the animals in the center of the building where good ventilation along the floor cannot be easily secured. When the arrangement is as shown, in Fig. 88, the floors may be ventilated from an outside opening, as previously described. The outside walls furnish room for the harness, and at the point where they will dry more quickly than in any other part of the stable, unless a separate wellventilated harness-room be provided. Where but few horses are kept, the big barn floor is frequently used for the feed-hall. This results in placing the horses with their heads away from the light. Where the stables are thus arranged, they are likely to be over-ventilated. To overcome this, flap doors are hung at the front of the mangers, which may be closed at night in cold weather. The panes in barn and stable windows should be small; eight by ten is a suitable size. Small window-panes are less likely to be broken than large ones, since the numerous bars of the sash serve as fenders. Then, too, small panes are more cheaply replaced than large ones.

Where there are several colts on the farm, a cheap shelter should be constructed into which the colts may retire from the hot sun when the flies become troublesome. There should be doors in each end which may be left open to secure a draft of air. The door opening may be covered with large pieces of coarse material. The animals soon learn to pass into the structure and, in doing so, brush off the flies. Inside, it is dark, as no windows are provided, and the colts are comfortable and are not stamping the grass. In the cool of the evening, ther go out to graze. Sometimes the structure 
is made tall enough to store hay in the loft, in which case the colts are wintered in the building, being fed but once a day. Mr. A. C. Chase, of Syracuse, N. Y., has found this method of rearing Morgan colts most satisfactory.

\section{VENTILATION}

Horse stables should be kept cooler in winter than cow stables. The modern stable, like the modern house,

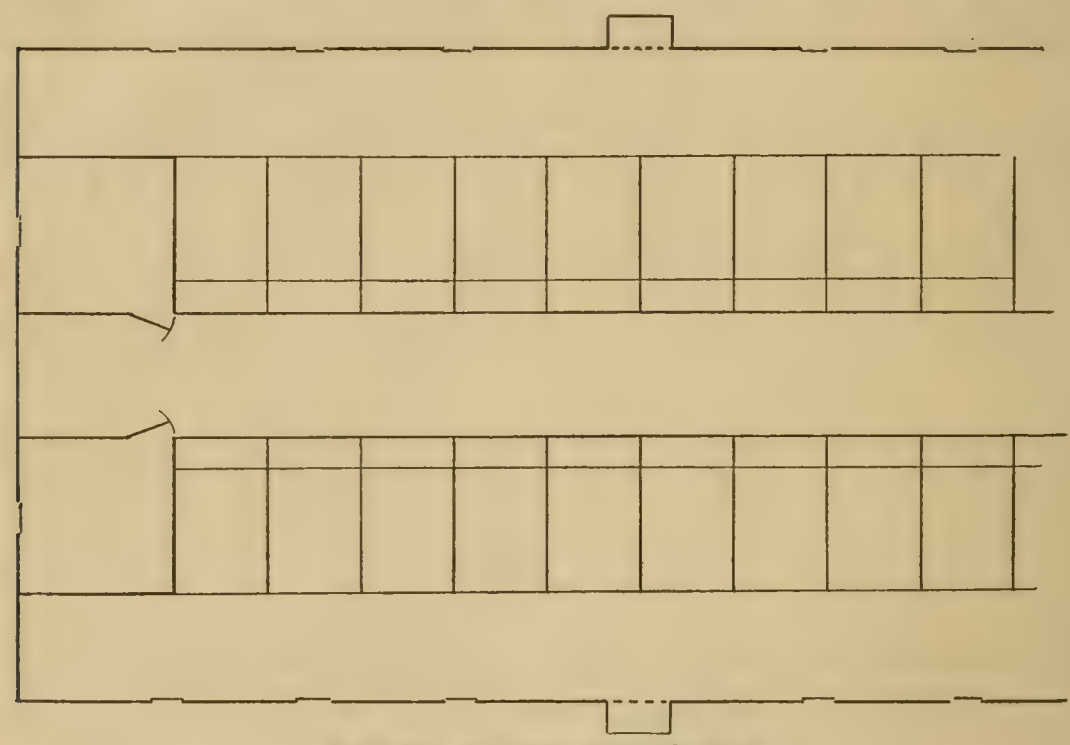

FIG. 88. An ideal arrangement

is usually kept much too warm in winter. It is easier to ventilate horse stables than cow stables, since, if the introduction of an abundance of fresh air does lower the temperature to or even below the freezing point at times, no harm is done; provided, however, the air is admitted at many small openings. (See Blankets, Chapter $\mathrm{XV}$.) Large and few openings tend to produce strong 
and dangerous drafts. If the stable is planned similar to the diagram, Fig. 88, the horizontal ventilatingtube arrangement may be adopted as follows: Place a box of about ten inches by one foot six inches flatwise against the ceiling and over the hallway in front of the

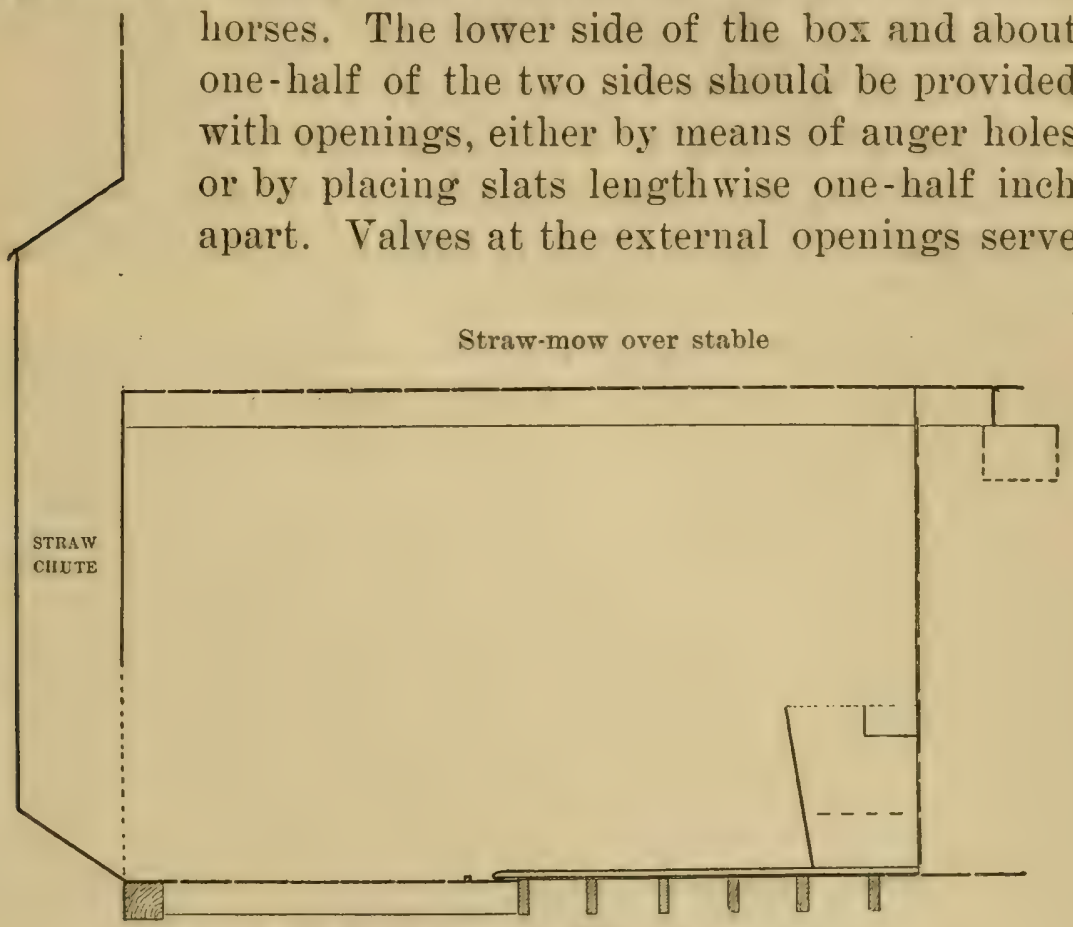

Fı. 89. A straw chute and ventilator combined

to prevent too rapid egress of air out of the building, in windy, cold weather. The straw chute may also be used in part as a ventilator. Fig. 89 .

The walls of the stable should not be too tight, or the moisture of the dampish air in the stable will condense on the inside walls. A damp stable is very objectionable. If not enough fresh air enters the stables 
through the many minute cracks of the outside wall, the window-sashes may be raised and lowered to suit the temperature and other conditions. Horses kept in cool stables are healthier, more vigorous and less likely to suffer from contagious and other diseases than are those kept in overheated stables. However, if they are not blanketed, their hair will not be so smooth, short and soft as it would be if they were kept in warm stables, - that is, those where the temperature seldom falls below $40^{\circ}$ Fahr., and is usually between $50^{\circ}$ and $75^{\circ}$ Fahr.' (See Blankets, Chap. XV.)

The decomposition of the excrements, especially the urine which soaks into the floor, goes on more slowly in cold than in warm stables; hence the air in cool stables is likely to be purer and better than in warm ones. Most horses are subjected to many vicissitudes of weather while at work; therefore their vigor should not be reduced, nor should their skins be made oversensitive, by being placed in stables where the temperature is so high as to weaken appetite and relax the system. (See Grooming, Chap. XV.)

The most unhealthy stables I have ever inspected were in northern New York. They were boarded inside and ont with first-class matched pine lumber. The windows were few and closely fitted. In the winter, they swelled so tight, as did also the doors, that they could neither be opened nor closed readily. The boxstalls were nearly air-tight. Their inner surfaces were saturated with condensed moisture, and even large drops of water adhered to or dropped from the ceiling. In two of these barns, the ground feed was spoiling on 
the second floor, because of the condensed moisture and the breath of the animals in the stable. One of these barns was fitted with elaborate, expensive and highly recommended metal ventilating appliances. In both of these barns, icicles more than a foot long depended in many places from the rafters and roof-boards in winter. We have gone from the one extreme of sieve-like boarding and open floors to the other - air tight boxes. A happy medium should be adopted.

Unmatched, surfaced, vertical, outside boarding, properly battened, supplemented in cold climates with inside, unmatched but jointed covering, will be ample protection from the cold and wind, except, perhaps, in extremely exposed localities. If added protection is needed, the space between the two boardings, which may be about one foot apart, may be filled with cut straw or chaff. A dry wall, through which the air passes slowly and upon which little or no moisture will condense, is secured, and a much more satisfactory one than can be constructed with matched lumber and building-paper. In rare cases, even with such a wall, the dampness in the stable, in extreme cold weather when doors and windows are closed, may be too great. If so, cut several small openings near the floor and provide them with fine wire-screen covers and a drop-lid for closing them when they admit too much air, and place one or more ventilating tubes at right angles to the one already described above. In any case, cold air is better than over-moist air. The air can now be directed into and out of the stable without creating drafts or depositing moisture. The simplest and most direct way 
of managing air in stable or house is usually the most satisfactory; since the air is likely to be acted upon by pressure and counter-pressure currents, and contraction and expansion, the best planned complex system too often utterly fails. Warm air wll carry more moisture than cold air. If, then, cold, dryish air be introduced into the stable near the floor, or mid-way between floor and ceiling, and is then warmed by the heat of the animals, it will take up the moisture as thrown off by respiration, and, as the air becomes warmer, it will become lighter and rise where it will find easy egress out of the stable, either at one end or one side, through the perforated box at the ceiling. At which point it escapes will depend upon the pressure or the direction of the wind. Moist and vitiated air, like honse sewage, should be removed by the straightest, quickest, simplest and most direct route.

\section{MANURES}

A good and convenient arrangement, though not by any means the best, is to provide a covered yard beneath the stable, into which the excrements may be thrown for temporary storage. In such an arrangement, the danger is that the basement story will be built largely under ground and be too low. If so, it cannot be suitably lighted and ventilated. If properly constructed, and the floor above is made tight and the manure is cared for as it should be, such arrangement will be fairly satisfactory. If a lower story (not a cellar) is used for the temporary storage of the manures 
and for temporary shelter for farm implements in the summer, care must be taken to prevent the manure from heating. Horse excrements, if unmixed with those of the cows, should be thoroughly wet from time to time and, if convenient, solidified by the tramping of animals. Some salt may be used on the manure, a quart for each load. This will retard heating and dis-

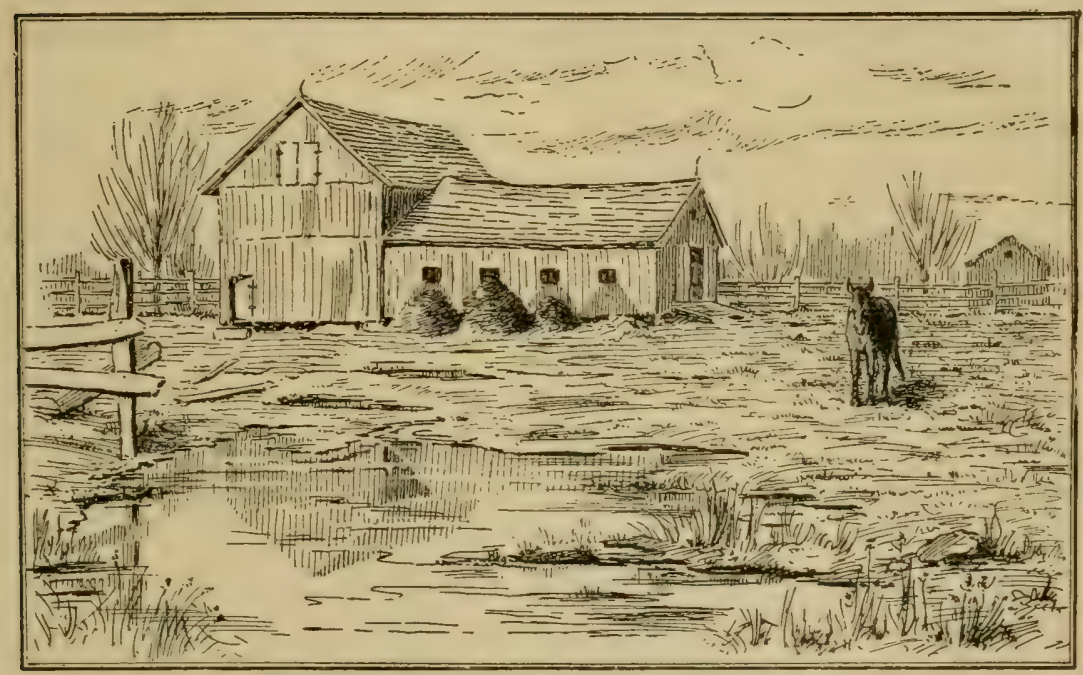

FiG. 90. There are better ways than this

courage the flies from breeding in the manure. Dry earth, or better gypsum, should be sprinkled daily on the floors of the stables where they are damp. One quart of fine dry earth, or half that much of grpsum will be sufficient for each stall. By such treatment, sanitation will be promoted and the manures be conserved. Grpsum is better than dry earth in the stables, since it acts not only as an absorbent and disinfectant, but, when the manure is applied to the land, the gypsum 
helps to make the potash in the soil available. But no stable treatment will conserve manures when thrown out under the eaves. Fig. 90 shows the worst possible disposition that can be made of a valuable product from the stable. The manure from the horse stable, in any case, should be carefully husbanded, since the amount, including bedding, usually reaches six to eight tons per horse per year. The value per day of the excrements ranges from three to five cents and from ten to fifteen dollars per year, per horse, provided the horses are in the stables the greater part of the time. (See "Fertility of the Land.") If means justify, a lean-to or a separate small building may be constructed for temporary storage of manures; in which case they may have to be transported daily to the storage building. Swine or cattle may, in some cases, be allowed to roam over the manure for a portion of each day in the winter with benefit to the manure and to the animals.

\section{FLOORS, STALLS AND MANGERS}

Sometimes horses may be placed on the second floor above a covered yard, or above other animals. In any case, the stable floor should be water-tight. Wooden floors, all things considered, are usually the best; but conditions may be such as to justify the use of other materials. Brick, cement and stone floors are somewhat objectionable for the following reasons, - they are hard for the horses to stand upon, are slippery, and, if bedding is not abundant, are damp, and they absorb the heat of the horse when it is lying down. A good, tight stable floor may be made as follows (Fig. 91): 
Lay an unmatched rough inch floor, $\mathrm{C}$; upon this place strong tarred building paper, $\mathrm{B}$, with joints well lapped. Saw and prepare the two-inch planks which are to form the floor, A. For every four hundred square feet of floor, procure one barrel of Trinidad

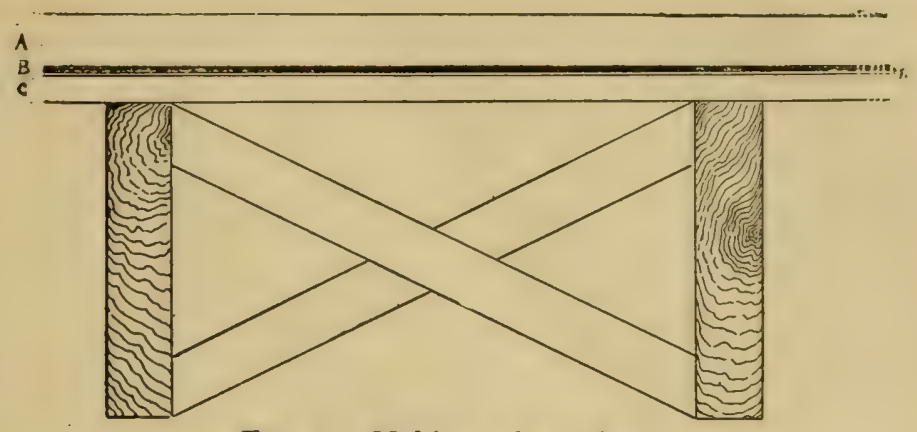

FIG. 91. Making a barn floor

asphalt and three gallons of gas-tar. A large iron kettle may be used for heating and mixing the material, which should be in proportion of about one to ten. With an axe remove the barrel, and chop off and place in the kettle pieces of asphalt until it is not much more than one-half full, then add the due proportion of gas-tar. 'The kettle should be placed in a rude arch at a little distance from the building. By means of a slow fire, heat the material. If by chance the material should take fire invert the kettle. When all is ready, dip the hot mixture into a galvanized iron pail and pour it in a small stream on the paper, spreading it to the width of the plank intended to be laid, by means of a shingle or paddle. Lay the plank in the hot material, being careful that when it is spiked down the hot asphalt does not fly into the face. Then proceed to 
lay other planks in like manner. Finally pour some of the material into the cracks, if there should be any. ${ }^{1}$ Should the floor become worn in time and need repairing, even up the surface by spreading thin cement mortar upon it, and upon this lay a second plank floor. The cement mortar will assist in making the floor watertight and in preventing dry rot. Barn floors which have become worn from driving over them may be treated in like manner.

When the second floor is laid on the first (when it becomes worn), a portion of the stall may be provided with a removable grating, which will measurably prevent the horse from becoming soiled. This is objectionable in some respects, because the horse must be removed and the grating lifted if the stable is made clean. After having tried several methods, and observed many, for caring for and removing the liquid voidings, I know of none better than to absorb them by use of chaff or straw bedding of virions kinds placed just ahead of the cleat shown in Fig. 89. The planks of the floor of the stall should be laid at right angles to those of the rear walk-way and two inches higher, their rear ends lapping upon the plank walk two to four inches. The planks upon which the animals stand are not infrequently laid with a fall from front to rear of two to three inches. Such a floor is eruel to the horse and does not promote cleanliness. One inch fall in six feet is sufficient. Horses when worked hard, if left free in the field, seek to place the heels of their feet, especially their front ones, higher than their toes

${ }^{1}$ A floor laid as described, eighteen years ago, is still in good repair. 
and their front parts lower than their hind parts. By so doing they rest the back tendons and the back side of their legs, the parts which are subjected to the greatest strain when at work; hence a floor which has a marked rearward fall is objectionable. Sizable farmhorses should have stalls ranging from five to six feet wide, since the stables are cleaned, horses groomed and harnessed without moving them from their stalls.

The box for feeding grain should be large, made of hard wood with level, broad bottom. The edges of the box and the strong bars placed in front and at the rear of the feed-bunk would be better covered with bandiron. That part of the manger designed for hay is usually too large, that for receiving the grain too small. Horses are inclined to eat their grain too fast. A large flat-bottomed grain-box tends to make them eat slowly, and hence to insalivate their food. Horses are usually fed too much hay. If the manger is large, it is difficult to prevent the attendant from over-feeding, unless he is required to weigh eaeh horse's hay ration, a thing usually impracticable.

The hay should not be thrown from an upper story directly into the manger, no matter what kind it is, neither should it be thrown direct from the mow in front of the horse, but into a small room separated by a door from the stable proper. This room should be large enough to permit of the hay being shaken up and sprinkled with water when occasion requires. Neither should the bedding be thrown down in such a manner as to cover the harness and horses with dust.

Fig. 89 shows a straw chute constructed on the 
outside of the stable but opening into the straw-mow above and into the stable below. The door, shown by dotted line, is hung by means of weights, moves perpendicularly, and is closed when the bedding is being thrown into the chute and opened when the bedding is being removed to the several stalls. The chute may also be used as a ventilator.

\section{PADDOCKS}

A few paddocks, or better, small fields, should be provided near the barn for the dams and foals and other horses on occasion. They should be provided in any case if live stock is being raised. The enclosure should be large enough to allow of some pasturage. Paddocks are usually so small that the grass is destroyed by the tramping of the animals. Not only will such small fields serve to separate the dam and foal from other livestock, but they may be made the means of advertising the fact that good animals are being reared, provided they are suitably located. They should, where possible, be in sight of the front veranda and abut on the public highway, that the passer-by may linger to see and be persuaded to purchase. Such fields and the colts are to the breeder what plate-glass windows and their display are to the merchant. The merchant never puts his finest goods in the back end of the store, or where they cannot be seen readily. Increase the productivity of the large fields, and then these small fields will not be missed when laid down in permanent pastures and used for displaying the best animals. 


\section{CHAPTER XXII}

LINE OF DRAFT, WEIGHT OF HORSES AND WAGON TIRES

IT IS not enough to have good horses well nourished; their powers should be directed along most efficient lines. Figure 92 illustrates how one span may lift and roll out of its resting place a stone so large that it may require three spans of animals to draw it when placed on a stone-boat. However, oxen are better than horses for this purpose. If it is desired to haul a heavy $\log$ for a short distance, the chain is attached at the lowest point, or under the side of the log. In some of the old English works on plowing (Fig. 93), the line of draft is represented as starting at the center of resistance, thence running in a straight line through the clevice at the end of the beam, and ending

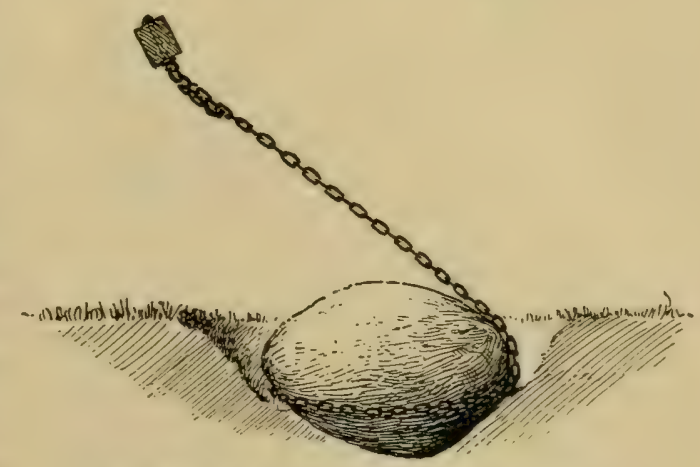

FIG. 92. Energy efficiently directed. where the traces are attached to the hames. The American plowman uses short traces, which results in bending the line of draft upwards, thus diminishing the 


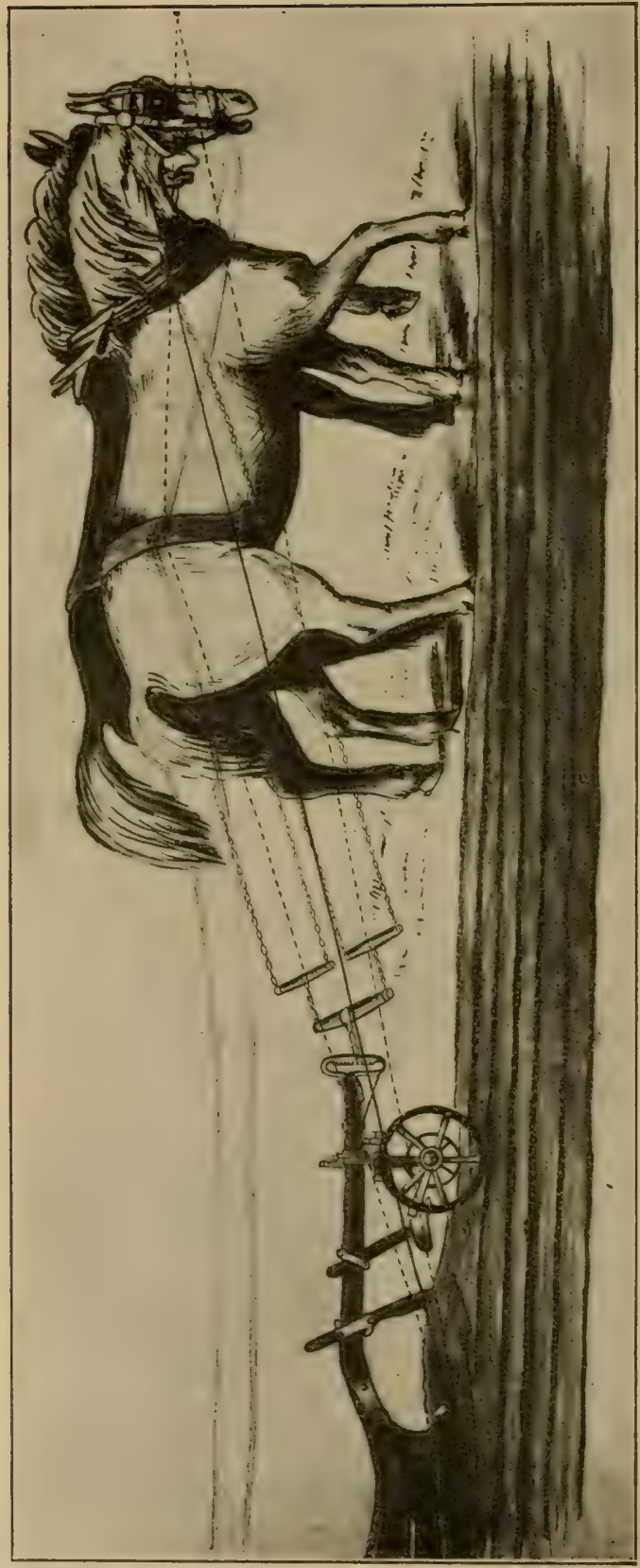

friction of the sole of the plow. (Fig. 94.) The bent line of draft tends, of course, to raise the plow out of the ground, but this is overcome by giving the point of the plow a little more piteh. It is often \& observed by farmers that tall horses $\Xi$ appear to plow with i less effort than low E ones. This is no $\therefore$ doubt a fact, since the line of draft is bent more by the tall horses than by the low ones. g Horsemen all know that teams are most efficient in moving heavy loads when hitched close to them. The reasons for this may be found in the greater bend of the line of draft and in 
the greater traction power of the animals. In other words, the closer the horses are to their load, the more of the weight of the load is placed on the horse. His shoulders not being at right angles to the direction which the load is to take, ? a part of the load is thrown upon the body of the horse. This relieves some of the friction of the load and practically gives more weight to the horse, and this, in turn, tends to hold him to the ground and increases his traction power. In early days, farm products and merchandise were transported largely by teams of four or more horses. The smallest horse was put on the nigh (lefthand) side of the pole (tongue). The pole horses were not called on to do their full share of the work where the roads were' good, but were kept in part as a reserve. When a supreme

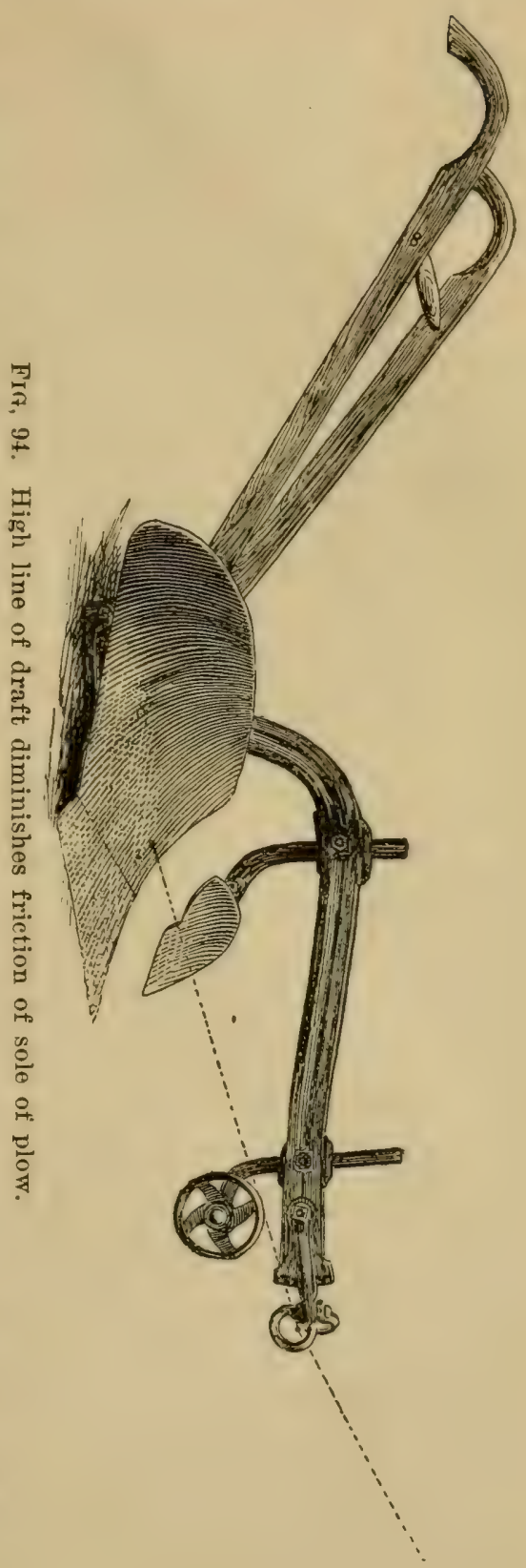


effort had to be made, the driver leaped on to the little horse, when, for a short time, by reason of his added weight, he was nearly equal in draft power to the larger horse.

Low-wheeled wagons are becoming somewhat common on the farm; they should become more common, although they run harder, other things being equal, than wagous with wheels of standard size. However, the length of haul on the farm is so short that the increase of draft due to the small wheels may be ignored, especially since human physical energy is far more expensive than horse energy. It is not economical to lift heavy material unnecessarily high for the purpose of easing the horses, or for the fun of throwing the material down again. Farm-wagons should have, as a rule, wide tires, although, under some circumstances, they increase the draft over narrow-tired ones seriously. Wagons with wide tires run easier on hard pavements, be they smooth, as of brick or asphalt, or roughish, as when constructed of stone. But on dirt roads covered with two or three inches of stiff mud, the wide-tired wagon is a "horse-killer," or so pronounced to be by good teamsters. The use of widetired wagons tends to prolong the life of the good road; but this is no reason why wide-tired wagons should be used at the expense of horse-flesh to improve dirt roads which become "villainous" every spring and fall. Narrow tires push away and cut through the mud and find a hard bottom. Wide tires push down and climb over the mud, and by so doing the draft is increased. 
When horses are used for draft purposes on pavements, their weight becomes a factor of prime importance. Manifestly, it is not convenient in great cities (especially American cities) to hitch several horses to one wagon. Fortunately, rnost of our streets are wide enough to permit of two being driven abreast, and, when so driven, they are most efficient in backing a load. On pavements, horses get but a precarious foothold for pulling. On moderately soft ground, they are able, by placing the feet well back, to bring the soles of the feet at an angle of fifteen to twenty degrees from the horizontal, or the direction of the movement of the load. On the smooth pavernents, no such advantage can be taken, and here efficiency of draft depends largely on the weight of the horse. If, then, friction on the pavement becomes so important, can the line of draft be so adjusted as to increase it? It is evident that if the point of attachment to the load be low, the friction of the feet of the horse on the pavement will be increased; if the point of attachment be high, it will be diminished. Therefore the doubletrees should be placed in a supporting iron under the tongue of the wagon, especially if the wagon has low front wheels and is used for heavy traffic. The farther back the doubletrees are placed, and the shorter the traces, the more pronounced will be the angle of draft and the greater the traction power.

A horse weighing 1,500 pounds when tested, by placing the attachment to the load but six inches from the ground, was able to pull 2,310 pounds as measured by dynamometer. When he was attached to the load at 
the height of two feet, he was able to pull 1,980 pounds. When attached at a height of three feet, he was able to pull 1,732 pounds.

When horses are attached to light vehicles where light draft, rapid movement, safety and beauty are desired, the point of attachment to the vehicle should be high. Horses used for light work are often "frisky," and they may get over the traces if they are hitched low.

When driving a single horse to a light sleigh, he should be placed immediately in front of it, if he is to be driven only in the city. In the country, the horse is attached in front of the right-hand runner, that he may travel in the right-hand beaten track. In the United States, the law directs that, when teams meet, they shall turn to the right; in most European countries, teams meeting turn to the left, which is far safer and more convenient. The awkward American custom is due without doubt to the almost universal use of oxen in the pioneer days. Since oxen are driven by walking on the left side of them, it is most convenient to turn to the right. The driver of horses sits on the right; logically, he should turn to the left.

We now come to auother method of attaching horses to two-wheeled vehicles, which first became common in London and later, happily, was introduced into some of our American cities. The hansom-calb is a light two-wheeled covered carriage with the driver's seat elevated behind, the reins being passed over the top. It is so balanced on the axle that, when loaded with one or two passengers and driver, the tendency 
is for the shafts (thills) to rise. This tendency is prevented by a wide, padded belly-band. This method of attachment practically transfers a part of the weight of the front end of the horse to the axle, and this results in great gain, as it relieves some of the concussion of the horse's front feet on the pavement. Since the draft of the load is light, the horse can well spare some of this weight, and this may result in preserving the soundness of the front feet. Many times, horses with front feet slightly affected are used in hansoms; because there is opportunity to relieve some of the pain due to slight unsoundness.

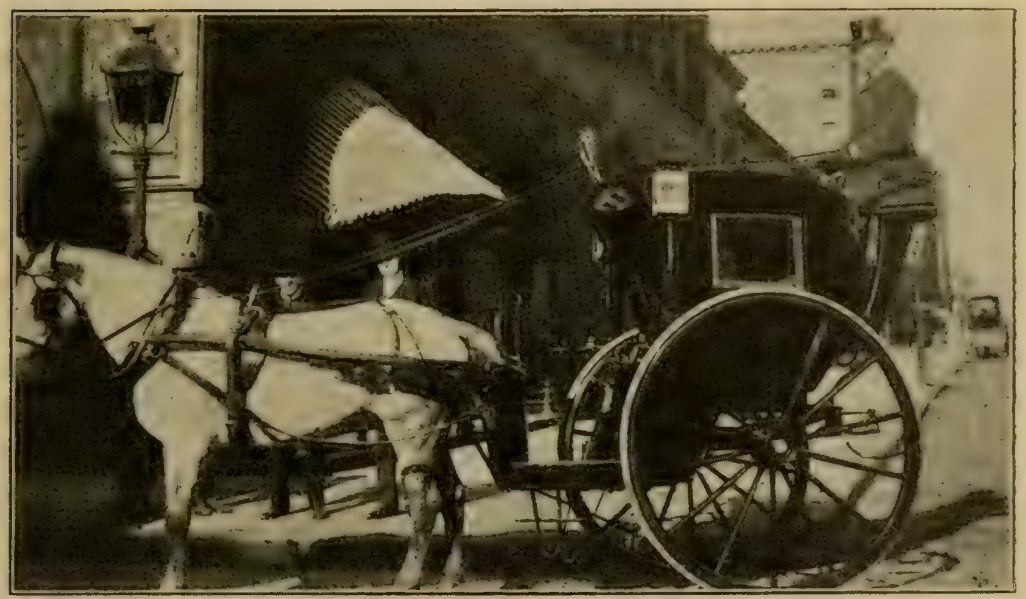

Fig. 95, Saves front feet of horse. 


\section{APPENDIX I}

\section{THE BREEDING IN CANADA OF HORSES FOR $A R M Y \quad U S E$}

By the kindness of J. G. Rutherford, Chief Veterinary Inspector

WHILE the supply of horses suitable for military use has always, even in times of peace, been a serious question, the experience of our South African troubles has given it an importance altogether new and somewhat startling. It has now been clearly shown that troops under modern conditions of warfare must be able to move rapidly from place to place, and that the mounted soldier has thus an immense advantage over the less mobile infantry man.

This development has led to the purchase by the British Government, during the present campaign, of a very much larger number of horses than would otherwise have been required. Nor has the lesson been learned by Britain alone; all military nations have been closely watching the operations in South Africa, and there is no room for doubt that the general demand for horses suitable for army purposes will be much greater in the future than in the past. Of the horses purchased for use in Africa the Dominion has by no means furnished her fair share, although, in addition to those taken by our own contingents, a considerable number have been picked up in Eastern Canada by Lt.-Col. Dent, of the Remount Department of the British Army. It is not, however, an easy matter at present to obtain in this country any large number of horses altogether suitable for army use. No encouragement to produce them has, until very recently, been shown to breeders, and, there being no very active home demand for any but the very best of the sorts now asked for, they have not been bred to anything like the extent of which the country is capable. 
After the visit of Colonel Ravenhill in 1887, the western ranchers, in expectation of a market, went to much trouble and expense in securing and importing suitable foundation stock, and as a result were successful in producing many first-class cavalry-horses. As, however, beyond a limited number taken by the Northwest Mounted Police and a few by foreign buyers, there was no sale for them as such, the breeders have largely turned their attention to other and, under the circumstances, more profitable lines of stock.

The natural conditions in Canada are, it need hardly be said, most favorable for the production of the animals wanted, while in the event of serious international disturbance Canadian horses would always be available for Imperial use, while it might be impossible to procure them in foreign countries. Again, through the medium of our great trans-continental railway they could be shipped from either Atlantic or Pacific ports to any part of the world where they might be required.

In view of the strong probability that the demand hitherto lacking will in the future be such as to warrant the breeding in fair numbers of the horses needed for military use, a brief description of those now being sought for and purchased by the agents of the British war office, and a few hints as to how they may be produced, will not be out of place.

They are of three fairly distinct types as required for artillery, cavalry and mounted infantry.

At the Canadian horse-show held in Toronto in April, 1900, the Dominion Government gave special prizes for each of these classes, and as Lt.-Col. Dent, the Imperial remount officer detailed to purchase in Canada, was one of the judges, thus making the selections authoritative, a description of each first prize animal, together with its measurements, will be appended to the general list of requirements in all three divisions.

\section{THE ARTILLERY-HORSE}

The artillery-horse asked for by the army buyers is really a smart, active van-or express-horse on short legs, with plenty of bone and substance and enough quality to ensure staying power 
in fairly fast work. He should stand from fifteen and two-tenths to sixteen hands, weigh not less than 1,300 pounds, and measure at least eight inches below the knee and seventy-two inches in girth. Considerable variation in type is permissible, the work of the horse artillery demanding greater speed and therefore more warm blood than are necessary for ordinary field artillery, while in all batteries properly horsed, the lead and center pairs are slightly taller and more rangy than the wheelers, the latter requiring greater strength and substance. The first prize entry at Toronto last spring was of the lighter sort, being, in fact, the pure-bred hackney mare 'Cassandra.' She stood 16 hands, weighed 1,325 pounds and girthed 76 inches. She measured $8 \frac{1}{4}$ inches below the knee and $201 / 4$ inches round the arm; from erest to withers 36 inches, withers to croup 29 inches, croup to tail, an important point in all military horses, 19 inches. Although in this particular instance the prize went to a hackney, it does not, by any means, follow that gun-horses should be either wholly or partly of that breed. They may be obtained by the judicious use of the thoroughbred horse on mares of size, substance and action, or by stinting good half-bred or strong roadster mares to a biggish hackney or breedy coach sire. So long as they show sufficient quality to ensure activity and endurance, and at the same time meet the requirements as to size and substance, the question of pedigree is of secondary importance.

\section{THE CAVALRY-HORSE}

The cavalry-horse is of a somewhat different type, and one at present too rare in Canada, owing to the preference shown by many light horse breeders for the American trotting sire, an animal possessing but few of the qualities and characteristics of the riding horse.

Colonel Ravenhill, in his report, says:-" A malformation in the Canadian horses which might advantageously be brought to the notice of breeders is that their quarters are short and very drooping, a serious defect in a military horse. Indeed, we had to reject as unsuitable a considerable proportion on this account; this is 
not only a great dissight, but where a mounted soldier has to carry a kit on his horse's back it amounts to an insuperable objection; it has arisen from the too extensive use of the American trotter for stud purposes, this defect being very apparent in that horse. This is an additional reason for the more continuous introduction of the English thoroughbred, or such horses as are very straight in their backs and quarters, with tail set high."

To get good cavalry-horses the thoroughbred sire is almost indispensable, as in no other way can the lengths rein, sloping shoulder, deep chest, strong loin and long quarter, so necessary in this class, be obtained with auy certainty or regularity. Freedom of movement is essential, but high action and great trotting speed are neither required nor wanted. Horses of this class should stand not less than $\mathbf{1 5 . 1}$ nor more than 15.3 , and should measure at least 8 inches below the knee and 70 inches in girth.

The first prize at Toronto was taken by a brown gelding named "General," said to be by a thoroughbred horse. He was a remarkable well-proportioned weight carrier of considerable length and great substance. His measurements were as follows: Height 15.3, cannon bone 8 inches, arm 21 inches, crest to withers 37 inches, wither's to croup 33 inches, croup to tail 15 inches, girth 74 inches.

Horses of this stamp can best be procured by the use of selected thoroughbred sires on strong half-bred ma:es, on the better class of roadster mares, or on mares from hackney or coach siles, provided they show some blood and quality. On mares having a preponderance of warm blood or those showing any inclination to weediness, a good hackney horse might be advantageously used.

\section{THE MOUNTED INFANTRY - HORSE}

The mounted infantry-horse, for which such an unprecedented demand has recently arisen, and which is likely to be even more sought after if present war conditions continue to prevail, is a smaller and cheaper animal than either of those already described. $\mathrm{H}_{\theta}$ is, in fact, a cob, a strong pony on short legs, with as much quality as can consistently be looked for in conjunction with the 
substance required to carry an armed man. He must have a fair shoulder and a good back, be deep through the heart and stand squarely on good legs well furnished with bone. In height he may be from 14.1 to 15.1 , but 14.3 is the favorite standard with Lt.-Col. Dent. Strength is the great desideratum, but a reasonable amount of activity is indispensable.

The little horse "Hero" which took first prize in Toronto, stood 15.1, measured $73 / 4$ inches below the knee and $19 \frac{1}{2}$ around the arm; from crest to withers he was 34 inches, withers to croup 27 inches, croup to tail 15 inches. He girthed 73 inches and, as the measurements show, was an excellent type of the weight-carrying cob. Such horses can be obtained by a stout thoroughbred sire from French Canadian or other strong pony mares, or by the judicious use of the hackney horse on the smaller roadsters and on those little mares too common in Canada, resulting from the ill-advised use of the racing or rather sprinting type of thoroughbred on light mares of trotting blood or other mixed breeding.

\section{GENERAL REQUIREMENTS}

In time of peace no horses are bought at less than four nor more than seven years old.

As regards color, bays, browns, chestnuts and blacks are preferred; a few grays are required for special corps, but oddcolored horses are not wanted.

No unsound or seriously blemished horse will be taken; the veterinary examination is fairly strict but is also strictly fair. Undocked horses are preferred, and no horse with a very short docked tail will be taken.

In time of war, however, when the demand, as a rule, exceeds the available supply, purchasing officers overlook many minor defects, provided the animals offered are sound and serviceable, while conforming generally to the requirements of the service. 


\section{ADVICE T.O BREEDERS}

Breeders on the western ranges will, no doubt, find it profitable from this time forward, to devote considerable attention to the production of horses especially adapted for military use.

In the other portions of the Dominion the supply of such horses can be enormously increased with but little extra effort or expense on the part of the breeder.

Immense numbers of light horses and ponies are annually bred in Canada of which many when grown are, owing to their nondescript character, of but little value. If the breeders of these animals would send their lighter mares to pure-bred stallions, of the British breeds, intelligently selected with a view to the production of a definite type of military horse, a vast improvement in our clean-legged stock would speedily manifest itself.

High prices would then, as now, be easily obtainable for really superior animals; most of the others would find ready sale for army use as well as for other purposes, while the misfits and object lessons would be less numerous and, except by comparison, not less valuable, than they are at present.

[The admirable instructions for breeding army horses in Canada, as set forth in the previous pages, are applicable when applied to breeding the same class of horses in the United States.]-Author.

Note.-With horsemen, the figures $15.1,15.3$ are read fifteen hands, one inch, and fifteen hands, three inches. See pp. 356, 357. 


\section{APPENDIX II}

\section{COMPUTING RATIONS FOR FARM ANIMALS}

Prepared by John L. Stone, Assistant Professor of Agronomy, Cornell University, Ithaca, N: Y.

For more than a third of a century, the subject of feeding to farm animals a "balanced ration," or one that conforms quite closely to a "standard" that has been fixed by carefully conducted experiments with the kind of animal for which it is recommended, has been before American stock feeders. The general utility of feeding standards is almost universally admitted by those who have given the matter study, and the number of feeders who are endeavoring to conform their practices to the standards is continually increasing.

The tables of feeding stuffs and the methods of using them have been much simplified of late years, but judging by the large number of requests from farmers, received by the agricultural papers and the Experiment Stations, for formulas of balanced rations, adapted to the needs of the inquirers, the subject is still too complicated, or the labor involved too great, to be readily accomplished by the ordinary farmer. It is with a view of further simplifying the computation of rations and bringing it within the range of every feeder that the accompanying tables have been prepared. The effort has been to carry the computations as near to completion as possible, so that the user will simply need to take from the table the figures corresponding to the kinds and amounts of the feeds used in the proposed ration and add them together, to be able to compare it with the standard. The only advantage claimed for this publication is that, by the arrangement of the tables and by the eomputations made, the labor of formulating rations is very materially reduced, and it is hoped that many who have not heretofore attempted this work for themselves will be encouraged to do so. 


\section{PRINCIPLES OF FEEDING}

The various substances found in animal bodies may, for convenience, be grouped under four heads: water, ash or mineral matter, fat, and nitrogenous matter or protein. These substances occur in the animal body in somewhat varying proportions, depending upon age, condition, treatment, etc.

Water is an essential constituent of the animal body and constitutes from 40 to 60 per cent of its live weight. Ash occurs mainly in the bones and constitutes from 2 to 5 per cent of the live weight. The fat occurs in greatly varying proportions, but rarely is less than 6 or more than 30 per cent. All those substances containing nitrogen are classed as protein. They constitute an important group, of which washed lean meat and the white of egg may be taken as types. They contain about 16 per cent of the element nitrogen and are the only class into the composition of which this element enters. All the working machinery of the body, such as flesh, skin, bones; hair, internal organs, brain and nerves, contain a large proportion of protein.

\section{COMPOSITION OF FOOD MATERIALS}

The same four groups of substances found in animal bodies, viz.: water, ash, fat and protein, are also found in the food they consume and, in addition, the food of herbivorous animals contains a class called carbohydrates.

Thater.-All foodstuffs, no matter how dry they may seem, contain a considerable amount of water. In grains and dried fodders it ranges from 8 to 15 per cent of the material, in green forage and silage it is about 80 per cent, while in some roots it amounts to 90 per cent. While water is essential to animal life and the water in the food fulfils the same function as that drunk by the animal, we do not value food materials for the water they contain, and computations are based upon the water-free or dry matter.

Ash.-When a foodstuff is burned till the organic matter is all driven off, the residue is the ash. It is composed largely of lime, 
magnesia, potash, soda, iron, chlorine, and carbonic, sulfuric and phosphoric acids. The ash of the food is the source of the mineral matter of the animal body, and as such is of great importance. Ordinary combinations of feeding stuffs, however, contain an abundant supply of mineral matter for the use of the animal, so it is not a matter of practical concern except as it has a bearing on the mineral elements of fertility in the manure.

Fats.- This group embraces the materials which may be dissolved from a feeding stuff by ether. It includes, besides the true fats, wax and coloring matter. Fat in the food may be either stored in the body as fat, or burned to produce heat and energy.

Carbohydrates. - This term includes two groups, nitrogen-free extract, such as starch, sugar, gum, etc., and fiber, or the woody parts of plants. The former are quite freely digested, the latter much less so, though fulfilling the same function to the extent it is digested. The carbohydrates constitute the largest part of vegetable foods. They are not stored in the animal body as such, but are converted into fat or used (burned) to produce heat and energy.

Since the carbohydrates and fat serve nearly the same purpose in the animal economy, they may, for convenience, be grouped together. Experiments, however, have shown that fat is about $2 \frac{1}{4}$ times as effective as a food as are the carbohydrates. Hence it is customary to multiply the amount of fat by $2 \frac{1}{4}$ to reduce it to a "starch equivalent" before adding it to the amount of the carbohydrates.

Protein.- The protein of foods, like that of the animal body, is characterized by containing nitrogen. It, therefore, is frequently termed "nitrogenous matter." The term albumenoids is sometimes used to designate this group, though it more correctly implies a certain class of protein substances. The function of protein in the food is, first of all, to build up and repair the working machinery of the body, and to supply protein for the production of milk, wool, etc. No other food constituent can fulfil this function.

The importance of a sufficient supply of protein in the ration, is, therefore, apparent. If in excess of the amount required to 
build up and repair the wa:te of the body, the protein may be converted into fat and deposited as such or used to produce heat and energy. Its efficiency for these purposes is about the same as the earbohydrates, but as it is usually far more expensive to supply than the carbohydrates, economy would dictate that only so much should be supplied to the animal as will suffice to repair the wastes of the animal machinery and build up new growth in case of growing animals, or for the production of milk, wool, etc.

\section{COMPOUNDING OF RATIONS}

Nutritive ratio. - Since the protein on the one hand and the carbohydrates and fat on the other, serve, in the main, different purposes in the animal economy, it becomes evident that the relative amounts of these nutrients in the food are important. This relation is expressed as the "nutritive ratio," which means the relation of digestible protein to digestible carbohydrates and fat-the fat having been multiplied by $2 \frac{1}{4}$ before adding to the carbohydrates, as explained above. The nutritive ratio is found by dividing the carbohydrate, plus $2 \frac{1}{4}$ times the fat, by the protein. In the accompanying table, No. II, the sum of the carbohydrates and fat, thus obtained, is given in the third column, which divided by the protein, as given in the second column, gives the second term of the nutritive ratio in the fifth column.

A feeding stuff having a large proportion of carbohydrates and fat as compared to protein is said to have a "wide" nutritive ratio, while one having a small proportion of carbohydrates and fat as compared to protein has a "narrow" ratio. While these terms are relative, it may be said that a ratio greater than $1: 6$ is wide, while one less that $1: 5$ is narrow. The composition of feeding stuffs, that is, the proportion in which the different nutrients occur, is determined by chemical analysis, but the amount of each nutrient that is actually digestible has been determined by careful experiments with living animals. Only the digestible nutrients are considered in the tables given in this publication.

Feeding Standards.-The amount of nutrients required, and the proportions in which each should be given, vary with the kind of animal and the purpose for which it is kept,-whether it is grow- 
ing, being fattened, doing work, or producing milk or wool. Thus an ox at rest requires less food and the various nutr.ents in different proportions than an ox at work; a cow producing milk requires more food and the nutrients differently balanced than one not producing.

\section{TABLE I-FEeding Standards}

A-Per day and 1,000 pounds live weight.*

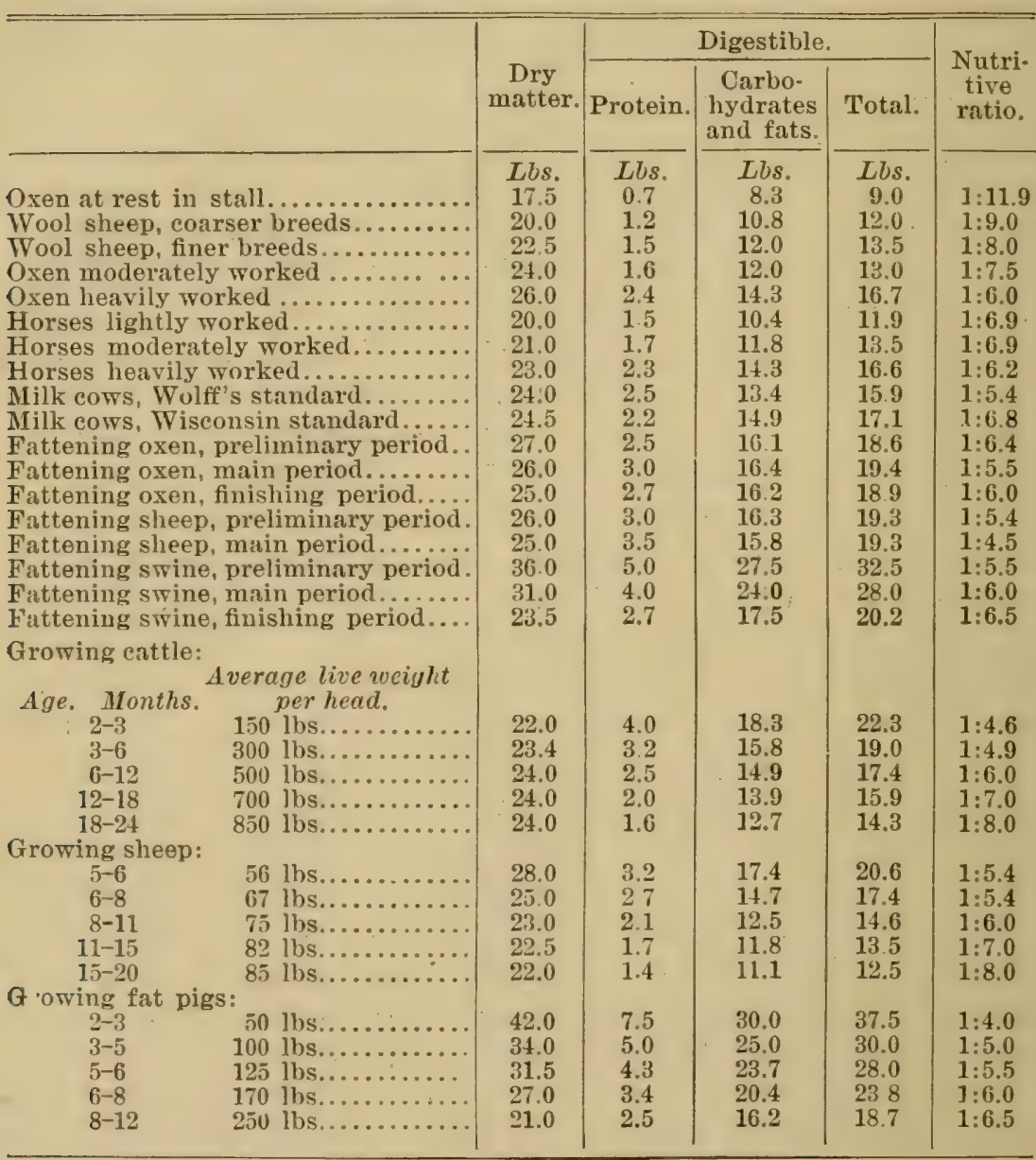

* The futtening rations are calculated for 1,000 lbs. live weight at the beginning of the fattening. 
Table I - Feeding Standards - Continued

B-Per day and per head.

\begin{tabular}{|c|c|c|c|c|c|c|}
\hline & \multirow[b]{2}{*}{$\begin{array}{c}\text { Dry } \\
\text { matter }\end{array}$} & \multicolumn{3}{|c|}{ Digestible } & \multirow{2}{*}{$\begin{array}{l}\text { Nutri- } \\
\text { tive } \\
\text { ratio }\end{array}$} \\
\hline & & & Protein & $\begin{array}{l}\text { Carbo- } \\
\text { hydrates } \\
\text { and fats } \\
\end{array}$ & Total & \\
\hline \multicolumn{2}{|l|}{ Growing cattle: } & Lbs. & Lbs. & Lbs. & $L b s$. & \\
\hline $2-3$ & 150 lbs............. & 3.3 & 0.6 & 2.8 & 3.4 . & $1: 4.6$ \\
\hline $3-6$ & $300 \mathrm{lbs}, \ldots \ldots \ldots \ldots$ & 7.0 & 1.0 & 4.9 & 5.9 & $1: 4.9$ \\
\hline $6-12$ & 500 lbs............. & 12.0 & 1.3 & 7.5 & 8.8 & $1: 6.0$ \\
\hline $12-18$ & 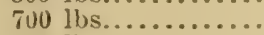 & 168 & 1.1 & 9.7 & 11.1 & $1: 7.0$ \\
\hline $18-34$ & 850 lbs............ & 20.4 & 1.4 & 11.1 & 12.5 & $1: 8.0$ \\
\hline \multicolumn{7}{|c|}{ Growing sheep: } \\
\hline $\begin{array}{l}5-6 \\
6-8\end{array}$ & $\begin{array}{l}56 \mathrm{lbs} . . . \ldots \ldots \ldots \\
67 \mathrm{lbs} . . . \ldots \ldots\end{array}$ & 1.6 & $\begin{array}{l}0.18 \\
0.18\end{array}$ & $\begin{array}{l}0.974 \\
0.981\end{array}$ & 1.154 & $1: 5.4$ \\
\hline $8-11$ & 75 lbs................. & 1.7 & 0.16 & 0.953 & 1.113 & $1: 6.0$ \\
\hline $11-15$ & 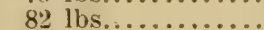 & 1.8 & 0.14 & 0.975 & 1.115 & $1: 7.0$ \\
\hline $15-20$ & 85 lbs................. & 1.9 & 0.12 & 0.955 & 1.075 & $1: 8.0$ \\
\hline \multicolumn{7}{|c|}{ Growing fat swine: } \\
\hline $2-3$ & $50 \operatorname{lbs} \ldots \ldots \ldots \ldots$ & 2.1 & 0.38 & 1.50 & 1.88 & $1: 4.0$ \\
\hline $3-5$ & 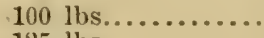 & 3.4 & 0.50 & 2.50 & 3.00 & $1: 5.0$ \\
\hline $5-6$ & 125 lbs....................... & 3.9 & 0.54 & 2.96 & 3.50 & $1: 5.5$ \\
\hline $6-8$ & 170 lbs............. & 4.6 & 0.58 & 3.47 & 4.05 & $1: 6.0$ \\
\hline $8-12$ & $250 \mathrm{lbs}, \ldots \ldots \ldots \ldots$ & 5.2 & 0.62 & 4.05 & 4.67 & $1: 6.5$ \\
\hline
\end{tabular}

Various investigator's have condensed the results of many experiments and much practical experience into what are called "feeding standards," which attempt to state what is in general, and under average conditions, a good ration for the purpose in view. While these standards cannot be considered as mathematically exact, still large practical experience has demonstrated their great value as aids to feeders.

In Table I, under the title of Feeding Standards, are given the approximate requirements of various classes of animals and under varying conditions. These standards are mostly from German sources, but they have been found very helpful to American feeders. They are presented here as arranged by Armsby, in Circular of Information No. 1, "Computation of Rations for Farm Animals," Pennsylvania State College. The standards are for animals of 1,000 pounds live weight, and may be increased or diminished for larger or smaller animals, though it is probable that the individuality of the animal, its power to assimilate and produce, will have more to do with the varying of the ration than its weight. 
It is permissible, perhaps, to depart from the amounts given in the first column under the head of "Dry Matter," more than in any other way. The digestive apparatus of farm animals is elastic and accommodates itself quite readily to the varying bulk of its food. In the last column is given the nutritive ratio, which should, perhaps, be adhered to with some care, trusting to the appetite of the animal (which will be controlled largely by its power of digesting and producing) to indicate the amount of nutrients required. As a rule the most rapid fattening or growth and abundant production are most economical, and these results are best secured by feeding an abundant and well-balanced ration (well up to the limit of the animal's appetite) while the dry matter is not permitted to rise much above the standard.

Table II gives a list of the feeding stuffs in most common use in New York state. Column one is headed "dry matter"; column two, "digestible protein"; column three, digestible carbohydrates $+\left(\right.$ fat $\times 2 \frac{1}{4}$ )"; column four, "total" (which is the sum of two and three); column five, "nutritive ratio." In each of these columns are given the computations of the various food stuffs from one pound up to the amount that is likely to be used in compounding any ration. In the case of the coarse fodders, to save space, the increase is made by more than one pound at a time, but intermediate amounts can readily be obtained from the table if desired. In no case are the calculations for ten pounds of a feeding stuff given, as these can be obtained at once from the figures for one pound, by simply moving the decimal point one place to the right.

These computations are based upon the table of "Average Digestible Nutrients in American Feeding Stuffs" given in Prof. W. A. Henry's recent book, "Feeds and Feeding." The aim has been to carry the computations involved in formulating rations as near completion as possible, and to present the figures in such simple form that no feeder will have difficulty in comparing the ration he is feeding with the standards and correcting it, if necessary, to conform thereto. 
TABLE II

Digestible Nutrients in the Stated Aiotnts of the More Cominon Feeding Stuffs

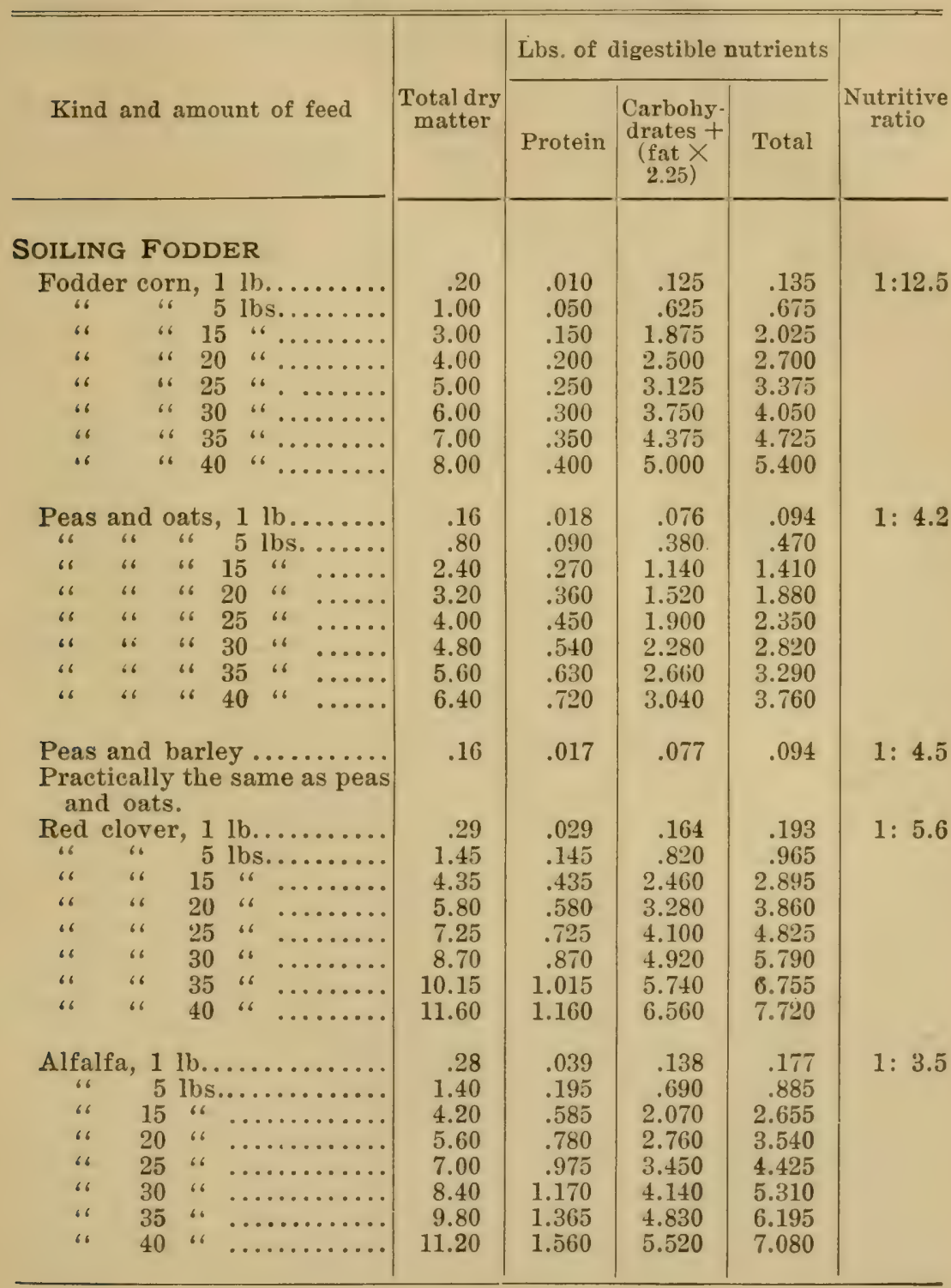




\section{TABLE II - Continued}

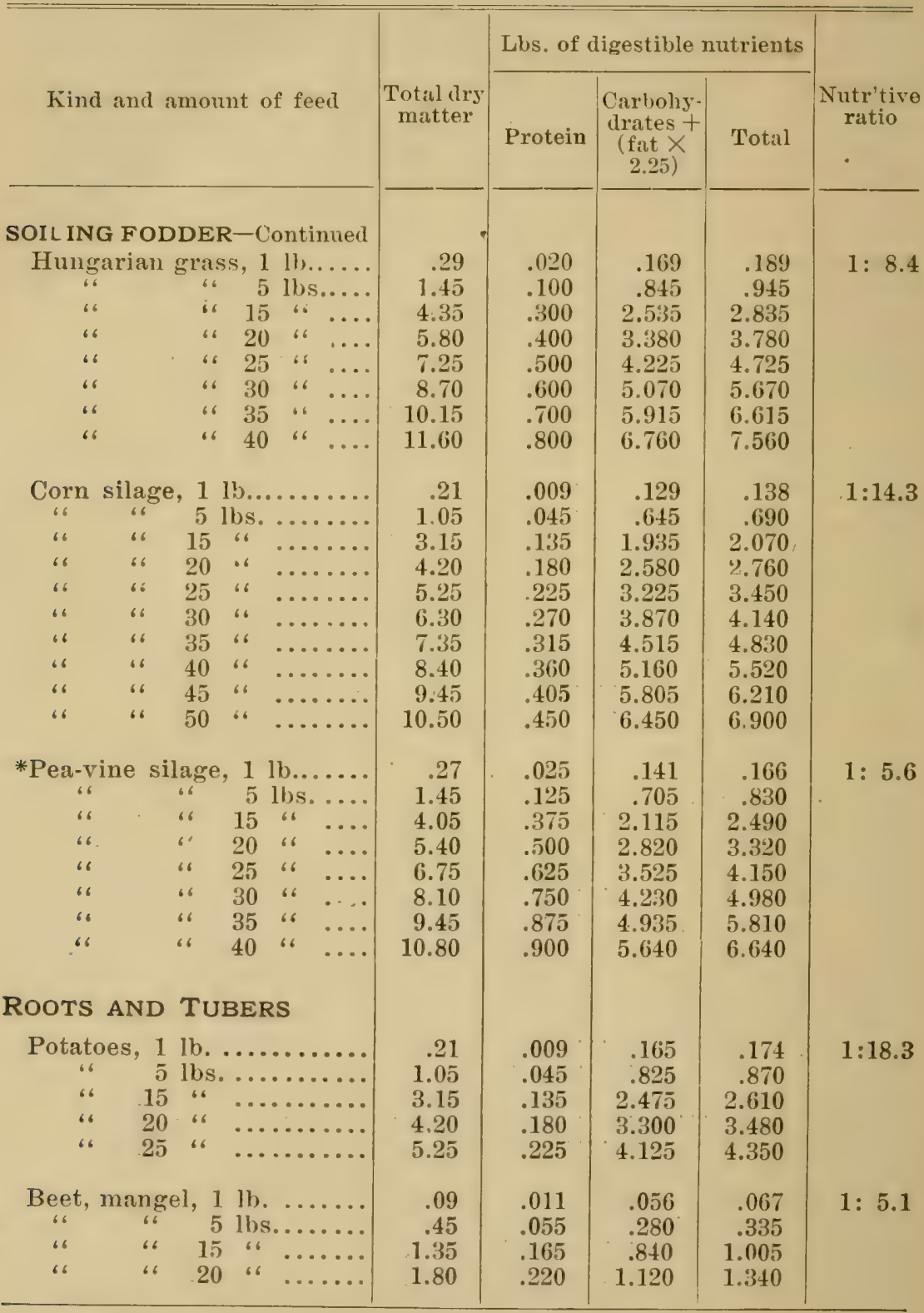

*Computed from recent analysis, by G. W. Cavanaugh. 
TABLE II - Continued

\begin{tabular}{|c|c|c|c|c|c|}
\hline \multirow[b]{2}{*}{ Kind and amount of feed } & \multirow[b]{2}{*}{$\begin{array}{c}\text { Total dry } \\
\text { matter }\end{array}$} & \multicolumn{3}{|c|}{ Lbs. of digestible nutrients } & \multirow[b]{2}{*}{$\begin{array}{l}\text { Nutr'tive } \\
\text { ratio }\end{array}$} \\
\hline & & Protein & $\begin{array}{l}\text { Carbohy- } \\
\text { drates }+ \\
\text { (fat } X \\
\quad 2.25)\end{array}$ & Total & \\
\hline $\begin{array}{l}\text { ROOTS and TUBERS-Cont'd. } \\
\text { Beet, mangel, } 25 \text { lbs...... }\end{array}$ & $\begin{array}{l}2.25 \\
2.70\end{array}$ & $\begin{array}{l}.275 \\
.330\end{array}$ & $\begin{array}{l}1.400 \\
1.680\end{array}$ & $\begin{array}{l}1.675 \\
2.010\end{array}$ & \\
\hline 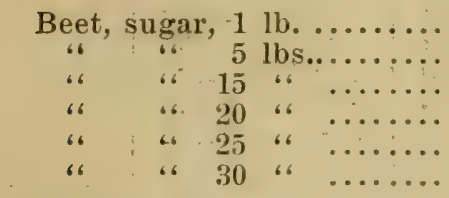 & $\begin{array}{l}.13 \\
.65 \\
1.95 \\
2.60 \\
3.25 \\
3.90\end{array}$ & $\begin{array}{l}.011 \\
.055 \\
.165 \\
220 \\
.275 \\
.330\end{array}$ & $\begin{array}{r}.104 \\
.520 \\
1.560 \\
2.080 \\
2.600 \\
3.120\end{array}$ & $\begin{array}{r}.115 \\
.575 \\
1.725 \\
2.300 \\
2.875 \\
3.450\end{array}$ & $1: 9.4$ \\
\hline 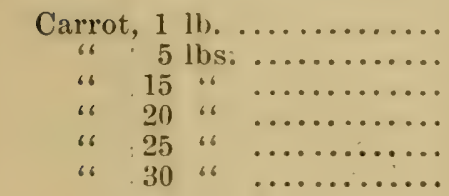 & $\begin{array}{l}.11 \\
.55 \\
1.65 \\
2.20 \\
2.75 \\
3.30\end{array}$ & $\begin{array}{l}.008 \\
.040 \\
.120 \\
.160 \\
.200 \\
.240\end{array}$ & $\begin{array}{r}.082 \\
.410 \\
1.230 \\
1.640 \\
2.050 \\
2.460\end{array}$ & $\begin{array}{r}.090 \\
.450 \\
1.350 \\
1.800 \\
2.250 \\
2.700\end{array}$ & $1: 10.3$ \\
\hline 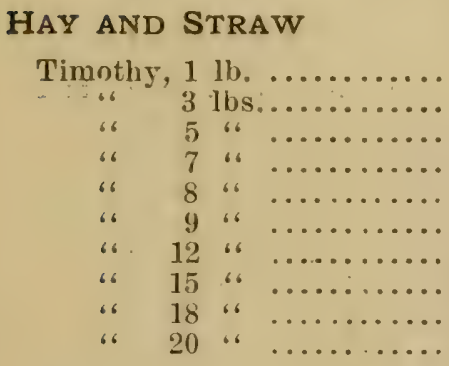 & $\begin{array}{r}.87 \\
2.61 \\
4.35 \\
6.09 \\
6.96 \\
7.83 \\
10.44 \\
13.05 \\
15.66 \\
17.40\end{array}$ & $\begin{array}{l}.028 \\
.081 \\
.140 \\
.196 \\
.224 \\
.252 \\
.336 \\
.420 \\
.504 \\
.560\end{array}$ & $\begin{array}{l}.465 \\
1.395 \\
2.325 \\
3.255 \\
3.720 \\
4.185 \\
5580 \\
6.975 \\
8.370 \\
9.300\end{array}$ & $\begin{array}{l}.493 \\
1.479 \\
2.465 \\
3.451 \\
3.944 \\
4.437 \\
5.916 \\
7.395 \\
8.874 \\
9.860\end{array}$ & $1: 16.6$ \\
\hline 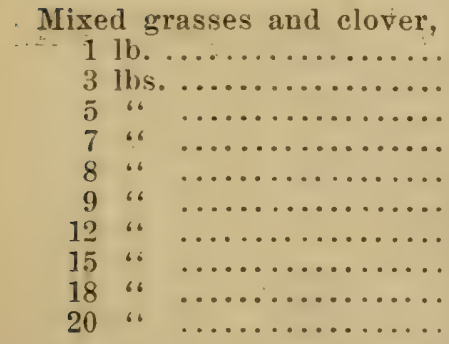 & $\begin{array}{r}.87 \\
2.61 \\
4.35 \\
6.09 \\
6.96 \\
7.83 \\
10.44 \\
1305 \\
15.96 \\
17.40\end{array}$ & $\begin{array}{l}.062 \\
.186 \\
.310 \\
.434 \\
.496 \\
.558 \\
.744 \\
.930 \\
1.116 \\
1.240\end{array}$ & $\begin{array}{l}.460 \\
1.381 \\
2.300 \\
3.220 \\
3.680 \\
4.140 \\
5.520 \\
6.900 \\
8.280 \\
9.200\end{array}$ & $\begin{array}{r}.522 \\
1.566 \\
2.610 \\
3.654 \\
4.176 \\
4.698 \\
6.264 \\
7.830 \\
9.393 \\
10.440\end{array}$ & $1: 7.4$ \\
\hline
\end{tabular}




\section{TABLE II - Continued}

HAY and STRAW-Continued.

Hungarian hay, 1 lb......

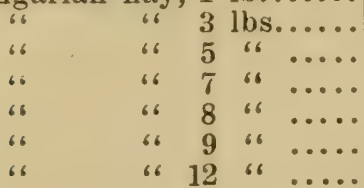

Red clover hay, 1 lb..... $66{ }_{66}^{66} 3$ lbs.... $66 \quad 66 \quad 66 \quad 566 \ldots$ 66 66 66 $76 \ldots \ldots$ $66 \quad 66 \quad 66 \quad 866 \ldots$ $66 \quad 66 \quad 66 \quad 96 \ldots$ $66 \quad 66 \quad 6612 \quad 66 \ldots \ldots$

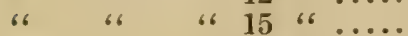

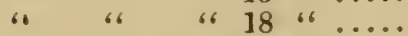
66 $66 \quad 66 \quad 20 \quad 66 \ldots$

Alfalfa hay, $1 \mathrm{lb}$.

$$
\begin{aligned}
& 64 \text { 66 } 3 \text { lbs } 6.0 . \\
& 6 \text { 6 } 66 \quad 566 \ldots \ldots
\end{aligned}
$$

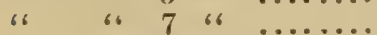

$$
\begin{aligned}
& 66 \quad 66 \quad 8 \quad 66 \quad \ldots \ldots \ldots
\end{aligned}
$$

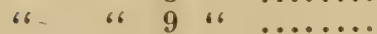

$$
\begin{aligned}
& \text { 66 } 612 \text { 6 } 12 \quad \ldots \ldots \ldots \\
& 6 ! \quad 6615 \text { 66 } \ldots \ldots \ldots . \\
& 66 \quad 66 \quad 18 \quad 66 \quad \ldots \ldots \ldots . \\
& 66 \\
& \text { 6 } 20
\end{aligned}
$$

\begin{tabular}{|c|c|c|c|}
\hline & 5 & lbs & ..... \\
\hline 66 & 8 & 66 & \\
\hline 66 & 12 & 66 & \\
\hline 66 & 15 & 66 & \\
\hline 66 & 18 & 66 & \\
\hline 66 & 20 & 6 & \\
\hline
\end{tabular}

Corn fodder, 1 lb.........

Corn stover, 1 lb.........

5 los...........

8 66........

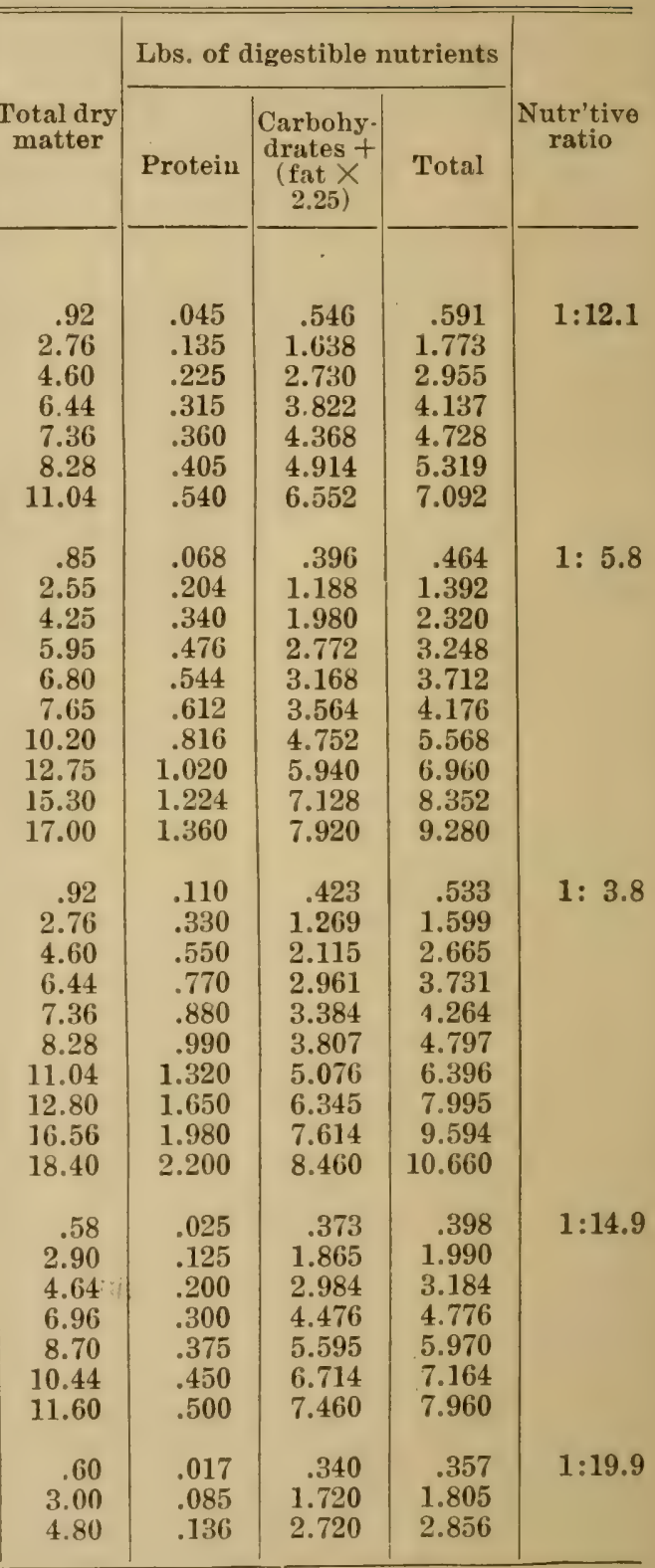




\section{TABLE II - Continued}

Find and amount of feel

HAY and STRAW-Continued. Corn stover, 12 lbs........

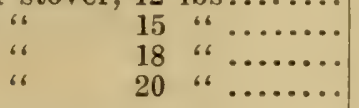

Pea-vine straw, 1 lb......

$$
\begin{aligned}
& 66 \text { lbs..... } \\
& 66 \quad 566 \ldots \\
& 686 \ldots \ldots \\
& 16 \\
& 66 \\
& 12 \\
& 6 \\
& 15 \text { " }
\end{aligned}
$$$$
66
$$

*Bean straw, 1 lb

Wheat straw, 1 lb........

$$
\begin{aligned}
& 3 \text { lbs.......... } \\
& 5 \text { " } \ldots \ldots \ldots \\
& 8 \text { ، } 3 \ldots \ldots \\
& 12 \\
& 15
\end{aligned}
$$

Oat straw, 1 Ib

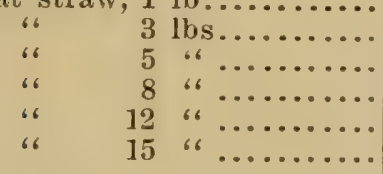

\section{GRAIN}

Corn (av,), 1 lb.

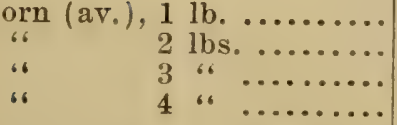

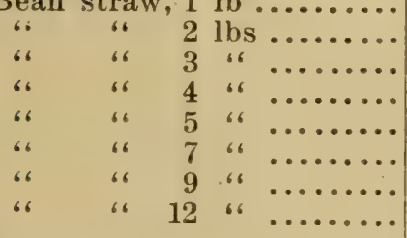

Total drs matter

7.20

9.00

10.80

12.00

.86

2.58

4.30

6.88

10.32

12.90

.95

1.90

2.85

3.80

4.75

6.65

8.55

11.40

.90

2.70

4.50

7.20

10.80

13.50

.91

2.73

4.55

7.28

10.92

13.65

.89
1.78
2.67
3.56
Lbs. of digestible nutrients

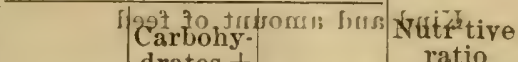

Protein

drates
$(\mathrm{f} a t-X$

2.25)

-

$4.080 \%$

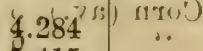

5.160

6.120

6.880

5.415

6.426

.306

.340

.043

.129

.215

.344

.516

.645

.036

.072

.108

.144

.180

.252

.324

.432

.341

1.023

$1.705^{\circ}$

2.728

4.092

5.115

.397

.794

1.191

1.588

1.985

2.779

3.573

4.764

.004

.012

.020

.032

.048

.060

.372

1.016

1.860

2.976

4.064

5.580

.012

.036

.060

.096

.144

.180

.404

1.212

2.020

3.232

4.848

6.060

3.220

I. 384

- 1.920

3.073

4.608

5.760

fง: 1 tif 7.9

..

is

..

.

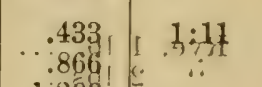

1.299

1.732

2.165

3.031

3.897

5.196

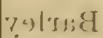

$.376^{\circ}$

1:93

1.128

1.880

3.008

4.512

5.640

.416

1.248

2.080

3.328

4.992

6.240

$\therefore$ is 0

$1: 33.6$

..

.$$
\text { , }
$$$$
\text { . }
$$$$
\text { . }
$$$$
\text { .. }
$$$$
\text { , }
$$$$
\text { . }
$$

.764

.079

.158

.237

1.528

.843

1: 9.7

2.292

1.686

2.529

\&
.204

*Computed from recent analysis by $G$. W. Cavanaugh. 
DABLIE II - Continued

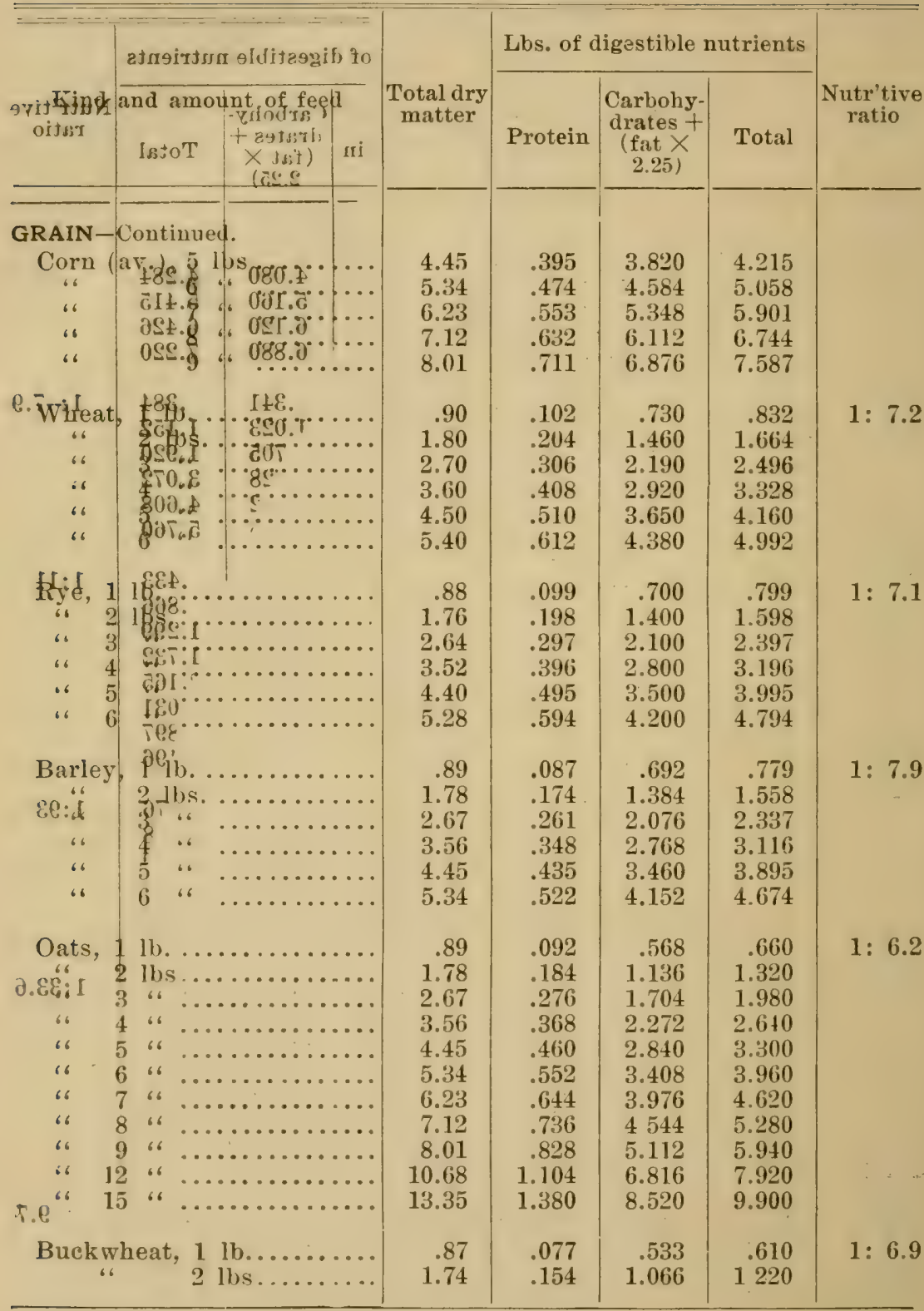


TABLE II - Continued

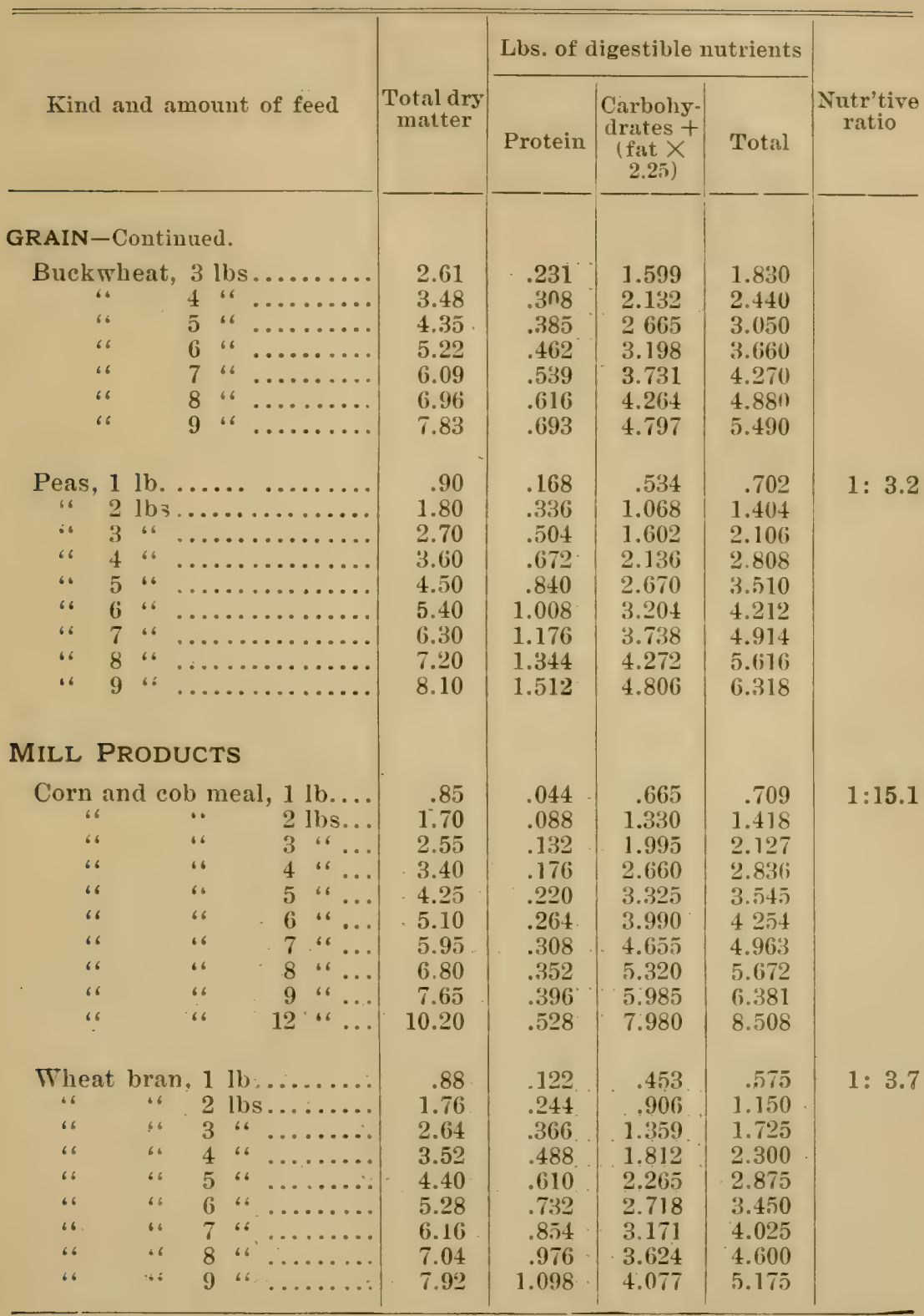


TABLE II - Continued

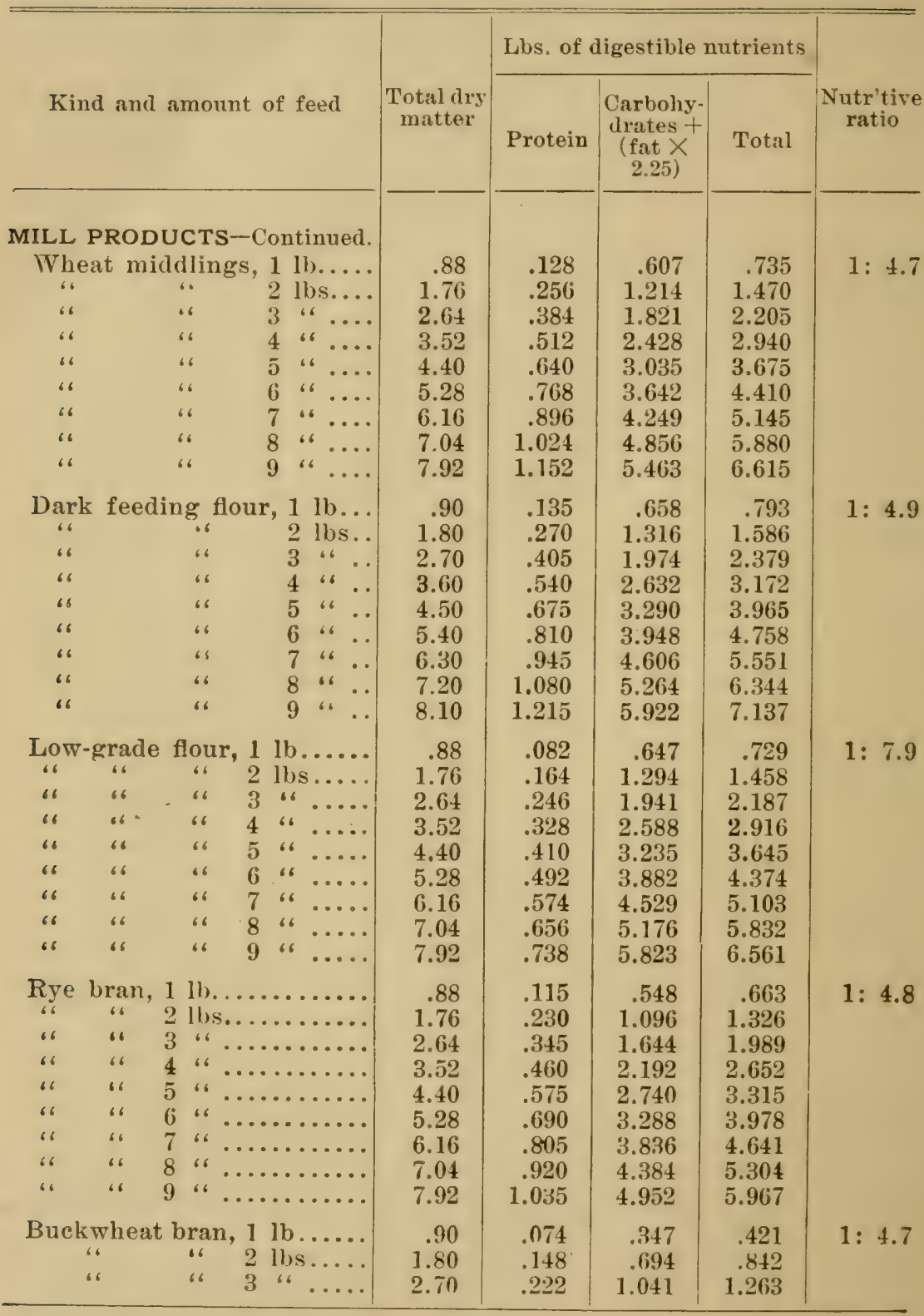


TABLE II - Continued

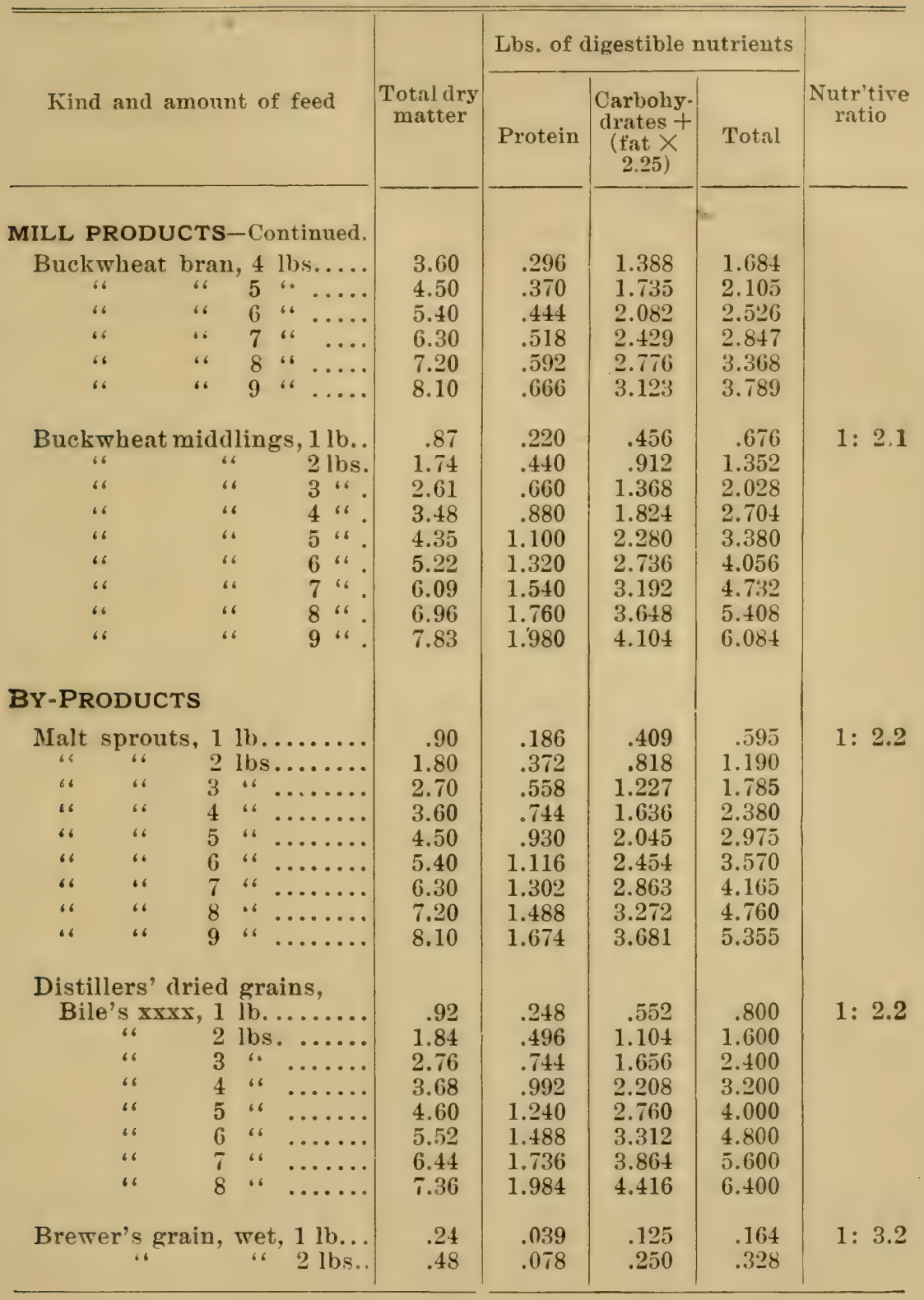




\section{TABLE II - Continued}

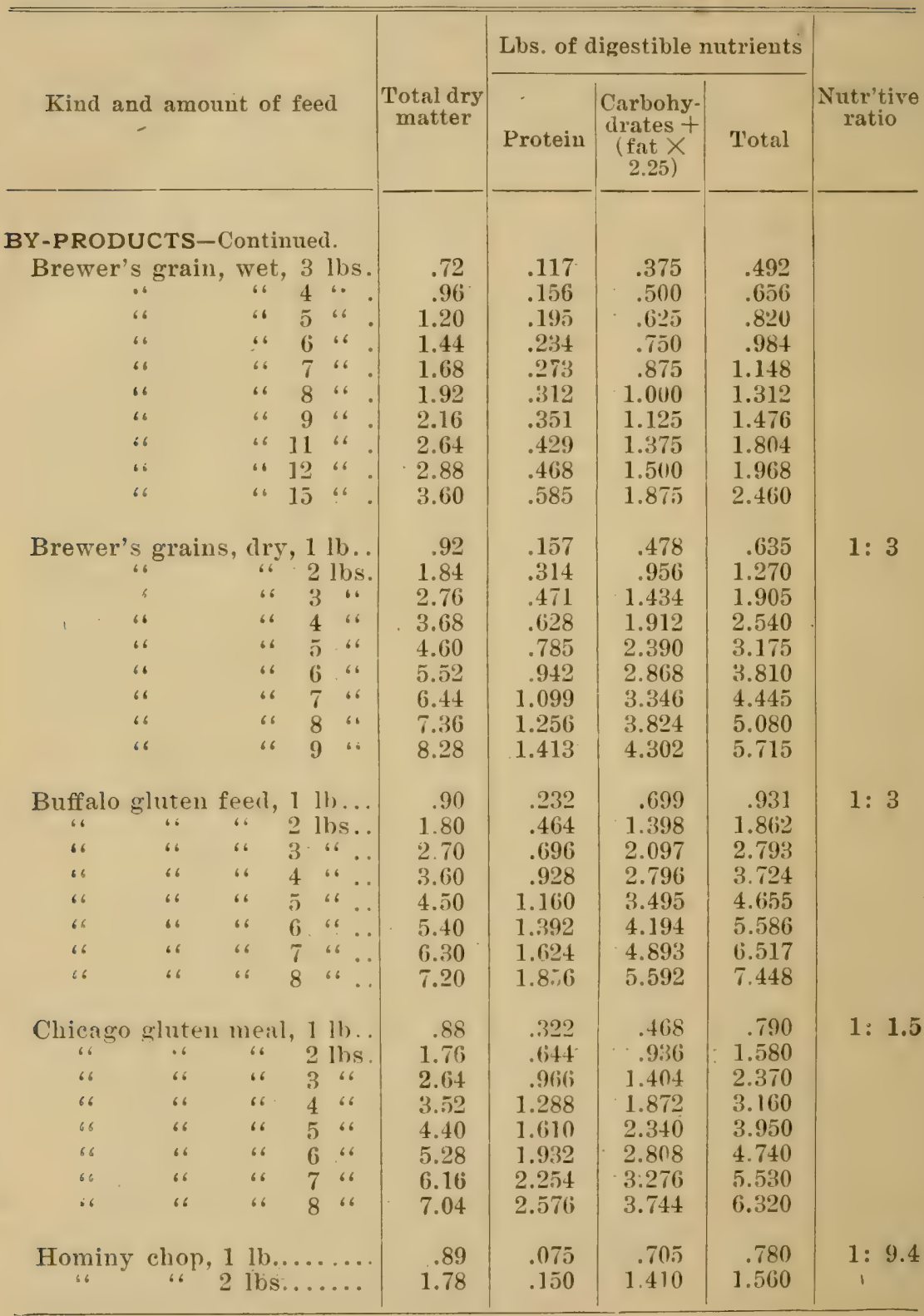


TABLE II - Continued

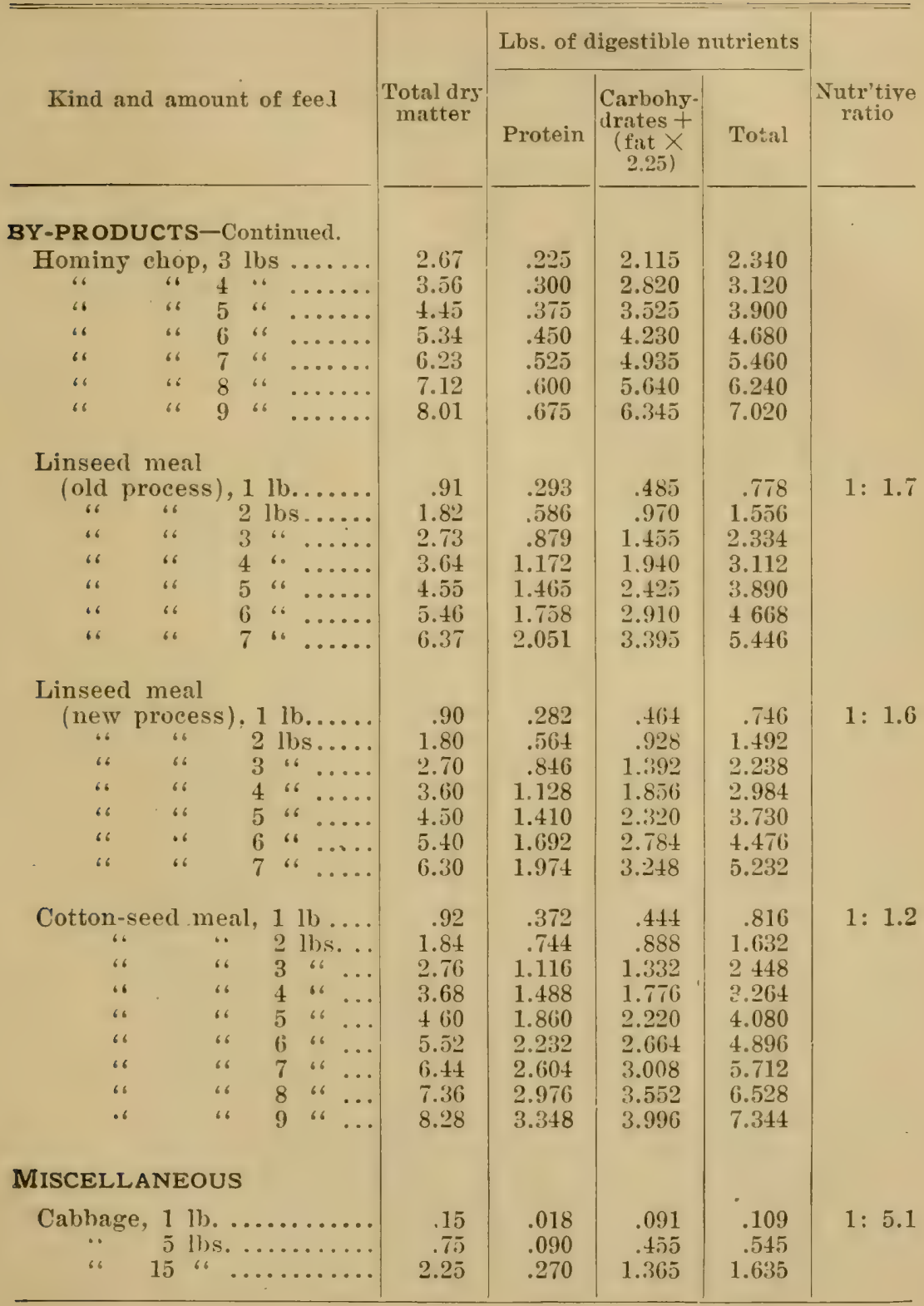


TABLE II - Continued

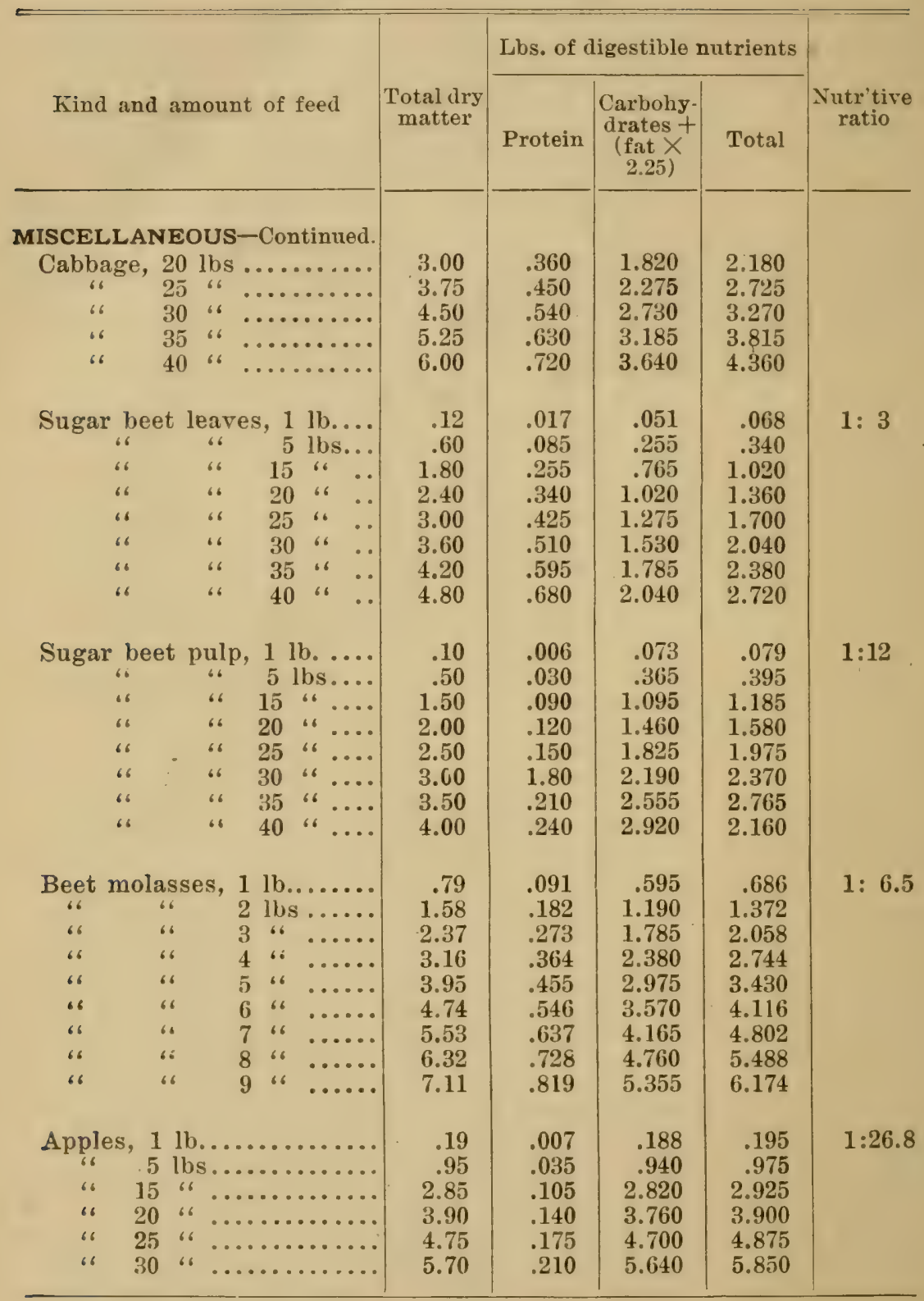


TABLE II-Continued

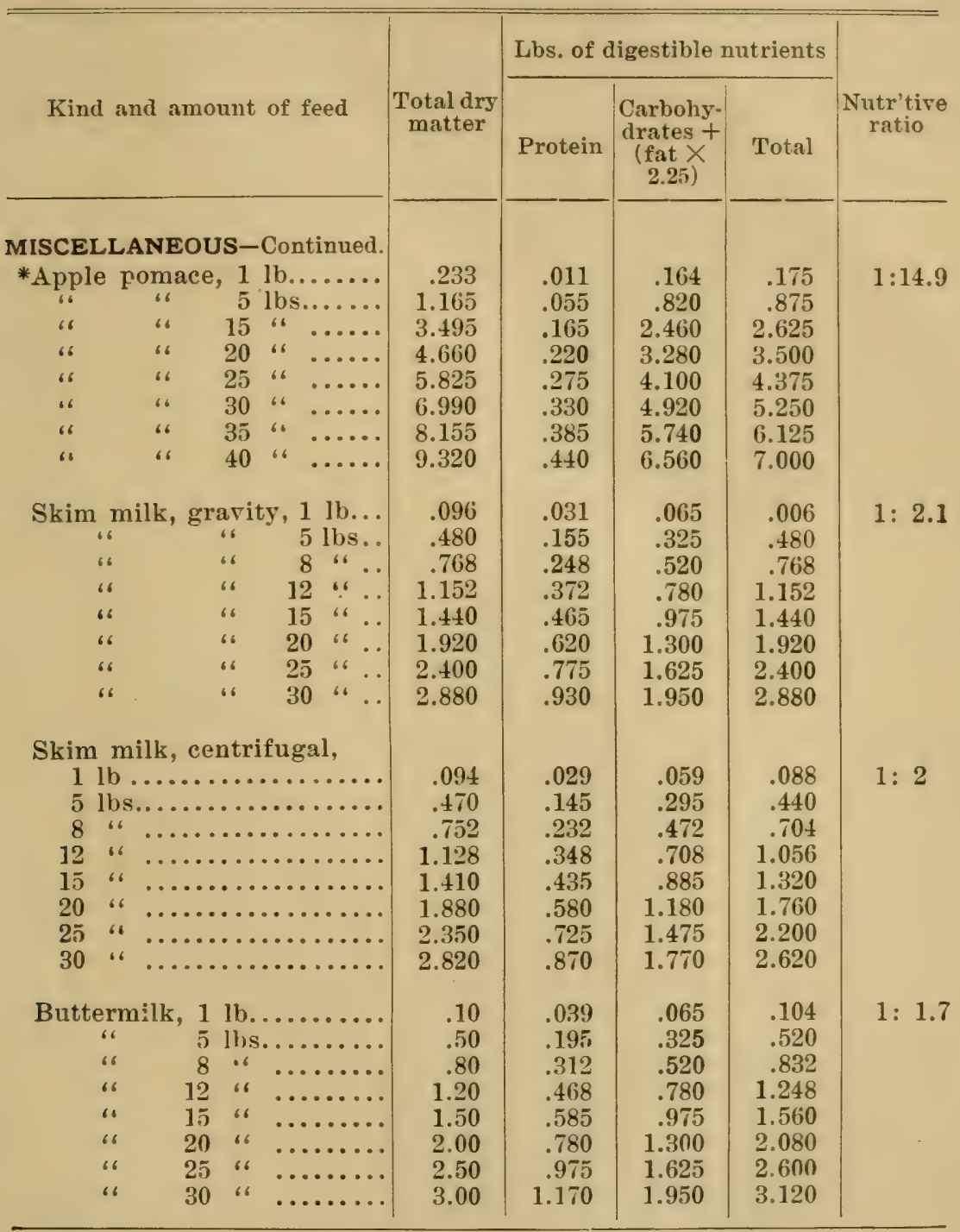

*From Bulletin of Information No. 1, Pennsylvania State College. 
To illustrate how these tables may be used, we will examine a system of feeding which the writer observed the present season in a certain section of the state, and was told was quite extensively practiced. The section referred to is devoted almost exclusively to dairying, and timothy hay constitutes the greater portion of the coarse fodder during the feeding season. Oats are about the only grain grown. Corn is purchased and ground with the oats, in about equal weights, to make "chop," which is fed with the hay. The cows will not greatly vary from 1,000 pounds live weight. While these corvs are in full flow of milk in the spring before pasture is ready, they are fed about 20 pounds of hay and 8 pounds of chop per day. Turning to the tables, we find that 20 pounds of hay, 4 pounds of oats and 4 pounds of corn contain digestible nutrients as follows:--

\begin{tabular}{|c|c|c|c|c|c|}
\hline & $\begin{array}{c}\text { Dry } \\
\text { matter }\end{array}$ & Protein & C. H. and & Total & $\begin{array}{l}\text { Nutritive } \\
\text { Ratio }\end{array}$ \\
\hline 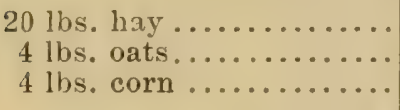 & $\begin{array}{r}17.40 \\
3.56 \\
3.56\end{array}$ & $\begin{array}{l}.560 \\
.368 \\
.316\end{array}$ & $\begin{array}{l}9.300 \\
2.772 \\
3.056\end{array}$ & $\begin{array}{l}9.860 \\
2.640 \\
3.372\end{array}$ & \\
\hline 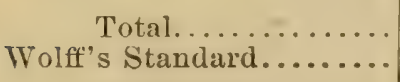 & $\begin{array}{l}24.52 \\
24.00\end{array}$ & $\begin{array}{l}1.244 \\
2.5\end{array}$ & $\begin{array}{l}1+628 \\
13.4\end{array}$ & $\begin{array}{l}15.8 \pi 2 \\
15.9\end{array}$ & $\begin{array}{l}1: 11.7 \\
1: 5.4\end{array}$ \\
\hline
\end{tabular}

Upon comparison of the nutrients furnished by this ration with Wolff's standard as given in Table $I$, it is discovered that while the dry matter and total nutrients are not far out of the way, the protein is much too small, the carbohydrates and fat are somewhat too great, while the nutritive ratio is far too wide.

This result might readily have been foreseen had we paused a moment to note the nutritive ratio of each of the three foods entering into the ration. They are, timothy hay, $1: 166$; oats, 1:6.2; corn, 1:9.7. Neither of them is as narrow as the standard, and it is impossible to combine them into a ration that is approximately balanced. As corn is a purchased product, the natural suggestion is that the corn should be replaced by some food having a high proportion of protein, or, in other words, a very narrow nutritive ratio. Consulting the table, it is found that among such are linseed meal, cotton-seed meal, gluten feed, 
malt sprouts, buckwheat, middlings, etc. As buckwheat middlings is a Now York State product and can readily be put in stock during the winter, it is suggested to substitute it for the corn in the ration. Again taking the figures from the table, we have:-

\begin{tabular}{|c|c|c|c|c|c|}
\hline & $\begin{array}{l}\text { Dry } \\
\text { matter }\end{array}$ & Protein & C. $\underset{\text { Fat }}{\mathrm{H} \text {, and }}$ & Total & $\begin{array}{c}\text { Nutritive } \\
\text { Ratio }\end{array}$ \\
\hline $\begin{array}{r}20 \text { lbs. timothy hay........ } \\
4 \text { lbs. oats................ } \\
4 \text { lbs. buckwheat mid's.. }\end{array}$ & $\begin{array}{r}17.40 \\
3.56 \\
3.48\end{array}$ & $\begin{array}{l}.560 \\
.368 \\
.880\end{array}$ & $\begin{array}{l}9.300 \\
2.272 \\
1.824\end{array}$ & $\begin{array}{l}9.860 \\
2.640 \\
2.704\end{array}$ & \\
\hline 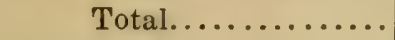 & 24.44 & 1.808 & 13.396 & 15.204 & $1: 7.4$ \\
\hline
\end{tabular}

While this ration is much improved over the previous one and will produce a much freer flow of milk, it is still too wide to produce the best results.

If the timothy hay is reduced two pounds, and two pounds of cotton-seed meal put in its place, we get:-

\begin{tabular}{|c|c|c|c|c|c|}
\hline & $\begin{array}{c}\text { Dry } \\
\text { matter }\end{array}$ & Protein & C. $\underset{\text { Fat }}{\text { Hat }}$ & Total & $\begin{array}{c}\text { Nutritive } \\
\text { Ratio }\end{array}$ \\
\hline $\begin{array}{r}18 \text { lbs. timothy hay........ } \\
4 \text { lbs. oats............... } \\
4 \text { lbs. buckwheat mid's.. } \\
2 \text { lbs. cottonseed meal .. }\end{array}$ & $\begin{array}{r}15.66 \\
3.56 \\
3.48 \\
1.84\end{array}$ & $\begin{array}{l}.504 \\
.368 \\
.880 \\
.744\end{array}$ & $\begin{array}{l}8.370 \\
2.272 \\
1.824 \\
.888\end{array}$ & $\begin{array}{l}8.874 \\
2.640 \\
2.704 \\
1.632\end{array}$ & \\
\hline Total............... & 24.54 & 2.496 & 13.354 & 15.850 & $1: 5.3$ \\
\hline
\end{tabular}

This ration corresponds very closely to the standard; and while the purchase of the cotton-seed meal will add somewhat to the expense, still it is the experience of careful feeders that the increased production will abundantly pay for thus securing a proper balance to the ration.

The same result may be obtained by using other feeding stuffs having a narrow nutritive ratio. The question is likely to be raised, which of the various feeding stuffs offered in the market may most economically be used in supplementing the homegrown foods to produce a balanced ration? This question is best answered by formulating properly balanced rations containing each of the foods under consideration, and by assigning the actual market value per pound to each of the constituents of the ration, its cost is readily ascertained and the cheapest may be selected. 
Elements of Fertility in 1,000 Pounds

\begin{tabular}{|c|c|c|c|c|c|c|}
\hline & Water & Ash & $\begin{array}{l}\text { Nitro- } \\
\text { gen }\end{array}$ & $\begin{array}{l}\text { Phos- } \\
\text { phoric } \\
\text { acid }\end{array}$ & Potash & $\begin{array}{l}\text { Esti- } \\
\text { mated } \\
\text { value } \\
\text { per ton }\end{array}$ \\
\hline Alfalfa (green) ......... & 760 & 22.1 & 6.2 & 1.5 & 3.5 & $\$ 218$ \\
\hline 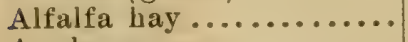 & 153 & 80.2 & 17.6 & 6.1 & 17.9 & 708 \\
\hline Apple pomace............ & 740 & 8.2 & 1.7 & .1 & .3 & 26 \\
\hline 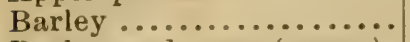 & 143 & 24.8 & 13.9 & 7.9 & 4.8 & 504 \\
\hline Barley and peas (green). & 755 & 16.7 & 2.7 & 1.8 & 5.05 & 138 \\
\hline 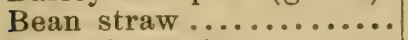 & 53 & 69. & 11.4 & 2.1 & 18.4 & 504 \\
\hline Beets (sugar)............. & 820 & 8.1 & 1.7 & .8 & 3.7 & 88 \\
\hline Brewer's grains, dry..... & 95 & 47.2 & 25.1 & 16.1 & 2. & 870 \\
\hline Brewer's grains, wet..... & 762 & 12.4 & 6.2 & 4.2 & .5 & 216 \\
\hline 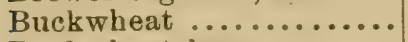 & 141 & 27.7 & 12.3 & 6.9 & 3. & 434 \\
\hline Buckwheat bran ........ & 156 & 28. & 11.8 & 4.2 & 12.7 & 482 \\
\hline Buckwheat mid., coarse . & 120 & 47. & 35.2 & 12.3 & 11.4 & 1198 \\
\hline 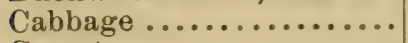 & 856 & 14.1 & 2.8 & 2.2 & 5.2 & 148 \\
\hline 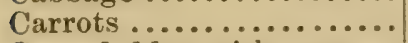 & 870 & 10. & 1.2 & .9 & 2.6 & 65 \\
\hline Corn fodder with ears... & 92 & 37.4 & 4. & 2.9 & 14. & 264 \\
\hline Corn silage (green)...... & 779 & .... & 1.4 & 1.1 & 3.7 & 82 \\
\hline 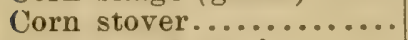 & 150 & 45.3 & 2.7 & 3.8 & 16.4 & 257 \\
\hline Cotton-seed meal ........ & 88 & 70.5 & 59.5 & 30.4 & 15.8 & 2082 \\
\hline Gluten meal ........... & 86 & 7.3 & 41.2 & 3.3 & .5 & 1118 \\
\hline Hominy feed ........... & 89 & 22.1 & 12. & 9.8 & 4.9 & 468 \\
\hline Hungarian grass (green). & 870 & 12. & 3.2 & .7 & 4.7 & 138 \\
\hline Indian corn $\ldots . . . \ldots .$. & 130 & 14.8 & 12.6 & 5.7 & 3.7 & 434 \\
\hline Linseed meal, new $\mathrm{P} \ldots$. & 110 & 62.1 & 45.1 & 17.4 & 13.4 & 1540 \\
\hline Linseed meal, old P...... & 89 & 61. & 46.8 & 16.6 & 13.7 & 1583 \\
\hline Maize fodder (green) .... & 828 & 14.7 & 1.6 & 1.1 & 3.9 & 90 \\
\hline Malt sprouts............. & 120 & 75.1 & 29.7 & 17.4 & 19.9 & 1168 \\
\hline Mangel-wurzel............ & 873 & 12.2 & 1.7 & .9 & 3.8 & 90 \\
\hline 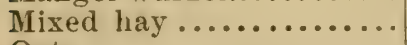 & 137 & 64.5 & 9.9 & 4.1 & 13.2 & 433 \\
\hline 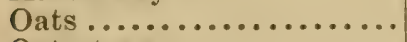 & 133 & 31. & 14.7 & 6.9 & 4.8 & 516 \\
\hline 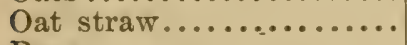 & 145 & 57. & 1.9 & 2.8 & 17.7 & 238 \\
\hline 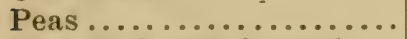 & 140 & 28.1 & 26.8 & 8.4 & 10.1 & 910 \\
\hline Peas and oats (green) .. & 467 & 16.05 & 2.8 & 1.65 & 6.25 & 150 \\
\hline Pea vine straw............ & 136 & 66. & 6.8 & 3.5 & 10.2 & 314 \\
\hline Red clover (green)....... & 790 & 16. & 4.6 & 1.5 & 4.8 & $186^{\circ}$ \\
\hline Red clover hay .......... & 170 & 62.1 & 10.8 & 5.5 & 18.7 & 520 \\
\hline 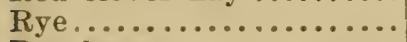 & 134 & 19.8 & 15.8 & 8.6 & 5.8 & 572 \\
\hline Rye bran .... & 125 & 46. & 18.4 & 22.8 & 14. & 846 \\
\hline Skim milk, centrifugal... & 906 & 7.4 & 4.6 & 2.1 & 2. & 165 \\
\hline Sugar-beet leaves........ & 880 & 23.9 & 2.7 & 1.5 & 6.2 & 125 \\
\hline Sugar-beet pulp.......... & 898 & 5.8 & .96 & .2 & .4 & 32 \\
\hline Timothy hay..... & 143 & 41.1 & 4.4 & 5. & 14.1 & 295 \\
\hline Turnips............ & 905 & 8. & 1.8 & 1. & 3.9 & 94 \\
\hline 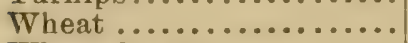 & 134 & 17.1 & 16.3 & 8.7 & 5.5 & 584 \\
\hline Wheat bran......... & 132 & 58. & 19.5 & 26.9 & 15.2 & 924 \\
\hline Theat middlings......... & 126 & 27. & 20.4 & 13.5 & 7.4 & 760 \\
\hline 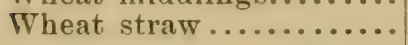 & 136 & 53. & .64 & 2.2 & 6.3 & 94 \\
\hline
\end{tabular}




\section{APPENDIX III}

LIVE-STUCK REGISTRY ASSOCIATIONS, WITH THE NAMES OF THE SECRETARIES OR EDITORS

\section{HORSES}

Anerican Thoroughbred Stud Book, James E. Wheeler, 173 Fifth Ave., New York.

American Hackney Stud Book,

A. H. Godfrey, Astor Court Bldg., West 34th St., New Yor's.

Dominion of Canada Hackney Stud Book,

Henry Wade, Toronto, Ont.

American Morgan Registry,

Jos. Battell, Middlebury, Vt.

Anerican Clydesdale Stud Book,

Alex. Galbraith, Janesville, Wis.

Dominion of Canada Clydesdale Stud Book,

Henry Wade, Toronto, Ont.

AMerican Shire Horse Association,

Charles Burgess, Wenona, Ill.

Dominion of Canada Shire Horse Stud Book,

Henry Wade, Toronto, Ont.

Anerican Cleveland Bay Stud Book,

R. P. Stericker, Janesville, Wis.

Anerican Suffolk Punch Association,

Alex. Galbraith, Janesville, Wis.

Percheron Stud Book of America,

S. D. Thompson, Wayne, Ill.

American French Coach Horse Societr,

S. D. Thompson, Wayne, Ill. 
National Register of French Draft Horses,

C. E. Stubbs, Fairfield, Iowa.

National Register of Norman Horses,

Theo. Butterworth, Quincy, Ill.

American Belgtan Draft Horse Association,

J. D. Conner, Jr., Wabash, Ind.

German Coach Horse Association,

J. Crouch, Lafayette, Ind.

Oldemburg Coach Horse Association,

C. E. Stubbs, Fairfield, Iowa

american Trotting Register Association,

J. H. Steiner, 355 Dearborn St., Chicago, Ill.

american Saddle Horse Breeders' Association,

I. B. Nall, Louisville, Ky.

American Jack Stock Stud Book,

J. H. Fullton, Grassland, Tenn.

american Shetland Club Stud Book,

Mortimer Levering, Lafayette, Ind.

\section{CATTLE}

Adrerican Short-Horn Breeders' Association,

John W. Groves, Springfield, Ill.

Dominion of Canada Short-Horn Herd Book,

Henry Wade, Toronto, Ont.

american Polled Durham Herd Book,

J. H. Miller, Mexico, Ind.

American Hereford Cattle Breeders' Association,

C. R. Thomas, Independence, Mo.

Dominion of Canada Hereford. Herd Book,

Henry Wade, Toronto, Ont.

American Aberdeen-Angus Herd Book,

Thomas McFarlane, Harvey, IIl. 
Dominion of Canada Polled Angus Herd Book,

Henry Wade, Toronto, Ont.

American Galloway Brekders' Association,

Frank B. Hearne, Independence, Mo.

Ainerican Jersey Cattle Club Hern Register,

J. J. Hemingway, 8 West 17th St., New York.

AirericaN Jersey Herd Book,

O. B. Hadwen, Worcester, Mass.

Maine State Jersey Cattle Association Herd Book,

N. R. Pike, Winthrop, Me.

Ainerican Guernsey Cattle Club Herd Register,

Wm. H. Caldwell, Peterboro, N. H.

Holstein-Friesian Herd Book,

Frederick L. Houghton, Brattleboro, Vt.

Holstein-Friesian Herd Book of Canada,

J. W. Clemons, St. George, Ont.

Dutch Belted Herd Book,

H. B. Richards, Easton, Pa.

American Branch Association North Holland Herd Book,

Fred. H. Beach, Dover, N. J.

ATrShiRE RECORD,

C. M. Winslow, Brandon, Vt.

Canadian Ayrshire Herd Book,

Henry Wadə, Toronto, Ont.

AMerican Devon ReCORd,

L. P. Sisson, Wheeling, W. Va.

Canada Devon Record,

Henry Wade, 'Toronto, Ont.

Swiss RECORD,

N. S. Fish, Groton, Conn.

Red Polled Herd Book,

J. MeLain Smith, Dayton, Ohio.

American Sussex Association, Overton Lea, Nashville, Tenn. 
American Holderness Herd Book,

T. A. Cole, Solsville, N. Y.

Kerry Catthe,

Henry S. Ambler, Chatham, N. Y.

\section{SHEEP, GOATS AND RABBITS}

American Shropshire Sheep Record,

Mortimer Levering, Lafayette, Ind.

Flock Record of Hampshire-Down Shem,

C. A. Tyler, Nottawa, Mich.

American Leicester Record,

A. J. Temple, Cameron, Ill.

Dorset-Horn Sheep Breeders' Association of America,

M. A. Cooper, Washington, $\mathrm{Pa}$.

Dorset-Horn Continental Club,

J. E. Wing, Mechaniesburg, Ohio.

American Cheviot Sheep Societr,

F. E. Dawley, Fayetteville, N. Y.

AMERICAN Cotswold ReCord,

Geo. Harding \& Son, Waukesha, Wis.

American Southiown Association,

Frank S. Springer, Springfield, Ill.

AMERICAN OxFord-DOWN RECORD,

W. A. Shafor, Middletown, Ohio.

Standard American Merino Sheep Breeders' Association,

John P. Ray, Hemlock Lake, N. Y.

Standard Delaine Spanish Merino Sheep Breeders' AssoclaTION,

S. M. Cleaves, East Bethlehem, Pa.

National Merino Sheep Register Assoclation,

C. C. Johnson, Canonsburg, Pa.

Register Michigan Merino Shefp Breeders' Associaton,

E. N. Ball, Hamburg, Mich. 
Register N. Y. State American Merino Sheep Breeders' Association,

J. Horatio Earll, Skaneateles, N. Y.

Register Vermont Merino Sheep Breeders' Association, Lewis A. Skiff, Middlebury, Vt.

U. S. Merino Sheep Breeders' Registry Association, J. A. B. Walker, Enon Valley, Pa.

Black Top Spanish Merino Sheep Register, W. G. Berry, Houstonville, Pa.

Improved Black Top Merino Association,

L. M. Harsh, Union City, Mich.

Standard Delaine Merino Sheep Breeders' Association, Alexander Turnbull, Cedarville, Ohio.

National Delaine Merino Sheep Breeders' Association, John C. MeNary, Canonsburg, Pa.

National Dickinson Record Co.,

H. G. MeDowell, Canton, Ohio.

American Ramaoullete Sheep Breeders' Association,

E. V. Burnham, Woodstock, Ohio.

Ohio Merino Breeders' Association,

Wesley Bishop, Troyton, Ohio.

Vermont Atwood Club Register,

Geo. Hammond, Middlebury, Vt.

National Improved Saxony Sheep Breeders' Association,

John G. Clark, R. D. No. 9, Washington, Pa.

American Lincoln Sheep Breeders' Association,

L. C. Graham, Cameron, Ill.

National Lincoln Sheep Breeders' Association,

Bert Smith, Charlotte, Mich.

INTERNational Lincoln Society,

H. A. Daniels, Millington, Mich.

American Suffolk Flock Registri Association,

F. A. Franklin, Atlantic, Iowa. 
Doinnion Sheep Breeders' Flonk Book of all Breeds, Henry Wade, Toronto, Ont.

Auerican Angora Goat Breeders' Association,

C. P. Bailey, San Jose, Cal.

American Belgian Hare Registry Association,

Dr. E. R. Allen, Kansas City, Mo.

\section{SWINE}

Auerican Berkshire Association,

Chas. F. Mills, Springfield, Ill.

Central Poland-China Record,

W. H. Morris, Indianapolis, Ind.

Standard Poland-China Record,

Geo. F. Woodworth, Marysville, Mo.

Ohio Poland-China Record,

Carl Freigau, Dayton, Ohio.

Aurerican Poland-China Record Co.,

William M. McFadden, West Liberty, Iowa.

National Chester-White Record,

Thos. Sharpless, Westehester, Pa.

Standard Chester-White Record Association,

W. H. Morris, Indianapolis, Ind.

Auerican Chester-White ReCord,

Carl Freigau, Dayton, Ohio.

AMERICAN DURoc-Jersey Record,

A. V. Braderick, Connersville, Ind.

National Duroc-Jersey Record,

Robt. J. Evans, El Paso, Ill.

Cheshire Herd Book,

B. B. Badger, Ouaquaga, N. Y.

VICTORIA SWINE RECORD,

H. Davis, Dyer, Ind. 
Record Improved Essex Swine,

F. M. Srout, MeLean, Ill.

Smali-Yorkshire Swine Register,

Geo. W. Harris, Box 3432, New York.

National Berkshire Record Association,

E. K. Morris, Indianapolis, Ind.

AMerican Yorkshire Club,

W. F. Wileox, Minneapolis, Minn.

American Suffolk Association,

W. F. Watson, Winchester, Ind.

Tamirorth Strine Association,

E. N. Ball, Hamburg, Mich.

Gothland Strine Breeders' Association,

Grant W. Spear, Aurora, III.

Dominion SWine Breeders' Record of all Breeds,

Henry Wade, Toronto, Ont. 


\section{APPENDIX IV}

\section{NUMBER AND TALUE OF HORSES}

\section{From Report of the Twelfth United States Census}

Horses were reported on 4,532,018 farms and ranges, June 1, 1900 , and in 1,373,661 barns and other inclosures not on farms or ranges. The number on farms and ranges comprised $1,315,208$ colts under 1 year old, 1,447,747 horses 1 and under 2 years, and $15,517,052$ horses 2 years and over. The numbers not on farms and ranges were, for the three classes named, 33,090; 30,402, and $2,873,389$, respectively. There was, therefore, a total for the United States of $18,390,441$ work-horses and 2,826,447 too young for work, making a grand total of $21,210,888$ horses, of which' 86.8 per cent were on farms and ranges and 13.2 per cent in barns and inclosures elsewhere.

\section{Number and Value of Horses and Colts in the UNited States in 1900}

\begin{tabular}{|c|c|c|c|c|c|c|}
\hline \multirow{3}{*}{$\begin{array}{l}\text { States and } \\
\text { Territories }\end{array}$} & \multicolumn{6}{|c|}{ HoRSES } \\
\hline & \multicolumn{2}{|c|}{ Colts, under 1 year } & \multicolumn{2}{|c|}{$\begin{array}{c}\text { Colts, } 1 \text { and under } \\
2 \text { years }\end{array}$} & \multicolumn{2}{|c|}{2 years and over } \\
\hline & Number & Value & Number & Value & Number & Value \\
\hline The United States* & $1,315,208$ & $\$ 25,900,109$ & $1,447,747$ & $\$ 48,335,128$ & $15,517,052$ & $\$ 822,720,106$ \\
\hline North Atlantic & 57,744 & $\$ 1,8+8,932$ & 82,978 & $\$ 4,669,92 \mathrm{i}$ & $\iota, 558,417$ & $\$ 116,830,468$ \\
\hline $\begin{array}{l}\text { Division ....... } \\
\text { North Central }\end{array}$ & 56,527 & $1,324,033$ & 60,944 & $2,482,859$ & 953,599 & $56,098,624$ \\
\hline $\begin{array}{l}\text { Division ....... } \\
\text { South Central }\end{array}$ & 723,896 & $15,993,815$ & 802,439 & $30,298,014$ & $8,267,927$ & $469,738,862$ \\
\hline Division ......... & 248,894 & $4,487,897$ & 241,086 & $6,476,530$ & $2,934,783$ & $120,179,811$ \\
\hline Western Division & 227.768 & $2,242,194$ & 258,778 & $4,371,311$ & $1,791,240$ & $59,469,942$ \\
\hline
\end{tabular}

*Data for Alaska and Hawaii included in totals for United States, but not in those for the five geographical divisions. 
Number and Value of Horses and Colts in the UNITED STATES IN 1900 -Continued

\begin{tabular}{|c|c|c|c|c|c|c|}
\hline \multirow{3}{*}{$\begin{array}{l}\text { States and } \\
\text { Territories }\end{array}$} & \multicolumn{6}{|c|}{ Horses } \\
\hline & \multicolumn{2}{|c|}{ Colts, under 1 year } & \multicolumn{2}{|c|}{$\begin{array}{c}\text { Colts, } 1 \text { and under } \\
2 \text { years }\end{array}$} & \multicolumn{2}{|c|}{2 yeurs and over } \\
\hline & Number & Value & Number & Value & Number & Value \\
\hline Alabamat...... & 8,724 & $\$ 203,492$ & 7,846 & $\$ 299,118$ & 136,073 & $\$ 7,403,511$ \\
\hline Alaska ... & & & & & 5 & 465 \\
\hline Arizona ....... & 18,976 & 82,610 & 22,283 & 152,878 & 83,804 & ],466,417 \\
\hline Arkansas. & 16,815 & 289,075 & 14,179 & 381,735 & 222,596 & $9,493,685$. \\
\hline California ..... & 23,049 & 423,427 & 24,639 & 763,613 & 373,605 & $16,657,953$ \\
\hline Colorado....... & 23,645 & 291,280 & 27,360 & 530,164 & 185,541 & $6,487,282$ \\
\hline Connecticut.... & 429 & 17,952 & 1,480 & 94,030 & 50,667 & $3,701,650$ \\
\hline Delaware...... & 1,590 & 42,110 & 1,903 & 84,427 & 26,229 & $1,641,088$ \\
\hline Dist. of Col'm'a & 16 & 590 & 24 & 1,475 & 814 & 55,297 \\
\hline Florida ........ & 2,239 & 42,156 & 2,185 & 75,232 & 38,387 & $2,172,751$ \\
\hline (ieorgia....... & 4,028 & $99,9: 35$ & 4,525 & 189,539 & 118,854 & $6,802,754$ \\
\hline Hawaii. & 379 & 3,238 & 1,522 & 36,489 & 11,081 & 401,934 \\
\hline Idaho.......... & 18,212 & 136,246 & 20,832 & 278,326 & 131,076 & $3,708,771$ \\
\hline Illinois ....... & 107,967 & $2,518,050$ & 115,377 & $4,575,418$ & $1,126,875$ & $62,604,632$ \\
\hline Indiana....... & 52,426 & $1,308,117$ & 54,820 & $2,365,668$ & 644,469 & $36,968,203$ \\
\hline Indian Terri'y. & 20.054 & 213,041 & 19,253 & 324,049 & 178,392 & $5,686,628$ \\
\hline lowa........... & 124,527 & $2,991,078$ & 133,589 & $5,359,392$ & $1,134,457$ & $69,370,107$ \\
\hline Kansas ........ & 72,539 & $1,465,610$ & 78,447 & $2,462,398$ & 828,709 & $39,830,326$ \\
\hline Kentucky.. & 26,487 & $1,062,057$ & 24,927 & $1,428,700$ & 400,283 & $22,057,785$ \\
\hline Louisiana. . & 13,510 & 166,312 & 12,076 & 274,190 & 168,786 & $6,184,115$ \\
\hline Maine.... & 2,834 & 78,537 & 3,955 & 201,548 & 99,510 & $6,778,904$ \\
\hline Maryland ...... & 8,942 & 231,074 & 9,938 & 455,204 & 130,114 & 6,416 \\
\hline Massachusetts. & 799 & 47,177 & & 16 & & 9,159 \\
\hline Michigan ...... & 31.018 & 746,534 & 38,406 & $1,711,541$ & 517,135 & $33,450,482$ \\
\hline Minnesota ..... & $4 \bar{i}, \overline{0} 04$ & 970,772 & 51,399 & $2,031,557$ & 599,566 & $39,252,715$ \\
\hline Mississippi .... & 17.089 & 367,069 & 14,489 & 495,714 & 197,733 & $10,020,068$ \\
\hline Missouri...... & 58,177 & $1,277,129$ & 63,214 & $2,070,506$ & 845,646 & $38,747,179$ \\
\hline Montana....... & 39,838 & 364,743 & 44,850 & 839,334 & 245,284 & $6,584,595$ \\
\hline Nebraska...... & 66,776 & $1,284,984$ & 73,082 & $2,316,583$ & 655,460 & $33,061,792$ \\
\hline Nerarla.... & 10,778 & 56,296 & 11,001 & 102,188 & 58,516 & $1,113,852$ \\
\hline New Hampshire & 702 & 23.847 & 1,543 & 90,816 & 52,621 & $3,726,007$ \\
\hline New Jersey.... & 1.826 & 153,251 & & 240,380 & 89,144 & $7,188,613$ \\
\hline New Mexico ... & 16,666 & 99,127 & 16,550 & 177,458 & 97,937 & $1,943,884$ \\
\hline New York.... & 20,027 & 650,894 & 30,033 & $1,771,023$ & 578,378 & $45,556,014$ \\
\hline North Carolina. & 5,807 & 131,675 & 5,927 & 233,882 & 147,419 & $8,430,054$ \\
\hline North Dakota.. & 28,625 & 546,743 & $32,1: 31$ & $1,127,100$ & 299,192 & $21,054,668$ \\
\hline Ohio........... & $5 \overline{5}, 324$ & $1,395,896$ & 67,332 & $3,037,402$ & 755,549 & $45,725,947$ \\
\hline Oklahoma ..... & 26,933 & 423,331 & 28,382 & 656,139 & 248,316 & $9,535,824$ \\
\hline Oregon.... & 26.138 & 267,521 & 27,682 & 480,133 & 234,112 & $7,903,406$ \\
\hline Pennsylvania.. & 28,547 & 806,696 & 36,584 & $1,916,501$ & 525,850 & $38,225,630$ \\
\hline Rhode Island ... & 91 & 4,740 & 179 & 13,779 & 11,120 & 962,429 \\
\hline South Carolina. & 2,701 & 69,778 & 3,188 & 161,587 & 72,530 & $4,615,538$ \\
\hline
\end{tabular}




\section{Number and Value of Horses and Colts in the United States in 1900 - Continued}

\begin{tabular}{|c|c|c|c|c|c|c|}
\hline \multirow{3}{*}{$\begin{array}{l}\text { States and } \\
\text { Territories }\end{array}$} & \multicolumn{6}{|c|}{ HoRses } \\
\hline & \multicolumn{2}{|c|}{ Colts, under 1 year } & \multicolumn{2}{|c|}{$\begin{array}{c}\text { Colts, } 1 \text { and under } \\
2 \text { years }\end{array}$} & \multicolumn{2}{|c|}{2 years and over } \\
\hline & Number & Value & Number & Value & Number & Value \\
\hline South Dakota.. & 47,124 & $\$ 700,748$ & 52,659 & $\$ 1,369,292$ & 380,985 & $\$ 18,015,647$ \\
\hline Tennessee.... & 23,853 & 6633,620 & 23,109 & 993,396 & 305,426 & $18,024,501$ \\
\hline 'Texas ......... & 95,429 & $1,099,900$ & 96,825 & $1,623,489$ & $1,077,178$ & $31,77: 3,694$ \\
\hline Utah ... & 11,395 & 122,843 & 13,515 & 247,348 & 90,974 & $3,026,122$ \\
\hline Vermont....... & $2,+89$ & $65.8: 38$ & $\left.3,85^{\circ}\right)$ & 181,727 & 79,190 & $5,072,032$ \\
\hline Virginia ....... & 19,257 & $441,8: 58$ & 20,291 & 780,009 & 258,974 & $14,104,537$ \\
\hline Washington.... & 22,359 & 253,658 & 30,312 & 502,760 & 191,314 & $7,794,016$ \\
\hline West Virginia.. & 11,947 & 264,857 & 12,963 & 501,504 & 160,278 & $9,610,189$ \\
\hline Wisconsin ..... & 33,889 & 788,154 & $41,98: 3$ & $1,871,157$ & $\pm 79,884$ & $31,6.57 .164$ \\
\hline Wyoming...... & 16,712 & 144,443 & 19,754 & 297,109 & $99,0 \div 7$ & 2.783 .644 \\
\hline
\end{tabular}

Number and Value of Horses and Colts on Farms and Ranges in the United States, June 1, 1900, with Average Talces

\begin{tabular}{|c|c|c|c|}
\hline Classes & Number & Value & $\begin{array}{c}\text { Average } \\
\text { value }\end{array}$ \\
\hline All horses. & $18,280,007$ & $\$ 896,955,343$ & $\$ 1907$ \\
\hline 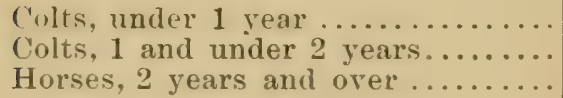 & $\begin{array}{r}1,315,208 \\
1,447,747 \\
15,517,052\end{array}$ & $\begin{array}{r}\$ 25,900,109 \\
48,335,128 \\
822,720,106\end{array}$ & $\begin{array}{rl}\$ 19 & 69 \\
33 & 39 \\
53 & 02\end{array}$ \\
\hline
\end{tabular}

Number of Horses, June 1, 1900, in Cities of Specified Nuibers AND INHABITANTS

\section{Ciasstaied By Population}

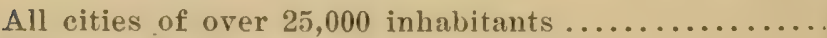

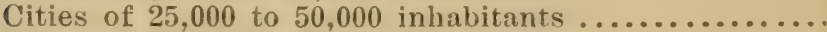

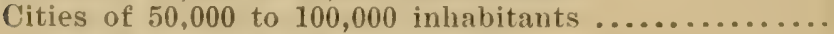

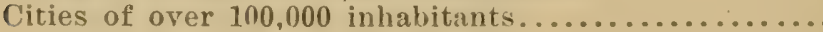

Number to 100,000 inhabitants 
Number and Estmated Value of Horses and Colts yot on Farms or Ranges, and Estimated Value of ali. HoRses in the United States, June 1, 1900

\begin{tabular}{|c|c|c|c|}
\hline \multirow[b]{2}{*}{ CraAsSES } & \multicolumn{2}{|c|}{ Not on farms or ranges } & \multirow{2}{*}{$\begin{array}{l}\text { Estimated } \\
\text { value of all } \\
\text { horses }\end{array}$} \\
\hline & Number & $\begin{array}{l}\text { Estimated } \\
\text { value }\end{array}$ & \\
\hline 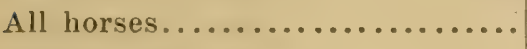 & $2,936,881$ & $\$ 154,013,750$ & $\$ 1,050,969,093$ \\
\hline Colts, under 1 year. . & 33,090 & $\$ 651,542$ & $\$ 26,551,651$ \\
\hline Colts, 1 and under 2 years....... & 30,402 & $1,015,123$ & $49,350,251$ \\
\hline Horses, 2 years and over....... & $2,873,389$ & $152,347,085$ & $975,067,191$ \\
\hline
\end{tabular}

Number of Horses on Farms and Ranges in the United States, by Geographical Divisions; Summary 1850 to 1900

(Expressed in thousands)

\begin{tabular}{|c|c|c|c|c|c|c|}
\hline GEographIC DIVISION & $* 1900$ & $\dagger 1890$ & $\dagger 1880$ & +1870 & $\dagger 1860$ & +1850 \\
\hline he United Sta & 16,965 & $\pm 15,266$ & 10,357 & 7,145 & 6,249 & 4,337 \\
\hline North Atlonti & 1,641 & 1,739 & 1,555 & 1.336 & 1,280 & 1.074 \\
\hline & & & & & & 1 \\
\hline Nol & 9 & $\pm 8,5$ & & & 2 & 399 \\
\hline 0 & & & & & 1.436 & 1,056 \\
\hline Wes & 2,050 & $\pm 1,611$ & 613 & 294 & 217 & 37 \\
\hline Alaska and Hawaii & 13 & & & $\ldots$ & ... & ... \\
\hline
\end{tabular}

* Exclusive of spring colts.

† No separate report or estimate of range animals made.

$\ddagger$ Including estimated number of range animals separately reported,

Nryber of Horses Exported froy the United States, 1891 to 1901

\begin{tabular}{|c|c|c|c|}
\hline YEAR & NuMber & YEAR & NuMBER \\
\hline $\begin{array}{l}1891 \ldots \ldots \ldots \ldots \ldots \\
1892 \ldots \ldots \ldots \ldots \ldots \\
1893 \ldots \ldots \ldots \ldots \\
1894 \ldots \ldots \ldots \ldots \\
1895 \ldots \ldots \ldots \ldots \\
1896 \ldots \ldots \ldots \ldots\end{array}$ & $\begin{array}{r}3,110 \\
3,226 \\
2,967 \\
5,246 \\
13,984 \\
25,126\end{array}$ & $\begin{array}{l}1897 \ldots \ldots \ldots \ldots \ldots \ldots \\
1898 \ldots \ldots \ldots \ldots \ldots \ldots \\
1899 \ldots \ldots \ldots \ldots \\
1900 \ldots \ldots \ldots \ldots \\
1901 \ldots \ldots \ldots \ldots \\
\end{array}$ & $\begin{array}{l}39,532 \\
51,150 \\
45,778 \\
64,722 \\
82,250\end{array}$ \\
\hline
\end{tabular}


Estimated Average Value of Horses in the United States; SUMMARY, 1880 TO 1900

\begin{tabular}{|c|c|c|c|}
\hline YEAR & VALUE & YEAR & VALUE \\
\hline $1880 \ldots \ldots \ldots$ & $\$ 5475$ & $1891 \ldots \ldots \ldots \ldots \ldots$ & $\$ 6700$ \\
\hline ......... & 5844 & $1892 \ldots \ldots \ldots \ldots \ldots$ & 6501 \\
\hline $1882 \ldots \ldots \ldots \ldots \ldots$ & 5853 & $1893 \ldots \ldots \ldots \ldots \ldots$ & 6122 \\
\hline $1883 \ldots \ldots \ldots \ldots$ & $70 \quad 59$ & $1894 \ldots \ldots \ldots \ldots \ldots$ & 4783 \\
\hline $1884 \ldots \ldots \ldots \ldots$ & $74 \quad 64$ & $1895 \ldots \ldots \ldots \ldots \ldots$ & $36 \quad 29$ \\
\hline $1885 \ldots \ldots \ldots \ldots$ & 7370 & $1896 \ldots \ldots \ldots \ldots$ & 3307 \\
\hline $1886 \ldots \ldots \ldots \ldots$ & 7127 & $1897 \ldots \ldots \ldots \ldots$ & 3151 \\
\hline $1887 \ldots \ldots \ldots \ldots \ldots$ & 7215 & $1898 \ldots \ldots \ldots \ldots \ldots$ & 3426 \\
\hline $1888 \ldots \ldots \ldots \ldots$ & 7182 & $1899 \ldots \ldots \ldots \ldots \ldots$ & 3740 \\
\hline $1889 \ldots \ldots \ldots \ldots$ & 7189 & $1900 \ldots \ldots \ldots \ldots$ & 4461 \\
\hline $1890 \ldots \ldots \ldots \ldots \ldots$ & 6884 & Census $1900 \ldots . .$. & 4907 \\
\hline
\end{tabular}




\section{INDEX}

Abderame, Saracen chief, 156.

Accidents in pacing, 85 .

Air, warm and cool, 340.

Alexander I., 63.

American boy and the horse, 3, 4, 15. breeds, dearth of, 42 . thoroughbred, 61 . trotters discussed, 43.

Americans poor drivers, 297.

Animals for illustration, 149.

Appendix I., 354- 59 .

II, 360 .

III. Live-stock registry, 381-387.

IV. Number and value of horses, 388-392.

Arabian horse in France, 32.

in Great Britain, 29.

Army-horses, breeding of, 354.

Artillery-horses, 355.

Ashes for horses, 311.

Association, National Trotting Horse Breeders', 74.

Atavism explained, 201.

Attachment, high and low, 351.

Backing horses, 315.

the horse, 290.

Bakewell, Robert, 141.

Beauty valuable, 234.

Beginner, suggestions for, 222.

Belgium draft, characteristies, 169 ; description, 171; draft, 168; origin, 168; size of, 169; stallion, Fig. of, 169,170 .

Bits, kinds of, 285.

Black horse of Europe, 139.

Blankets for draft-horses, 312. how to use them, 293.
Boulonnais, description of. 168; draft, 168; origin, 168.

Breeders' Gazette, 151.

Breeding for the army, 354.

generations discussed, 183.

hor'ses, 267.

laws of, 178 .

laws of, discussed, 176.

mares, how secured, 204.

mistakes of, 175.

modified by inheritance, 181.

nondeseripts, 33 .

plan of, 202.

principles of, 174 .

remarks on, $76,77,78$.

scientific, $76,77,78$.

stockholders interested, 202.

studied under eight heads, 180.

theory not correct, 181.

variations, 177.

Brecds, explanation of, 49.

formation of, discussed, 44 .

how originated, 145.

suitably placed, 223 .

Bressay of Pittsford, Shetland. 127.

British horse, 61.

Broadhead, Colonel, 69.

Broken-gaited horses, 85

Brood-mare, characteristics, 208; de. seription of, 206; Fig. of, 205; filley. Fig. of. 207; first lesson, 207; how worked, 217 ; kept on farms, 225; paddosks for, 217.

Bronco-gaited, 134.

Canadian horses to United States, 87.

Cattle, wild, 179.

Cavalry-horses, 69, 356. 
Champion Welsh pony mare, 129.

Charles II., 39.

Chase, A. C., 336.

Chaucer, 70.

Chillingham Park, 179.

Cities' demand for heavy horses, 229.

Cleveland Bay, diseussed, 102.

Climate, effect of, on conformation, 190, the part it plays, 189.

severe effects of, on conformation, 191.

Clydo Dunsmore, combination, 148.

Clydesdale, 17, 31, 39; description of, 141; diminution of feather, 144; Figs. of, 140, 142, 144, 146; Borthwick, Imported, 144; in Great Britain, 144; in the U.S., 144; Lord Stewart, Fig. of, 140; mare, 146 ; origin, 141; wasp-waisted, 143 ; weight of, 143.

Coaclier, trotters as sires of, 103.

Coach-horses, 95 ; a good one, 101; carriages for, 99 ; checked high, 96 ; Cleveland Bay, 100; deseription of, 95, 97; desirable characteristies, 98; discussed, 95; for America, 99; for leisure class, 96 ; size of, 95 ; uses of, 97.

Color of horses, 235.

Colts, and the farm boy, 272; being thrown, 279; building for, 335; cost of, 269 ; cost of raising, 225,269 ; defined, 218; educate the farm boy, 273; education, 275; education in detail, 276; fall, versus spring, 210; how subdued, 280 ; in mixed husbandry, 269 ; plan of breeding, 211 ; presented by father, 274; profits in raising, 271; ready for second lesson, 278; receiving first lesson, 27T; sale of, 213; two-toed, Fig. of, 239; versus cows, 212, 270; when to breed, 211.

Commoner's horse, 47.

Computing rations for farm animals, 360.

Conditions to be made superior, 194.

Constipation, how relieved, 310.
Cool stables, 338.

Cow-hocked legs, Fig. of, 238.

Cresceus, 74; Fig. of, 75.

Crossing, rules for, 196.

Crusades, 63.

Curtis, G. W., 159.

Custom of the road, 352.

Dam and sire, influence of, 197.

Damp stables, 338.

Dan Pateh, 80 ; Fig. of, 83. .

Demi-Sangs, 10 .

Denmark, foundation of saddlers, 88 .

Description of the horse wanted, 48 .

Discovering blemishes, 244.

Discussion of feeding rations, 360-363.

Domestication, 21.

Draft breeds, 156; British, 156; French, 156.

Draft-colt, first lesson. Fig. of, 209.

Draft-horse, 139: heavy, 2; imported, 64; medium, 2, 5; in Great Britain, 30 .

Draft, line of, 348,349 ; Fig. of, 348 ;

F'ig, of, $3+9$.

Driving badly, 288, 290.

colts, 302.

draft-horses, 314

farm-horses, 314 .

good and bad, 298.

in Great Britain, 299.

instructions, 287.

jockey stylo, 300 .

plow-horses, 300 .

position of hands in, 299.

pullers, 300 .

roadsters, 299.

slack rein, 301.

system of, 301.

trotters, 299.

Duchess of Geneva, 52.

pedigree illustrated, 553.

Du Hays, Charles, 31, 32, 156.

Dunsmore Combination Clyde, 148.

Eads, James B., 177.

Economical application of energy, 347. 
Edward II., 64.

Effects of careless coupling, 347.

food, 347 .

native ability, 347 .

propitious climate, 228.

Energy economically applied, 350 .

efficiently applied, Fig. 92, 347.

English Shire, 147; description of, 147;

Fig. 33, 148.

English stud-book, 61.

Evolution, law of, 196.

Exile of Pittsford, Shetland, 126.

Experimental breeding, 139.

Exportation in Great Britain, forbidden, 27,

Family horse, 234.

Farm-horse in Great Britain, 26. in United States, 2, 4, 8, 12.

Feeding balanced rations, 308 .

brood-mare, 214, 215.

coarse material, 304.

draft-horses, 303.

experiments, 305 .

foal, 214.

foal, milk temperature of, 220 .

foal, succulent food, 220 .

grass, 307.

horses, 281.

quantity, 304 .

rations, 215.

discussion, 360-363.

when, 304.

when at light work, 306 .

Foal, care of, when young, 221.

Foals, number of, in $1880,68$.

Feet, conformation of, 245.

Fields and paddocks, 346.

Fitting the harness, 284.

Flemish horses, 26; compared with

Belgians, 173; described, 171; draft,

140, 171; illustration, Fig. 45, 172.

Flying Childers, 147.

Fly-nets-use explained, 312.

Food, effect of, 187.

Foods for horses, 282.

quantity fed, 283.

Foreign horses in stud, 65.
Forester, Frank, 38.

describes English breeding, 39.

Formation of breeds discussed, 44.

Foundation stock, 36 .

discussed, 36.

for army-horses, 359.

French coach-horse, 105; Fig. 15, 106; description, 104, 106, 107; government control, 105; origin, 104.

French draft-horse, 161-167; stud-book, 161-167; description of, 167 .

Friction relieved, 349 .

Fright, 18.

Full-blood explained, 146.

Gaited bronco, 134.

Gallipoli, 159.

Galloways, 125.

Geddes, George, 15.

General-purpose horse, 2.

German coach at World's Fair, 109; description of, 109; Fig. 16, 108; stud-book, 109.

Gestation, period of, 219.

Godolphin, 159.

Godolphin Arabian, 65.

Good driving, 297.

Gould, J. S., 13.

Grade defined, 58.

Grades, breeding of, 226.

Grooming the horse, 292.

Habit, a factor in improvement, 192.

Hackney, 110; back ideal, 110; breeding of, 114; Cadet, Fig. 17, 111; Cassatt, A. J., 113, 114; Coutts, Burdett, 112; description of, 112; demand for, 113, 114; Faudango, Fig. 18, 113; how produced. 111; importations from Europe, 114; in England, 111; Little Wonder, 112; limbs flexible, 112; Lawrence, Preścott, 113; pleasing appearance satisfies the eye, 113; size of, 112; Stevens, Frederick C., 113; sold, 114 ; west of Ohio river, 114.

Hands in driving, 297. See, also, Driving. 
Hansom-eab, 352; Fig. 95, 353.

Harness, fitting of, 284.

Hay, provision for, 345 .

Henry III., 64.

Herbert, on the horse, 62.

Hoppling racers, 85 .

Horses, abandoned by DeSoto, 34; action of, 73 ; beauty of, 78 ; bred by the commoner, 268; breeding, 267; bones of, in Kirkdale cave, 35; Conestoga, 35; care of legs, 294; color of, 78; character wanted and how procured, 46-47; days' work, 291; divided into groups, 237; Eng. lish books on, 71; fat and lean, 281; feeding of, 281; for war purposes, 104; fossil remains of, 34 ; in France, 31; in Great Britain, 26; grooming of, 292; guaranteed, 232; imported, 64; imported by Columbus, 35 ; in hansoms, 353 ; landed by Cortez, 35; love for, 1,3 ; modified by climate, 189; modified by Puritans, 40; nondescript, value of, 46 ; number and value, Appendix IV., 388-392, saddlers, 71 ; slege of Azof, 34; to Canada, 35; to New York, 35; to Pennsylvania, 35; two varieties, 122; use of, 41; watering of, 290; when blanketed, 293; when ridden, 72; when to elean, 295; wild, 34; wild, of South America, 34 ; winter work for, 224 ; see, also, Farm-horse, Draft-horse, Pony. Roadster.

Horse-power, 9, 10.

Hunter, 30, 115; Canadian breeders of, 121; description of, 119; heavy weight, Fig. of, 117; how trained, 118; investment required, 115; number raised, 121; Ontario, Fig. of, 120; Peer, F. S., 115; sires, 116; thoroughbred, foundation of, 118; Virginia, breeders of, 121.
Importation, before 1776, 1; into Great Britain, 26; United States, 5; laws, 64; of racing blood, 39 .

Improvement, due largely to food and environment, 231.

infusion of better blood, 231 .

use, 231.

of herd, how accomplished, 195.

discussed, 227.

Infantry-horses, 357 .

Influence, relative, of sire and dam, 200. Inheritance discussed, 185.

Inspecting the horse, 239.

Job, tribute of, 69.

Jockeying, 63.

Joe Patchen, 80.

Judging horses, 233.

Julius Cæsar, Welsh Pony, 132

King James, 65.

Large horses difficult to produce, 236.

Light vehicles, 352.

Lighting stables, 334.

Line of draft, 348; Fig. of, 348 .

Live-stock registry. 381-387.

Load, how attached, 351.

Lord Stewart, Clydesdale, 140.

Lou Dillon, 74; Fig. of, 72.

Major Delmar, 74.

Mangers, construction of, 345 .

Manures, care of, 340 .

waste of, 341 .

Martel, Charles, 156.

Mand S., 74.

Mental and museular efficieney, 188.

Morgan horse modified, 48.

Moses, genealogy of, 56; illustrated, 57.

Movement, Welsh pony, 131.

Mules, in United States, 12.

Nature's modes of action, 178 .

Neck, an all-embracing, Fig. of, 243.

an undesirable, Fig. of, 242 .

of Goldsmith Maid, Hig. of, $2+1$. 
North America, horses indigenous to, 33.

Number and value of horses, Appendix IV.. 388-392.

Oriental blood introduced, 158. breeds, 61. See, also, Arabian horse. Over-draw checks, 285.

Pacers, 72; Narragansett, 37; as a driver, 84 ; breeding diseussed, 82 . compared with trotters, 84 .

discussed, 78 .

pure-gaited, 80 .

time of, 80 .

Pacing horses, 78.

Paddocks and fields, 346.

Palo Alto, 74.

Parturition, approach and signs of, 219.

Patterson, John, 141.

Pedigrees, Alphea Czar, 55.

Angus Ladd, 54.

begun 1829,6 i .

how based, 50 .

knowledge of, stimulates, 59 .

reliance on, 60 .

short and long, 52, 54 .

Percheron horse, 31; mare, Fig. of, 163;

Normans, 161; Stallion, Fig. of, 160 ; stallion, Fig. of, 164; stallion, Fig. of, 166; studbook, 161; weight of, 166.

Percherons changed, old to new, 158; color of, 165; conformation, 165 ; description of, 162; early importations, 159.

Photographing animals, 148.

Plow, invention of, 13.

Plymouth Rocks, how bred, 59.

Pointer, Fig. of, 238.

Ponies, 122; child's horse, 127; African, 122; breeding, 136; Bressay, Fig. of, 127; color of, 133; Corsica, 122; Creole, 135; Dartmoor family, 130; demand for, 125; Exmoors family, 130; Exile, Fig. of, 126; foundation stock, 138; gaited broncho, Fig. of, 134; Fig. of, 123; Fig. of two, 124;
Indian, 135; Julius Casar, -Fig. of, 132; Mexican, 123; mustangs, 133; new forest family, 130; polo-pony breeding, 137; Shetlands, 125; size of, 124, 128; subject to asthma, 128; Titor-Welch, Fig of, 129; useful, 128 ; Welsh pony, Fig. of, 131; Welsh breeding, 130.

Pony, 3; from Europe, 37; Indian mustang, 37.

Potency and prepoteney, 186.

Prince Alert, 80; Fig. of, 81.

Progress by selection, 194.

Pullers, how cured, 285.

Punishing the horse, 289.

Quartette of Clydesdales, Fig. of, 142.

Quilters, Sir W. Cuthbert, 154.

Race-course, 1: established, 62.

established, United States, 66.

Race-horses kep by statesmen, 66 .

Races, number of, 68 .

Racing, 72.

forbidden by Cromwell, 27.

Records of trotters, 73 .

Registration, how governed, 51.

Registry of live-stock, 381-38\%.

Rein, cruel use of, 286.

Reisinger, Roe, 61.

Richard II., 64.

Roadster, 3.

Roman conquest, 61.

horse, 62.

Rules for shoeing, 332 .

Saddlex, American, 86, 87, 94; association, 89 ; at rest, Fig. 4,45 ; at rest, Fig. of, 332; at World's Fair, 90; breeding, 88; color of, 90 ; cut of, Fig. 13, 92; description of, 90 ; for park riding, 91 ; foundation of, $8 \overline{7}$; gaits of, 89; Kentucky, 87; movement of feet, 93; Northern, 91; noted, 88; not popular in New York, 94; Roman, 86; rumning walk. 83; size of, 90; Southern, 91; South United States, 86. 
Salting horses, 311 .

amount of, 311.

Star Pointer, 80.

Saunders, J. H., 160.

Selection, the part it plays, 193.

Selling horses, 232.

Sex, government of, 198.

facts, eited, 199.

Shetland, Exile of Pitsford, 126.

Shire filley, Fig. of, 151.

Short-horn, Herd-book, 51.

Sire and dam, influence of, 197.

Size and weight of horses, 313.

Solling colts, 218.

Spanish horse, 27

horses, 62 .

Stables, arrangement, Fig. 88, 336; cool, 338; damp, 338; faulty con. struction, 338; lighting of, 334; plan of, Fig. 89, 337: too warm, 336 , 338 ; ventilation of, 333,337 ; floors, how made, 342; walls, how made, 339; walls, how repaired, 344 .

Stallion, selection of, 230.

Stalls for brood-mares, 217.

Stanford, Governor, 69.

Statisties:-France, 7; Germany, 7;

Great Britain, 6; Netherlands, 8:

United States, 5, 6, 8.

Stone, Prof. John L., 360.

Straw, provision for, Fig. 89, 345.

Stud-book, how formed, 50 .

Sub-breeds defined, 58.

Success, Fig. of, 157.

Suggestions for the beginner, 222.

Suffolk Punch, color, 152; description of, 153; Fig. of, 152; foundation stock, 152; improved, 153; mare, Fig. of, 154.

Sunol, 74

Tables of standard feeding rations, $364-369$.

Teeth at advanced nge, Fig. of, 263; cross-sections of, Fig. of, 260; discussed,246; horses' ages told by, 262 ; ten months old, Fig. of, 249; side view, very old horse, Fig. of, 264; temporary, Fig. of, 249; wear of, six cuts, Fig. of, 265; six weeks old, Fig, of, 248; two weeks old, Fig. of, 247; eight years old, Fig. of, 259: eight year's old, side view of, Fig. of, 261; four years old, Fig. of, 252; four years old, side view of, Fig. of, 253; five year's old, Fig. of, 254; five years old, side view of, Fig. of, 255; seven years old, Fig. of, 257; seven years old, side view of, Fig. of, 258 ; six years old, Fig. of, 256; six years old, side view of. Fig. of, 256 ; three years old, Fig. of, 251; two years old, Fig. of, 250.

Thirty war-horses, 64 .

Thoroughbred, Tennessee and Kentucky, 69.

as drivers, 69.

crossed with, 68 .

horse, 28,30 .

importations into United States, 66. training, 16, 17.

Tribe explained, 50.

Tricks of the trade, 233.

Traitor Shire stallion, Fig. of, 150.

Trotter in England, 71.

in Austria, 71.

in France, 71.

in Italy, 71.

in Russia, 71 .

Trotters compared with pacers, 84 .

Trotting gait, natural, 70 .

horse, 70 .

Trotting records, 73 .

Unsightly ears, Fig. of, 240.

head, Fig. of, 240.

Use a factor in improvement, 192.

Variations, cause of, 193.

Ventilation, 333.

Wagon, draft of, 350 .

low.wheeled, 350 .

wide-tired, 350. 
Walters, William T., 156.

War-horse, 22.

Water, temperature of, 309 .

Watering horses, 290, 308. when hot, 309 .

Welsh Pony mare, Champion, 129.

White Turk, 27.
Wild horse, 4.

William the Conqueror, 62.

Work day, length of, 291.

Xenophon, 22.

Youatt, 67. 



\section{The Best and Nervest Rural Books}

DOOKS ON LEADING TOPICS

13 CONNECTED WITH AGRICULTURAL AND RURAL LIFE ARE HERE MENTIONED. EACH BOOK IS THE WORK OF A SPECIALIST, UNDER THE EDITORIAL SUPERVISION OF PROFESSOR L. H. BAILEY, OF THE CORNELL UNIVERSITY, OR BY PROFESSOR BAILEY HIMSELF, AND IS READABLE, CLEAR-CUT AND PRACTICAL。 


\section{THE RURAL SCIENCE SERIES}

Includes books which state the underlying principles of agriculture in plain language. They are suitable for consultation alike by the amateur or professional tiller of the soil, the scientist or the student, and are freely illustrated and finely made.

The following volumes are now reary:

THE SOIL. By F. H. KING, of the University of Wisconsin. 303 pp. 45 illustrations. 75 cents.

THE FERTILITY OF THE LAND. By I. P. ROBERTS, of Cornell University. $421 \mathrm{pp.} 45$ illustrations. $\$ 1.25$.

THE SPRAYING OF PLANTS. By E. G. LODFMAN, late of Cornell University. 399 pp. 92 illustrations. $\$ 1.00$.

MILK AND ITS PRODUCTS. By H. H. WING, of Cornell University. $311 \mathrm{pp} .43$ illustrations. $\$ 1.00$.

THE PRINCIPLES OF FRUIT-GROWING. By L. H. BAILEY. 516 pp. 120 illustrations. $\$ 1.25$.

BUSH-FRUITS. By F. W. CARD, of Rhode Island College of Agriculture and Mechanic Arts. 537 pp. 113 illustrations. $\$ 1.50$.

FERTILIZERS. By E. B. Voorhess, of New Jersey Experiment Station. 332 pp. \$1.00.

THE PRINCIPLES OF AGRICULTURE. By L. H. Bailey. 300 pp. 92 illustrations. \$1.25.

IRRIGATION AND DRAINAGE. By F. H. KING, Lniversity of Wisconsin. $502 \mathrm{pp} .163$ illustrations. $\$ 1.50$.

THE FARMSTEAD. By I. P. RoBERTS. 350 pp. 138 illustrations. $\$ 1.25$.

RURAL WEALTH AND WELFARE. By GEORGE T. FAIRCHILD, Ex-President of the Agricultural College of Kansas. 381 pp. 14 charts. \$1.25.

THE PRINCIPLES OF VEGETABLE-GARDENING. By L. H. BAILEY. $468 \mathrm{pp} .144$ illustrations. $\$ 1.25$.

THE FEEDING OF ANIMALS. By W. H. JoRdAN, of New York State Experiment Station. $450 \mathrm{pp}$. $\$ 1.25$ net.

FARM POULTRY. By Georfe C. WATson, of Penusylvania State College. 341 pp. $\$ 1.25$ net.

THE FARMER'S BUSINESS HANDBOOK. By I. P. ROBERTS, of Cornell University. 300 pp. $\$ 1.00$ net.

THE CARE OF ANIMALS. By Nelson S. MAyo, of Kansas State Agricultural ('ollege. $458 \mathrm{pp}$. $\$ 1.25$ net.

THE HORSE. By I. P. ROBERTS, of Cornell University.

New volumes will be added from time to time to the Rural Science Series. The following are in preparation:

PHYSIOLOGY OF PLANTS. By .J. C. Arthtr, Purdue University.

THE PRINUIPLES OF STOCK BREEDING. BY W. H. BREWER, of Yale University.

PLAN'T PATHOLOGY. By B. T. GallowaY and associates, of U. S. Depart. ment of Agriculture.

THE POME FRUITS (Apples, Pears, Quinces). By L. H. BaILeq. 


\section{THE GARDEN-CRAFT SERIES}

Comprises practical handbooks for the horticulturist, explaining and illustrating in detail the various important methods which experience has demonstratcd to be the most satisfactory. They may be called manuals of practice, and thongh all are prepared by Professor BAlley, of Cornell University, they include the opinions and methods of successful specialists in many lines, thus combining the results of the observations and experiences of $\mathrm{nu}$ merous students in this and other lands. They are written in the clear, strong, concise English and in the entertaining style which characterize the author. The volumes are compact, uniform in style, clearly printed, and illustrated as the subject demands. They are of convenient shape for the pocket, and are substantially bound in flexible green cloth.

THE HORTICULTURIST'S RULE BOOK. By L. H. BaILer. 312 pp. 75 cents.

THE NURSERY-BOOK. By L. H. BAILEY. 365 pp. 152 illustrations. \$1. PLANT-BREEDING. By L. H. BAILEY. 293 pp. 20 illustrations. \$1.00.

THE FORCING-B00K. By L. H. BAILEY. 266 pp. 88 illustrations. $\$ 1.00$. GARDEN-MAKING. By L. H. BAILeY. 417 pp. 256 illustrations. \$1.00. THE PRUAING-300K. By L. H. BAILEY. 545 pp. 331 illustrations. $\$ 1.50$. THE PRACTICAL GARDEN-BOOK. By C. E. HUNN and L. H. HAILEY. 250 pp. Many marginal cuts. $\$ 1.00$. 


\section{THE SURVIVAL OF THE UNLIKE: A Collection of Evolution Essays Suggested by the Study of Domestic Plants. By L. H. BAILEY, Professor of Horticulture in the Cornell University.}

FOURTH EDITION-515 PAGES - 22 ILLUSTRATIONS - $\$ 2.00$

To those interested in the underlying philosophy of plant life, this volume, written in a most entertaining style, and fully illustrated, will prove welcome. It treats of the modification of plants under cultivation upon the evolution theory, and its attitude on this interesting "subject is characterized by the author's well-known originality and independence of thought. Incidentally, there is stated much that will be valuable and suggestive to the working horticulturist, as well as to the man or woman impelled by a love of nature to horticultural pursuits. It may well be called, indeed, a philosophy of horticulture, in which all interested may find inspiration and instruction.

The Survival of the UnLIKe comprises thirty essays touching upon The General Fact and Philosophy of Evolution (The Plant Individual, Experimental Erolution, Coxey's Army and the Russian Thistle, Recent Progress, etc.); Expounding the Fact and Causes of Variation (The Supposed Correlations of Quality in Fruits, Natural History of Synonyms, Reflective Impressions, Relation of Seedbearing to Cultiration, Variation after Birth, Relation between American and Eastern Asian Fruits, Horticultural Geography, Problems of Climate and Plants, American Fruits, Acclimatization, Sex in Fruits, Novelties, Promising Varieties, etc.); axd Tracing the Evolution of Particular Types of Plants (the Cultivated Strawberry, Battle of the Plums, Grapes, Progress of the Carnation. Petunia, The Garden Tomato, etc.). 


\section{THE EVOLUTION OF OUR NA. TIVE FRUITS. By L. H. BAILEY, Pro. fessor of Horticulture in the Cornell University.}

472 PACES - 126 ILLUSTRATIONS $-\$ 2.00$

In this entertaining volume, the origin and de. velopment of the fruits peculiar to North America are inquired into, and the personality of those horticultural pioneers whose almost forgotten labors have given us our most valuable fruits is touched upon. There has been careful research into the history of the various fruits, including inspection of the records of the great European botanists who have given attention to American economic botany. The conclusions reached, the information presented, and the suggestions as to future developments, cannot but be valuable to any thoughtful fruit-grower, while the terse style of the anthor is at its best in his treatment of the subject.

The Erolution of our Native Fruits discusses The Rise of the American Grape (North America a Natural Vineland, Attempts to Cultivate the European Grape, The Experiments of the Dufours, The Branch of Promise, John Adlum and the Catawba, Rise of Commercial Viticulture, Why Did the Early Vine Experiments Fail ? Synopsis of the American Grapes); The Strange History of the Mulberries (The Early Silk Industry, The "Multicaulis Craze,"); Evolu. tion of American Plums and Cherries (Native Plums in General, The Chickasaw, Hortulana, Marianna and Beach Plum Grouns, Pacific Coast Plum, Various Other Types of Plums, Native Cherrics, Dwarf Cherry Group); Native Apples (Indigenous Species, Amelioration has begun); Origin of American Raspberry-growing (Early American History, Present Types, Outlying Types); Evolution of Blackberry and Dewberry Cniture (The High-bush Blackberry and Its Kin, The Dewberries, Botanical Names); Various Types of Berry-like Fruits (The Gooseberry, Native Currants, Juneberry, Buffalo Berry, Elderberry, High-bush Cranberry, Cranberry, Strawberry); Various Types of Tree Fruits (Persimmon, Custard-Apple Tribe, Thorn-Apples, Nut-Fruits); General Remarks on the Improvement of our Native Fruits (What Has Been Done, What Probably Should Be Done). 


\section{T ESSONS WITH PLANTS: Sugges- tions for Seeing and Interpreting Some of the Common Forms of Vegetation. By L. H. BAILEY, Professor of Horticulture in the Cornell University, with delineations from nature by W. S. HOLDSWORTH, of the Agricultural College of Michigan.}

\section{SECOND EDITION-421 PAGES-448 ILLUSTRATIONS-12 MO- ELOYH-B 1.10 NET}

There are two ways of looking at nature. The old way, which you have found so unsatisfactory, was to classify everything-to consider leaves, roots, and whole plants as formal herbarium specimens, forgetting that each had its own story of growth and development, struggle and success, to tell. Nothing stifles a natural love for plants more effectually than that old way.

The new way is to watch the life of every growing thing, to look upon each plant as a living ereature, whose life is a story as fascinating as the story of any favorite hero. "Lessons with Plants" is a book of stories, or rather, a book of plays, for we can see each chapter acted out if we take the trouble to look at the actors.

"I have spent some time in most delightful examination of it, and the longer I look, the better I like it. I find it not only full of interest, but eminently suggestive. I know of no book which begins to do so much to open the eyes of the student-whether pupil or teacher - to the wealth of meaning contained in simple plant forms. Above all else, it seems to be full of suggestions that help one to learn the language or plants, so they may talk to him."-DARWIN L. BARDWEL,, Superintendent of schools, Bing. hamton.

"It is an admirable book, and cannot fail both to awaken interest in the subject, and to serve as a helpful and reliable guide to young students of plant life. It will, I think, fill an important place in secondary schools, and comes at an opportune time, when helps of this kind are needed and aagerly sought."-Professor V. M. SPALDING, University of Michigan.

\section{FIRST LESSONS WITH PLANTS}

An Abridgement of the above. 117 pages-116 illustrations -40 cents net. 


\section{DOTANY: An Elementary Text for Schools. \\ By L. H. BAILEY.}

\section{E PAGES-60O ILLUSTRATIONS- $\$ .10$ NET}

"This book is made for the pupil: 'Lessons With Plants" was made to supplement the work of the teacher." This is the opening sentence of the preface, showing that the book is a companion to "Lessons With Plants," which has now become a standard teacher's book. The present book is the handsomest elementary botanical text-book yet made. The illustrations illustrate. They are artistic. The old formal and unnatural Botany is being rapidly outgrown. The book disparages mere laboratory work of the old kind: the pupil is taught to see things as they grow and behave. The pupil who goes through this book will understand the meaning of the plants which he seos day by day. It is a revolt from the dry-as-dust teaching of botany. It cares little for science for science' sake, but its point of view is nature-study in its best sense. The book is divided into four parts, any or all of which may be used in the school: the plant itself; the plant in its environment; histoiogy, or the minute structure of plants; the kinds of plants (with a key, and descriptions of 300 common species). The introduction contains advier to teachers. The book is brand new from start to finish.

"An exceedingly attractive text-book."-Educational Review.

"It is a school book of the modern methods."-The Dial.

"It would be hard to find a better manual for schools or for indi. vidual use." The Outlook:

\section{'THE MACMILLAN COMPANY}




\section{THE CYCLOPEDIA OF AMERICAN HORTICULTURE : By L. H. BAILEY, of Cornell University, assisted by WILHELM MILLER, and many expert cultivators and botanists.}

\section{VOLS.-OVER 2800 ORIGINAL ENGRAVINCS - CLOTH-OCTAVO 920.00 NET PER SET. HALF MOROCCO, \$32.0O NET PER SET}

'This great work comprises directions for the cultivation of horticultural crops and original descriptions of all the species of fruits, vegetables. flowers and ornamental plants known to be in the market in the United States and Canada. "It has the unique distinction of presenting for the first time, in a carefully arranged and perfectly accessible form, the best knowledge of the best specialists in America upon gardening, îruit-growing, vegetable culture, forestry, and the like, as well as exact botanical information. The contributors are eminent cultivators or specialists, and the arrangement is very systematic, clear and convenient for ready reference."

"We have here a work which every ambitious gardener will wish to place on his shelf heside his Nicholson and his Loudon, and for such users of it it too advanced nomenclature would have been confusing to the last degrce. With the safe names here given, there is little liability to serious perplexity. There is a growing impatience with much of the controversy concerning revision of names of organisms, whether of plants or animals. Those investigators who are busied with the ecological aspects of organisms, and also those who are chiefly concerned with the application of plants to the arts of agriculture, horticulture, and so on, care for the names of organisms under examination only so far as these aid in recognition and identification. To introduce unnecessary confusion is a serious blunder. Professor Bailey has avoider the risk of confusion. In short, in range, treatment and editing, the (yclopedia appears to be einpluatisally useful; . . . a work worthy of ranking by the side of the Century Dictionary."-The Nation.

This work is sold only by subscription, and terms and further information may be had of the publishers.

\section{THE MACMILLAN COMPANY}













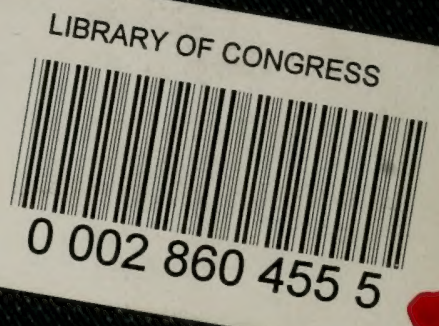

